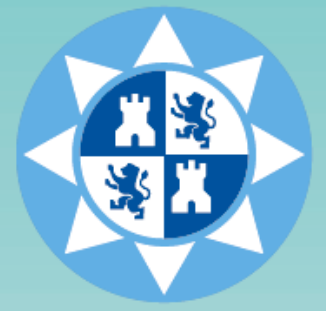

Universidad Politécnica de Cartagena Departamento de Expresión Gráfica

\author{
Tesis doctoral
}

\title{
Modelado Geométrico Personalizado de la Córnea Humana y su Aplicación a la Detección de Ectasias Corneales
}

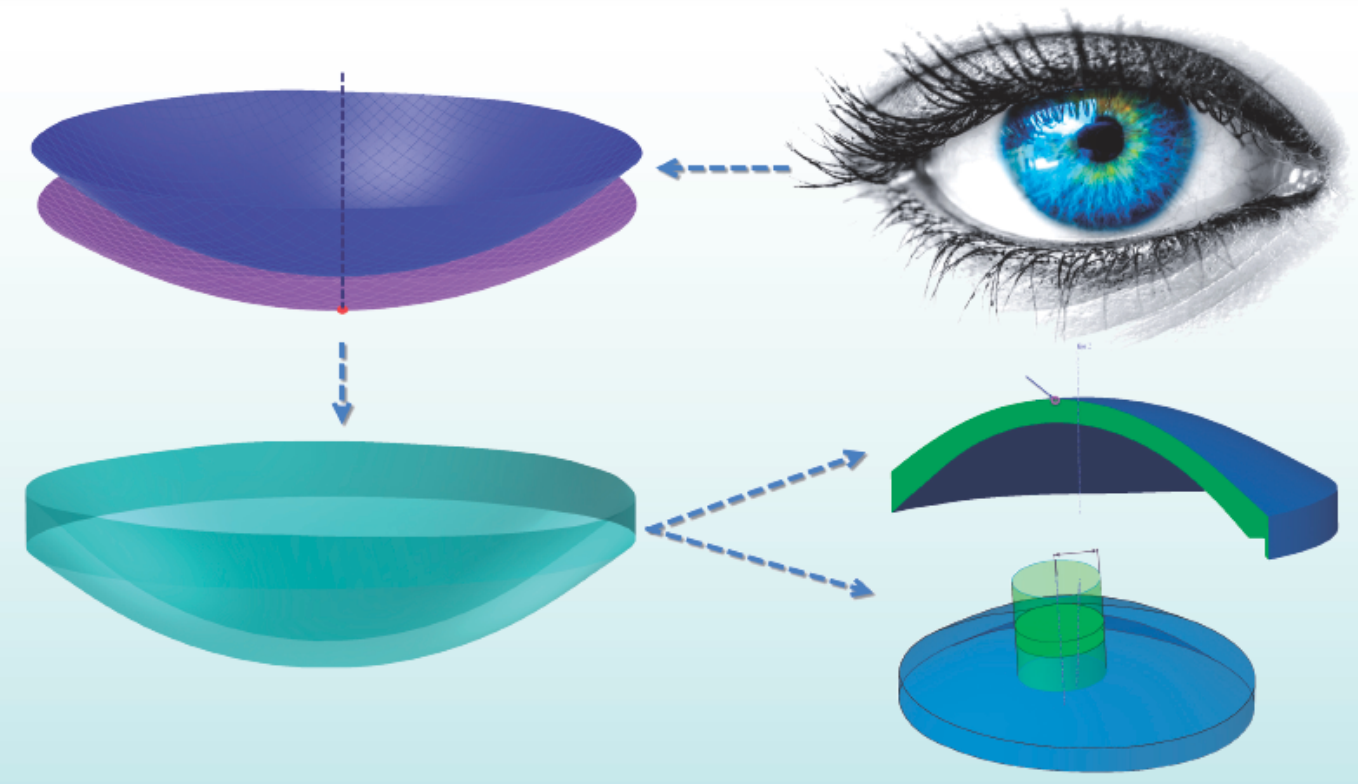

Autor:

Francisco Cavas Martínez

Directores:

Dr. Daniel García Fernández-Pacheco Dr. Ernesto de la Cruz Sánchez 


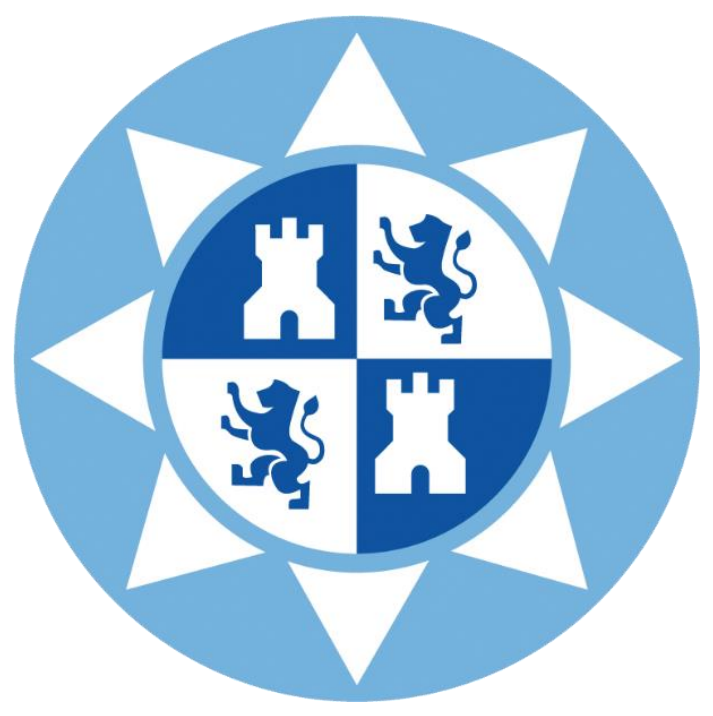

Universidad Politécnica de Cartagena Departamento de Expresión Gráfica

\section{MODELADO GEOMÉTRICO PERSONALIZADO DE LA CÓRNEA HUMANA Y SU APLICACIÓN A LA DETECCIÓN DE ECTASIAS CORNEALES}

Tesis doctoral 2015

Francisco Cavas Martínez

Directores:

Dr. Daniel García Fernández-Pacheco Dr. Ernesto de la Cruz Sánchez 
Que la curiosidad sea más grande que el miedo

Gustavo Cereti 


\section{CONFORMIDAD DE SOLICITUD DEAUTORIZACIÓN DE DEPÓSITO DE TESIS DOCTORAL POR EL/LA DIRECTOR/A DE LA TESIS}

D. Daniel García Fernández-Pacheco Director y D. Ernesto de la Cruz Sánchez Co-Director de la Tesis doctoral Modelado geométrico personalizado de la córnea humana y su aplicación a la detección de Ectasias Corneales.

Dña. Sonia Busquier Sáez Tutora de la Tesis doctoral Modelado geométrico personalizado de la córnea humana y su aplicación a la detección de Ectasias Corneales.

\section{INFORMA:}

Que la referida Tesis Doctoral, ha sido realizada por D. Francisco Cavas Martínez, dentro del programa de doctorado en Tecnologías Industriales, dando mi conformidad para que sea presentada ante la Comisión de Doctorado para ser autorizado su depósito.

La rama de conocimiento en la que esta tesis ha sido desarrollada es:

․ Ciencias

- Ciencias Sociales y Jurídicas

- Ingeniería y Arquitectura

En Cartagena, a 15 de Julio de 2015

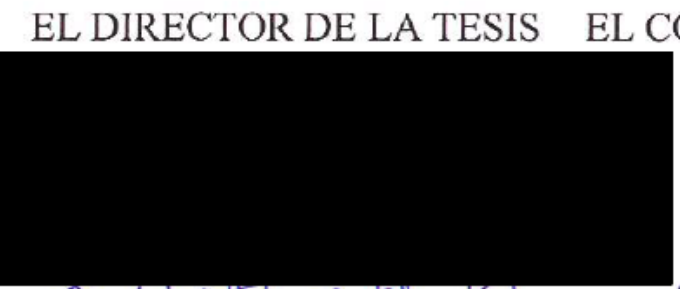

Edo.: Laniel varía ldez- tachers Fdo
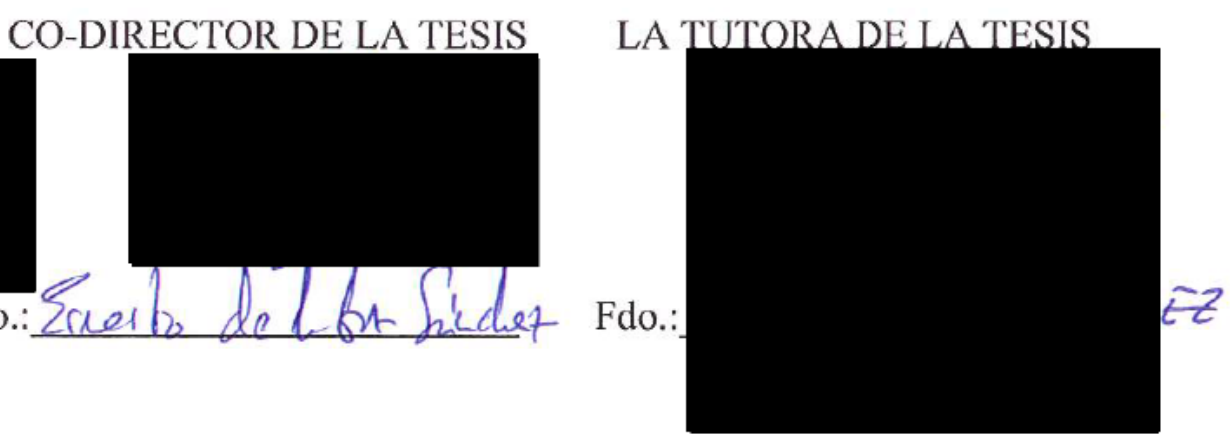


\section{Universidad \\ Politécnica \\ de Cartagena}

DT-17

\section{CONFORMIDAD DE DEPÓSITO DE TESIS DOCTORAL POR LA COMISIÓN ACADÉMICA DEL PROGRAMA}

D. Juan Suardíaz Muro, Presidente de la Comisión Académica del Programa de Doctorado en Tecnologías Industriales

\section{INFORMA:}

Que la Tesis Doctoral titulada,"Modelado geométrico personalizado de la córnea humana y su aplicación a la detección de Ectasias Corneales", ha sido realizada, dentro del mencionado programa de doctorado, por D. Francisco Cavas Martínez,

bajo la dirección y supervisión de los Drs. Daniel García Fernández-Pacheco y Ernesto de la Cruz Sánchez.

En reunión de la Comisión Académica de fecha 15/07/2015, visto que en la misma se acreditan los indicios de calidad correspondientes y la autorización del Director de la misma, se acordó dar la conformidad, con la finalidad de que sea autorizado su depósito por la Comisión de Doctorado.

La Rama de conocimiento por la que esta tesis ha sido desarrollada es:

$\checkmark$ Ciencias

Ciencias Sociales y Jurídicas

口 Ingeniería y Arquitectura

En Cartagena, a 20 de julio de 2015

EL PRESIDENTE DE LA COMISIÓN ACADÉMICA DEL PROGRAMA

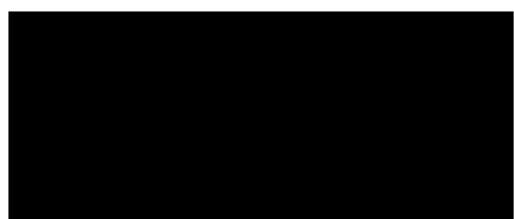

Fdo: Juah Suardíaz Muro 
Esta tesis se ha realizado en parte gracias a la financiación del proyecto del Fondo Europeo de Desarrollo Regional (FEDER) y del Ministerio Español de Economía y Competitividad, Instituto Carlos III, Red Temática de Investigación Cooperativa en Salud (RETICS) «Prevención, detección precoz y tratamiento de la patología ocular prevalente, degenerativa y crónica». Subprograma «dioptrio ocular y patologías frecuentes» (RD12/0034/0007)
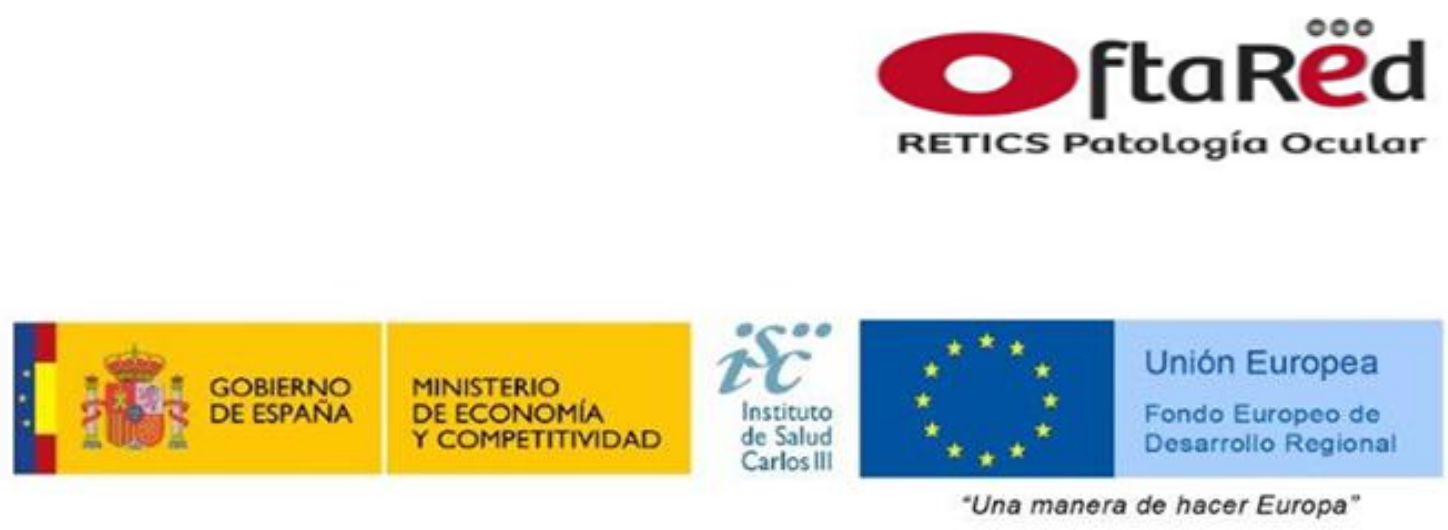
A Ana, Carlota y Virtu

en la confianza de poder ofrecerles cosas aún mejores 


\section{Agradecimientos}

Quiero expresar mi más sincero agradecimiento a todas las personas que se han visto implicadas de forma directa o indirecta en el desarrollo de esta Tesis Doctoral. No exagero al decir, que sin su cooperación, la elaboración de ésta hubiera resultado imposible.

A mis directores los doctores Daniel García Fernández-Pacheco y Ernesto de la Cruz Sánchez agradecerles, no sólo por su dedicación como directores de la Tesis, sino también por la fe mostrada en su planteamiento y su continuo estímulo, sin el cual, a este trabajo le quedaría aún un largo camino por recorrer. Gracias amigos.

Al Departamento de Expresión Gráfica de la Universidad Politécnica de Cartagena al que pertenezco y a las personas que lo constituyen, por el apoyo incondicional mostrado durante la realización de este trabajo de Tesis, por los valiosos consejos ofrecidos y por las numerosas horas que han extraído de su tiempo y han dedicado al mío. Especialmente quisiera agradecer al profesor José Nieto Martínez, por permitirme desarrollar esta nueva línea de investigación dentro de su grupo de investigación "Ingeniería Multidisciplinar y de Seguridad", y al profesor Francisco José Fernández Cañavate por facilitarme, en calidad de director del Departamento de Expresión Gráfica, todos los recursos necesarios para llevar a buen fin la elaboración de esta Tesis Doctoral; gracias a ambos por vuestro inestimable apoyo durante esta etapa. También mi agradecimiento a los compañeros del departamento recientemente jubilados. Gracias compañeros.

A la Corporación Oftalmológica Vissum por haberme facilitado los equipos y los datos clínicos para la elaboración de este trabajo. A todo su equipo de especialistas en Oftalmología y en Óptica, liderados por el Dr. Jorge L. Alió, por su inestimable orientación en los aspectos anatómicos y clínicos relacionados con los estudios llevados a cabo, y en especial a mi amigo y director de I+D el ingeniero Laurent Bataille, por haberme abierto las puertas del apasionante mundo de la Investigación Biomédica. A todos, muchas gracias.

A mis antiguos alumnos y ahora ingenieros Alejandro Freire, Francisco Bernal y Ramón Alifa, quienes han colaborado conmigo en diferentes etapas de este trabajo de Tesis. A todos mis amigos y amigas, a quienes he tenido ciertamente abandonados durante estos últimos años, pero cuando he podido disfrutar de vuestra compañía, ésta ha sido realmente gratificante. Gracias a todos.

Gracias Trini, Pedro (desde los cielos), Adeli, Ramón, Ana, Antonio, Maria, Carlos, Pedro y Celia, por vuestro constante apoyo y estímulo que sólo puedo interpretar como una muestra de confianza en mi capacidad para llevar a cabo esta tarea.

Finalmente, desearía mostrar mi más profundo agradecimiento a mis padres, Domingo y Adelina, por creer en mí y haberme dado todos sus recursos para formarme como persona. Os quiero. 
Nuestras horas son minutos

cuando esperamos saber,

y siglos cuando sabemos

lo que se puede aprender.

Antonio Machado (1875-1939) 


\title{
Índice de contenidos
}

\author{
RESUMEN
}

1 INTRODUCCIÓN

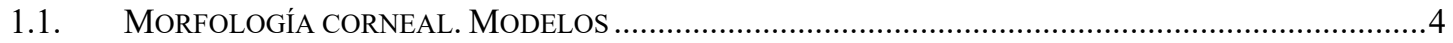

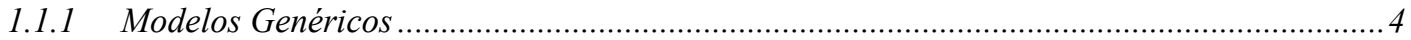

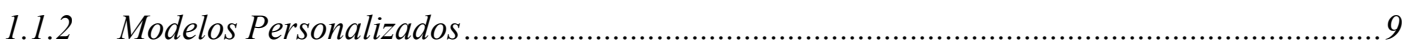

1.2. MÉTODOS DE RECONSTRUCCIÓN DE LA SUPERFICIE CORNEAL .................................................. 19

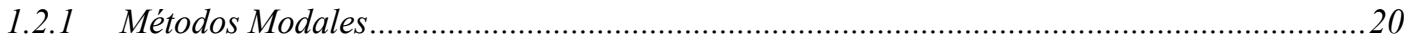

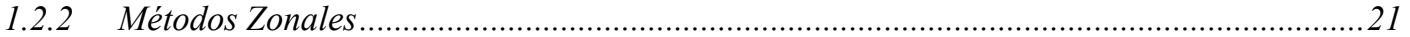

1.2.3 Consideraciones previas al proceso de reconstrucción de la superficie corneal ....................22

1.3. DISEÑO GEOMÉTRICO ASISTIDO POR ORDENADOR .................................................................23

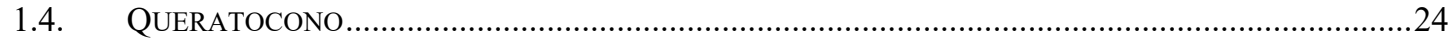

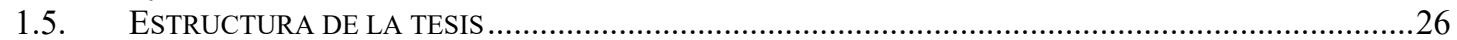

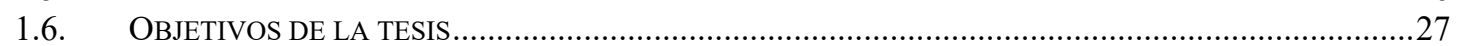

2 MARCO TEÓRICO

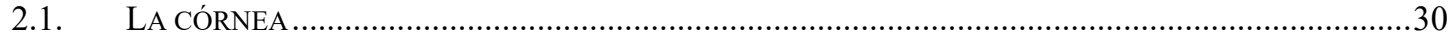

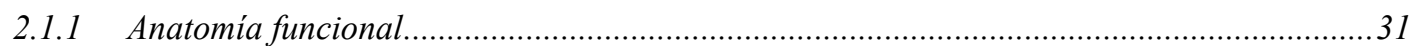

2.1.2 Caracterización morfológica de la córnea ...........................................................................49

2.2. DISEÑO GEOMÉTRICO ASISTIDO POR ORDENADOR .................................................................94

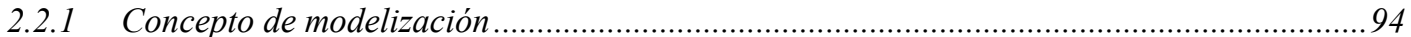

2.2.2 Historia del Diseño Geométrico Asistido por Ordenador .....................................................97

2.2.3 Fundamento teórico de las funciones B-Spline y NURBS ................................................ 101

2.2.4 Curvas y superficies generadas a partir de NURBS........................................................ 104

2.2.5 Diseño de una superficie con forma libre ................................................................... 108

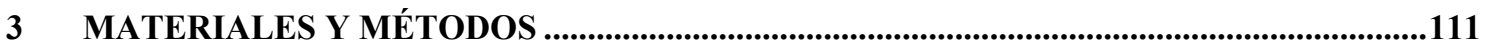

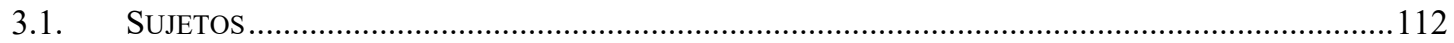

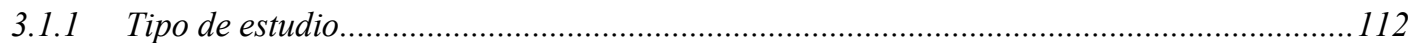

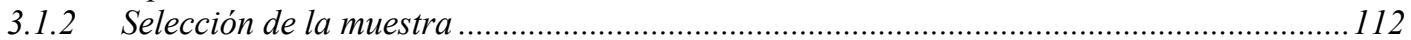

3.1.3 Historial Clínico y exploración morfológica ....................................................................114

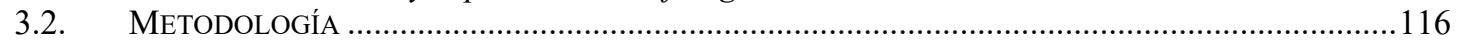

3.2.1 Reconstrucción geométrica $3 D$ de la córnea ............................................................ 116

3.2.2 Caracterización y diagnosis de la córnea .......................................................................... 127

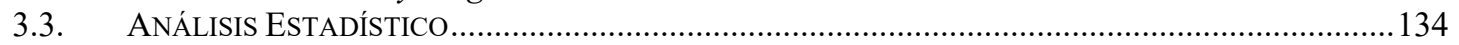

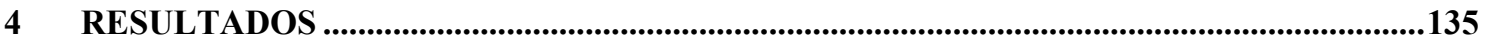

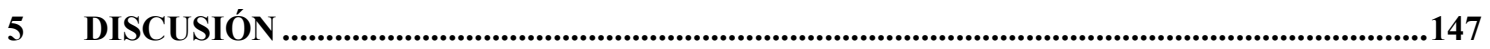

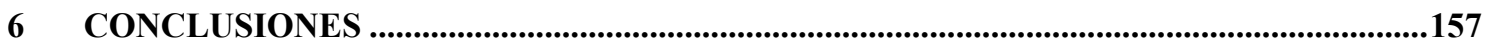

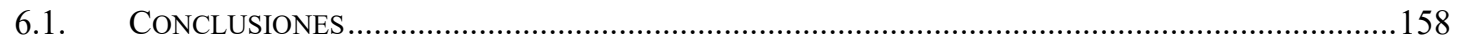

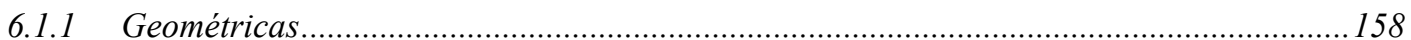

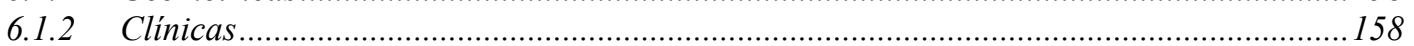

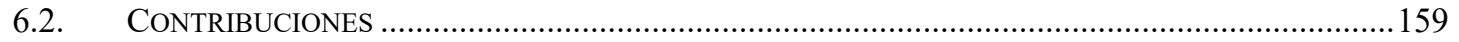

6.2.1 Publicaciones indexadas en el Journal Citation Reports ..............................................159

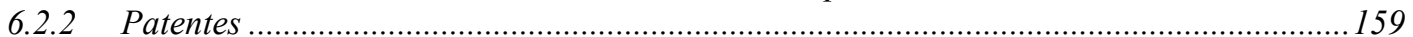

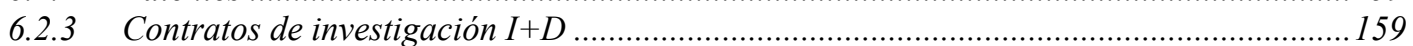

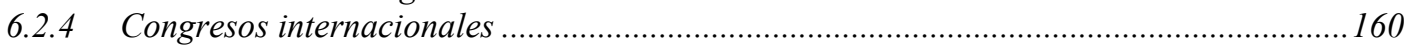

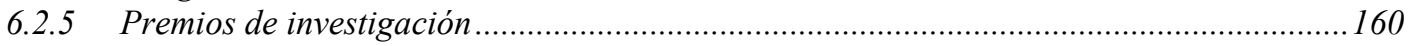

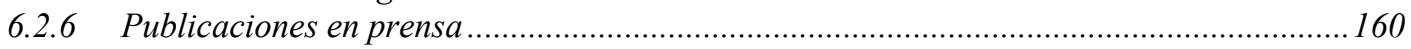

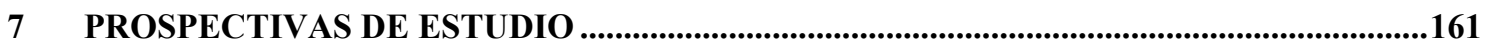

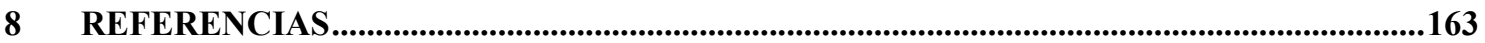




\section{Índice de figuras}

FIGURA 1.1 ESTRUCTURA COMPLETA DEL OJO HUMANO ...................................................................

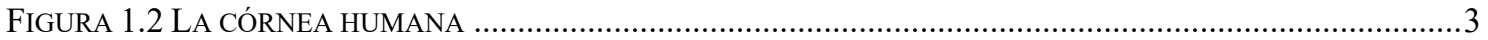

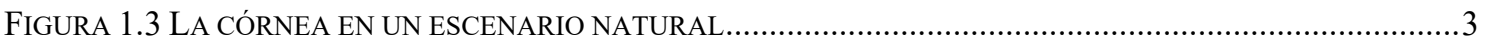

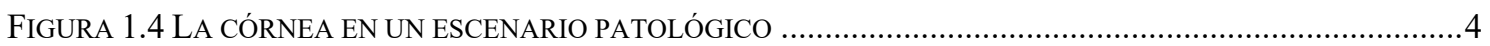

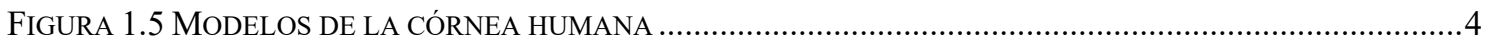

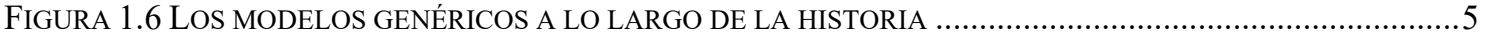

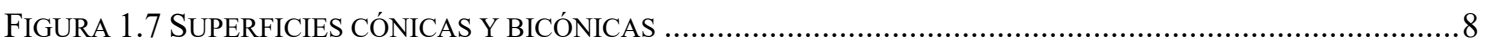

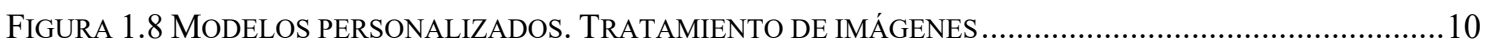

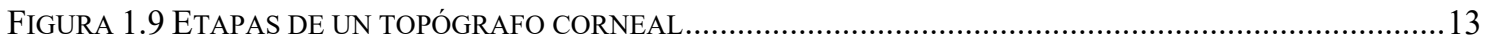

FIGURA 1.10 TECNOLOGÍAS EN LAS QUE ESTÁN BASADOS LOS TOPÓGRAFOS CORNEALES ...........................15

FIGURA 1.11 MÉTODOS DE RECONSTRUCCIÓN DE LA SUPERFICIE CORNEAL .............................................19

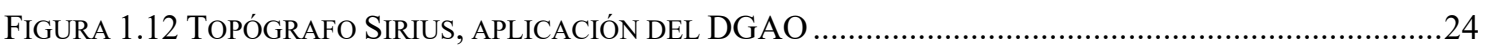

FIGURA 1.13 CÓRNEA CON QUERATOCONO. VISTA EN PLANTA Y DE PERFIL............................................25

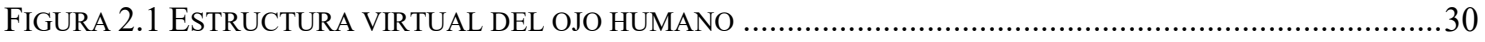

FIGURA 2.2 FOTOGRAFÍA FRONTAL E IMAGEN SAGITAL DE UNA CÓRNEA SANA.........................................31

FIGURA 2.3 COMPARATIVA DE LA ESTRUCTURA ANATÓMICA DE LA CÓRNEA CON UNA CÚPULA ARQUITECTÓNICA

FIGURA 2.4 IMAGEN MICROSCÓPICA DE LA CAPA LAGRIMAL, ESTRATOS DE LA CÓRNEA Y HUMOR ACUOSO

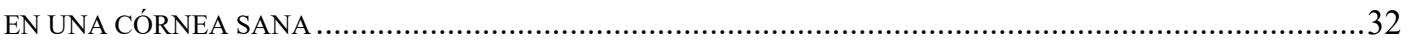

FIGURA 2.5 PARÁMETROS FÍSICOS PROMEDIO DE LA CÓRNEA SANA, IMAGEN EN CORTE SAGITAL .................33

FIGURA 2.6 IMAGEN MICROSCÓPICA DE LA ESTRUCTURA DE UNA CÓRNEA SANA .......................................34

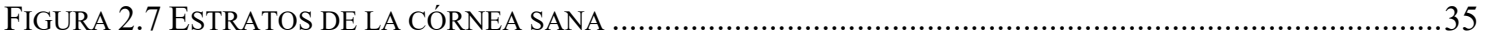

FIGURA 2.8 FOTOGRAFÍA FRONTAL E IMAGEN SAGITAL DE UNA CÓRNEA CON QUERATOCONO ...................41

FIGURA 2.9 FOTO DE PERFIL DE LA CÓRNEA CON QUERATOCONO APORTADA POR TOPÓGRAFO CORNEAL ...42

FIGURA 2.10 UBICACIÓN DEL QUERATOCONO EN LA CÓRNEA RESPECTO LAS HEMIMERIDIADOS NASAL,

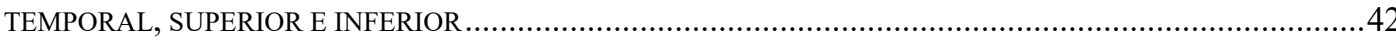

FIGURA 2.11 GRADO DE SEVERIDAD DEL QUERATOCONO EN FUNCIÓN DE LA CLASIFICACIÓN DE AMSLERKRUMEICH.

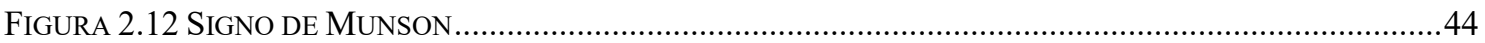

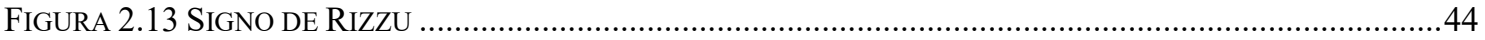

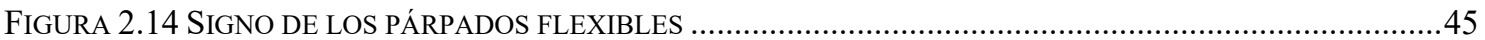

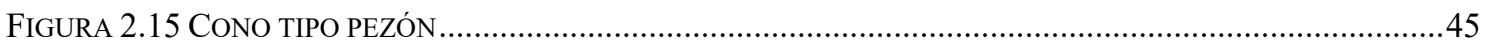

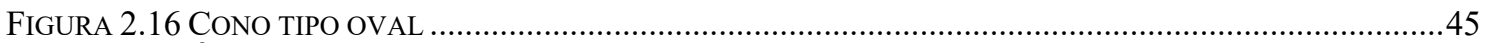

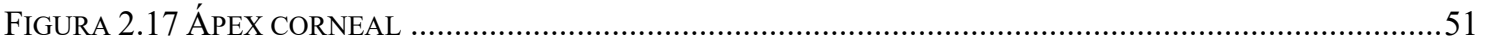

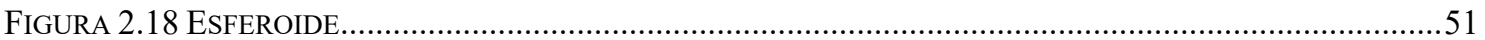

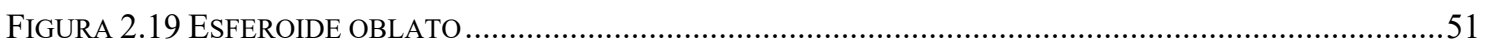

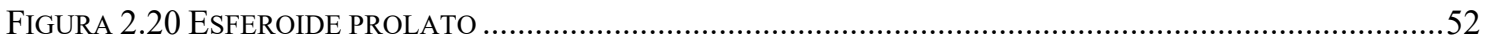

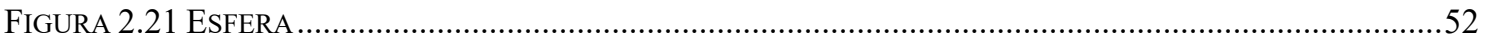

FIGURA 2.22 SECCIONES DE DIFERENTES TIPOS DE CURVA CURVAS CÓNICAS (CALOSSI, 2007)..................53

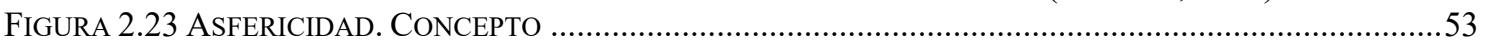

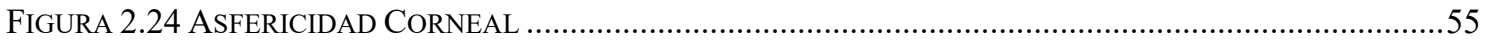

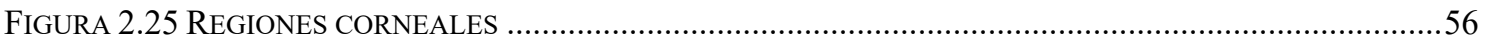

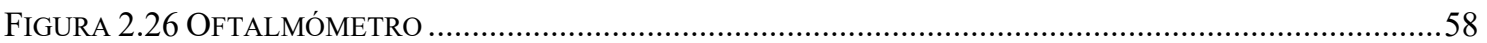

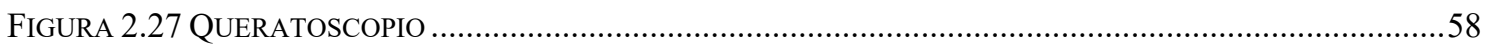

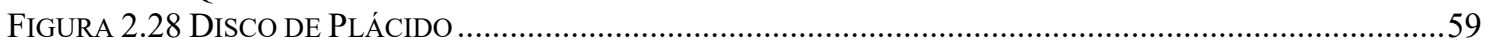

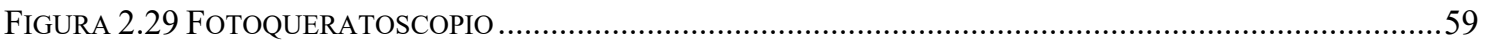

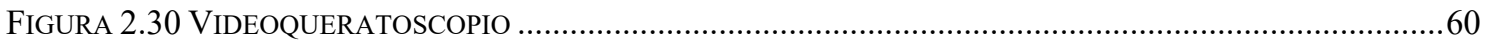

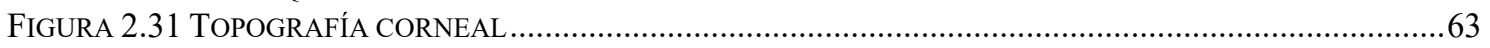

FIGURA 2.32 INTEGRACIÓN DE TECNOLOGÍAS: SISTEMA BASADO EN LA PROYECCIÓN DE UNA HENDIDURA DE

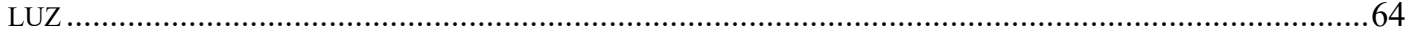

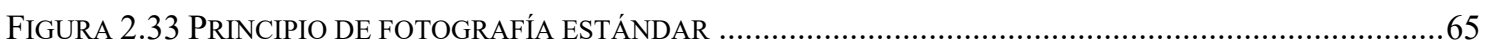

FIGURA 2.34 DEFECTOS VISUALES EN LA FOTOGRAFÍA ESTÁNDAR ...................................................65

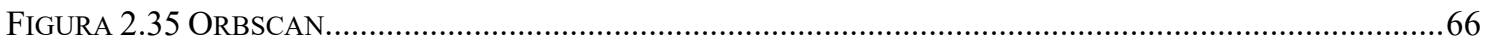

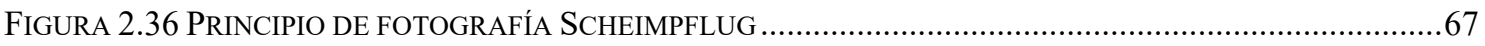




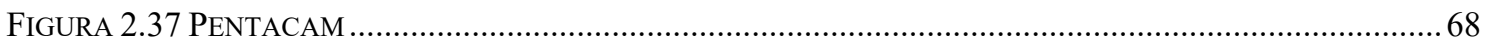

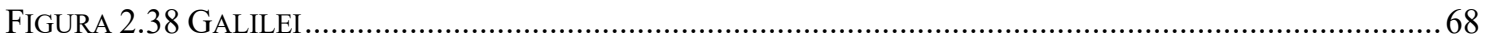

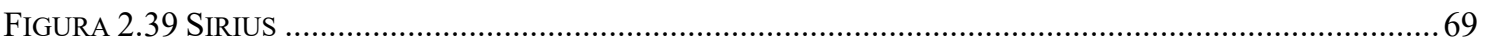

FIGURA 2.40 INTEGRACIÓN TECNOLOGÍAS EN EL TOPÓGRAFO CORNEAL SIRIUS ...................................... 70

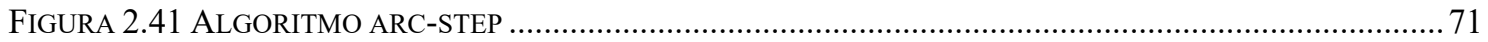

FIGURA 2.42 ARCOS MERIDIANOS TOPOGRÁFICOS RESPECTO A SUPERFICIE DE REFERENCIA SMA .............71

FIGURA 2.43 BORROSIDAD/DEFORMACIÓN EN EL PRINCIPIO DE FOTOGRAFÍA SCHEIMPFLUG......................72

FigURA 2.44 TERCERA DiMENSIÓN (A). ROTACIÓN DE LA CÁMARA FOTOGRÁFICA SOBRE EL GLOBO

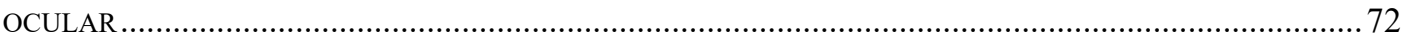

FIGURA 2.45 TERCERA DIMENSIÓN (B). ROTACIÓN DE LA CÁMARA FOTOGRÁFICA SOBRE LA CÓRNEA .......73

FIGURA 2.46 PATRONES TOPOGRÁFICOS CARACTERÍSTICOS DEL QUERATOCONO......................................75

FIGURA 2.47 INCIDENCIA DEL QUERATOCONO SOBRE LAS REGIONES CORNEALES ..................................75

FIGURA 2.48 PATRONES TOPOGRÁFICOS. PAJARITAS ..........................................................................76

FIGURA 2.49 ALGORITMO GEOMÉTRICO DE RECONSTRUCCIÓN DE UN MAPA SAGITAL DE LA CÓRNEA .........77

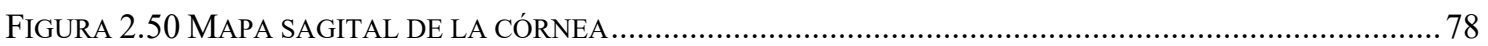

FIGURA 2.51 ALGORITMO GEOMÉTRICO DE RECONSTRUCCIÓN DE UN MAPA TANGENCIAL DE LA CÓRNEA.. 78

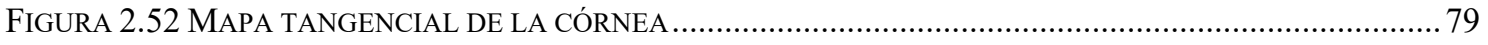

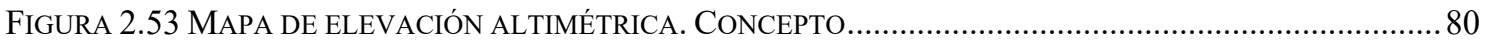

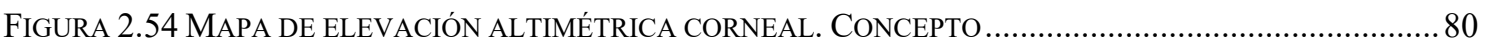

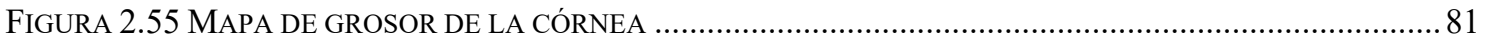

FIGURA 2.56 MAPA 3D DE LA SUPERFICIE CORNEAL ANTERIOR, EQUIPO SIRIUS (CSO, ITALIA)..................8 82

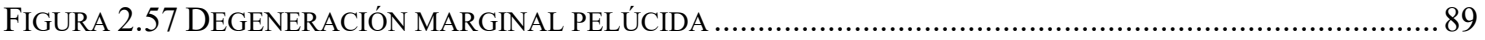

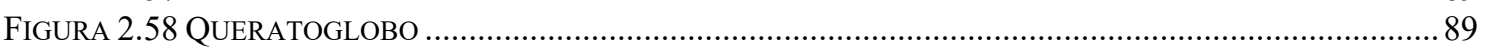

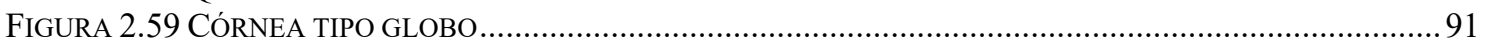

FIGURA 2.60 CÓRNEA CON ASTIGMATISMO DEBIDO A LA PATOLOGÍA DEL QUERATOCONO ........................92

FIGURA 3.1 ETAPAS PRINCIPALES PARA EL PROCEDIMIENTO DE DIAGNÓSTICO …................................. 116

FIGURA 3.2 ESQUEMA DEL PROCEDIMIENTO DE RECONSTRUCCIÓN GEOMÉTRICA 3D DE LA CÓRNEA........ 117

FIGURA 3.3 REPRESENTACIÓN DE LOS DATOS EN FORMATO POLAR EN EL FICHERO CSV PROPORCIONADO

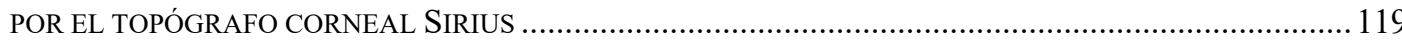

FIGURA 3.4 EXTRACCIÓN Y CONVERSIÓN DE DATOS A PARTIR DEL FICHERO CSV PROPORCIONADO POR EL

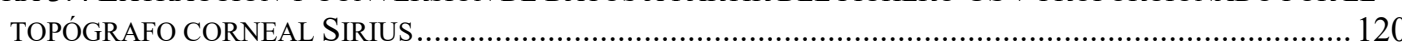

FIGURA 3.5 IMPORTACIÓN DE LAS NUBES DE PUNTOS CORRESPONDIENTES A AMBAS SUPERFICIES

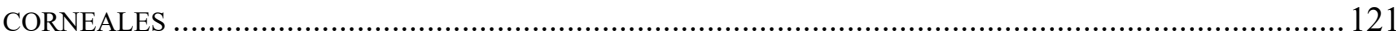

FIGURA 3.6 CONFIGURACIÓN DE LA FUNCIÓN “PARCHE” PARA RECONSTRUCCIÓN DE SUPERFICIES........... 122

FIGURA 3.7 RESULTADO TRAS APLICAR LA FUNCIÓN “PARCHE” SOBRE LAS NUBES DE PUNTOS DE AMBAS SUPERFICIES CORNEALES......

FIGURA 3.8 POSICIONAMIENTO DE UN CILINDRO DE RADIO R= 4 MM PARA RECORTAR LAS SUPERFICIES GENERADAS POR LA FUNCIÓN "PARCHE" ............................................................................. 124

FIGURA 3.9 SUPERFICIES DEFINITIVAS TRAS APLICAR EL RECORTE CON EL CILINDRO A LAS SUPERFICIES GENERADAS CON LA FUNCIÓN "PARCHE"

FIGURA 3.10 ANÁLISIS DE LA DESVIACIÓN PUNTO-SUPERFICIE PARA LA RECONSTRUCCIÓN DE LA CARA ANTERIOR DE: A) UNA CÓRNEA SANA, B) UNA CÓRNEA CON QUERATOCONO EN ESTADO AVANZADO125

FIGURA 3.11 CREACIÓN DE LA SUPERFICIE PERIMETRAL Y UNIÓN DE LAS TRES SUPERFICIES EN UNA ÚNICA

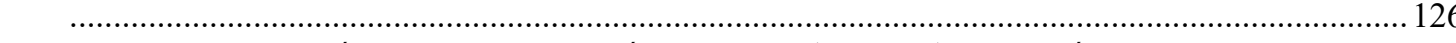

FIGURA 3.12 MODELOS SÓLIDOS 3D DE UNA CÓRNEA SANA (EN AZUL) Y UNA CÓRNEA CON QUERATOCONO (EN ROJO) GENERADOS MEDIANTE EL SOFTWARE SOLIDWORKS $®$

FIGURA 3.13 ÁREA DE LA SUPERFICIE CORNEAL ANTERIOR (EN VERDE) CALCULADA EN UNA CÓRNEA SANA (EN AZUL) Y EN UNA CÓRNEA CON QUERATOCONO (EN ROJO)

FIGURA 3.14 ÁREA DE LA SUPERFICIE CORNEAL POSTERIOR (EN VERDE) CALCULADA EN UNA CÓRNEA SANA (EN AZUL) Y EN UNA CÓRNEA CON QUERATOCONO (EN ROJO) .................................................. 127

FIGURA 3.15 ÁREA DEL PLANO SAGITAL QUE PASA POR EL ÁPEX ANTERIOR (EN VERDE) CALCULADA EN UNA CÓRNEA SANA (EN AZUL) Y EN UNA CÓRNEA CON QUERATOCONO (EN ROJO) ................................... 128

FIGURA 3.16 DESVIACIÓN DEL ÁPEX ANTERIOR CALCULADA PARA UNA CÓRNEA SANA (EN AZUL) Y PARA UNA CÓRNEA CON QUERATOCONO (EN ROJO)

FIGURA 3.17 DESVIACIÓN DEL ÁPEX POSTERIOR CALCULADA PARA UNA CÓRNEA SANA (EN AZUL) Y PARA UNA CÓRNEA CON QUERATOCONO (EN ROJO) 
FIGURA 3.18 ÁREA DEL PLANO SAGITAL QUE PASA POR EL PUNTO DE MÍNIMO ESPESOR ANTERIOR (EN VERDE) CALCULADA EN UNA CÓRNEA SANA (EN AZUL) Y EN UNA CÓRNEA CON QUERATOCONO (EN ROJO)

FIGURA 3.19 DESVIACIÓN DEL PUNTO DE MÍNIMO ESPESOR ANTERIOR CALCULADA PARA UNA CÓRNEA SANA (EN AZUL) Y PARA UNA CÓRNEA CON QUERATOCONO (EN ROJO)

FIGURA 3.20 DESVIACIÓN DEL PUNTO DE MÍNIMO ESPESOR POSTERIOR CALCULADA PARA UNA CÓRNEA SANA (EN AZUL) Y PARA UNA CÓRNEA CON QUERATOCONO (EN ROJO)

FiguRA 3.21 PROCEDIMIENTO PARA EL CÁLCULO DEL VOLUMEN CILÍNDRICO CORNEAL R-X

FIGURA 3.22 REPRESENTACIÓN ESQUEMÁTICA DE LAS DIFERENCIAS DE LOS VOLÚMENES CILÍNDRICO CORNEALES CON RADIO 0.5, 1.0, 1.5 Y 2.0 MM PARA UNA CÓRNEA SANA (EN AZUL) Y UNA CÓRNEA CON QUERATOCONO (EN ROJO).

FIGURA 4.1 DiAGRAMAS DE CAJA Y BIGOTES (P10-90) CON LOS VALORES DE VOLUMEN TOTAL Y LAS DIFERENTES ÁREAS MODELADAS EN FUNCIÓN DE CADA GRUPO (ESCALA AMSLER- KRUMEICH) .......138

FIGURA 4.2 DiAGRAMAS DE CAJA Y BIGOTES (P10-90) CON LOS VALORES LAS DIFERENTES DESVIACIONES EN FUNCIÓN DE CADA GRUPO (ESCALA AMSLER- KRUMEICH).

FigURA 4.3 DiAGRAMAS DE CAJA Y BIGOTES (P10-90) CON LOS VALORES DE POSICIÓN DE LOS CENTROS DE MASAS EN FUNCIÓN DE CADA GRUPO (ESCALA AMSLER- KRUMEICH)

FIGURA 4.4 DiAGRAMAS DE CAJA Y BIGOTES (P10-90) CON LOS VALORES DEL VOLUMEN DE LOS DIFERENTES CILINDROS CORNEALES EN FUNCIÓN DE CADA GRUPO (ESCALA AMSLER- KRUMEICH). 141

FIGURA 4.5 REPRESENTACIÓN ESQUEMÁTICA DE LA DIFERENCIA EN LOS VOLÚMENES DE LOS CILINDROS CORNEALES CON RADIO 0.5, 1.0, 1.5 Y 2.0 ENTRE CÓRNEAS NORMALES (A-D) Y CÓRNEAS CON QUERATOCONO (E-H).....

FIGURA 4.6 REPRESENTACIÓN GRÁFICA DE LA SENSIBILIDAD VERSUS LA ESPECIFICIDAD DE LAS VARIABLES CON UN ÁREA BAJO LA CURVA SUPERIOR A 0.7 


\section{Índice de tablas}

TABLA 2.1 RELACIÓN ENTRE LAS DISTINTOS TIPOS DE CURVAS GEOMÉTRICAS DE LA CÓRNEA EN FUNCIÓN DE LOS PARÁMETROS ASFERICIDAD Y SU RELACIÓN CON LA EXCENTRICIDAD Y FACTOR DE FORMA, ADAPTADA DE MONTALBÁN (2013).

TABLA 2.2 CLASIFICACIÓN DEL QUERATOCONO CLÍNICO SEGÚN AMSLER-KRUMEICH, ADAPTADA DE MONTALBÁN (2013).

TABLA 4.1 DESCRIPTIVOS BÁSICOS (MEDIA E IC 95\%) Y DIFERENCIAS ENTRE GRUPOS EN LAS VARIABLES MODELADAS

TABLA 4.2 DIFERENCIAS ENTRE EL GRUPO NORMAL (FIGS. 7A-D) VERSUS EL GRUPO DE QUERATOCONO (FIGS. 7E-H EN EL VOLUMEN CILÍNDRICO CORNEAL DE RADIO 0.5, 1.0, 1.5 Y 2.0 MM (MEDIA Y DESVIACIÓN TÍPICA; U-MANN-WHITNEY-WILCOXON TEST)

TABLA 4.3 COMPARATIVA ENTRE GRUPOS ESTABLECIDOS CON LA CLASLIFICACIÓN DE AMSLERKRUMEICH; TEST DE KRUSKALL-WALLIS Y TAMAÑO DEL EFECTO (ES) ${ }^{1}$...

TABLA 4.4 ANÁLISIS ROC DE LA SENSIBILIDAD VERSUS 1-ESPECIFICIDAD EN EL DIAGNÓSTICO PARA LAS VARIABLES ESTUDIADAS 


\section{Resumen}

La córnea es una estructura biológica viva cuya arquitectura presenta una morfología singular, ya sea en un estado natural o patológico. Esta singularidad ha sido caracterizada a lo largo de toda la historia en el campo de la oftalmología y la óptica a través de la generación de modelos genéricos o de modelos personalizados de la córnea humana. Hoy en día, el desarrollo de nuevas tecnologías permite caracterizar la morfología corneal a partir de los denominados equipos topográficos; estos equipos aportan una caracterización personalizada de índole cualitativa y cuantitativa al médico oftalmólogo. Sin embargo, los sistemas de diagnóstico de las patologías corneales están basados en unos índices de valoración de la irregularidad de las superficies corneales que son calculados a partir de algoritmos específicos internos para cada topógrafo corneal y de los cuales se desconoce su programación.

Por este motivo en esta tesis doctoral se establece un nuevo procedimiento fundamentado en la geometría computacional para obtener un modelo sólido 3D personalizado in vivo de la córnea humana utilizando herramientas de Diseño Geométrico Asistido por Ordenador. Este modelo virtual reconstruye fidedignamente las superficies de la cara anterior y posterior de la córnea, a partir de unos datos aportados por los topógrafos corneales denominados datos en bruto (sin ningún trato mediante algoritmo) tanto para los ojos de pacientes sanos como para los ojos de pacientes diagnosticados con la patología ectásica más común, el queratocono.

A partir del nuevo modelo sólido obtenido, se definen unos índices de caracterización de la morfología corneal basados en variables geométricas, los cuales pueden ser utilizados como unos nuevos índices de diagnóstico de la patología ectásica objeto de estudio debido a que presentan una elevada sensibilidad y especificidad para su diagnóstico. 


\section{Abstract}

The cornea is a living biological structure whose architecture has a unique morphology, either in a natural or diseased condition. This uniqueness has been characterized throughout all history in the field of ophthalmology and optics through the generation of generic or customized models of human cornea. Today, the development of new technologies leads to characterize the corneal morphology from the so-called topographic devices; these devices provide a personalized qualitative and quantitative characterization of its nature for the ophthalmologist. However corneal pathological diagnosis systems are based on indicators of the irregularity of the corneal surfaces, which are calculated from specific internal algorithms for each corneal topographer and whose programming is unknown.

For that reason, this doctoral thesis establishes a new procedure based on computational geometry to obtain a 3D solid model, personalized and in vivo of the human cornea by using Computer Aided Geometrical Design tools. This virtual model represents accurately both the anterior and posterior corneal surfaces from a set of raw data (without any algorithm treatment) provided by the corneal topographers for both healthy corneas and corneas with the most common ectasic disease, the keratoconus.

The new solid model obtained is later analyzed to define a set of indices that enable the characterization of the corneal morphology and that are based on geometric variables. These indices can be used as new indicators for the diagnosis of the keratoconus disease due to their high sensibility and specificity. 
Introducción 
El órgano que se encarga del sentido de la vista en el ser humano es el ojo. Su estructura resulta extremadamente compleja y está integrada por un sistema óptico consistente en un conjunto de órganos con una determinada capacidad refractiva, que al actuar como lentes hacen converger en la retina los rayos de luz que proceden del exterior, dando lugar a que se forme la imagen óptica (Figura 1.1). Estos rayos constituyen el estímulo visual que se transforma en impulsos electroquímicos, los cuales se conducen hasta el cerebro a través del nervio óptico para su procesamiento. De esta forma el ser humano adquiere la capacidad de percibir la forma de los objetos que le rodean (Hermsen y Dreyer, 1982).
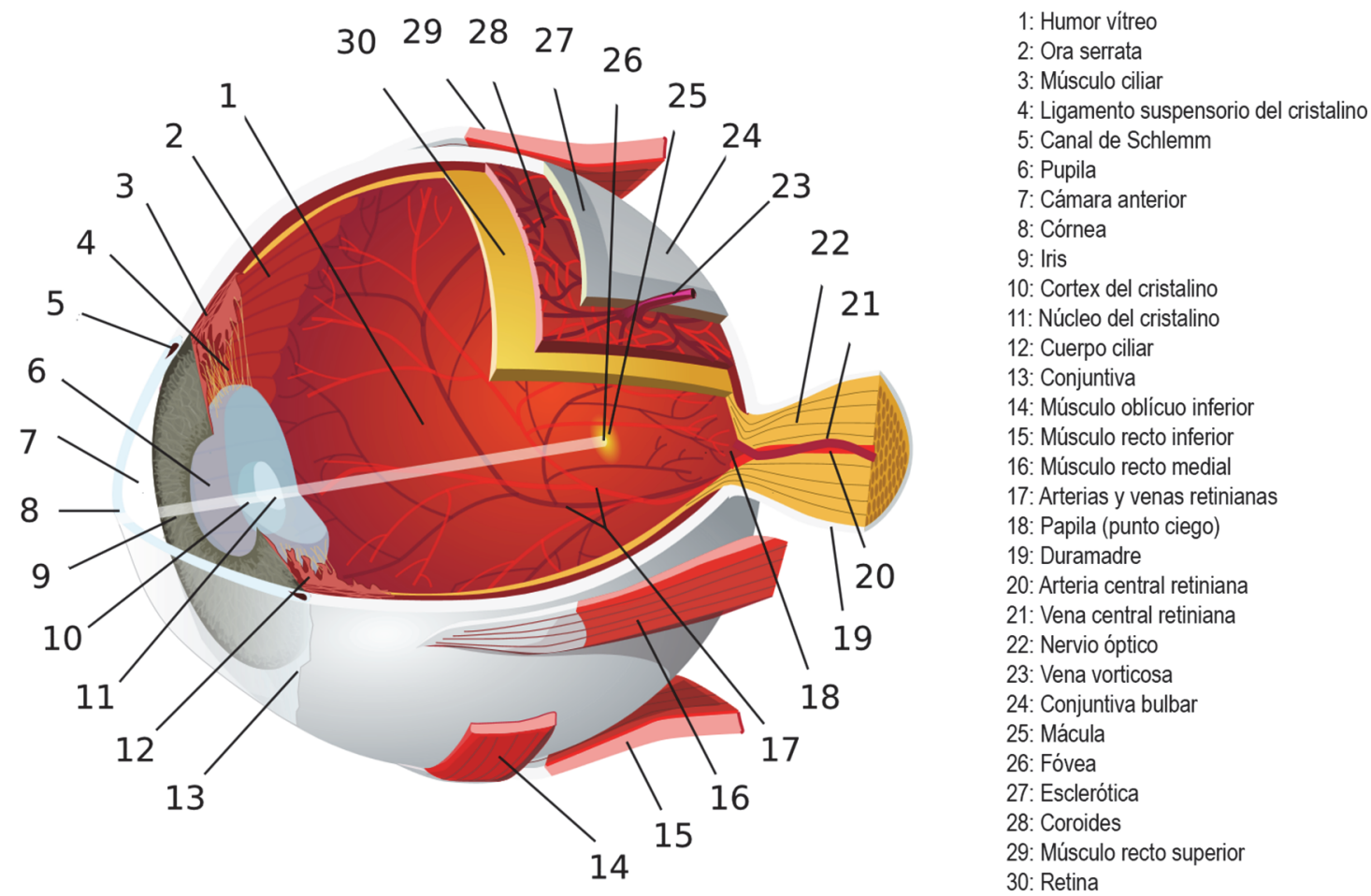

Figura 1.1 Estructura completa del Ojo humano

Una parte fundamental del ojo humano es la córnea (Figura 1.2), que es el elemento refractivo más importante del dioptrio ocular por su ubicación anatómica (Hermsen y Dreyer, 1982). Para que esta importante función pueda ser desempeñada, la cualidad de transparencia debe:

- Mantenerse de forma constante.

- Ser capaz de enfrentarse a los cambios morfológicos que el crecimiento, el envejecimiento natural, el daño o las deformaciones de los tejidos van a provocar durante su vida (Fung, 1993; Akpek y Smith, 2013).

- Tener la capacidad de regenerarse frente a diferentes agresiones externas a las que se ve sometida por su relación con el medio ambiente (Oie y Nishida, 2013). 


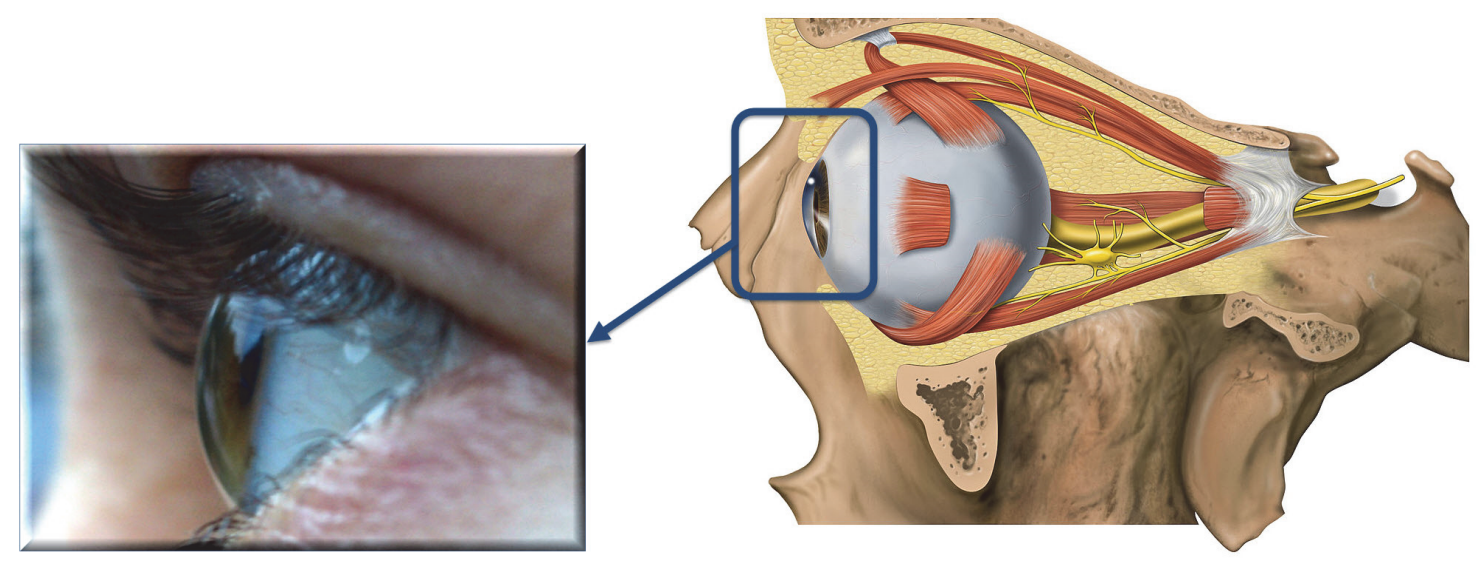

Figura 1.2 La córnea humana

Asimismo, la caracterización morfológica de la córnea en la práctica clínica ha sufrido una creciente demanda debido a la importancia de su estudio para comprender que determinados cambios en la córnea afectan a la calidad visual de los pacientes (Piñero et al., 2010a), a la evolución, diagnóstico y tratamiento de determinadas patologías corneales (Levy et al., 2004; Vryghem et al., 2010; Ambrósio et al., 2011), y a la planificación de cirugías oftalmológicas (Alessio et al., 2001; Ribeiro et al., 2012).

Es por ello, que la córnea debe ser estudiada bajo dos escenarios:

- Escenario natural o en ausencia de alteraciones anómalas (Figura 1.3). En este caso los tejidos que forman parte de la arquitectura corneal están sometidos a un equilibrio dinámico entre factores oculares intracorneales (espesor del ápex, densidad corneal, etc.) y factores oculares extracorneales (presión intraocular, presión atmosférica de la superficie anterior de la córnea, etc.), manteniendo un comportamiento equilibrado entre tensiones y deformaciones (estado de mínima energía), y adquiriendo un estilo geométrico singular con una curvatura estable en toda su superficie y con un poder óptico óptimo (Buey Salas y Peris Martinez, 2014).
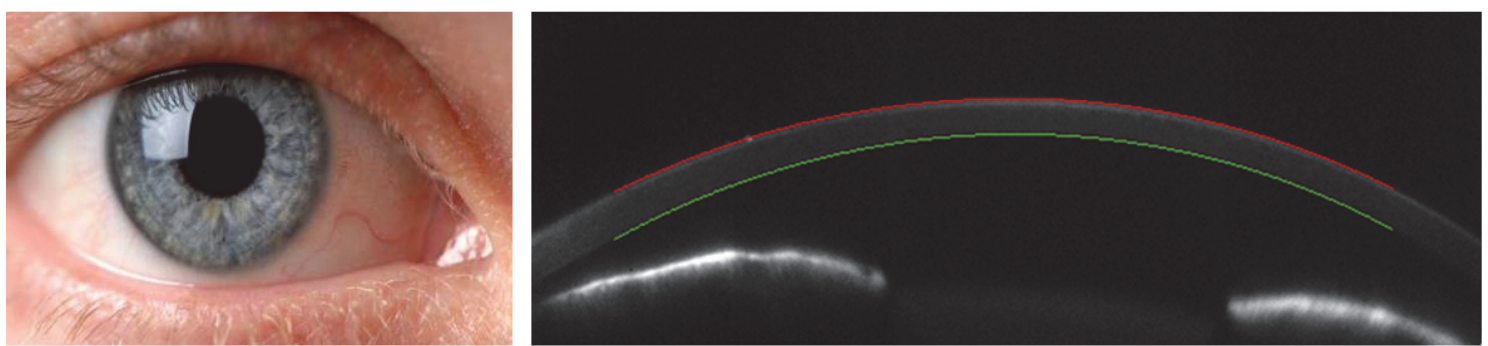

Figura 1.3 La córnea en un escenario natural

- Escenario patológico o con presencia de alteraciones anómalas (Figura 1.4), en el cual los tejidos que forman parte de la arquitectura corneal poseen una debilidad estructural debido a un proceso patológico, tal y como sucede con las patologías ectásicas corneales como el queratocono (Rabinowitz, 1998). Esta debilidad en la estructura se manifiesta a nivel clínico por una alteración de la 
morfología de su superficie, lo que implica una redistribución de la paquimetría corneal, cambios en la geometría de su superficie y una pérdida de su poder óptico (Piñero et al., 2010a).
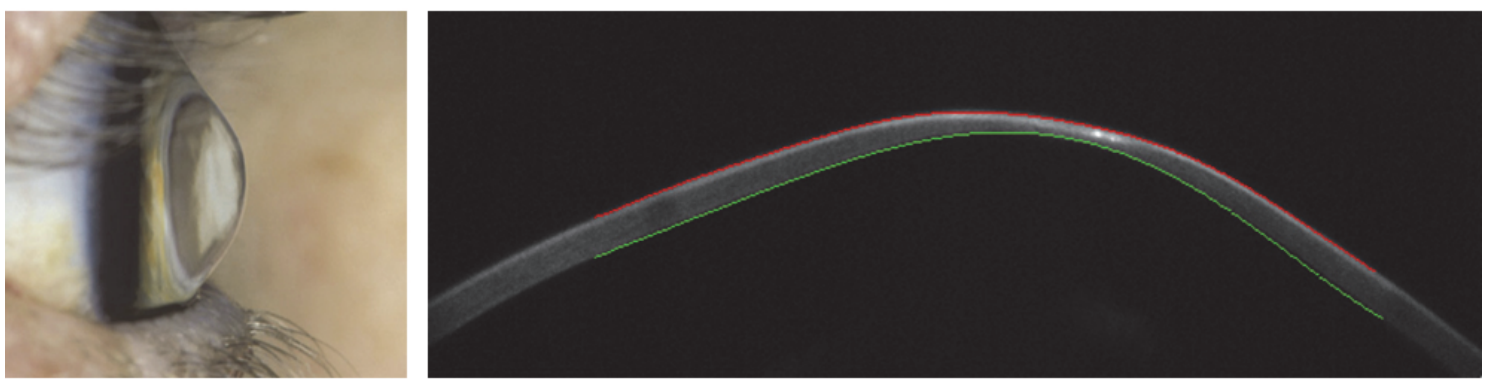

Figura 1.4 La córnea en un escenario patológico

\subsection{Morfología corneal. Modelos}

El conocimiento de la morfología corneal ha sido adquirido a lo largo de la historia del ser humano en función del objetivo del análisis a realizar, pudiendo tener diferentes finalidades, como una finalidad óptica o de diagnóstico clínico de una determinada patología, etc. En todos estos casos se puede optar por dos estrategias de modelado diferentes: modelos genéricos o modelos personalizados (Figura 1.5).

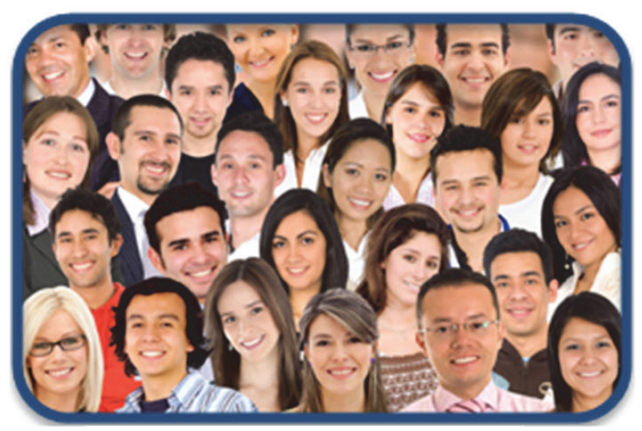

Modelos genéricos

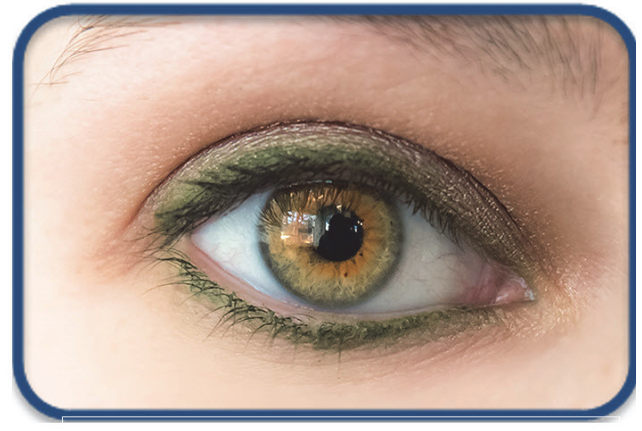

Modelos personalizados

Figura 1.5 Modelos de la córnea humana

\subsubsection{Modelos Genéricos}

Estos modelos están basados en dimensiones promedio válidos para reproducir y extraer resultados de aplicación a toda la población. En este contexto, el modelado de la córnea humana, al igual que el modelado de cualquier otro órgano humano que sea objeto de estudio, debe comenzar por determinar el objetivo (normalmente para cuantificar las propiedades ópticas y mecánicas) y el alcance de la caracterización morfológica. De esta forma se establece el nivel de detalle geométrico o de cualquier otro aspecto que forma parte de la fase de desarrollo del modelo (Lanchares et al., 2008). 


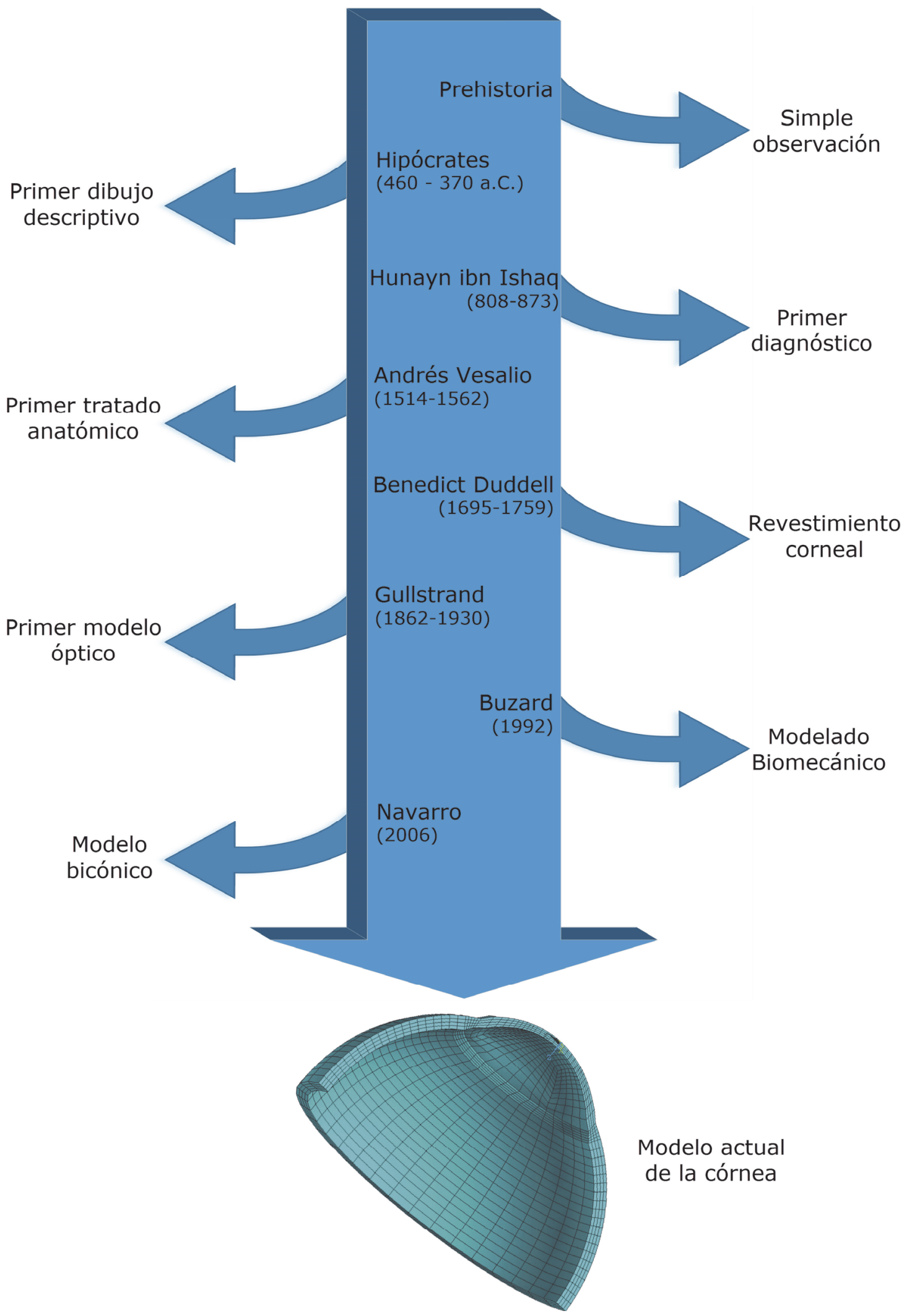

Figura 1.6 Los modelos genéricos a lo largo de la historia 
Los primeros modelos genéricos (Figura 1.6) surgieron por simple observación del aspecto externo de la superficie ocular, tal y como ha quedado reproducido en numerosas pinturas de los tiempos prehistóricos, y posteriormente, en base a disecciones y estudios anatómicos, los cuales se llevaron a cabo con grandes dificultades por la falta de medios para conservar los cuerpos y por las restricciones propias de cada época.

Asimismo, el primer dibujo descriptivo de la superficie corneal del que se tenga constancia corresponde a Hipócrates (460 - 370 a. C.) en la época de la Grecia Clásica. Con posterioridad, han sido presentados distintos modelos asociados a diferentes épocas, todos ellos más evolucionados que los anteriores en correlación con los avances científicos del momento (Güemez-Sandoval y Güemez-Sandoval, 2009).

Igualmente, el primer diagnóstico científico de la superficie ocular corresponde al médico de origen árabe Hunayn ibn Ishaq (808-873), quién representó en el mismo dibujo de la superficie ocular una sección sagital de éste (Duke-Elder y Wybar, 1961).

Sin embargo, el impulso al conocimiento anatómico no se produjo hasta la invención de la imprenta, donde Andrés Vesalio (1514-1562) escribió el primer tratado anatómico moderno titulado "De Humani Corporis Fabrica", basado en su propia investigación (Güemez-Sandoval y Güemez-Sandoval, 2009).

Por otra parte, la primera descripción detallada de la anatomía del revestimiento corneal apareció en 1729 en el libro titulado "Disease of the horney coat of the eye" escrito por el inglés Benedict Duddell (1695-1759), donde presentó una descripción detallada de las capas constitutivas del globo ocular (Wyman, 1992).

No obstante, no fue hasta principios del siglo XX donde el oftalmólogo Gullstrand (1862-1930) presentó el que está considerado como el primer modelo óptico preciso de la córnea, basado en seis superficies esféricas (Sulek, 1967; Timoney y Breathnach, 2013): dos superficies para modelar las caras anterior y posterior de la córnea, y cuatro superficies para modelar el gradiente del índice de refracción de la lente o núcleo, siendo este modelo el punto de partida para el desarrollo de una serie de modelos posteriores.

Si se realiza una revisión de la literatura existente se puede encontrar una amplia variedad de modelos ópticos siguiendo cada uno un enfoque diferente. Estos enfoques se clasifican según los siguientes paradigmas:

- Número de componentes anatómicos (superficies): reducida (una superficie refractiva) (Emsley, 1952; LeGrand y ElHage, 2013) versus anatómica (varias superficies refractivas) (Helmholtz, 1962; Liou y Brennan, 1997; Bakaraju et al., 2008).

- Dispersión cromática (índices de refracción dependientes de la longitud de onda): monocromática (Le Grand y El Hage, 2013) versus policromática (Navarro et al., 1985; Thibos et al., 1992). 
- Calidad óptica e imagen: paraxial (sus componentes se encuentran alineados utilizando un solo eje óptico y sus superficies refractivas son esféricas) (Le Grand y El Hage, 2013; Helmholtz, 1962) versus finito (sus componentes pueden estar alineados de forma arbitraria y sus superficies refractivas pueden ser no esféricas) (Lotmar, 1971; Navarro et al., 1985; Navarro et al., 2006; Smith et al., 2008).

- Índice de refracción: uniforme (Lotmar, 1971; Navarro et al., 1985) versus diverso (Lotmar y Lotmar, 1974; Liou y Brennan, 1997; Pomerantzeff et al., 1984; Maceo et al., 2011; Xie et al., 2015).

- Amplitud del campo visual: superficies refractivas en el eje (Le Grand y El Hage, 1980; Liou y Brennan, 1997) versus superficies refractivas fuera del eje (aberraciones periféricas) (Lotmar y Lotmar, 1974; Kooijman, 1983; EscuderoSanz y Navarro, 1999; Xie et al., 2014; Forster et al., 2015).

- Nivel de alojamiento o acomodación: relajado (sin cambios durante la acomodación) (Lotmar, 1971) versus corregido (considerando cambios durante el mecanismo de acomodación) (Navarro et al., 1985; Blaker, 1980; PopiolekMasajada y Kasprzak, 2002; Sheil et al., 2014).

- Alteraciones morfológicas relacionadas con la edad: independiente (Gullestrand, 1924) versus dependiente (Norrby, 2005; Goncharov y Dainty, 2007; Diaz et al., 2008; Navarro et al., 2013; Reilly, 2014).

Tal variedad de modelos refleja el hecho de que todos los modelos genéricos son incompletos, ya que el ojo humano real contiene además de la córnea otros elementos anatómicos, trabaja con luz policromática, presenta un rendimiento óptico limitado (aberraciones ópticas), posee un campo visual amplio, utiliza un mecanismo de acomodación para enfocar los objetos en función de la proximidad o lejanía de estos y evoluciona a lo largo de la vida, por lo que cualquier modelo debe de considerar a corto plazo el alojamiento y a largo plazo los cambios asociados al envejecimiento.

Por otra parte, a principios de la década de los años 90 a raíz de la publicación del primer caso de ectasia iatrogénica surgió un nuevo interés por el modelado biomecánico (Albertazzi, 2010), consistente en predecir mediante un modelo numérico desarrollado por el método de los elementos finitos la respuesta de la córnea ante diversas situaciones, como patológicas, cirugías y tratamientos no quirúrgicos ya sean invasivos o no (Buzard, 1992). La fiabilidad de estos modelos de comportamiento depende de la geometría adoptada de la córnea y de la bondad del valor de los parámetros que definen el comportamiento del material tanto a nivel microscópico como macroscópico.

En el ámbito de la biomecánica, desde los primeros trabajos basados en modelos bidimensionales asimétricos (Buzard, 1992; Bryant y McDonnell, 1996), hasta los más actuales (Vellara y Patel, 2015) se han empleado aproximaciones a la geometría corneal en base a los distintos modelos ópticos anteriormente comentados, pudiéndose adoptar diferentes aproximaciones a la geometría base de la córnea en función del modelo a 
considerar. En todos los casos se pretende que el modelo considerado sea capaz de representar las características esenciales de la córnea media.

Un estándar ampliamente aceptado en la comunidad oftalmológica consiste en utilizar como aproximación a la superficie corneal un modelo que esté basado en una superficie cónica o bicónica (Navarro et al., 2006), como por ejemplo los siguientes (Figura 1.7):

- Modelado esférico (Alustrué et al., 2006; Pandolfi y Manganiello, 2006; Fernandez et al., 2006; Gefen et al., 2009; Fuller y Alperin, 2013).

- Canónica de revolución o elipse corneal (Navarro et al., 2009).

- Superficie tórica (Smadja et al., 2013).

- Modelo bicónico (Elsheikh et al., 2009; Gatinel et al., 2009; Arba-Mosquera et al., 2010; Sourmelidis et al., 2011; Bao et al., 2013).

- Elipsoide de no revolución (Calosssi, 2007; González et al., 2008; Hang et al., 2013).

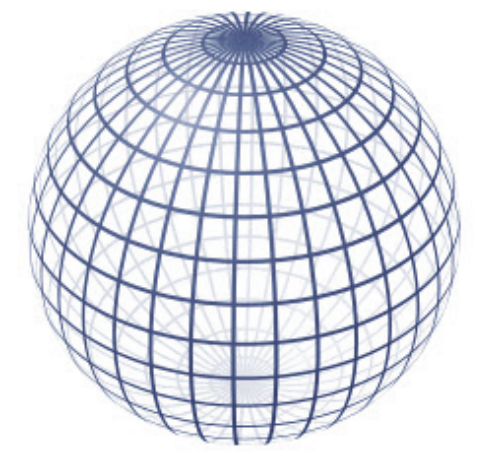

Esfera

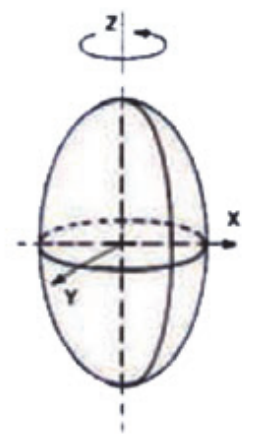

Elipsoide de revolución

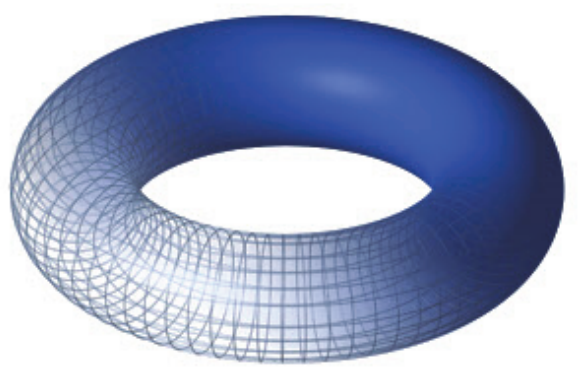

Superficie tórica

Figura 1.7 Superficies cónicas y bicónicas 
La presencia de tal variedad de modelos genéricos se debe a que la superficie corneal no se ajusta perfectamente a ninguna superficie analítica. En todos los casos se pretende que el modelo base geométrico propuesto sea capaz de capturar las características morfológicas esenciales de la córnea media, y al mismo tiempo haga que los valores residuales obtenidos, es decir las irregularidades que presenta la superficie corneal, sean menores que la superficie base.

De esta forma se consigue que la superficie base geométrica presente una descripción global de la morfología corneal de forma aceptable. En referencia al ajuste del residuo, éste se realiza normalmente por métodos matemáticos basados en los polinomios de Zernike.

En resumen, estos modelos son válidos cuando analizamos o reproducimos los resultados que le son de aplicación a un conjunto de la población en los campos de la óptica y la biomecánica corneal.

Sin embargo, estos modelos no son válidos para estudiar el diagnóstico clínico de determinadas patologías corneales al prescindir de las características individuales de cada paciente en particular.

\subsubsection{Modelos Personalizados}

Estos modelos, a diferencia de los genéricos, permiten estudiar el caso particular de un paciente específico con diferentes finalidades, como la óptica, donde puede ser valorada la agudeza visual de un paciente, o el diagnóstico clínico mediante la caracterización de una patología corneal, o el análisis del comportamiento biomecánico de los tejidos constitutivos de su estructura corneal, entre otros.

En todos estos casos la caracterización puede ser elaborada: i) a partir de los datos obtenidos mediante técnicas de tratamiento de imágenes, o ii) usando la información aportada por unos equipos específicos denominados topógrafos corneales.

\subsubsection{Caracterización a partir de técnicas de tratamiento de imágenes}

Esta técnica puede ser aplicada en los campos de la óptica, del diagnóstico clínico de patologías corneales o de lesiones oculares, de la anatomía ocular y de la biomecánica corneal.

En todos estos modelos, la fiabilidad depende del proceso de adquisición de datos y posterior tratamiento de las imágenes obtenidas de los equipos oftalmológicos como son los Tomógrafos de Coherencia Óptica (OCT en inglés), de Biomicroscopía Ultrasónica (BMU, en inglés) o de Resonancia Magnética (MRI en inglés) (Figura 1.8).

Los modelos personalizados obtenidos con una finalidad óptica están basados fundamentalmente en técnicas de tratamiento de imágenes obtenidas de un OCT, pudiendo así cuantificar la influencia del espesor corneal en el índice de refracción (Lai y Tang, 2014), o la influencia de la inclinación y del descentrado de una lente 
intraocular en la potencia corneal (Einighammer et al., 2009; Ribeiro et al., 2012; Wang et al., 2013). Otros equipos, como los biómetros, se pueden utilizar para medir la potencia corneal a partir de las imágenes generadas por éstos (Ribeiro et al., 2013).

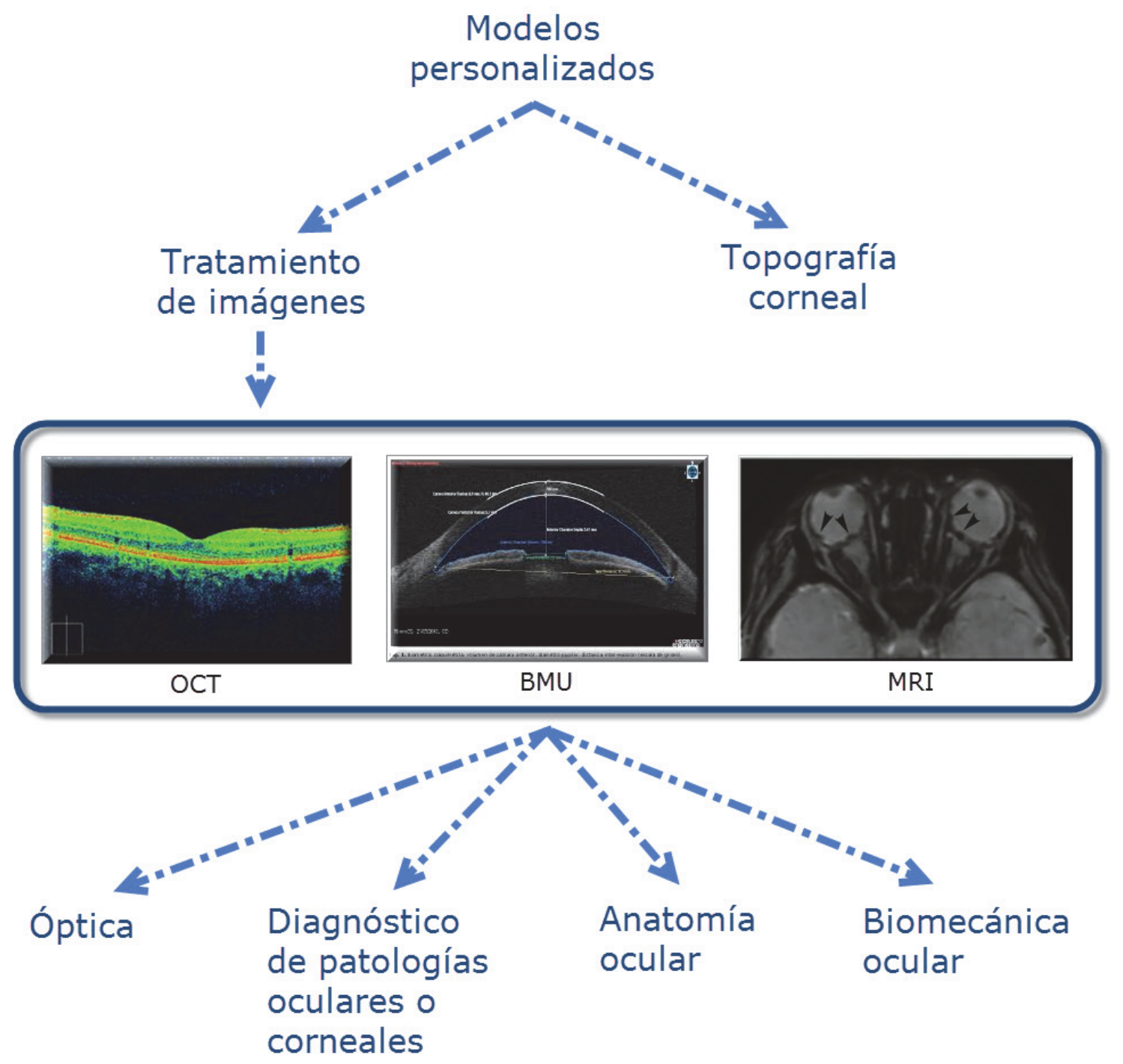

Figura 1.8 Modelos personalizados. Tratamiento de imágenes

Estas técnicas de tratamiento por imágenes obtenidas por OCT también han sido empleadas para el diagnóstico de patologías relacionadas con la morfología corneal, concretamente para el diagnóstico y tratamiento del Queratocono, que se considera la ectasia corneal más importante. El diagnóstico y tratamiento individualizado de esta patología puede implicar varias etapas: en primer lugar la caracterización de la patología a partir de la adquisición y tratamiento de las imágenes (Ortiz et al., 2011), caracterización del posterior tratamiento invasivo de la patología mediante la inserción de anillos intracorneales (Ortiz et al., 2012), y finalmente una valoración objetiva de la influencia en la mejora del tratamiento de la patología del queratocono en función de las características geométricas de los anillos intracorneales (Pérez-Merino et al., 2013). 
Además de la córnea, esta técnica permite también caracterizar otros componentes del ojo humano para el diagnóstico de alguna patología relacionada con su morfología, como por ejemplo:

- El canal de Schlemm a partir de imágenes obtenidas de un OCT por su relación con el Glaucoma (Kagemann et al., 2014).

- La membrana de Bowman a partir de imágenes de un microscopio de fuerza atómica por su influencia en la Calidad Visual de los pacientes (Talu et al., 2015).

- El nervio óptico a partir de microscopía confocal de barrido laser dada su relación con la enfermedad del Glaucoma (Allgier et al., 2011) o de un OCT (He y Bazan, 2012; Dorairaj et al., 2012; You et al., 2013).

- El Globo ocular a partir de imágenes obtenidas de resonancia magnética por su influencia en la miopía (Xing y Wei, 2014).

- La Esclera a partir de imágenes obtenidas por un microsopio confocal para correlacionar geométricamente las variaciones que sufre en función de la edad o el género (Vurgese et al., 2012).

- La retina a partir de un OCT para conocer sus variaciones morfológicas durante la enfermedad autoinmune uveoretinitis (Chu el al., 2013).

Asimismo, esta técnica puede ser utilizada para el diagnóstico clínico de patologías originadas a partir de lesiones oculares, como la irritación ocular originada por la inmersión de un cuerpo extraño en la lágrima ocular (Zorn-Kruppa et al., 2014), o la enfermedad del ojo seco a partir de la caracterización de las glándulas de Meibomio (Hwang et al., 2013), en ambos casos a partir de las imágenes generadas por el OCT.

Como se ha comentado anteriormente, lo más importante en la generación de un modelo personalizado mediante esta técnica es la fiabilidad del proceso de adquisición y tratamiento de las imágenes.

Una revisión de la literatura existente presenta algunos trabajos donde a raíz de la falta de datos para reconstruir la imagen capturada (fundamentalmente debido a un error durante el proceso de adquisición o a una errónea integración del binomio examinador-paciente) se recurre al empleo de software comercial para la reconstrucción de sus imágenes, lo que puede implicar un sesgado de los datos, como es el caso de la caracterización morfológica del segmento anterior del ojo a partir de imágenes obtenidas de un biomicroscopio ultrasónico realizada por Wang et al. (2015) y utilizando el software comercial Adobe Photoshop ${ }^{\circledR}$ para su reconstrucción, o la caracterización de la retina a partir de imágenes de un OCT realizada por Garcia Garrido et al. (2014) y retocadas con el software comercial CorelDraw ${ }^{\circledR}$.

Otros trabajos presentan un modelo tratado mediante software específico propio, como es el caso de la caracterización del segmento anterior a partir de imágenes obtenidas por un OCT realizada por Ang et al. (2013), en cuyo caso comparan las variables 
geométricas obtenidas con las variables aportadas por el OCT para comprobar la validez clínica de su método.

Dentro del campo de la anatomía fisiológica del cuerpo humano, algunos autores proponen la caracterización morfológica simplemente para conocer su morfología real, como es el caso de la caracterización del ojo humano llevada a cabo por Wang et al. (2010) y generada a partir de la definición del contorno de las imágenes realizadas sobre las secciones de corte al ojo en un escenario in vitro, es decir, fuera de un ambiente natural, utilizando para ello un equipo fotográfico. Sin embargo los autores manifiestan la dificultad de localización y adquisición de los datos de contorno de las imágenes generadas.

Otros ejemplos son la caracterización del limbo a partir de imágenes obtenidas de un OCT realizada por Bizheva et al. (2011), así como el modelo tridimensional de la superficie corneal anterior de un ojo humano generado a partir de imágenes obtenidas de un OCT por Zheng et al. (2013).

Sin embargo, todas estas caracterizaciones no tienen mayor finalidad que la presentación de la morfología de una estructura biológica, pero en lo que respecta a la córnea, la estructura biológica de interés en esta tesis, no consta hasta la fecha la adquisición y posterior tratamiento de las imágenes en una tecnología que permita la generación de un modelo en un formato virtual libre.

Por otro lado, también resulta de interés la generación de modelos personalizados en el campo de la biomecánica corneal (Nejad et al., 2014) mediante un análisis del comportamiento mecánico de los tejidos constitutivos de la estructura corneal de un paciente ante determinadas patologías y sus posteriores tratamientos invasivos o no. En este campo, inicialmente se debe caracterizar la geometría del paciente para la posterior simulación del modelo numérico desarrollado por elementos finitos y fundamentado en las características propias de los tejidos constitutivos de su estructura, las cuales se obtienen mediante equipos de ensayo biomecánico. Los datos para la generación del modelo geométrico se obtienen fundamentalmente a partir de las imágenes obtenidas por un equipo OCT (Studer et al., 2013; Lombardo et al., 2014; Kling et al., 2014) o por un equipo de microscopía óptica (Boote et al., 2013) o por un equipo de rayos X (Antony, 2015; Whitford et al., 2015). Otros autores definen la geometría a partir de un de un equipo específico diseñado para la realización de ensayos mecánicos (Kling y Marcos, 2013).

\subsubsection{Caracterización a partir de Topografía Corneal}

Otra técnica de caracterización personalizada para generar un modelo específico del paciente es la topografía corneal. Se trata de una técnica exploratoria no invasiva que permite analizar tanto de forma cualitativa como cuantitativa la morfología de la córnea, siendo capaz de identificar patrones normalizados y descartar alteraciones potencialmente devastadoras para la visión derivados de los trastornos patológicos 
ectásicos (Maldonado et al., 2008; Ambrósio et al., 2011; Piñero et al., 2012; Piñero, 2013; Ambrósio et al., 2013).

La topografía se realiza por medio de unos equipos denominados topógrafos corneales. Son unos instrumentos ampliamente utilizados por la comunidad médica oftalmológica que permiten una caracterización anatómica y geométrica de la córnea a partir de la reconstrucción de su superficie (Piñero, 2013).
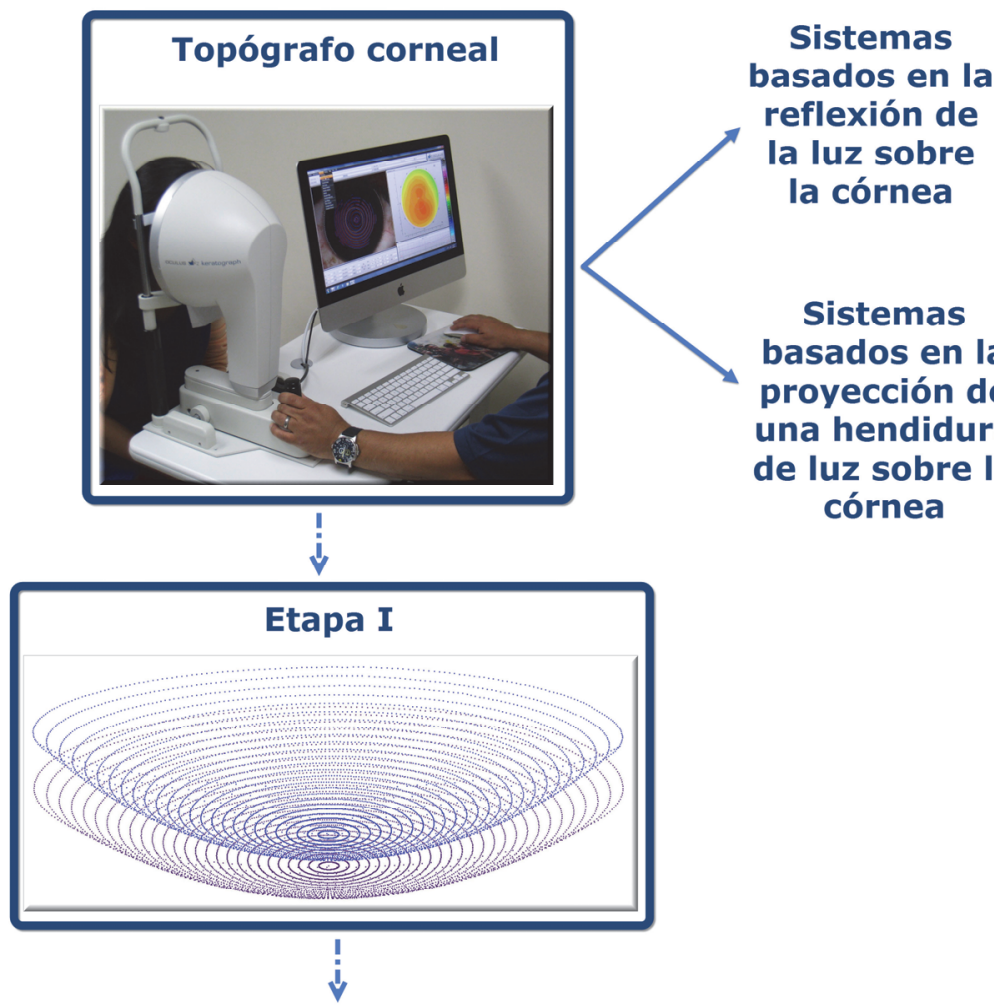

Sistemas basados en la proyección de una hendidura de luz sobre la córnea

Principio de fotografía estándar

Principio de fotografía Scheimpflug
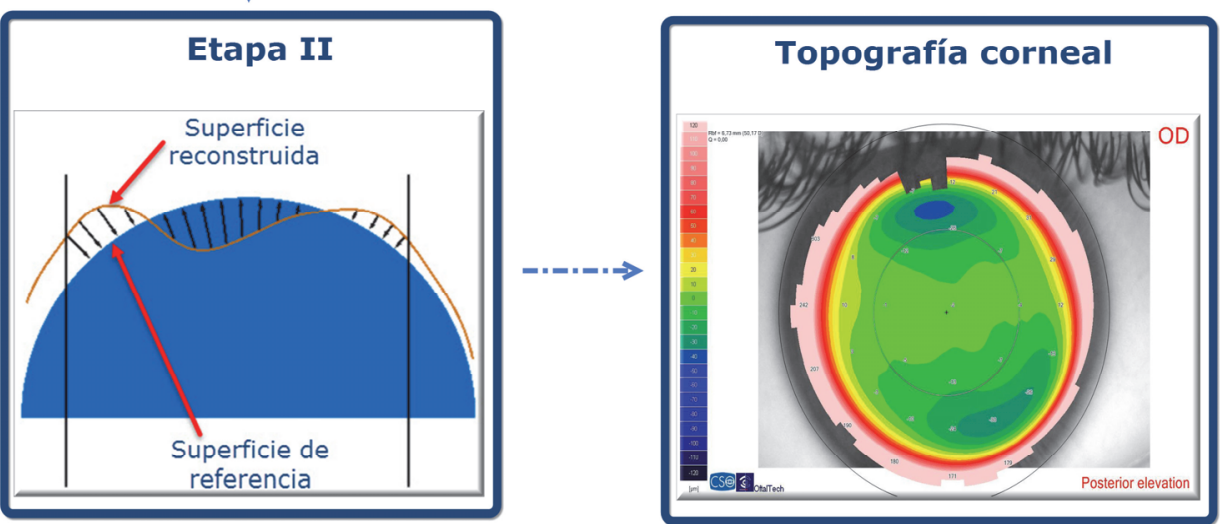

Figura 1.9 Etapas de un topógrafo corneal 
Los topógrafos corneales contemplan dos etapas claramente diferenciadas (Figura 1.9) para presentar al médico oftalmólogo los datos obtenidos de la topografía corneal que le sirvan a éste como base para el diagnóstico clínico de la ectasia corneal:

- Una primera etapa que corresponde al proceso de adquisición y tratamiento interno de los datos. Es en esta etapa donde los topógrafos obtienen los datos altimétricos en forma de matriz de elevaciones sobre un conjunto discreto y finito de puntos representativo de la superficie corneal, denominados datos en bruto (Cavas et al., 2014).

Además, es en esta etapa donde se manifiestan unos errores denominados intrínsecos y extrínsecos, los cuales serán descritos en un subcapítulo siguiente.

- Y una segunda etapa, donde a partir de los datos constitutivos de la matriz de elevaciones se procede a la reconstrucción de la superficie corneal para su posterior comparación con una superficie de referencia, normalmente una esfera, y obtener por comparación entre ambas superficies el mapa topográfico de la superficie corneal, la cual es objeto de análisis en un capítulo posterior.

Actualmente, los topógrafos corneales están basados en dos tecnologías: i) los sistemas basados en la reflexión de la luz sobre la córnea y ii) los sistemas basados en la proyección de una hendidura de luz sobre la córnea.

Ambas tecnologías (Figura 1.10) proporcionan diferentes mapas topográficos de la superficie corneal anterior, posterior y paquimétricos, así como unos índices resumen para el seguimiento y la valoración clínica de las topografías corneales. 
Sistemas basados en la reflexión de la luz sobre la córnea

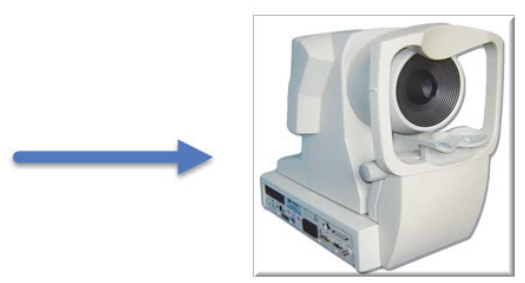

Discos de Plácido

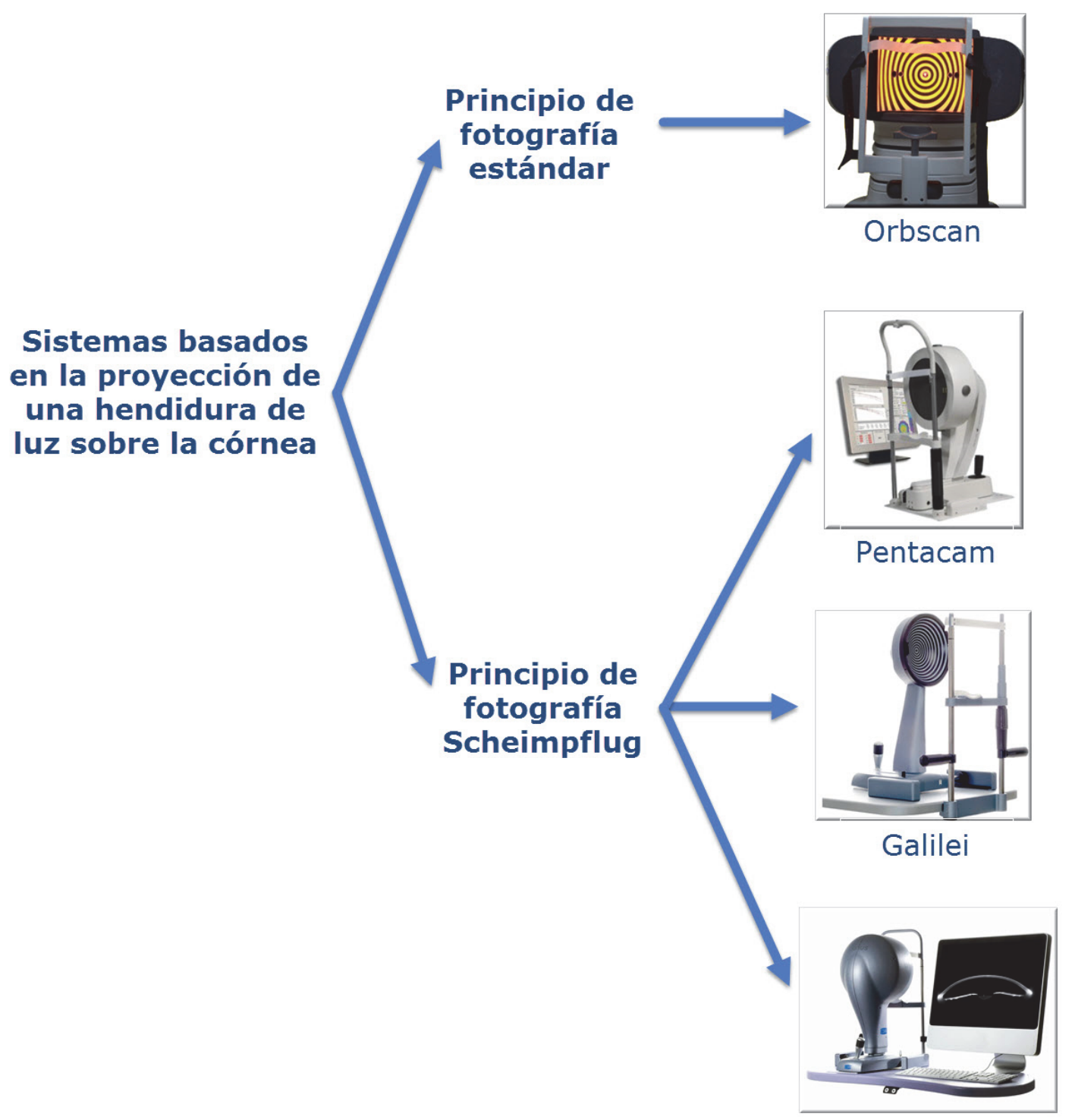

Sirius

Figura 1.10 Tecnologías en las que están basados los topógrafos corneales 


\subsection{Sistemas basados en la reflexión de la luz sobre la córnea}

Los topógrafos corneales basados en esta tecnología, también denominados video queratoscopios (Montalbán, 2013), se fundamentan en la aplicación de los principios de la óptica geométrica de los espejos convexos a un instrumento de dimensiones conocidas. En este caso, el instrumento es un conjunto de anillos concéntricos, los denominados Discos de Plácido, donde a partir de su proyección sobre la córnea se forma una imagen por reflexión en la superficie corneal. Dicha imagen es inicialmente capturada mediante una cámara fotográfica digital y posteriormente procesada por un equipo informático, con el objetivo de poder medir directamente sobre ella la curvatura radial de la superficie corneal, derivándose de estas medidas los datos de pendiente y de altura de la córnea, los cuales son presentados por el equipo en forma de datos queratométricos mediante una colección de mapas que siguen una escala de color definida por la Universidad de Lousiana, (Maldonado et al., 2006b).

\subsection{Sistemas basados en la proyección de una hendidura de luz sobre la córnea}

Los topógrafos corneales basados en esta tecnología se fundamentan en la integración de una doble tecnología: i) por un lado la proyección de un Disco de Plácido, donde a partir de la imagen especular obtenida por reflexión y mediante un algoritmo de reconstrucción se procede a la representación de la curvatura y la potencia refractiva; ii) y por otro lado la proyección de una hendidura de luz sobre la córnea, que debido a la estructura transparente que presenta la córnea y en base al principio de dispersión de Rayleigh (Karpecki, 2006), ésta puede ser fotografiada, proporcionando estas imágenes unos datos precisos de las elevaciones de la córnea para todo el segmento anterior. La combinación de ambas tecnologías permite a estos sistemas aportar una información bastante completa del segmento anterior del ojo humano.

Además, estos sistemas presentan dos variantes en función de la disposición espacial del sistema de captura fotográfica:

- Sistemas basados en el principio de fotografía estándar. Su principal característica es que el plano de la lente de la cámara fotográfica se sitúa espacialmente en paralelo con el de la imagen (Figura 2.33), por lo que sólo queda enfocada una pequeña región (Fernandez-García et al., 2015).

El principal sistema comercial es el Orbscan (Bausch \& Lomb Incorporated, USA), que fue el primer dispositivo comercial que valoró la superficie corneal posterior de una manera no invasiva y rápida. Este sistema combina la imagen especular de un disco de Plácido con la proyección de una lámpara de hendidura, ambos proyectados simultáneamente sobre la cara anterior de la córnea. Ésta es escaneada mediante un equipo fotográfico, el cual permite obtener 40 imágenes de ambas proyecciones, que posteriormente son tratadas por el equipo para obtener información sobre su topografía corneal. 
- Sistemas basados en el principio de fotografía Scheimpflug. Su principal característica es que el plano de la lente de la cámara fotográfica se sitúa espacialmente oblicuo con el de la imagen (Figura 2.36), es decir, las prolongaciones imaginarias de los planos de la película, de la lente y del plano de enfoque no son paralelas (Merklinger, 1993), y por ello aumenta la región de enfoque y mejora la nitidez de la imagen fotografiada (Dubbelman et al., 2006; Piñero et al., 2009; Pinero, 2013).

Los principales sistemas comerciales basados en este principio son Pentacam (Oculus, USA), Galilei (Ziemer, Suiza) y Sirius (CSO, Italia). Estos dispositivos están fundamentados en la captura de la imagen especular de un disco de Plácido por proyección de una hendidura de luz mediante el uso de una o dos cámaras rotatorias. Cada sistema comercial emplea una o dos cámaras rotatorias en función de su propia tecnología; en todos los casos ofrecen medidas de la curvatura corneal de ambas superficies corneales y otras medidas anatómicas del segmento anterior.

\subsection{Errores durante el proceso de medición y tratamiento de los datos topográficos. Primera Etapa}

El empleo en los topógrafos corneales de las tecnologías referenciadas anteriormente conlleva la generación de errores durante la primera etapa de adquisición y tratamiento de datos, distinguiéndose entre errores intrínsecos y extrínsecos.

\section{Errores Intrínsecos}

Estos errores son los derivados de los propios equipos, de forma que las mediciones realizadas comprenden de forma inevitable un error intrínseco en forma de ruido que debe ser tomado en consideración en cualquier tratamiento de los datos (Read et al. 2006; Kasprzak y Iskander, 2006; Turuwhenua, 2007; Read et al., 2009; Alkhaldi et al., 2010; Espinosa et al., 2013).

Además, respecto al diseño de los equipos, éstos presentan por un lado, limitaciones derivadas de los errores de medida y de digitalización (Hong et al., 2013), y por otro lado, limitaciones como consecuencia de los errores derivados de los algoritmos internos por la realización de suposiciones, redondeo o hipótesis de aproximación, lo que conlleva que:

- En ausencia de los datos adoptados para la reconstrucción de la superficie corneal éstos sean aportados internamente por los equipos, lo que puede inducir a un error derivado del sesgado de los datos (Auvinet et al. 2012; Zheng et al., 2013; Polette et al., 2014).

- Ante elevados niveles de irregularidad en la morfología corneal, como consecuencia de la patología ectásica corneal, no sean capaces de representar de forma apropiada la geometría real de la córnea (Rand et al., 1997; Turuwhenua, 2007; Espinosa et al., 2013; Saika et al., 2013). 
Todos estos factores crean una contaminación adicional de la medida. Para luchar contra ello se puede incluir un preprocesado de la señal que permita localizar y corregir las regiones de alta interferencia o datos incompletos. Sin embargo todas las soluciones propuestas son altamente costosas computacionalmente y difícilmente implementables en tiempo real, como la utilización del filtrado bidimensional de Gabor para detectar zonas sin el patrón direccional por los anillos (Alonso-Caneiro et al., 2008; Alonso-Caneiro et al., 2013) o la aplicación de técnicas de procesamiento de imágenes para mejorar los datos en zonas de información incompleta (Alkhaldi et al., 2009).

Recientes estudios aparecidos en la literatura científica demuestran que este tipo de errores pueden ser minorizados por los nuevos topógrafos corneales, no influyendo de forma significativa en la adquisición y tratamiento de datos (Hong et al., 2013; Huang et al. 2015), por lo que la comunidad médica oftalmológica acepta la existencia de estos errores, los cuales considera despreciables en comparación con la valiosa información que aportan los topógrafos para el diagnóstico de las patologías ectásicas corneales.

\section{Errores Extrínsecos}

Estos errores son los derivados de los que un examinador o clínico puede cometer a la hora de utilizar el equipo de medición, fundamentalmente en el momento del enfoque y de la alineación del topógrafo con el ojo del paciente examinado, lo que puede inducir a niveles erróneos de astigmatismo.

También se puede producir un error debido a una localización errónea del centro espacial de los anillos o de las coronas centrales de los Discos de Plácido, lo que implicará una pérdida de ajuste y de precisión de la medida sobre la región periférica corneal. Por lo tanto, es obvio que para obtener una mayor exactitud de las medidas obtenidas por los equipos es necesario un buen centrado, alineamiento y enfoque por parte del examinador o clínico (Wang et al., 2012).

Asimismo, también se producen errores extrínsecos derivados de la calidad de la película lagrimal. Una mala calidad de película junto con la rotura en la distribución de la lágrima inducirá la aparición de datos anómalos sobre la medida, lo que dará lugar a la aparición de regiones espaciales corneales falsamente irregulares (Montés-Micó et al., 2010).

Igualmente, otro error extrínseco, es el derivado de una inadecuada colaboración del paciente con el examinador, de manera que el paciente debe facilitar una buena apertura palpebral del ojo a examinar, con el fin de obtener una cobertura adecuada de la superficie corneal a examinar.

Además el examinador debe evitar en lo posible la obstrucción del campo visual derivada de las pestañas del paciente (Hamano, 2005). 
Actualmente, los equipos incorporan nuevas tecnologías que facilitan un índice que permite conocer de forma cuantitativa la calidad de la medida en base a los errores extrínsecos anteriormente descritos, repitiendo el proceso de medida en el caso de que los datos obtenidos no cumplan con un criterio mínimo estándar de fiabilidad e interpretación correcta de datos para un adecuado diagnóstico de la patología corneal (Wang et al., 2012).

\subsection{Métodos de reconstrucción de la superficie corneal}

Tal y como se ha comentado en el capítulo anterior, los topógrafos corneales contemplan dos etapas claramente diferenciadas para presentar al médico oftalmólogo los datos obtenidos de la topografía corneal:

- Una primera etapa, ya comentada, que corresponde al proceso de adquisición y tratamiento interno de los datos denominados en bruto, y que será objeto de un análisis en un subcapítulo posterior.

- Y una segunda etapa donde, a partir de los datos constitutivos de la matriz de elevaciones, se procede a la reconstrucción de la superficie corneal. Es aquí donde el algoritmo de reconstrucción para el ajuste de la superficie corneal puede ser fuente de errores mayores a los descritos en apartados previos. Este algoritmo de reconstrucción puede basarse en dos métodos de reconstrucción de superficies: los denominados métodos modales y los métodos zonales.

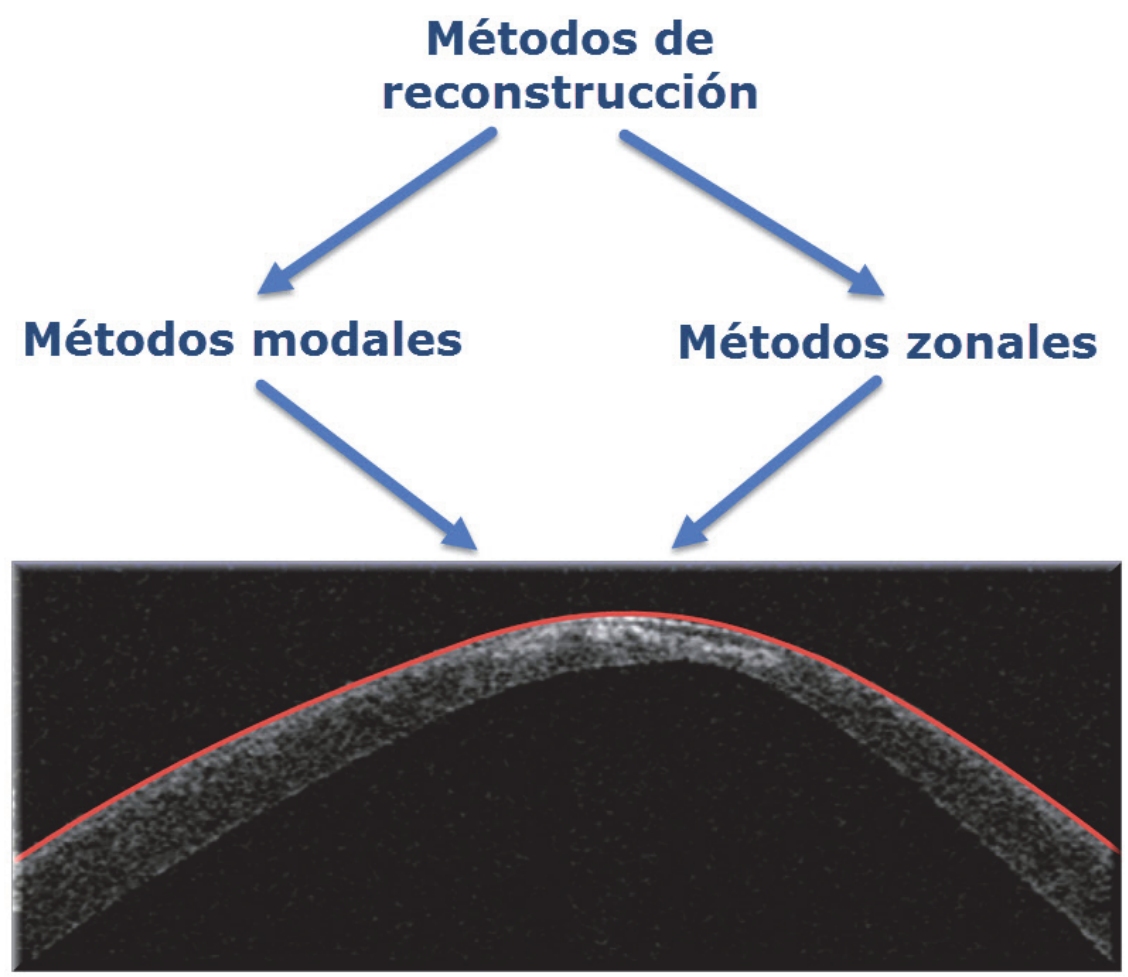

Figura 1.11 Métodos de reconstrucción de la superficie corneal 


\subsubsection{Métodos Modales}

Los métodos modales se basan en la aproximación a la superficie mediante una combinación de funciones básicas definidas globalmente en todo el dominio de los datos, pudiendo ésta depender de un determinado número de parámetros y de la cantidad necesaria de ellos para recuperar la información relevante de la superficie, tratando de evitar el sobre-ajuste del error de medición de los mismos (Ramos-López et al., 2011).

En el campo de la oftalmología, la gran mayoría de los métodos modales empleados para la reconstrucción de superficies a partir de alturas normalizadas utilizan los desarrollos basados en los polinomios de Zernike (ANSI, 2004; Klyce et al., 2004; Schneider et al., 2009; Espinosa et al., 2010), donde los coeficientes de expansión se interpretan en términos de aberraciones básicas o degradación de la imagen en los sistemas ópticos (Tyson, 1982; Conforti, 1983).

Sin embargo, este procedimiento adolece de una serie de problemas que han sido discutidos ampliamente en la literatura científica (Smolek y Klyce, 2005; Carvalho, 2005; Ares y Rollo; 2006; Ramos-López et al., 2011). En particular, existe una creciente preocupación por este método debido a que puede ser impreciso en situaciones anómalas, no pudiéndose obtener una reconstrucción fidedigna en los casos de topografías complejas, que son las de mayor interés clínico.

De forma adicional, presentan otro problema relacionado con una correcta estimación del número de polinomios de Zernike a usar en la reconstrucción: debido al carácter global del soporte de los mismos, para córneas sanas se requiere un número relativamente bajo de los mismos, mientras que para las corneas patológicas se requieren órdenes mucho más elevadas (Schwiegerling y Greivenkamp, 1989; Smolek y Klyce, 2005). Para resolver este problema existen técnicas de estimación objetiva del número de coeficientes de expansión a considerar en el polinomio de reconstrucción, pero son computacionalmente muy complejas (Iskander et al., 2008; Alkhaldi et al., 2009).

En base a los problemas descritos, se han propuesto varias técnicas alternativas:

- Reconstrucción usando la transformada discreta o continua de Fourier (Dai, 2006; Wang et al., 2007; Yoon et al., 2008).

- Reconstrucción usando un ajuste modal por mínimos cuadrados (Espinosa et al., 2010).

- Reconstrucción no lineal por funciones racionales (Schneider et al., 2009).

- Reconstrucción basada en funciones de base radial (Martinez-Finkelshtein et al., 2009; Ramos-López et al., 2011; Martinez-Finkelshtein et al., 2011).

- Reconstrucción mediante el uso de problemas de contorno para modelar la superficie corneal (Okrasinski y Plociniczak, 2012; Plociniczak et al., 2014). 
Sin embargo todas ellas adolecen de los mismos problemas que Zernike, inclusive de otros, como una elevada complejidad computacional en el manejo del error residual, o la presentación de resultados controvertidos.

\subsubsection{Métodos Zonales}

En los métodos zonales el domino de los datos se divide en subdominios más elementales y la superficie se aproxima en cada subdominio definido con independencia del resto (Espinosa et al., 2010; Ramos-López et al., 2011).

Este método de reconstrucción se caracteriza porque presenta flexibilidad y precisión en el ajuste al considerar datos dentro de una zona delimitada para el cálculo de un punto de la superficie. Esto significa que la representación es local, y por tanto, las irregularidades locales no afectan a la representación global de la superficie, en contraste con las funciones globales adoptadas en la reconstrucción modal, como superficies cuadráticas o polinomios de alto orden que carecen de la información a nivel local y por tanto, las irregularidades locales o defectos de la superficie no se pueden representar adecuadamente mediante estos enfoques (Zhu et al., 2010; CavasMartínez et al., 2014).

La herramienta más común son las Splines (Wahba, 1990), en particular las B-Splines (Halstead et al., 1995; Ares y Royo, 2006; Liu y Gao, 2003; Cavas-Martínez et al., 2014), que son funciones numéricamente estables, flexibles y presentan gran precisión en el ajuste (Pielg, 1991, Piegl y Tiller, 1997).

Las funciones B-Spline han sido ampliamente utilizadas en la ingeniería para la resolución de problemas asociados a los aspectos geométricos y computacionales que aparecen cuando se desean utilizar entidades que poseen elevados niveles de complejidad geométrica (Pielg, 1991; Piegl y Tiller, 1997).

Concretamente en el campo de la oftalmología, estas funciones B-Spline se han usado con éxito en las siguientes aplicaciones:

- Caracterización de la superficie topográfica corneal (Turuwhenua y Henderson, 2004; Turuwhenua, 2008; Zhu et al., 2010; Zhu et al., 2011; Cavas-Martínez et al., 2014).

- Caracterización del globo ocular (Xing y Wei, 2014).

- Diseño de lentes ópticas para el tratamiento del queratocono (Rosenthal y Cotter, 1995).

- Diseño de una prótesis de superficie ocular para una patología corneal denominada Queratoglobo (Mahadevan et al., 2014).

En resumen, en función de la descripción de los modelos y finalidades realizadas anteriormente, y en base a la singularidad que presenta la morfología de la superficie corneal, sería de gran interés y actualidad poder crear un modelo que combine las ventajas de los modelos personalizados con las ventajas que presenta la reconstrucción 
zonal mediante funciones B-Spline para la caracterización real de la morfología corneal, y que este modelo pudiera a su vez ser utilizado para el diagnóstico de determinadas patologías relacionadas con la modificación de la morfología corneal.

\subsubsection{Consideraciones previas al proceso de reconstrucción de la superficie corneal}

Se debe tener en cuenta que durante la primera etapa, donde se lleva a cabo el proceso de adquisición y tratamiento interno de los datos, algunos equipos permiten la exportación de los datos correspondientes a la matriz de elevaciones representativa de la superficie corneal. Estos datos, denominados en la literatura científica como datos en bruto, son obtenidos por un algoritmo interno de visión del topógrafo corneal (Ramos-Lopez et al., 2011; Roy y Dupss, 2011; Bao et al., 2013; Cavas-Martínez et al., 2014; Ariza-Gracia et al., 2015).

Algunos autores han realizado trabajos a partir de estos datos en bruto, como la caracterización geométrica de la córnea a partir de la evaluación de la simetría corneal utilizando parámetros de forma y posición (Bao et al., 2010), o el desarrollo de un modelo biomecánico personalizado basado en la obtención de la geometría del paciente (Roy y Dupss, 2011; Ariza-Gracia et al., 2015), ambos realizados a partir de las coordenadas cartesianas $(\mathrm{x}, \mathrm{y}, \mathrm{z})$ aportadas por el topógrafo Pentacam.

Sin embargo, en los dos casos se produce una interpolación de los datos en bruto debido a los problemas extrínsecos del trinomio examinador-equipo-paciente descritos anteriormente, y que afectan al proceso de medida. Esta interpolación de datos para obtener los puntos espaciales representativos de toda la región corneal supondrá un sesgado de éstos, implicando que durante el proceso de reconstrucción de la superficie corneal completa, pequeñas alteraciones morfológicas de ésta debidas a un grado incipiente de la patología corneal como el queratocono, no puedan ser fielmente reproducidas.

Hasta la fecha solamente se han considerado los datos espaciales obtenidos en bruto sin interpolación en la reconstrucción de la superficie anterior de la córnea (RamosLopez et al., 2011) a partir de los datos aportados por el topógrafo corneal EyeTop 2005 (CSO, Italia) y en la reconstrucción de las superficies corneales anterior y posterior (Cavas-Martínez et al., 2014) a partir de los datos aportados por el topógrafo corneal Sirius (CSO, Italia).

Por lo tanto, uno de los principales objetivos de esta tesis consiste en la creación de un modelo personalizado in vivo que permita caracterizar fielmente la morfología corneal. Para ello serán utilizados los datos espaciales en bruto aportados por el topógrafo Sirius (CSO, Italia), en forma de coordenadas cartesianas espaciales, y a partir de esta nube de puntos se procederá a la reconstrucción de la superficie corneal utilizando funciones B-Spline, lo que permitirá posteriormente generar un modelo virtual 3D que pueda ser utilizado para el diagnóstico de determinadas patologías relacionadas con la modificación de la morfología corneal. 


\subsection{Diseño geométrico asistido por ordenador}

En los últimos años la generación de modelos virtuales ha experimentado un importante avance tecnológico gracias el desarrollo de nuevas herramientas computacionales para la adquisición y procesamiento de imágenes (Eklund et al., 2013), posibilitando así la generación de formas tridimensionales (Sun et al., 2004) y la formulación de modelos de comportamiento que reproduzcan con más fidelidad la geometría de una estructura sólida (Lohfeld et al., 2005).

Una de estas herramientas es el Diseño Geométrico Asistido por Ordenador (DGAO), el cual surgió para tratar de resolver las necesidades tecnológicas de las empresas en los sectores de la automoción y la aeronáutica. El DGAO permite estudiar aspectos geométricos y computacionales de cualquier entidad física compleja, como superficies y volúmenes para generar modelos virtuales (Farin et al., 2002), los cuales se diferencian de los modelos físicos por no suponer un proceso destructivo y reducir los costes en términos de producción y tiempo (Pottmann et al., 2005; Cui et al., 2014).

Concretamente en el campo de la Bioingeniería, el desarrollo de modelos virtuales a través del DGAO permite caracterizar estructuras biológicas, estableciendo nuevos procedimientos de experimentación en el ámbito de la medicina (Lohfeld et al., 2005), con diferentes finalidades:

- Diagnóstico clínico y posterior tratamiento de la patología mediante técnicas invasivas o no (Lee et al., 2009; Almeida y Bártolo, 2013; Whu et al., 2015).

- Análisis del comportamiento en un escenario patológico mediante métodos numéricos (Brand et al., 2014; C IC et al., 2014; Schmidt et al., 2015).

- Fines educativos mediante la generación de modelos virtuales 3D (Rocha et al., 2014) o mediante la obtención del modelo físico utilizando impresoras 3D (Schubert et al., 2014).

A excepción de la presente tesis, no se ha encontrado ningún trabajo en la literatura científica que emplee la herramienta de Diseño Geométrico Asistido por Ordenador para generar un modelo virtual completo de la córnea.

En el campo de la óptica se han encontrado algunos modelos que proponen el uso del DGAO para la generación únicamente de la superficie corneal y su posterior análisis óptico a partir de los puntos espaciales obtenidos por los datos aportados por los topógrafos corneales para su posterior utilización mediante las funciones cónicas o bicónicas anteriormente descritas (Donnelly, 2008; Talu et al., 2011; Giovanzana, 2011) o a partir de las imágenes realizadas a los cortes realizados a ojos de pollo ex vivo (Genest, 2010; Wong et al., 2012). Sin embargo, en ambos casos el modelo generado de la córnea no resulta completo, ya que para generar la nube de puntos (NURBS) constitutivos de la superficie corneal que posteriormente será reconstruida a partir del 
uso del DGAO se realiza una interpolación de los datos, además solo reconstruye la superficie corneal con un interés óptico.

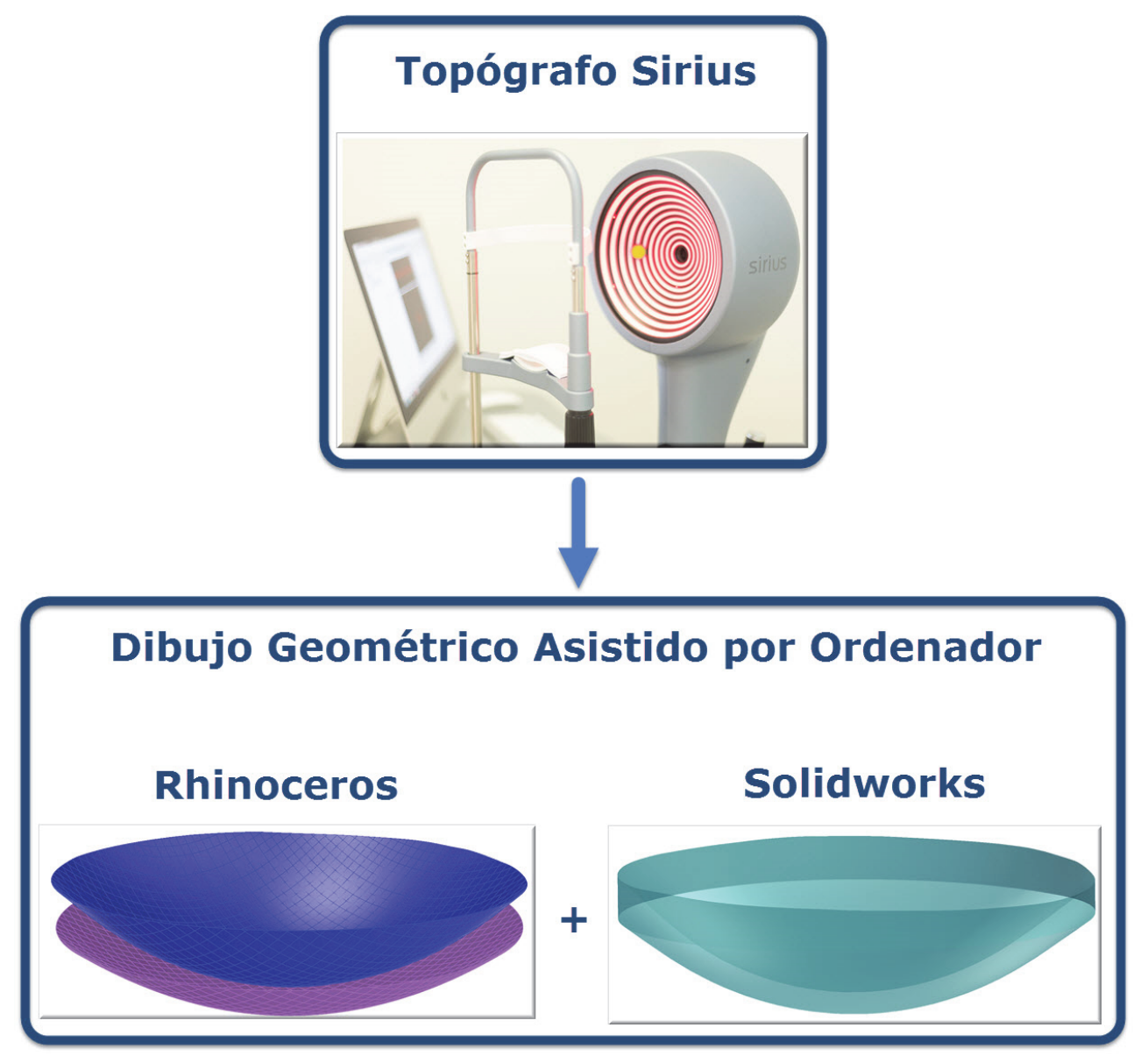

Figura 1.12 Topógrafo Sirius, aplicación del DGAO

Por lo tanto, resulta de especial interés poder crear un modelo personalizado in vivo representativo de la córnea en un entorno virtual. Para ello se utilizará la herramienta denominada Diseño Geométrico Asistido por Ordenador (DGAO) (Figura 1.12), la cual se presenta como una solución válida y eficaz para resolver y caracterizar superficies geométricas complejas.

\subsection{Queratocono}

El modelado de la superficie de la cara anterior y posterior de la córnea puede ser utilizado para el diagnóstico de una de las patologías ectásicas más comunes, el denominado queratocono. Se trata de una patología que altera de forma irregular la superficie de la cara anterior y posterior de la córnea, provocando una pérdida de visión casi total en los casos más graves (Rabinowitz, 1998). 
Clínicamente se manifiesta por una modificación de la morfología de su superficie, lo que implica una redistribución de la paquimetría corneal, cambios en la geometría de su superficie y una pérdida de su poder óptico (Piñero et al., 2010a).

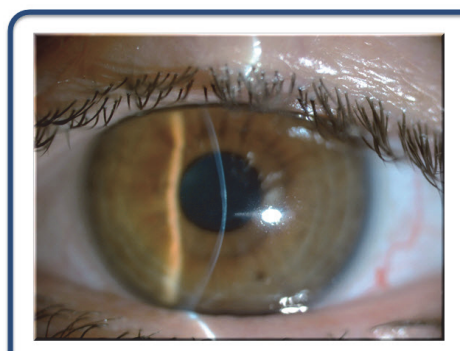

Vista frontal

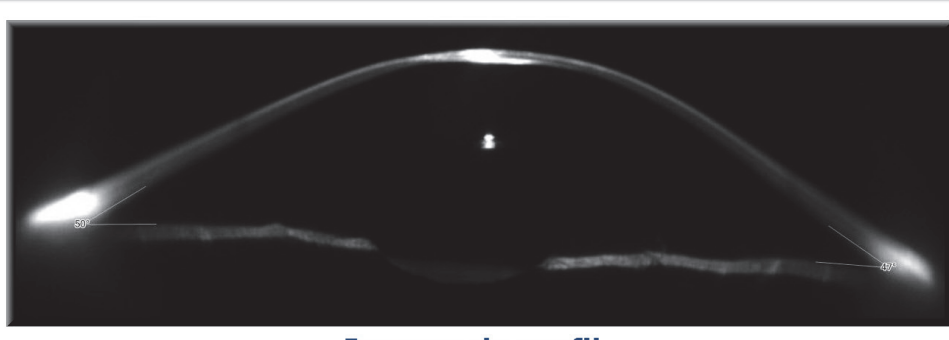

Imagen de perfil

Figura 1.13 Córnea con queratocono. Vista en planta y de perfil

El diagnóstico clínico del queratocono se realiza actualmente a partir de unos índices o descriptores topográficos corneales que utilizan complicadas fórmulas basadas fundamentalmente en perfiles de grosor, mapas paquimétricos y mapas de curvatura (Dingeldein et al., 1989; Wilson y Klyce, 1991; Maeda et al., 1994; Smolek y Klyce, 1997; Rabinowitz y Rasheed, 2000; Abad et al., 2007; Ambrosio et al., 2011a), es decir, los índices o descriptores no son obtenidos directamente por los equipos y están calculados por algoritmos internos de los propios topógrafos. Estos algoritmos, además, pueden ser fuente de errores asociados a posibles suposiciones o hipótesis implícitas para simplificar los cálculos de los índices topográficos propuestos (Espinosa et al., 2013).

En la literatura científica solamente nos consta la existencia de un trabajo que define unos índices para caracterizar, en un entorno en dos dimensiones, el queratocono en base a datos espaciales en bruto. Además este trabajo presenta unos resultados que validan clínicamente los nuevos índices propuestos como índices de diagnóstico clínico (Ramos-López et al., 2011).

En base a todo lo anteriormente expuesto, resultaría de gran interés para la comunidad oftalmológica poder contar con unos índices geométricos flexibles y rigurosos para el diagnóstico del queratocono basados en una fuente primara de información, es decir, datos no procesados por algoritmos internos de los topógrafos, que además fueran fáciles de calcular e interpretar en un entorno virtual en tres dimensiones, y que mejorasen la capacidad de discriminación de esta enfermedad ante un comportamiento natural o sano. 


\subsection{Estructura de la tesis}

La presente tesis doctoral se estructura en 6 capítulos:

\section{Capítulo 1. Introducción.}

Este capítulo contiene los argumentos que motivan el trabajo de investigación y los antecedentes sobre los que se plantean los objetivos de la tesis. Para ello se realiza una descripción de los modelos de caracterización de la morfología corneal y de los métodos de reconstrucción de la superficie corneal existentes en el campo de la oftalmología. También se describen las principales características del concepto DGAO y de la patología ectásica objeto de estudio en esta tesis, el queratocono. El capítulo finaliza con una descripción de los objetivos definidos en esta tesis doctoral.

\section{Capítulo 2. Marco teórico}

Por un lado, en este capítulo se realiza una descripción de la anatomía funcional y de la caracterización morfológica de la córnea en un escenario natural o sano y en otro patológico o queratocónico. Por otro lado, se realiza una descripción histórica de las curvas y superficies utilizadas en DGAO, así como una descripción con mayor profundidad de las curvas B-Spline por ser las utilizadas en este trabajo de tesis doctoral.

\section{Capítulo 3. Materiales y Métodos}

Se describen los sujetos que participan en el ensayo clínico, considerando su historial clínico y la exploración morfológica realizada para diferenciar entre los grupos de control de ojos sanos y ojos diagnosticados con queratocono. Por otro lado, se describe la metodología de reconstrucción del modelo sólido 3D de la córnea utilizado y se definen sobre el modelo virtual obtenido las variables geométricas que van a ser utilizadas como índices cuantitativos de valoración de la irregularidad corneal.

\section{Capítulo 4. Resultados}

Se realiza un análisis estadístico de todos los índices propuestos para la caracterización de la morfología corneal, seleccionando aquellos índices que presentan una mayor sensibilidad y especificidad, los cuales podrán ser utilizados como unos nuevos índices de diagnóstico clínico del queratocono.

\section{Capítulo 5. Discusión}

En base al nuevo modelo sólido 3D de la córnea y a los nuevos índices de diagnóstico clínico del queratocono obtenidos, se realiza una discusión respecto a los modelos corneales existentes en la literatura científica y a los índices utilizados en oftalmología para el diagnóstico del queratocono. Además, y a partir del análisis estadístico 
realizado, se justifica clínicamente la elevada sensibilidad y especificidad de los nuevos índices de diagnóstico clínico obtenidos.

\section{Capítulo 6. Conclusiones}

Se presentan las conclusiones de este trabajo de investigación y se describen las contribuciones y colaboraciones realizadas durante su desarrollo.

\section{Capítulo 7. Prospectivas de estudio}

Se definen las nuevas líneas de trabajo y propuestas para trabajos futuros.

\subsection{Objetivos de la tesis}

En relación con los problemas anteriormente mencionados, esta memoria de tesis doctoral reúne las siguientes principales aportaciones:

- Generación de un modelo sólido personalizado 3D in vivo representativo de la morfología corneal a partir de la reconstrucción zonal de las superficies de la córnea usando los datos espaciales en bruto aportados por los topógrafos corneales.

- Definición de unos nuevos índices de diagnóstico para la caracterización de la patología ectásica corneal más común, el queratocono, basados en unas variables geométricas definidas a partir del modelo 3D obtenido de la córnea.

Ambos objetivos se han conseguido utilizado una herramienta computacional basada en el Diseño Geométrico Asistido por Ordenador.

El enfoque de esta tesis doctoral es marcadamente aplicado y los resultados obtenidos han sido contrastados con los aportados por los topógrafos corneales existentes actualmente. No se trata de excluir los índices topográficos existentes en la actualidad y ampliamente aceptados por la comunidad oftalmológica para el diagnóstico del queratocono, sino de aportar unos nuevos índices que faciliten el diagnóstico clínico de esta patología ectásica al médico oftalmólogo. 
Marco teórico 


\subsection{La córnea}

La estructura del ojo humano es muy compleja y está integrada por un sistema óptico consistente en un conjunto de elementos con una determinada capacidad refractiva que actúan como lentes (Figura 2.1).

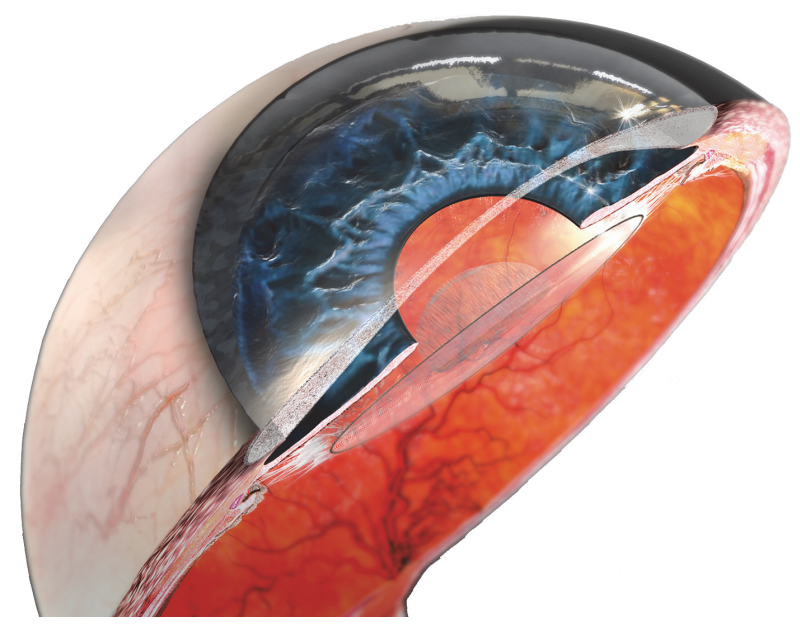

Figura 2.1 Estructura virtual del ojo humano

El elemento refractivo más importante del dioptrio ocular es la córnea (Hermsen y Dreyer, 1982). Esta estructura "no es un trozo de plástico" (Roberts, 2000), sino que al ser una estructura biológica presenta una morfología variable en diferentes escenarios. En base a esta variabilidad, resulta fundamental:

- Conocer la anatomía y la morfología de la córnea a nivel microscópico y macroscópico en un escenario natural y en un escenario patológico, concretamente el correspondiente a la ectasia corneal más importante, el queratocono.

- Conocer, por un lado, las tecnologías en las que están basadas los actuales equipos topográficos para la caracterización de la morfología corneal, y por otro lado, los índices de valoración de la superficie corneal que presentan dichos equipos para el diagnóstico clínico del queratocono.

- Conocer la nomenclatura y clasificaciones clínicas del queratocono actualmente utilizadas por la comunidad oftalmológica.

El presente subcapítulo de tesis doctoral se estructura dividido a su vez en tres subcapítulos relacionados: en el primero se realiza una descripción anatómica de la córnea sana y de la córnea queratocónica a nivel microscópico y a nivel macroscópico; en el segundo se realiza una descripción de la morfología de la córnea sana y patológica a partir de los datos aportados por los topógrafos corneales basados en diferentes tecnologías; y en el tercero, se describe la nomenclatura propia de la enfermedad analizada en este estudio, el queratocono, así como los actuales índices de valoración de la morfología corneal basados en sistemas cuantitativos de detección univariante y multivariante, realizándose una descripción de las clasificaciones del 
queratocono clínico, con especial énfasis en la clasificación de Amsler-Krumeich por ser la clasificación clínica utilizada en la presente tesis doctoral y una de las más extendidas en la oftalmología contemporánea.

\subsubsection{Anatomía funcional}

La córnea es una estructura biológica transparente con una curvatura regular que le permite actuar como una lente convergente (¡Error! No se encuentra el origen de la referencia.). Además realiza una importante función de protección del segmento anterior del ojo humano frente al medio ambiente exterior, especialmente ante la penetración de cuerpos extraños y ante determinados traumatismos.

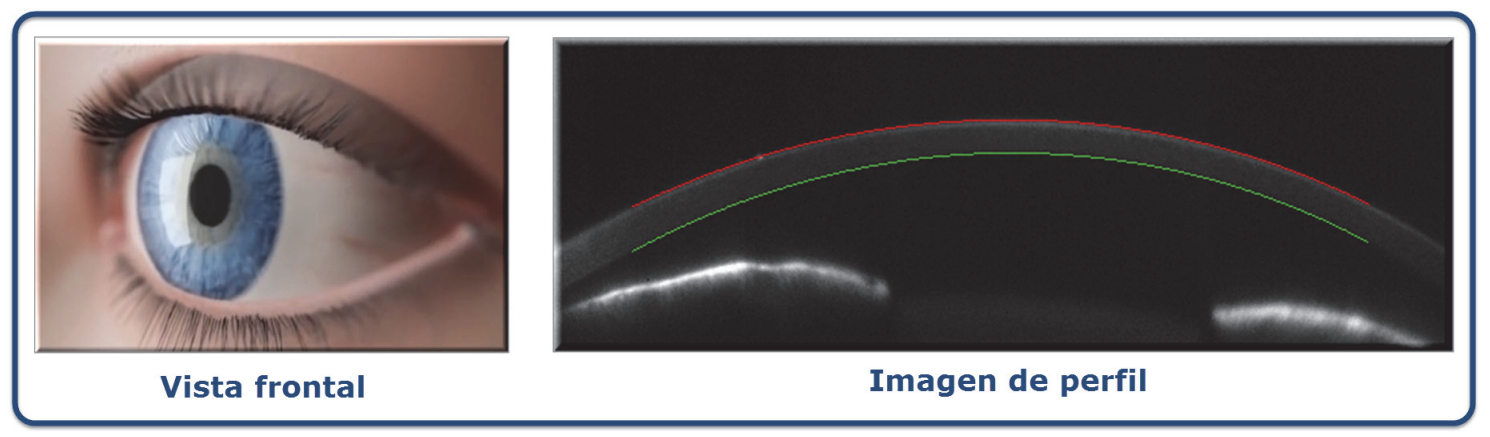

Figura 2.2 Fotografía frontal e imagen sagital de una córnea sana

La descripción de la anatomía del cuerpo humano nos presenta la córnea (Figura 2.1) situada delante de la esclerótica, constituyendo con ésta un borde en la zona de transición denominada limbo esclero-corneal. En el interior de este tejido se localiza un canal sin pared propia y con una morfología en forma de circunferencia, denominado conducto de Schlemm. Este conducto se encuentra ubicado en el ángulo iridocorneal de la cámara anterior del ojo humano, y realiza una importante función en la regulación de la presión intraocular de la cámara anterior, ya que es por este conducto por donde drena el humor acuoso hacia la circulación sanguínea (Young y Heath, 2000). Por otra parte, en la región periférica corneal existen unos vasos sanguíneos y linfáticos, y un plexo nervioso, cuyas ramificaciones se distribuyen por toda esta región.

En el presente subcapítulo se describe a nivel macroscópico y a nivel microscópico la anatomía funcional de la córnea sana y de la córnea queratocónica. Así mismo, a nivel microscópico se describe la zona de transición entre el ambiente exterior y la córnea o película lagrimal, los estratos o capas constitutivos de la arquitectura corneal y la distribución de los nervios en la región corneal, la denominada inervación corneal.

\subsubsection{Córnea sana}

La naturaleza confiere a la estructura corneal de un estilo y de una métrica singular, dotando a los tejidos constitutivos de su anatomía de una organización particular que le conceden unas propiedades adaptadas a los requerimientos funcionales propios de cada uno de ellos. La córnea sana presenta una estructura anatómica funcional 
transparente con una apariencia esferoide similar a la de un casquete o cúpula de una iglesia (Figura 2.3).

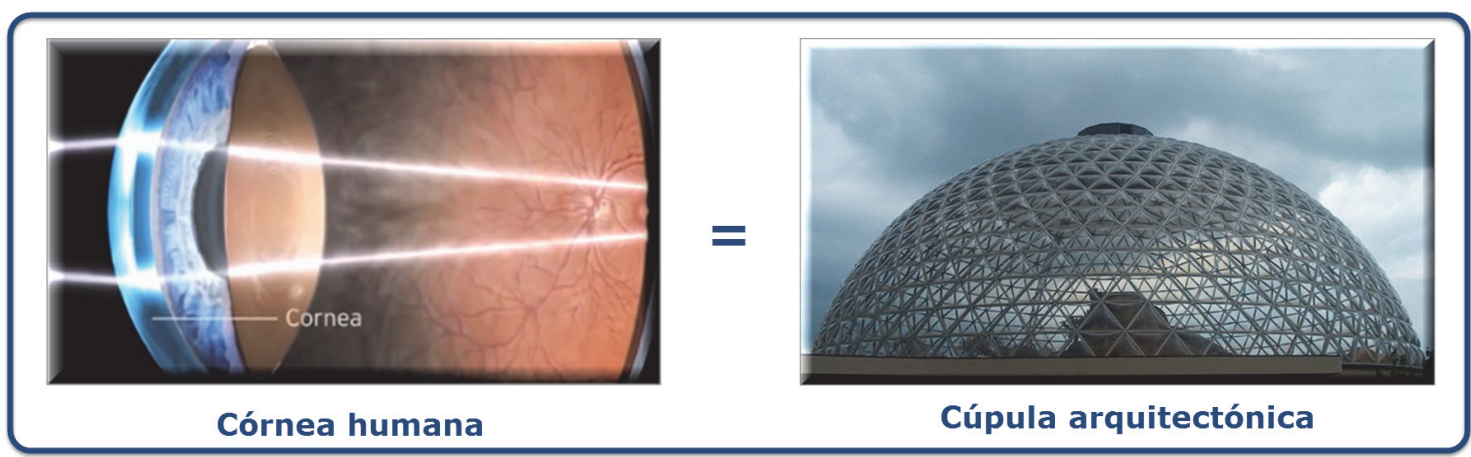

Figura 2.3 Comparativa de la estructura anatómica de la córnea con una cúpula arquitectónica

La córnea posee dos caras perfectamente definidas, la cara anterior y la cara posterior. La superficie de su cara anterior está en contacto con la película lagrimal y la superficie de la cara posterior está en contacto con el humor acuoso (Figura 2.4).

La estructura corneal está constituida por un tejido muy diferenciado y posee varias funciones, siendo la más importante la de ser el primer elemento refractivo ocular, debido a las propiedades de transparencia y de curvatura que presenta en toda su estructura.

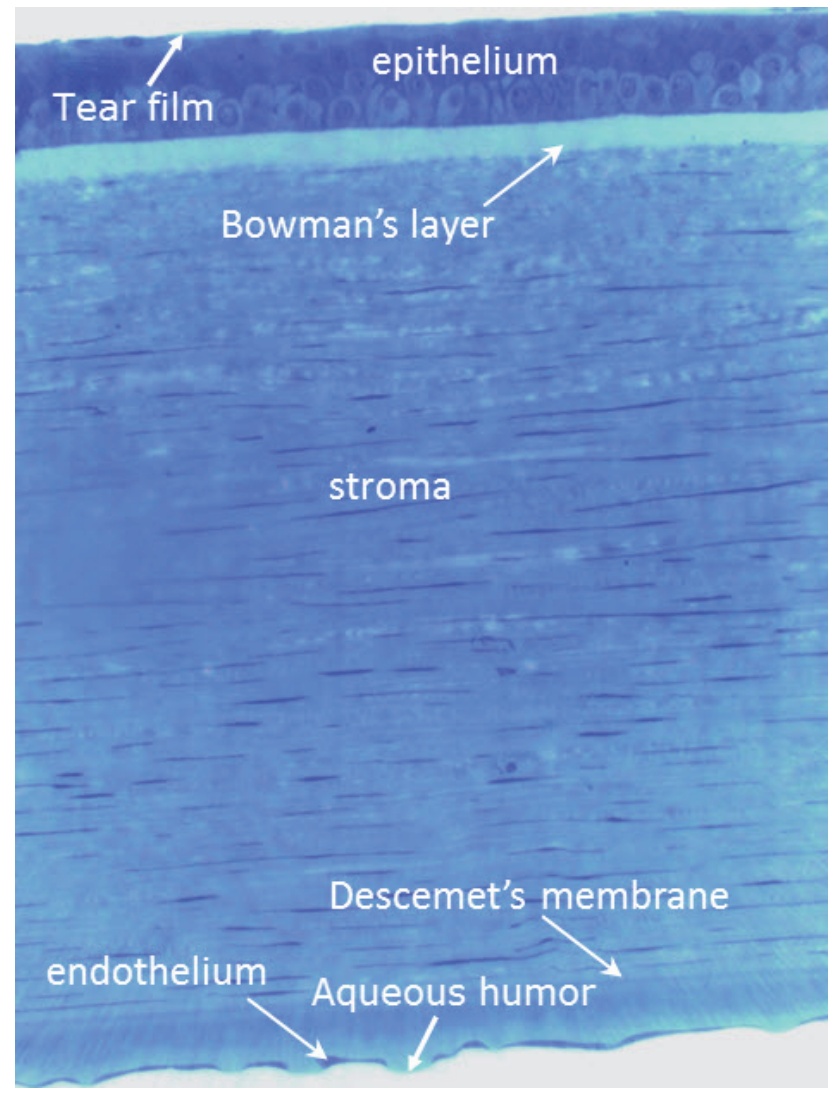

Figura 2.4 Imagen microscópica de la capa lagrimal, estratos de la córnea y humor acuoso en una córnea sana 


\subsection{Análisis Macroscópico}

A nivel macroscópico, los valores de los parámetros físicos descriptivos de la córnea varían en función de las características individuales de cada persona. En base a valores descriptivos promedio tenemos (Buey Salas y Peris Martínez, 2014) (Figura 2.5):

- Posee un diámetro horizontal mayor de aproximadamente $12.5 \mathrm{~mm}$.

- Su espesor promedio en la región periférica es de aproximadamente unos 0.65 $\mathrm{mm}$ y en la región central de aproximadamente unos $0.52 \mathrm{~mm}$.

- La curvatura externa de la córnea presenta un radio promedio en torno a 7.8 $\mathrm{mm}$, presentando una morfología prácticamente esférica en el tercio central (zona óptica) y una menor curvatura en la región periférica. Interiormente, el radio medio de la curvatura está en torno a los $6.8 \mathrm{~mm}$.

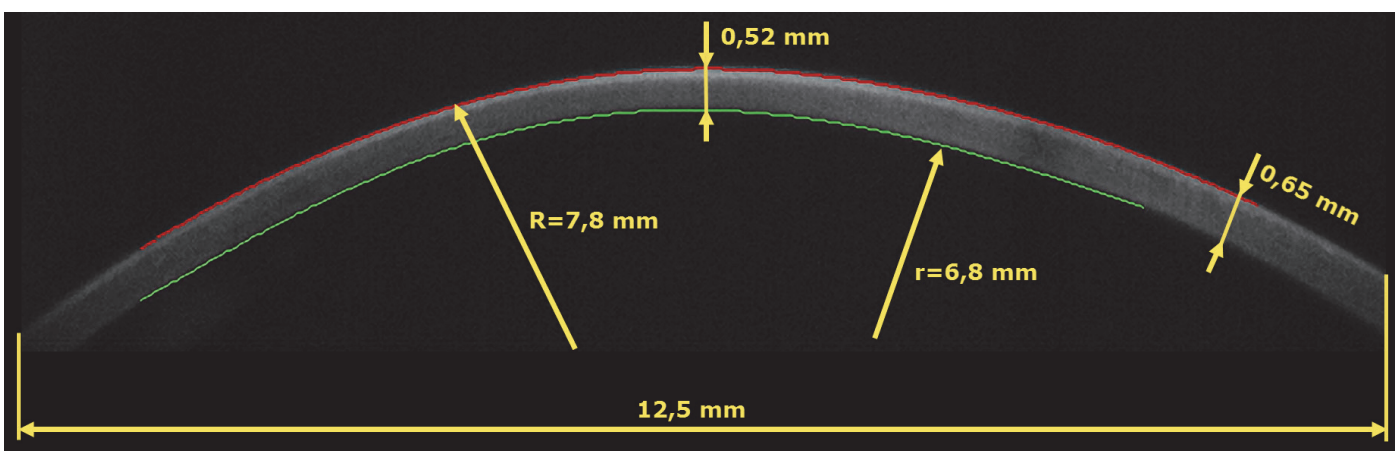

Figura 2.5 Parámetros físicos promedio de la córnea sana, imagen en corte sagital

El poder de refracción neto de la córnea es de 43 dioptrías (D), lo que equivale al $70 \%$ del total del ojo (Gipson et al., 2004).

\subsection{Análisis Microscópico}

A nivel microscópico, el análisis funcional de la estructura biológica de la córnea nos muestra claramente que han de considerarse 3 partes: una primera que está compuesta de una región de transición entre el ambiente exterior y la propia estructura bilógica de la córnea, la denominada película lagrimal; otra segunda que está constituida por los estratos o capas de la córnea, que son el epitelio corneal, la capa de Bowman, el estroma Corneal, la capa de Dua, la membrana de Descemet y el endotelio corneal; y otra tercera parte en relación a la distribución espacial de los nervios o fibrillas nerviosas de la córnea o inervación corneal.

Si bien la película lagrimal y la región de la inervación corneal no son capas integradas en los estratos de la arquitectura corneal, no podemos dejar de considerarlas en el contexto de la córnea sana, debido a que el análisis de la anatomía funcional de la córnea no debe de entenderse de forma aislada, sino como una unidad de la superficie ocular (Argüeso et al., 2007) (Figura 2.6). 


\subsection{Película lagrimal}

Se trata de una capa localizada físicamente en una zona de transición entre el ambiente exterior y las capas de la córnea. Su misión es la de lubricar y humedecer la córnea, preservando así su integridad física ante los factores externos. Físicamente se caracteriza porque tiene unos $7 \mu \mathrm{m}$ de espesor, aunque esto es variable debido a su naturaleza fluida y al parpadeo que presenta cada persona de forma individualizada (Buey Salas y Peris Martínez, 2014).

La película lagrimal presenta una estructura dividida clásicamente en lipídica, acuosa y mucínica, aunque se conoce que este esquema no resulta tan simple, es decir, que no es un triestato de lípidos, agua y mucina, sino un gel de mucina con una capa lipídica flotando sobre él (Argüeso et al., 2007; Cher, 2012).

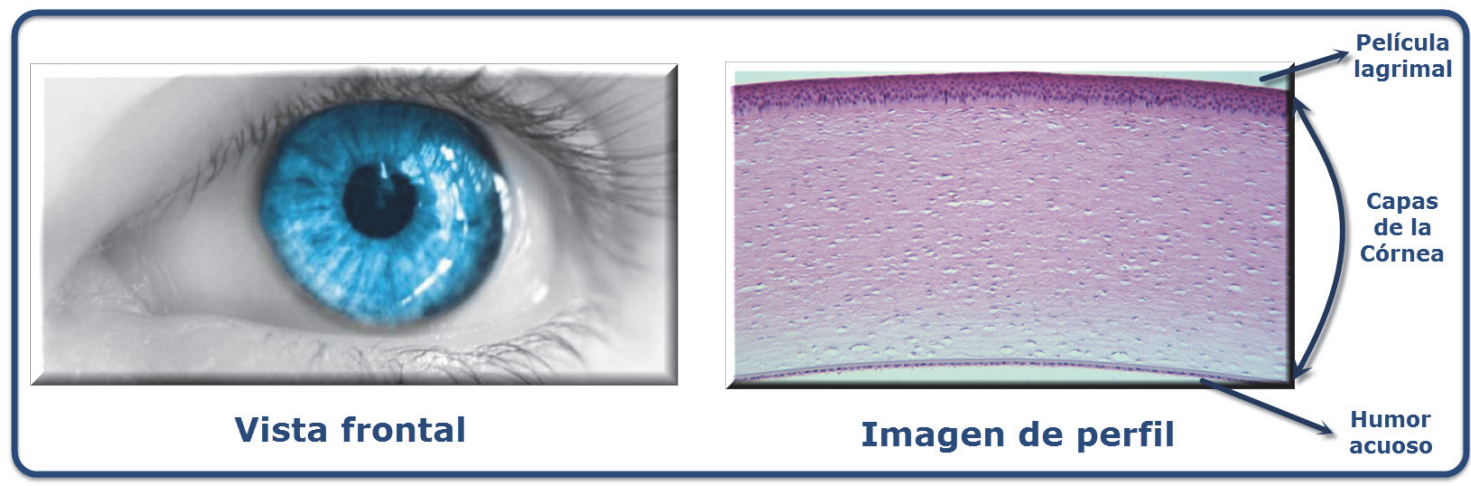

Figura 2.6 Imagen microscópica de la estructura de una córnea sana

\subsection{Estratos de la córnea}

Los estratos o capas constitutivas de la estructura de la córnea son seis: epitelio corneal, capa de Bowman, estroma corneal, capa de Dua, membrana de Descemet y endotelio corneal. Estos estratos le confieren a la córnea sana un estilo geométrico natural muy especial (Figura 2.7).

\section{Epitelio corneal}

Se trata de un epitelio escamoso pluriestratificado no queratimizado, con un espesor de 50-56 $\mu \mathrm{m}$, distribuido entre 5-7 capas de células epiteliales en el área de la región central corneal y entre 8-10 capas en la zona de la región periférica (Li et al., 1997).

El epitelio corneal es avascular y ejerce una importante función metabólica y de barrera defensiva ante los agentes externos, puesto que la mayoría de los elementos patógenos no tienen la capacidad de poder atravesarla cuando está íntegro. Además, su estructura está compuesta por un denso entramado celular, lo que le permite presentar una fuerte resistencia mecánica a la abrasión ante un movimiento natural, como es el parpadeo, o por el uso de lentes de contacto (Montalbán, 2013; Buey Salas y Peris Martínez, 2014).

También presenta una rápida cicatrización, lo que es debido a que se recambia constantemente por descamación de las células superficiales (Thoft et al., 1983). 


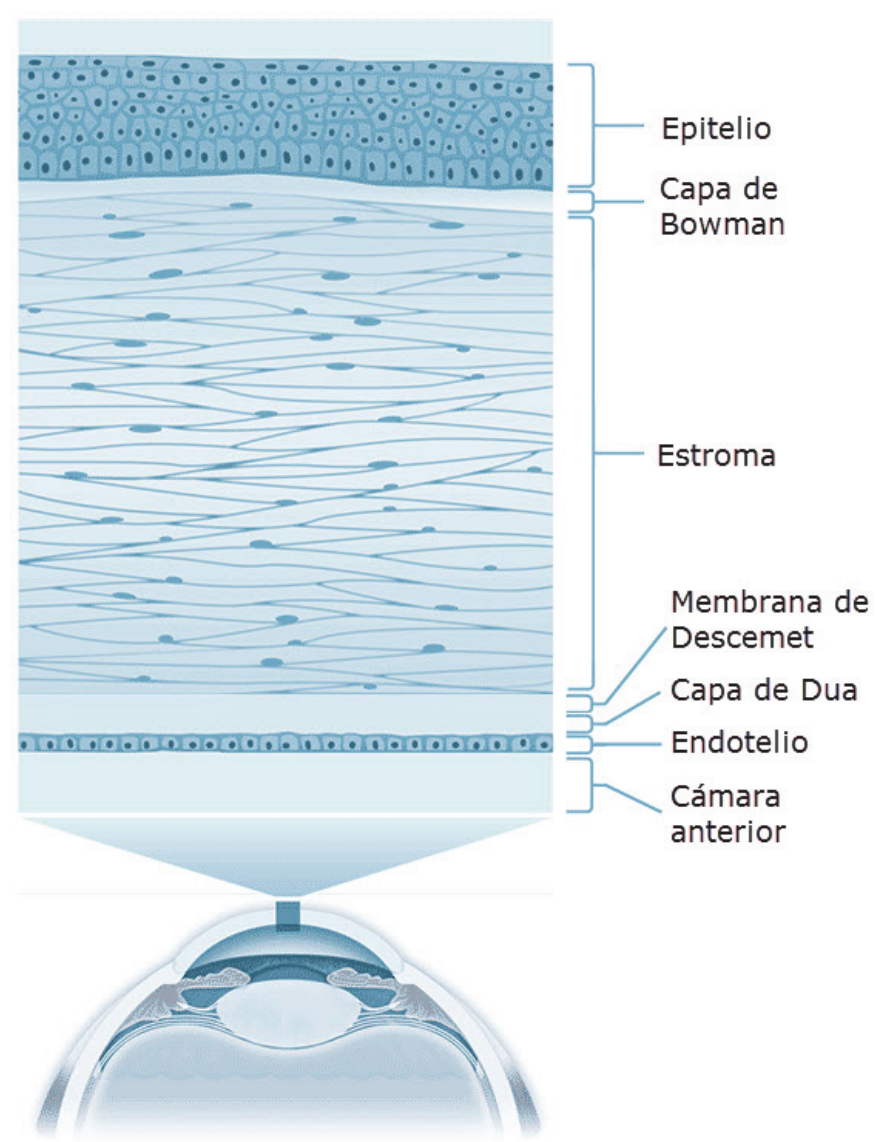

Figura 2.7 Estratos de la córnea sana

Así mismo, en el epitelio corneal se pueden distinguir tres tipos de células agrupados por estratos (Montalbán, 2013; Buey Salas y Peris Martínez, 2014):

- Escamosas, planas o apicales en la superficie. Presentan una forma poligonal con dos posibles caracterizaciones o capas superficiales al ser estudiadas por microscopía electrónica de barrido: por un lado, las células claras que son las más jóvenes, y por otro lado, las células oscuras que son hipermaduras y están próximas a la descamación.

- Intermedias o alares. Se caracterizan por presentar abundantes interdigitaciones con uniones desmosómicas que ejercen de barrera.

- Basales o columnares. Se trata de unas células ubicadas en la profundidad del epitelio componiendo una única capa de células columnares que descansa sobre la membrana basal. Además, se encuentran envueltas en su superficie anterior por núcleos ovales que se orientan perpendicularmente a la superficie. Así mismo, son células mitóticamente muy activas, desplazándose interiormente sus células hijas para transformarse en células intermedias. Estas células se asocian entre sí mediante microestructuras que además presentan un importante papel de comunicación y formación de barreras. Estas microestructuras son fundamentalmente tres: 
- Desmosomas: son unas fusiones intercelulares puntiformes que procuran estabilidad mecánica al epitelio, a partir de dos clases de proteínas: las Cadherinas e Integrinas.

- Uniones comunicantes: son microestructuras que unen las células basales en forma de canales de iónes y de moléculas hidrofílicas para el transporte de sustancias entre las células. Igualmente, estas células se fusionan con la membrana basal mediante fibras de queratina denominadas Hemidesmosomas, las cuales se fijan tanto a la membrana basal como a la Membrana de Bowman y al Estroma anterior mediante fibrillas de anclaje compuestas por colágeno tipo IV y VII. Bajo la lámina de las células basales se localiza una membrana basal de espesor $500 \AA$ producida por ellas. Mediante microscopía electrónica se ha observado que esta lámina está formada por una región clara anterior, denominada lámina lúcida, y por una región oscura posterior, denominada lámina densa. La lámina basal interviene en la fijación de células epiteliales al estroma corneal junto a sus fibrillas.

- Uniones estrechas: estas presentan la unión real de las bicapas lipídicas de las membranas celulares contiguas. Se localizan en las capas basales más superficiales. Estas uniones articulan un sistema para el sustento de la homeotasis interna de la córnea, ya que evitan el trasvase de todo tipo de células al espacio intercelular, generando así una barrera celular entre la córnea y el ambiente exterior.

Además, la células basales contienen tonofilamentos para conservar la morfología celular, como son los filamentos de actina, que desempeñan un papel importante en la migración celular durante el proceso de cicatrización de una herida (Gipson, 1977).

Por otro lado, las células superficiales en fricción con la lágrima conforman un proceso de descamación fisiológica en donde estas células trasvasadas a la lágrima son reemplazadas por otras localizadas en los estratos inferiores.

Existe otro tipo celular entre las células epiteliales, como son los linfocitos, que son pequeñas células de núcleo oscuro con múltiples prolongaciones dendríticas. Además, en la periferia del epitelio existen otras células inmunes presentadoras de antígenos, como las células de Langerhans o dendritiformes. En la región central, el epitelio carece de células dendríticas y de melanocitos, lo que justifica la buena tolerancia inmunológica que presenta el injerto corneal. Este escenario puede ser alterado ante una patología corneal (Montalbán, 2013; Buey Salas y Peris Martínez, 2014).

\section{Capa de Bowman}

Es una estructura acelerar cuyo nombre se debe al médico oftalmólogo inglés Sir William Bowman. La capa es una fina membrana de 8 a $20 \mu \mathrm{m}$ de espesor formada por fibras de colágeno tipo I y III (Tao et al., 2011). Se encuentra situada debajo de la membrana basal del epitelio corneal, siendo claramente diferenciable de éste. 
Físicamente se comporta como una barrera que impide el paso de las sustancias desde y hacia el estroma (Montalbán, 2013; Buey Salas y Peris Martínez, 2014). Esta capa carece de capacidad regeneradora debido a la ausencia de células, por lo que cualquier deterioro puede generar una reacción cicatricial (Sagrinati et al., 2006).

\section{Estroma corneal}

El estroma corneal comprende alrededor del 90\% del espesor corneal total (Gipson et al., 2004). Su grosor en la región central oscila entre 500 y $540 \mu \mathrm{m}$, y en la región periférica alcanza valores en torno a los $700 \mu \mathrm{m}$.

Está formado por una matriz extracelular y por las células corneales o queratocitos (Montalbán, 2013; Buey Salas y Peris Martínez, 2014):

- Matriz extracelular. Básicamente, está constituida por colágeno (tipos I, IV y V) y proteoglicanos (queratán sulfato -QS- y dermatán sulfato -DS-), que sostienen las uniones entre las fibras de colágeno estromales. Para ser transparente el estroma presenta una estructura singular, concretamente compuesta por densas fibrillas de colágeno tipo I y $\mathrm{V}$, empaquetadas regularmente en forma de láminas de diámetro entre 250 y $300 \mu \mathrm{m}$. Presentan una organización regular y una orientación espacial homogénea, como capas ortogonales entre sí, que cursan paralelas a la superficie, propagándose de limbo a limbo. Esta orientación se produce probablemente para compensar las deformaciones causadas por la musculatura intrínseca.

La condición óptica de transparencia del estroma viene fundamentada por el pequeño diámetro que presentan las fibras de colágeno, de aproximadamente $300 \AA$, y por su estrecha separación en torno a $550 \AA$, es decir, unas dimensiones inferiores a la dimensión crítica para crear la dispersión de la luz (Maurice, 1957). Esta caracterización crea una interfase destructiva entre las ondas que permite eliminar la dispersión de la luz, por lo que no se produce una dispersión luminosa apreciable, ya que ésta se produce cuando las fluctuaciones regionales superan los $2000 \AA$ A por hidratación excesiva o por edema (la luz es visible en el entorno de $4000 \AA$ a $7000 \AA$ ).

Por otro lado, la distribución de la red lamelar en el estroma no es homogénea, ya que presentan diferencias espaciales entre las distintas regiones corneales. Concretamente se entrecruzan más densamente en el tercio anterior de la córnea que en los dos tercios posteriores; además las lamelas sólo están adheridas ligeramente entre sí. Igualmente, también hay lamelas que presentan una disposición circular en el limbo o con una dirección anteroposterior con diferentes ángulos de cruzamiento, lo que le confiere una especial resistencia y morfología a la arquitectura del tejido (Meek et al., 1987).

Los principales colágenos formadores de fibras de la matriz son de tipo I y $\mathrm{V}$ (Birk et al., 1986). El colágeno del tipo $\mathrm{V}$ es el responsable de emprender el montaje de las fibras (Wenstrup et al., 2004; Wenstrup et al., 2006) y de la 
ordenación del diámetro de las mismas (Birk et al., 1990). El colágeno del tipo I no forma las fibras, sino que es el responsable de crear una estructura en forma de redes que proporcionan estabilidad mecánica a los basamentos membranosos, estando localizados en la membrana basal del epitelio corneal y en la membrana de Descemet (Lizarbe, 2001).

El espacio interlaminar contiene proteoglicanos QS, localizados en la región central y anterior del estroma, y proteoglicanos DS, localizados en la región central y periférica del estroma. Ambos se unen a las fibras de colágenos de forma ordenada, lo que es esencial para la disposición y el espaciamiento fibrilar. El espacio interfibrilar se determina por el pequeño y uniforme tamaño de los proteoglicanos. La presencia de éstos se justifica por la capacidad de atrapar cationes y agua, y por lo tanto son los responsables del estado de hidratación fisiológica corneal (Freund et al., 1995). La hidratación ideal de la córnea esta en torno al 78\%: pequeñas variaciones en el porcentaje de hidratación tienen efectos sobre la transparencia corneal (Freund et al., 1995).

En la matriz extracelular del núcleo hay cuatro proteínas del Queratán sulfato (QS): decorina (Li et al., 1992), lumicano (Cao et al., 2006), queratocono (Chakravarti, 2006) y mimecano (Funderburgh et al., 1997). Estas proteínas actúan durante las diferentes fases de crecimiento de las fibras de colágeno, estabilizándolo una vez formado (Rada et al., 1993; Neame et al., 2000).

El estroma posterior es más hidrófilo al presentar una mayor concentración del Queratán Sulfato (QS), mientras que el anterior es menos hidrófilo al presentar una concentración mayor del Dermatán Sulfato (DS).

- Células del estroma corneal. La célula principal del estroma es el queratocito. Se trata de unos fibroblastos de tamaño grande cuya principal función es la fabricación de colágeno y de proteoglinacos. En el estroma existen alrededor de 2.4 millones de queratocitos (Moller-Pederson et al., 1994), con una densidad un $30 \%$ superior en el estroma anterior con respecto el posterior (Moller-Pederson y Ehlers, 1995). Los queratocitos presentan un cuerpo celular plano con abundantes lamelipodios citoplasmáticos, lo que les confiere una morfología de naturaleza dendrítica, permitiéndoles estar interconectados a través de una pared tridimensional (Hahnel et al., 2000).

El queratocito posee el mismo tipo de colágeno que la matriz extracelular del estroma corneal al provenir de la cresta neural. Junto con los queratocitos pueden observarse pequeños haces fibrilares de colágenos recién sintetizados. Ante una lesión de la estructura del estroma, los queratocitos emigran a la región dañada y tratan de reparar la lesión transformándose en fibroblastos. Estas células transformadas tienen un incremento del retículo endoplásmico rugoso del aparato de Golgi, así como una disminución de las prolongaciones citoplasmáticas. De esta forma contribuyen a la formación de la cicatriz mediante la proliferación y formación del colágeno. 
En el estroma, concretamente en el espacio interfibrilar, también se observa una pequeña cantidad de leucocitos polimorfonucleares, células plasmáticas y macrófagos, que son células que proceden de los vasos sanguíneos de la periferia corneal. En el caso de la existencia de una inflamación en la zona, la presencia de estas células aumenta de forma notable.

Por otra parte, al ser el estroma la capa que comprende aproximadamente el $90 \%$ de la córnea, en el caso de la manifestación física de una patología a través de un edema o hinchazón, la tensión de las fibras posteriores del estroma es menor, mientras que las fibras anteriores del estroma de deforman o elongan pudiendo incluso cambiar el radio de curvatura de la cara anterior de la córnea, lo que se traduce en una modificación de la capacidad óptica del paciente (Boote et al., 2005; Petsche y Pinsky, 2013).

\section{Capa de Dua}

Se trata de una estructura descubierta en el año 2013 (Dua et al., 2013). Presenta un espesor de $15 \mu \mathrm{m}$ y se sitúa en la región comprendida entre el estroma de la córnea y la membrana de Descemet. A pesar de su delgadez es muy resistente e impermeable al aire. Constituye la sexta capa de la córnea (Buey Salas y Peris Martínez, 2014).

\section{Membrana de Descemet}

Se trata de una lámina basal gruesa que se localiza en el endotelio y tenuemente unida al estroma. Se caracteriza por aumentar su grosor a lo lardo de la vida: en el momento del nacimiento tiene un espesor de $3 \mu \mathrm{m}$, mientras que en edad adulta alcanza valores entre los 8 нm y $12 \mu \mathrm{m}$ (Johnson et al., 1982; Buey Salas y Peris Martínez, 2014). Se compone de tres subcapas, nombradas de dentro a fuera (Sawaguchi et al., 1998):

- Subcapa muy fina, de aproximadamente $0.3 \mu \mathrm{m}$, sin bandas. Es la más próxima al estroma.

- Subcapa anterior en banda que corresponde con la parte fetal. Esta subcapa la tenemos desde el nacimiento, con una dimensión entre $2 \mu \mathrm{m}$ y $4 \mu \mathrm{m}$.

- Subcapa posterior, sin bandas y muy homogénea. Es la subcapa que va aumentando su grosor a lo largo de toda la vida.

La membrana contiene fibras de colágeno tipo IV, fibronectina, glicoproteíanas y laminina (Kenny et al., 1997; Swaguchi et al., 1998) que le otorgan una elasticidad y resistencia mayores que las del estroma ante agresiones de naturaleza inflamatoria o traumáticas (McMenamin et al., 1997). Durante una intervención quirúrgica, la membrana puede ser cortada, enrollándose ésta hacia la cámara anterior del ojo, lo que provoca un cambio en la morfología de la región periférica corneal, estos engrosamientos reciben el nombre de cuerpos Hassall-Henle (Buey Salas y Peris Martínez, 2014).

Además, la membrana es una estructura muy elástica y muy resistente ante la acción de las enzimas proteólicas (Montalbán, 2013; Buey Salas y Peris Martínez, 2014). 
En comparación con la capa de Bowman, la membrana de Descemet se desprende del estroma con facilidad, reconstruyéndose con rapidez tras una patología tratada con tratamiento invasivo o no.

\section{Endotelio Corneal}

Se trata de una capa fina de células cuboideas y aplanadas que forman un mosaico con una geometría hexagonal. Se localizan a continuación de la membrana de Descemet. El otro lado de esta capa está en contacto con el humor acuoso, presentando una superficie lisa y favoreciendo unas buenas condiciones ópticas (Montalbán, 2013; Buey Salas y Peris Martínez, 2014).

La principal función del endotelio es la de regular la transferencia constante de agua y otras sustancias, como glucosa, amionácidos y otros nutrientes esenciales, desde el humor acuoso hacia el estroma. Esta actividad se produce en los espacios intercelulares hacia el estroma.

Además de la función de barrera, el endotelio tiene la facultad de eliminar el excedente del fluido almacenado en el estroma por el paso continuo de humor acuoso. De esta forma, el endotelio se comporta como una bomba activa, eliminando el sobrante de agua del estroma para mantener su espesor constante, hidratación y transparencia necesaria. En condiciones fisiológicas, el endotelio no presenta una actividad mitótica en el humano tras su nacimiento, lo que implica una pérdida o no renovación de la población celular, además de una minoración de su grosor que comprende toda la superficie corneal posterior. Esta pérdida de calidad o no renovación de la población celular se puede acrecentar ante una distrofia o como consecuencia de una patología o cirugía ocular (Montalbán, 2013; Buey Salas y Peris Martínez, 2014). Al nacer, el endotelio presenta una densidad celular en torno a unas 4000 celularas $/ \mathrm{mm}^{2}$, sufriendo una pérdida de densidad a un ritmo promedio del $0.22 \%$ anual entre los 17 y los 83 años de edad (McCarrey et al., 2008). A pesar del aumento de tamaño que pueden experimentar estas células a lo largo de su vida, pueden mantener su función de bomba activa del endotelio con densidades celulares relativamente bajas en torno a 500-700 celularas $/ \mathrm{mm}^{2}$ (Dawson et al., 2005).

Además de la densidad del número de células endoteliales para la conservación de la transparencia corneal, es importante su calidad. Ésta viene definida en base a tres parámetros:

- Aumento de la poligonalidad, es decir, el porcentaje de células hexagonales ha de ser superior al $60 \%$.

- Disminución del polimegatismo, es decir, la variedad del tamaño entre células debe ser inferior al $33 \%$.

- Mantenimiento del pleomorfismo o diversidad de formas. 
Por otro lado, la adherencia de las células endoteliales con la membrana de Descemet es muy débil, lo que les facilita extenderse para recubrir toda la cara de la superficie posterior de la córnea (Waring et al., 1982).

\subsection{Inervación corneal}

La primera rama del nervio trigémino es la responsable de la inervación sensorial de la córnea. Llega a través de las ramas ciliares largas y se suman a las ciliares cortas del nervio nasociliar. La conjuntiva límbica y el epitelio corneal límbico quedan inervados por ramas recurrentes que atraviesan la esclerótica. Una vez alcanzada la córnea, los nervios pierden la vaina de mielina, continuando como cilindros axónicos transparentes, y forman un plexo subepitelial denso bajo la capa de Bowman. Posteriormente atraviesan esta capa, finalizando como terminaciones axónicas simples entre las células epiteliales (Müller et al., 1997; Buey Salas y Peris Martínez, 2014).

Además, estos nervios no finalizan como especializaciones sensoriales ya que esto implicaría una reducción de la transparencia de la córnea, aunque puede parecer que las terminaciones se subdividen funcionalmente para recibir estímulos mecánicos, químicos o térmicos que afectan a la morfología corneal (Del Monte y King, 2001; Belmonte y Gallar, 2011).

\subsubsection{Ectasia corneal bilateral: el queratocono}

La patología ectásica más frecuente es el queratocono. Se trata de un término clínico que describe un adelgazamiento progresivo central o paracentral de la córnea que altera la morfología de la misma de forma asimétrica, provocando una protusión de la córnea en forma de cono (Figura 2.8). Esta patología está asociada con procesos de cicatrización corneal (Rabinowitz, 1998; Alió y Belda, 2004).

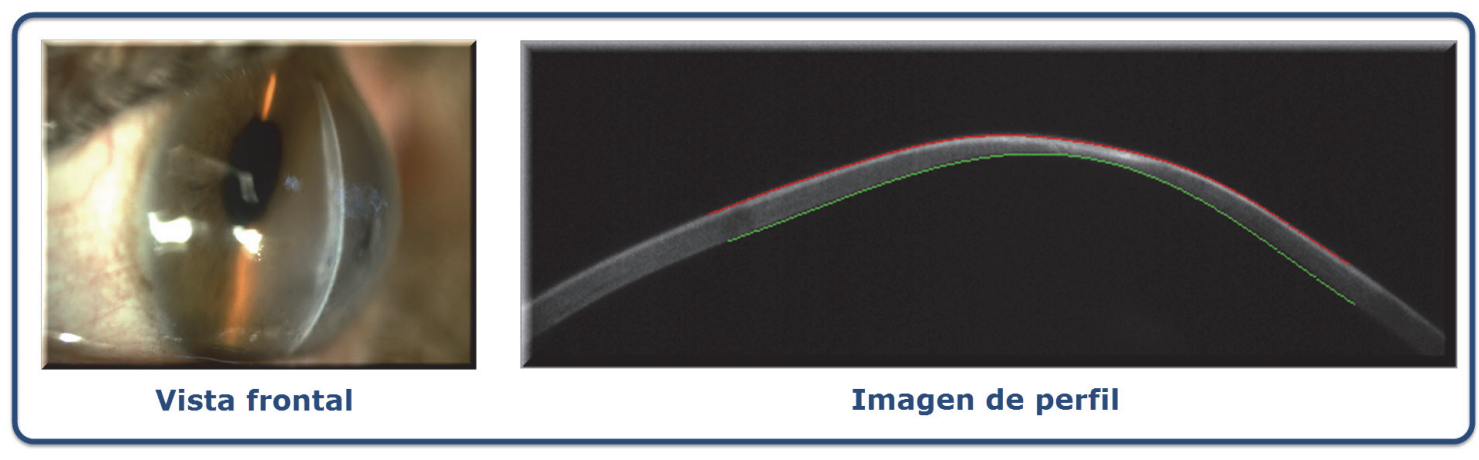

Figura 2.8 Fotografía frontal e imagen sagital de una córnea con queratocono

La protusión focal originada por la deformación corneal se produce, por un lado, por el excesivo adelgazamiento de una de las capas de la córnea, concretamente del estroma, y por otro lado, por la consecuente variación biomecánica que este proceso degenerativo compromete sobre la córnea (Figura 2.9) (Montalbán, 2013). 


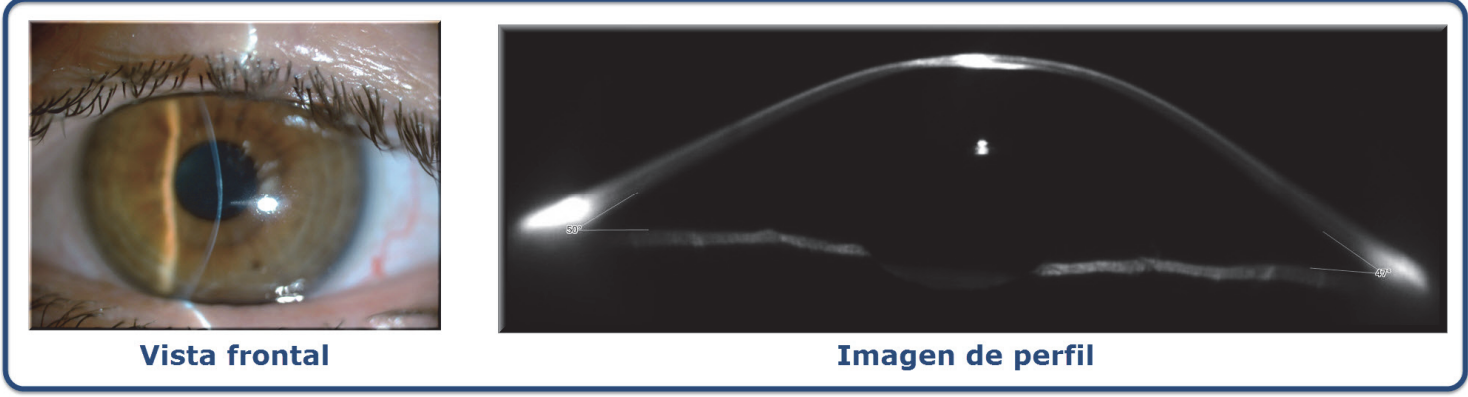

Figura 2.9 Foto de perfil de la córnea con queratocono aportada por topógrafo corneal

El queratocono es un proceso degenerativo no inflamatorio que puede afectar a ambos ojos. Esta patología se suele manifestar en la segunda década de la vida, normalmente en la pubertad (Kenndy et al., 1986), progresando hasta la cuarta década donde se estabiliza (Rabinowitz, 1998; Montalbán, 2013). La ubicación más habitual de esta alteración corneal es el área inferior temporal y el área central (Figura 2.10), si bien también puede ser localizado, aunque con menos frecuencia, en la zona superior (Prisant et al., 1997; Auffarth et al., 2000; Weed et al., 2005; Montalbán, 2013).

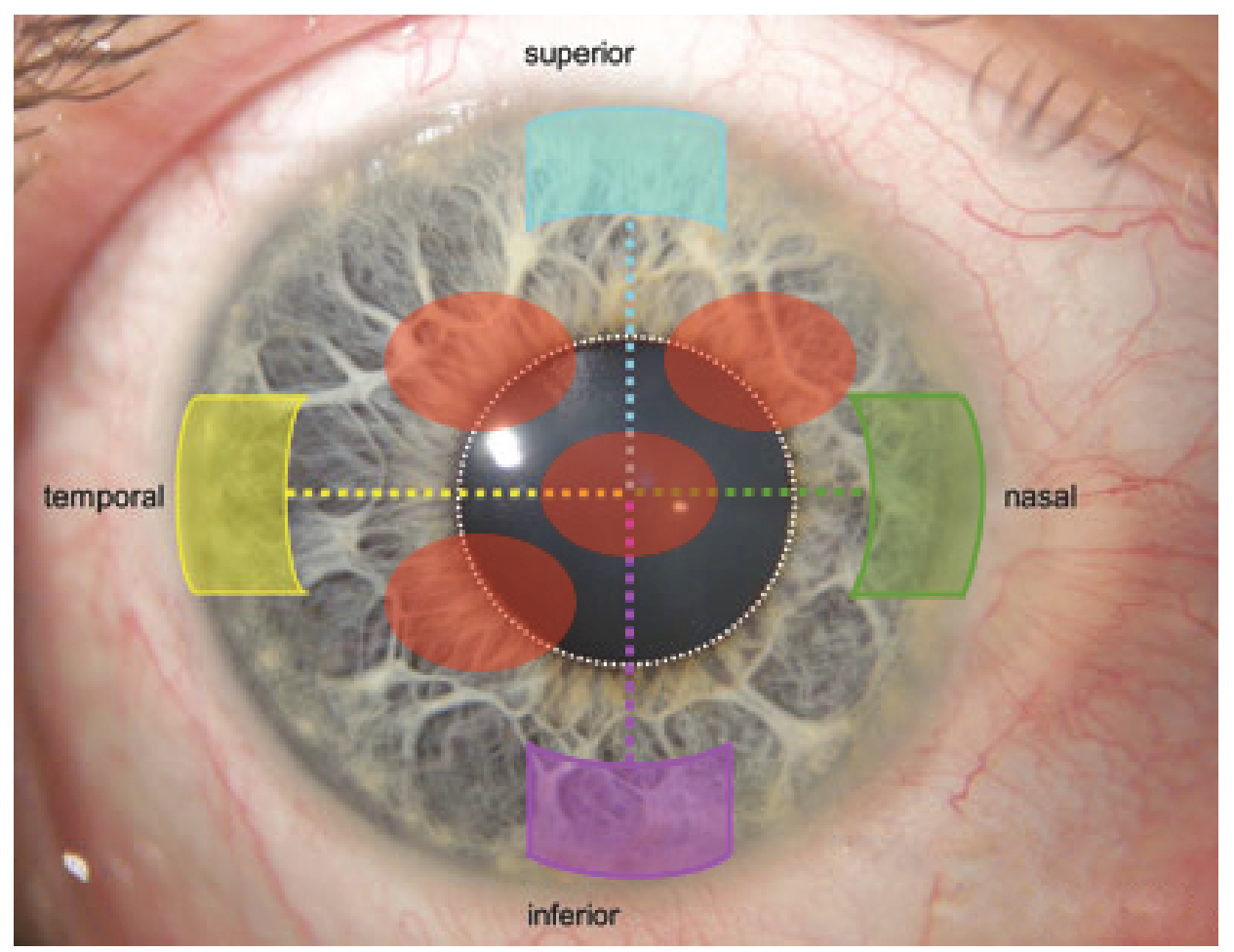

Figura 2.10 Ubicación del queratocono en la córnea respecto las hemimeridiados nasal, temporal, superior e inferior

Como consecuencia de esta protusión focal en forma de cono, más o menos extensa, en la superficie de la cara anterior de la córnea, ésta sufre una alteración de sus propiedades ópticas generando aberraciones de bajo y alto orden (Rabinowitz, 1998), es decir, altera de manera significativa la calidad visual de las personas que lo padecen, además de padecer una alta miopía y astigmatismo irregular (Alió y Shabayek, 2006). 
A nivel epidemiológico, los datos son muy diferentes y comportan rangos de prevalencia extensos, desde los 50 hasta los 235 casos por cada 10000 habitantes, en función de los criterios de diagnóstico clínico empleados en los distintos estudios (Kennedy et al., 1986). Además, es probable que los porcentajes de prevalencia sean superiores en un futuro no muy lejano por el desarrollo de nuevas tecnologías de diagnóstico y detección del queratocono, sobre todo en sus estadios más tempranos (Montalbán, 2013). Por otro lado, respecto al predominio del queratocono según el sexo, no se observan diferencias significativas entre hombres y mujeres (Kennedy et al., 1986). Así mismo, pese a que algunos estudios han presentado una mayor predisposición de la raza asiática en padecer el queratocono, no han sido manifestadas diferencias significativas de prevalencia según la raza (Montalbán, 2013).

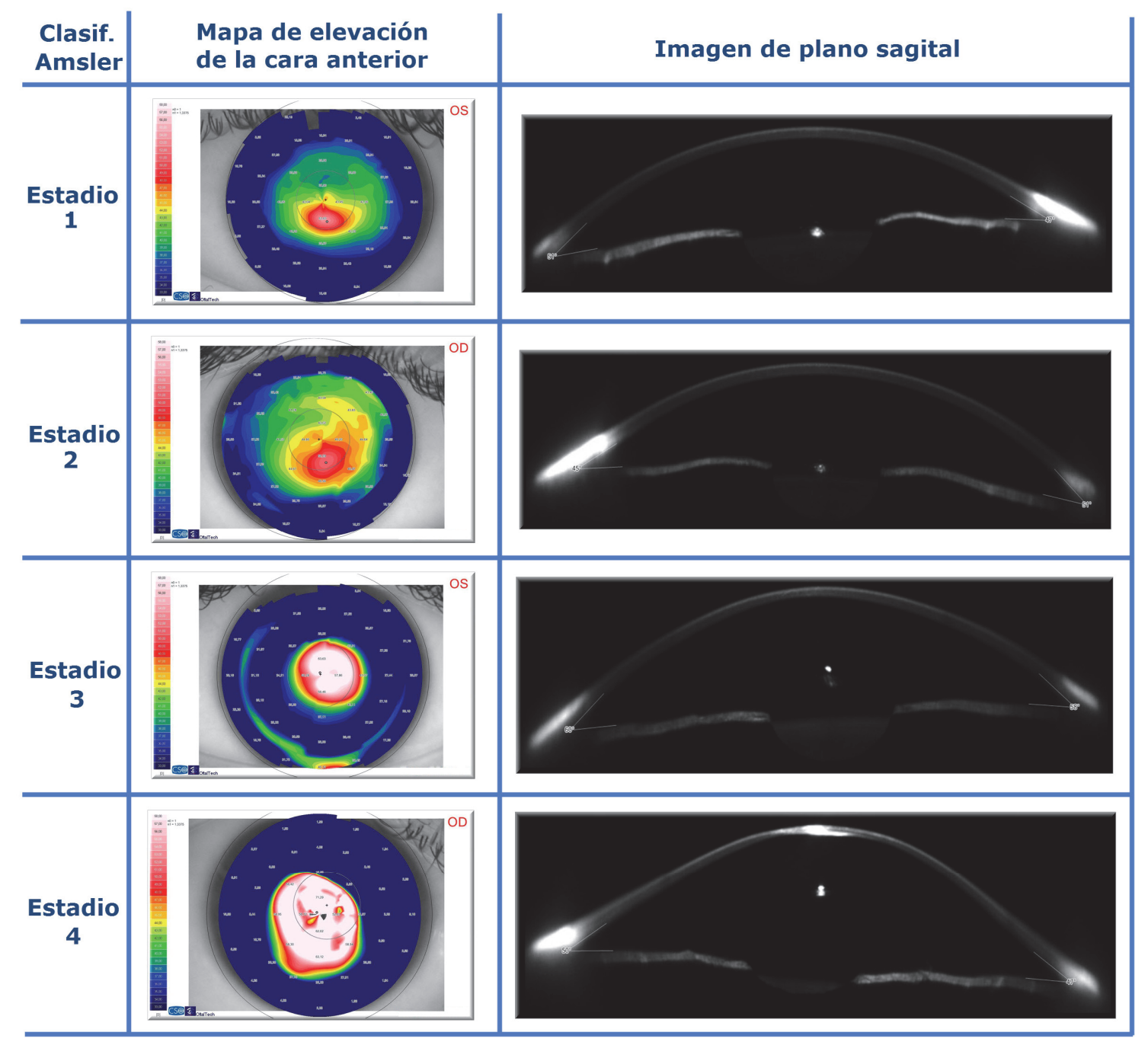

Figura 2.11 Grado de severidad del queratocono en función de la clasificación de AmslerKrumeich

En el transcurso de la enfermedad, desde su estadio más temprano o incipiente hasta el desarrollo completo de la enfermedad en su estadio más avanzado, se observan cambios a nivel anatómico y fisiológico. Esta deformación gradual de los tejidos constitutivos de la estructura corneal afecta a todas las capas de la córnea (Figura 2.11). 
El conocimiento anatómico de la córnea queratocónica debe ser realizado a nivel macroscópico y a nivel microscópico.

\subsection{Análisis macroscópico}

A nivel macroscópico, se pueden observar sin necesidad de recurrir a instrumentación oftalmológica los siguientes signos físicos (Buey Salas y Peris Martínez, 2014):

- Signo de Munson. Su presencia puede ser identificada haciendo que el paciente direccione su mirada hacia abajo, lo que provocará sobre el eje visual una angulación característica en el perfil horizontal del margen palpebral inferior obligado por el empuje del resalto corneal (Rabinowitz, 1998) (Figura 2.12).

- Signo de Rizzu. Se trata de un signo identificado por un reflejo cónico sobre la superficie de la cara anterior de la córnea en la región nasal, que se produce cuando una luz se emite desde la región corneal temporal (Rizzuti, 1970) (Figura 2.13).

- Síndrome de los párpados flexibles. Se trata de una sintomatología relacionada con los obesos masculinos y como posible indicio de la presencia del queratocono. Este síntoma es identificado porque la placa tarsal del párpado superior se torna débil y flexible. Además de este síntoma, el paciente manifiesta ectropión nocturno, ptosis y conjuntivitis papilar (Negris, 1992) (Figura 2.14).

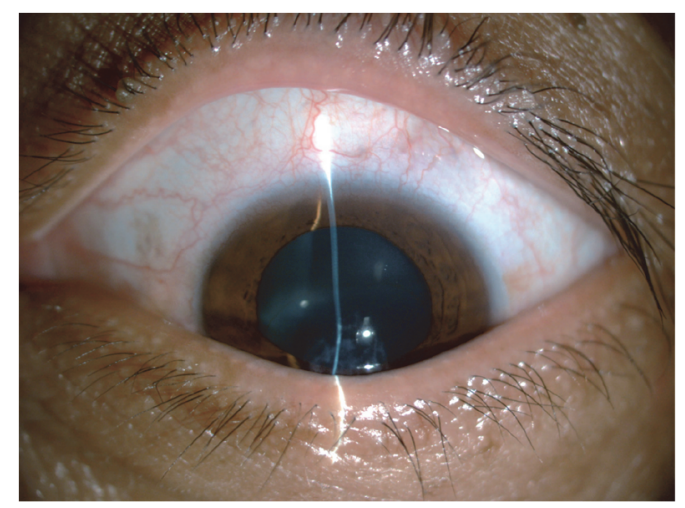

Figura 2.12 Signo de Munson

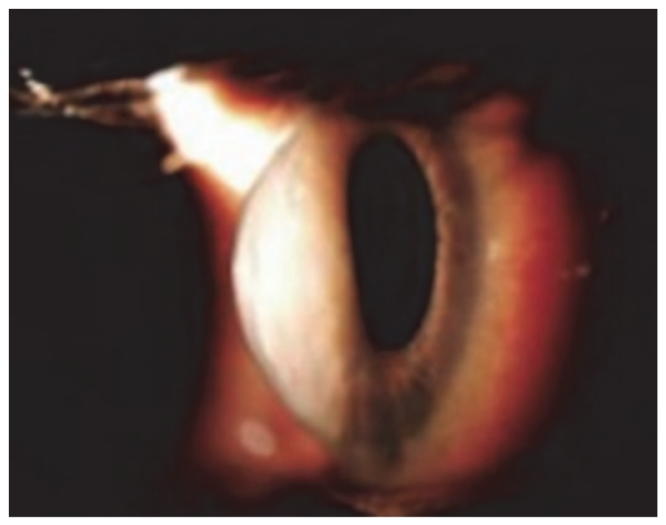

Figura 2.13 Signo de Rizzu 


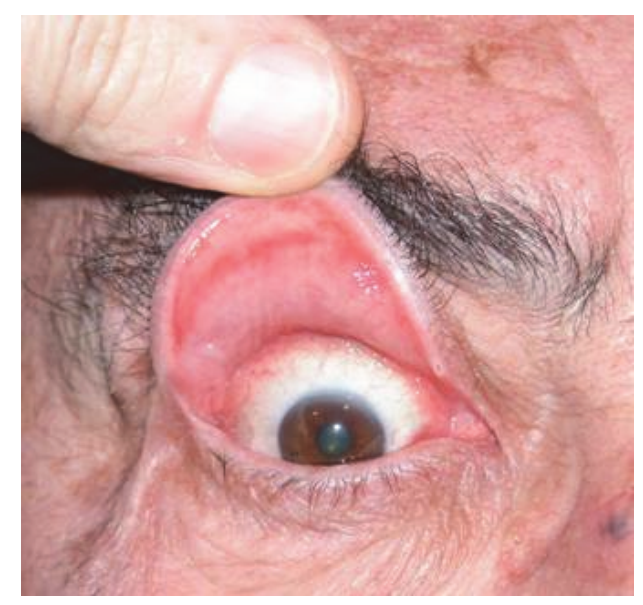

Figura 2.14 Signo de los párpados flexibles

Por otro lado, utilizando la instrumentación oftalmológica para la revisión de la superficie corneal de la cara anterior de los pacientes con queratocono en su estadio más avanzado, se ha observado a nivel morfológico dos tipos de conos (Rabinowitz, 1998):

- Los conos tipo pezón, localizados en la región central (Figura 2.15).

- Los conos tipo oval, localizados en la región inferior o inferotemporal (Figura 2.16).

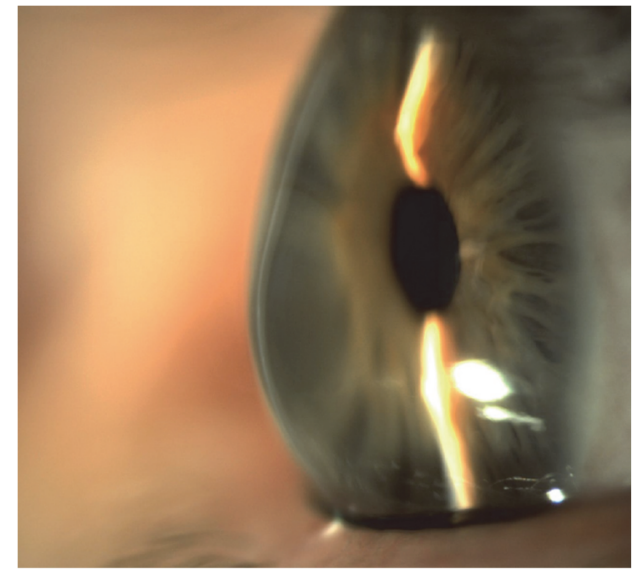

Figura 2.15 Cono tipo pezón

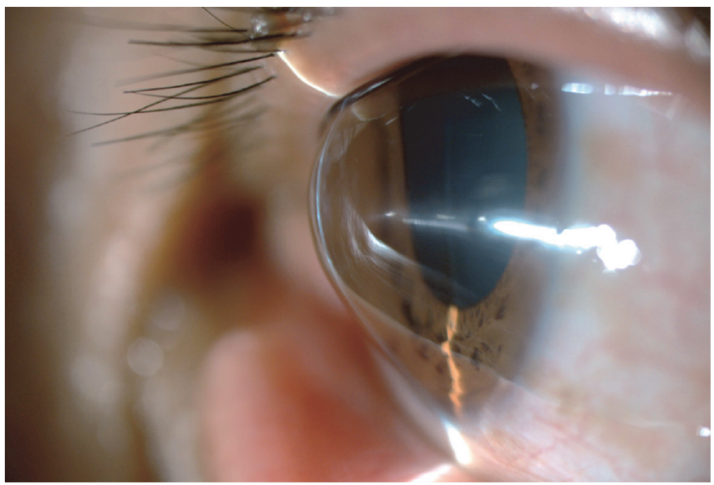

Figura 2.16 Cono tipo oval 


\subsection{Análisis microscópico}

A nivel microscópico, al igual que en el subcapítulo de "anatomía funcional de la Córnea", se puede observar que la estructura biológica de la córnea presenta 6 capas, pero han de considerarse tanto la película lagrimal como la inervación corneal en el contexto de la patología ectásica del queratocono al comportarse la córnea como una única unidad funcional.

\subsection{Película lagrimal}

Los elementos constitutivos de la película lagrimal han sido objeto de estudio por su fácil accesibilidad y por ser fuente de algunos factores pertenecientes a la etiopatogenia de las patologías corneales, como la del queratocono (Rabinowitz, 1998), donde se ha comprobado que los pacientes con esta enfermedad presentan una mayor concentración de productos de degradación de colágeno (Abalain et al., 2000; Buey Salas y Peris Martínez, 2014).

Asimismo, han sido detectados en la lágrima de los pacientes con queratocono elevados niveles de interleucina 6 (IL-6), metaloproteinasas (MMP-9) y factor de necrosis tumoral. Todos estos mediadores presentan distintas concentraciones en función del grado de severidad de la enfermedad, por lo que pueden ser utilizados como índices de monitorización de progresión de la enfermedad (Lema y Durán, 2005; Lema et al., 2009). Por lo tanto, la patología corneal del queratocono está relacionada con la alteración de la calidad de la película lagrimal y con el ojo seco (Cook, 2004; Buey Salas y Peris Martínez, 2014).

Asimismo, se conoce que tanto la inflamación como el incremento del mediador MMP9 articulan un importante papel en ambos procesos (Dogru et al., 2003; Chotikavanich et al., 2009; Buey Salas y Peris Martínez, 2014).

\subsection{Estratos de la córnea y su comportamiento en el queratocono}

Los estratos o capas constitutivas de la córnea queratocónica son seis: Epitelio Corneal, Capa de Bowman, Estroma Corneal, Capa de Dua, Membrana de Descemet y Endoelio Corneal. Estos estratos le confieren a la córnea una geometría muy singular que caracteriza la patología del queratocono.

\section{Epitelio corneal}

En la capa del epitelio, los pacientes con queratocono pueden presentar alteraciones conforme evoluciona la severidad de la patología (Montalbán, 2013; Buey Salas y Peris Martínez, 2014).

Se observa a nivel microscópico, que las capas epiteliales presentan a lo largo de su estructura numerosas irregularidades y un adelgazamiento de su morfología, sobre todo en la región corneal central o paracentral (Scroggs y Proia, 1992). En estas regiones se advierte una elongación tanto de las células superficiales como de las aladas. 
Por otro lado, las células basales presentan una morfología irregular y fragmentada, y con una importante concentración de ferrita a nivel intra y extracelular (Sawaguchi et al., 1998; Montalbán, 2013; Buey Salas y Peris Martínez, 2014). Estas células se localizan a nivel del epitelio en la base de la protusión de la córnea, mostrándose físicamente por un color pardo-amarillento que indica la existencia de ferrita. La concentración de este reservorio de hierro se manifiesta en forma de anillo, por ello se le conoce clínicamente con el nombre de Anillo de Fleischer (Cheng et al., 2001; Montalbán, 2013; Buey Salas y Peris Martínez, 2014).

\section{Capa de Bowman}

La patología del queratocono se manifiesta en la capa de Bowman en sus estadios más avanzados. Se observa una ruptura y discontinuidad de la capa en las zonas próximas al ápex del cono ya que es la zona donde se encuentran las cicatrices corneales (KaasHansen, 1993; Hollingsworth et al., 2005; Efron y Hollingsworth, 2008). Éstas se generan por la ruptura de la capa en dos capas, y como consecuencia de este fraccionamiento el epitelio experimenta un crecimiento hacia la superficie corneal, dando lugar a las cicatrices (Montalbán, 2013; Buey Salas y Peris Martínez, 2014).

Por otro lado, se observa una disminución de la capacidad de transparencia del nuevo tejido cicatricial a raíz de una distribución discontinua de un colágeno anormal formado a partir de la transformación de queratocitos en fibroblastos (Fini, 1999; Hollingsworth et al., 2005; Efron y Hollingsworth, 2008).

\section{Estroma Corneal}

El queratocono se manifiesta en la capa del estroma por un adelgazamiento de ésta debido a la compactación y a la pérdida de la organización de las fibrillas en la región del estroma anterior, así como de la disminución de las laminillas de colágeno, fibrobastos normales y degradados (Krachmer et al., 1984; Sherwin y Brookes, 2004; Dua et al., 2013). Todas estas alteraciones son más evidentes conforme el queratocono presenta estadios más severos (Boote et al., 2005; Montalbán, 2013; Buey Salas y Peris Martínez, 2014).

Además se observa un aumento de una sustancia fundamental denominada proteoglicano dematan-sulfato, aunque su concentración siga siendo inferior a los niveles de concentración presentes en las córneas normales (Sawaguchi et al., 1991; Buey Salas y Peris Martínez, 2014).

Por otro lado, como ha sido comentado en el subcapítulo anterior 2.1.1.1.2.2, la cualidad de transparencia que presenta la córnea es debido a una distribución espacial organizada de las fibras de colágeno, tanto por su orientación como por la separación entre ellas. No obstante, en córneas queratocónicas se observa una menor concentración de estas láminas en las zonas donde se produce el adelgazamiento a consecuencia de la patología ectásica (Montalbán, 2013). Es por ello que a través de la microscopía confocal se observa que en pacientes con queratocono avanzado la región 
del estroma inferior tiene unas bandas oscuras que se orientan en vertical y varían de anchura. Estas bandas presentan una conexión con los denominados pliegues o estrías de Vogt, por lo que son unas huellas propias que presentan los pacientes con queratocono. La presencia de estas formas o estrías se debe al estrés mecánico al que están sometidas las láminas de colágeno como consecuencia de la deformación que sufren los tejidos constitutivos de la estructura corneal a raíz de la patología ectásica del queratocono (Krachmer et al., 1984; Montalbán, 2013).

\section{Capa de Dua}

Es una capa muy delgada y resistente, de reciente descubrimiento, pero que no queda todavía claro su comportamiento o evolución ante la patología del queratocono, aunque muy probablemente será similar a la Membrana de Descemet (Dua et al., 2013).

\section{Membrana de Descemet}

En la membrana de Descemet se pueden distinguir tres estados morfológicos en función del grado de severidad del queratocono (Montalbán, 2013; Buey Salas y Peris Martínez, 2014):

- Estadios tempranos. No se observan cambios morfológicos relevantes.

- Estadios moderados. Aparecen micropliegues o estrías de Vogt que se forman como consecuencia de la distensión del tejido conforme evoluciona la enfermedad.

- Estadios avanzados. Se puede producir la ruptura de la membrana. Clínicamente se asocia a una hidratación masiva de la córnea por una entrada de humor acuoso en el estroma corneal y a la generación de un edema agudo en la región afectada, el cual se conoce con el nombre de hydrops (Rabinowitz, 1998).

Este proceso patológico se suele resolver en unas semanas al auto regenerarse la membrana, restableciendo el equilibrio acuoso de la córnea y remitiendo el edema.

\section{Endotelio corneal}

Se trata de una capa que puede ser normal en estadios tempranos y moderados del queratocono. Sin embargo, en estadios avanzados se observa un alargamiento de las células hacia la dirección de la protusión o del cono y un debilitamiento de esta monocapa de células (Hollingsworth y Efron, 2005; Weed et al., 2007; Ku et al., 2008; Montalbán, 2013). Esto implica un desprendimiento de la membrana de Descemet, del endotelio y de la parte posterior del estroma (Wygledowska-Promienska et al., 1999).

El desprendimiento de la membrana puede generar una pérdida de la concentración endotelial y edema (Jongebloed et al., 1989; Buey Salas y Peris Martínez, 2014). 


\subsection{Inervación corneal}

Los pacientes con queratocono presentan un aumento de la visibilidad de las fibras nerviosas (Kinoshita et al., 1991). Estos nervios corneales penetran en los espacios de los lugares de degradación generados entre el epitelio y el estroma (Brokes et al., 2003; Buey Salas y Peris Martínez, 2014).

\subsubsection{Conclusiones}

La córnea queratocónica presenta una anatomía funcional diferente a la córnea sana.

La córnea patológica adolece de una importante pérdida de espesor en el estroma debido a una aminoración del número de queratocitos y de las láminas de colágeno, degradando muchos de ellos a los fibroblastos. Este adelgazamiento se debe a la debilidad biomecánica que presenta la estructura corneal, generando tensiones sobre las fibras de colágeno estromales que pueden adoptar una configuración en forma de micropliegues o estrías.

Otras características morfológicas que presentan las córneas con esta patología ectásica son el denominado clínicamente anillo de Fleischer, el adelgazamiento epitelial y la rotura de la membrana de Bowman.

Todos estos cambios morfológicos se manifiestan de forma más evidente conforme el grado de severidad de esta patología avanza.

\subsubsection{Caracterización morfológica de la córnea}

La córnea posee una arquitectura y una métrica singular que modifica su morfología al pasar de un escenario natural a un escenario patológico.

Conocer desde el punto de vista clínico la morfología es importante para el diagnóstico de patologías relacionadas con ésta, así como para decidir el posterior tratamiento correctivo mediante técnicas invasivas o no.

Tradicionalmente, la caracterización morfológica de la córnea ha sido realizada desde una perspectiva bidimensional, y por ello, características morfológicas como la paquimetría, el espesor corneal o la superficie de sus caras anterior y posterior no han sido muy consideradas. Además, en este contexto la córnea se interpreta en oftalmología como una única superficie refractiva.

Con el desarrollo de nuevas tecnologías que permiten definir la esencia de un elemento en un entorno tridimensional, la percepción simplificada bidimensional ha pasado a ser otra más compleja, donde la córnea es concebida como un elemento refractivo tridimensional. El cambio que la córnea experimenta al pasar de un escenario natural a otro escenario patológico, concretamente con la patología ectásica bilateral denominada queratocono, implica una modificación en la capacidad visual de los pacientes (Alió y Shabayek, 2006). 
Por otra parte, es de interés descubrir qué se entiende actualmente en el campo de la oftalmología por la caracterización morfológica de una córnea sana y de la enfermedad objeto de diagnóstico en esta tesis, el queratocono en sus diferentes grados de severidad. Igualmente, han de describirse los instrumentos existentes actualmente en el mercado para la caracterización morfológica de la córnea a través de los topógrafos corneales, así como de los descriptores e índices topográficos utilizados para tal fin.

En el presente subcapítulo de tesis doctoral se describe a nivel morfológico la córnea sana y la córnea queratocónica, así como las diferentes tecnologías en las que están basados los actuales topógrafos corneales. Además se dedica un subcapítulo al topógrafo Sirius (CSO, Italia), por ser éste el equipo utilizado para caracterizar la superficie corneal en la presente tesis doctoral.

\subsubsection{La córnea en un escenario natural}

Esta regularidad sobre la superficie corneal hace que ésta actúe como una lente otorgando a la córnea la capacidad de ser el elemento refractivo más importante del esquema ocular. Así, la superficie de la cara anterior de la córnea es la responsable de dos tercios (43 D) del poder óptico total del ojo humano en el punto de mayor altura de la córnea denominado ápex corneal (Figura 2.17).

Una córnea sana presenta las siguientes caracterizaciones morfológicas:

- Respecto a la cara anterior. Presenta un rango de curvatura promedio en su superficie entre $7.75 \mathrm{~mm}$ y $7.89 \mathrm{~mm}$ (Dubbelman et al., 2002; Ho et al., 2008; Piñero el al., 2010b) y en el centro un rango de curvatura promedio de $7.79 \mathrm{~mm}$ (Dubbelman et al., 2006).

- Respecto a la cara posterior. Presenta un rango de curvatura promedio en su superficie entre $6.34 \mathrm{~mm}$ y $6.48 \mathrm{~mm}$ (Dubbelman et al., 2002; Ho et al., 2008; Piñero el al., 2010b) y en el centro un rango de curvatura promedio de $6.53 \mathrm{~mm}$ (Dubbelman et al., 2006; Atchison et al., 2008).

Entre ambas superficie se define la paquimetría o espesor corneal con un valor promedio en su centro geométrico en torno a $0.54 \mathrm{~mm}$ (Calossi, 2007; Atchison et al., 2008; Piñero et al., 2010b).

En la literatura científica existen trabajos que demuestran la tendencia a mantener estable los valores promedio de curvatura y de espesor corneal en un escenario sano (Atchinson et al., 2008).

Además de los parámetros descritos anteriormente, la caracterización de la córnea implica conocer la morfología de la superficie de la cara anterior y posterior de la córnea. Estas superficies son muy similares desde un punto de vista geométrico a las de un esferoide; se trata de una figura geométrica cuya curva generatriz se obtiene al girar una elipse alrededor de uno de sus ejes principales. Además la figura está dominada por dos ejes, el denominado Eje de Simetría, situado en el eje de coordenadas cartesianas y nombrado con la letra c, y el denominado Eje perpendicular 
al eje de simetría, nombrado con la letra a. Las letras c y a son definidas sobre el Esferoide por convenio internacional (Figura 2.18).

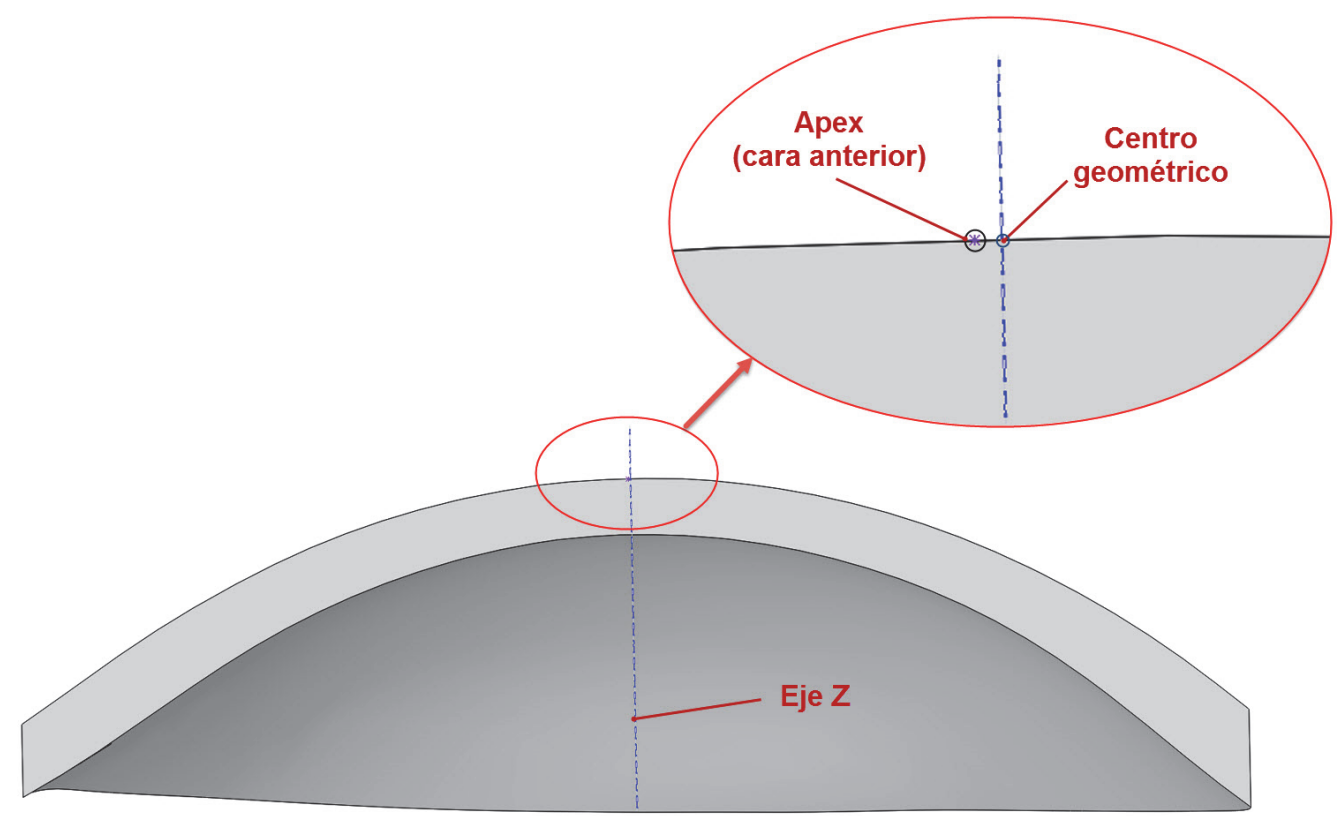

Figura 2.17 Ápex corneal

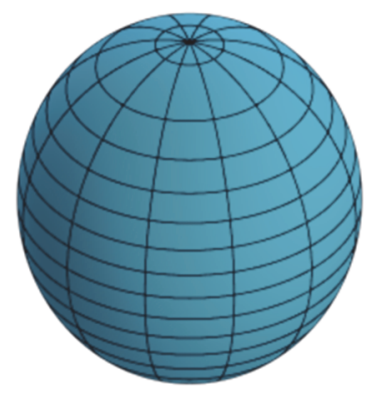

Figura 2.18 Esferoide

Además el esferoide puede simular tres configuraciones distintas en función de la relación entre sus ejes principales c y a:

- $\quad$ Esferoide Oblato. Si a>c, el eje de simetría es el menor (Figura 2.19).

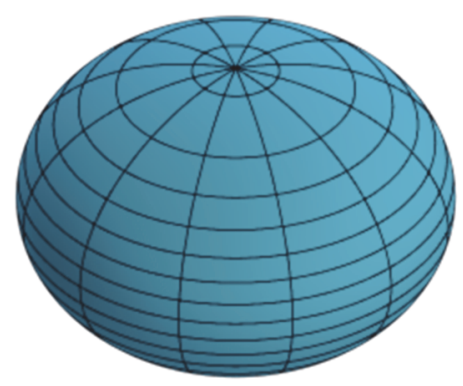

Figura 2.19 Esferoide oblato 
- Esferoide Prolato. Si a<c, el eje de simetría es el mayor (Figura 2.20).

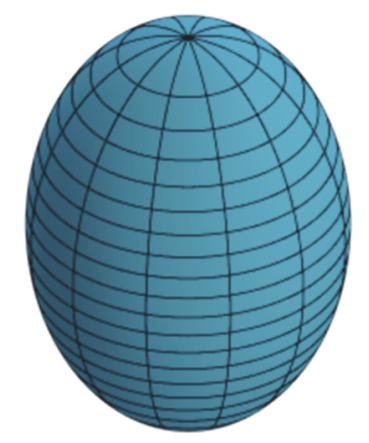

Figura 2.20 Esferoide prolato

- Esfera. Si a=c, el eje de simetría es igual (Figura 2.21). Este es un caso especial, dado que la superficie obtenida por la curva generatriz es una esfera, y por consiguiente esta curva no es una elipse, al tener sus ejes principales iguales, sino una circunferencia.

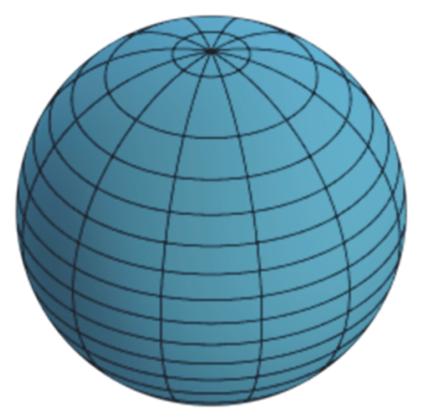

Figura 2.21 Esfera

Todo lo anteriormente expuesto es extrapolado al campo de la oftalmología, donde la córnea presenta un comportamiento geométrico muy similar al de un perfil de naturaleza elíptica (Piñero et al., 2010a):

$$
X^{2}-Y^{2}+(1+Q) Z^{2}-2 Z R=0
$$

Esta expresión matemática presenta tres coordenadas espaciales $(X, Y, Z)$, y en base a éstas la córnea es interpretada actualmente como un elemento refractivo tridimensional mediante tres parámetros definidos como (Figura 2.22):

- Asfericidad Corneal (Q): parámetro que caracteriza la naturaleza de la curva cónica a la cual representa la expresión matemática.

- Eje de revolución conocido (Z).

- Radio del Conoide (R): es el radio del punto más alto de la superficie de la cara anterior o del ápex corneal. 


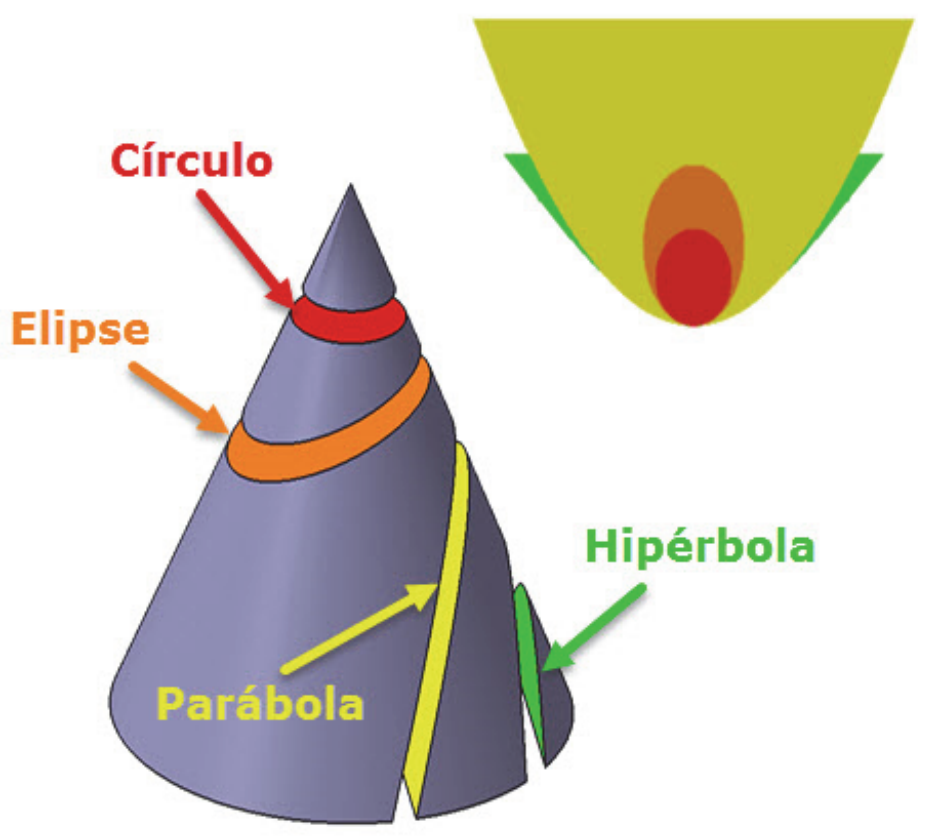

Figura 2.22 Secciones de diferentes tipos de curva curvas cónicas (Calossi, 2007)

Respecto a la Asfericidad Corneal, ésta se define como el grado de pendiente o de curvatura de la córnea desde la región central hasta la región periférica. Esta pendiente puede presentar una tendencia más plana, escenario geométrico de una córnea sana, o más curva, escenario geométrico de una córnea patológica (Figura 2.23).

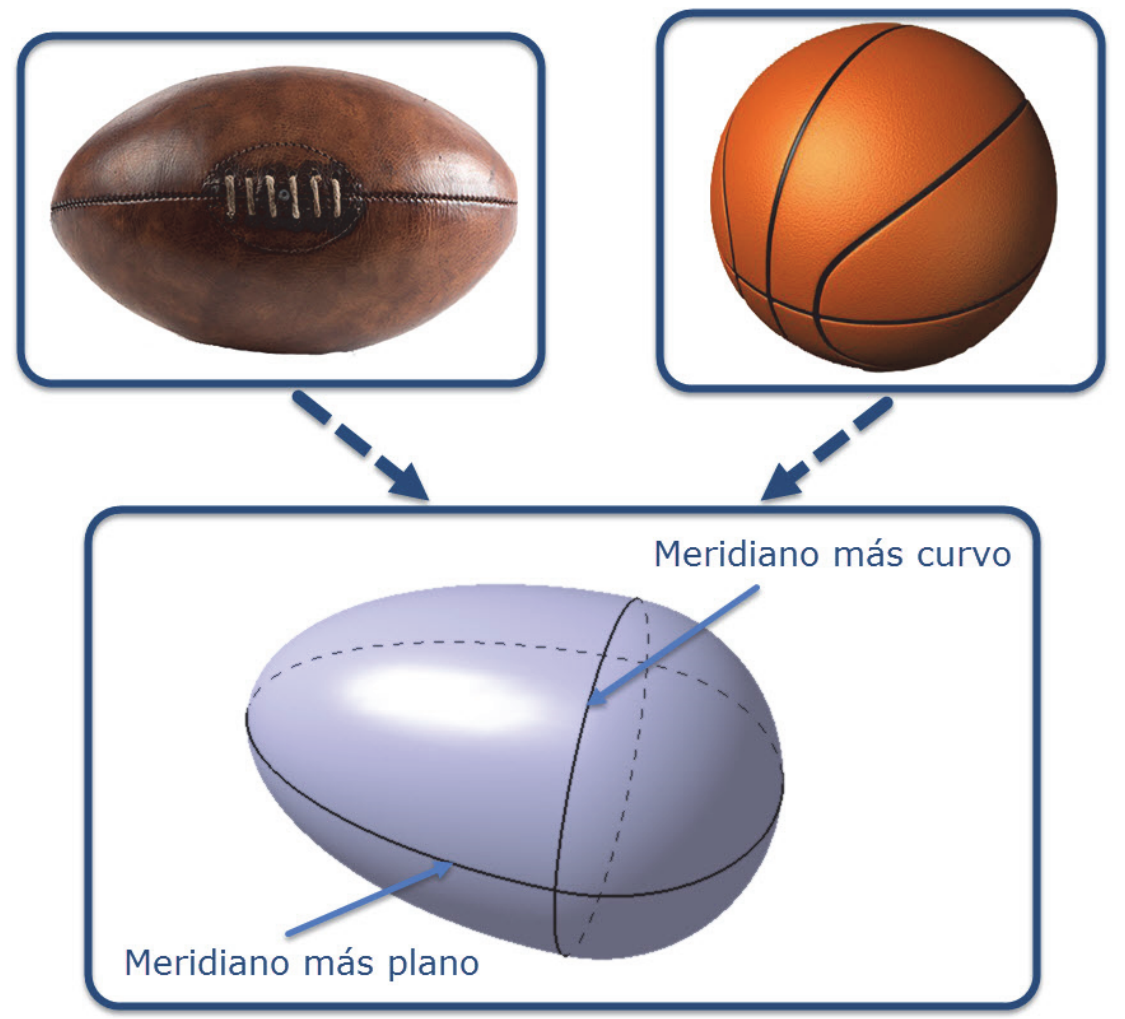

Figura 2.23 Asfericidad. Concepto 
El coeficiente de asfericidad corneal $(Q)$ puede ser calculado matemáticamente a partir de la relación entre los hemiejes centrales (b) y periféricos (a) del perfil elíptico corneal (Figura 2.23).

En base a lo anteriormente expuesto, el perfil elíptico de la superficie corneal puede definirse entre los siguientes (Montalbán, 2013):

- Esférico $(\mathrm{Q}=0)$. Es un caso singular, donde los hemiejes horizontal o periférico (a) y central o vertical (b) de la elipse son iguales, es decir la superficie corneal tiene la misma curvatura en la región central que en la región periférica.

- Elipse prolata $(0>Q>-1)$. En este caso, el perfil elíptico de la superficie corneal se aplana conforme se aleja del punto más alto o ápex de la superficie corneal. Este comportamiento se da en un escenario sano, lo que implica desde el punto de vista refractivo que la córnea posee una baja aberración esférica.

- Elipse oblata $(\mathrm{Q}>0)$. En este otro caso, el perfil elíptico de la superficie corneal se hace más curvo conforme se aleja del punto más alto o ápex corneal. Este comportamiento se da en un escenario patológico, lo que implica desde el punto de vista refractivo que la córnea posee una aberración esférica proporcional al factor $\mathrm{Q}$.

- Parábola o hiperbólica (Q<-1). Es un caso excepcional en los ojos sanos, y exclusivo de las patologías ectásicas centrales de la córnea. Desde el punto de vista de la superficie refractiva, la córnea posee un índice de aberración esférico negativo proporcional al factor $\mathrm{Q}$.

Por otro lado, el grado de curvatura de la córnea puede ser expresado en función de otros factores, además de la ya mencionada asfericidad, como son:

- Factor de excentricidad (e):

$$
e=-\sqrt{Q}
$$

- Factor de forma (p):

$$
p=1-e^{2} \quad \text { o } \quad p=Q+1
$$

Todos ellos relacionados entre sí (Tabla 2.1). 


$\begin{array}{cccc}\text { Sección Córnea } & \text { Excentricidad } & \text { Factor de forma } & \text { Asfericidad } \\ & e^{2} & p=1-e^{2} p=Q+1 & Q=-e^{2} \\ \text { Esfera } & e^{2}=1 & p=1 & Q=0 \\ \text { Elipse Oblata } & e^{2}<1 & p>1 & Q>0 \\ \text { Elipse Prolata } & 0<e^{2}<1 & 0<p<1 & 1<Q<0 \\ \text { Parábola } & e^{2}=1 & p=0 & Q=-1 \\ \text { Hipérbola } & e^{2}>1 & p<0 & Q<-1\end{array}$

Tabla 2.1 Relación entre las distintos tipos de curvas geométricas de la córnea en función de los parámetros asfericidad y su relación con la excentricidad y factor de forma, adaptada de Montalbán (2013)

Además, el perfil de la sección elíptica corneal se define en función del radio de curvatura central (Rc) (Figura 2.24), por lo que:

$$
\begin{aligned}
& p=\left(\frac{b}{a}\right)^{2}=R c / a \\
& Q=p-1
\end{aligned}
$$
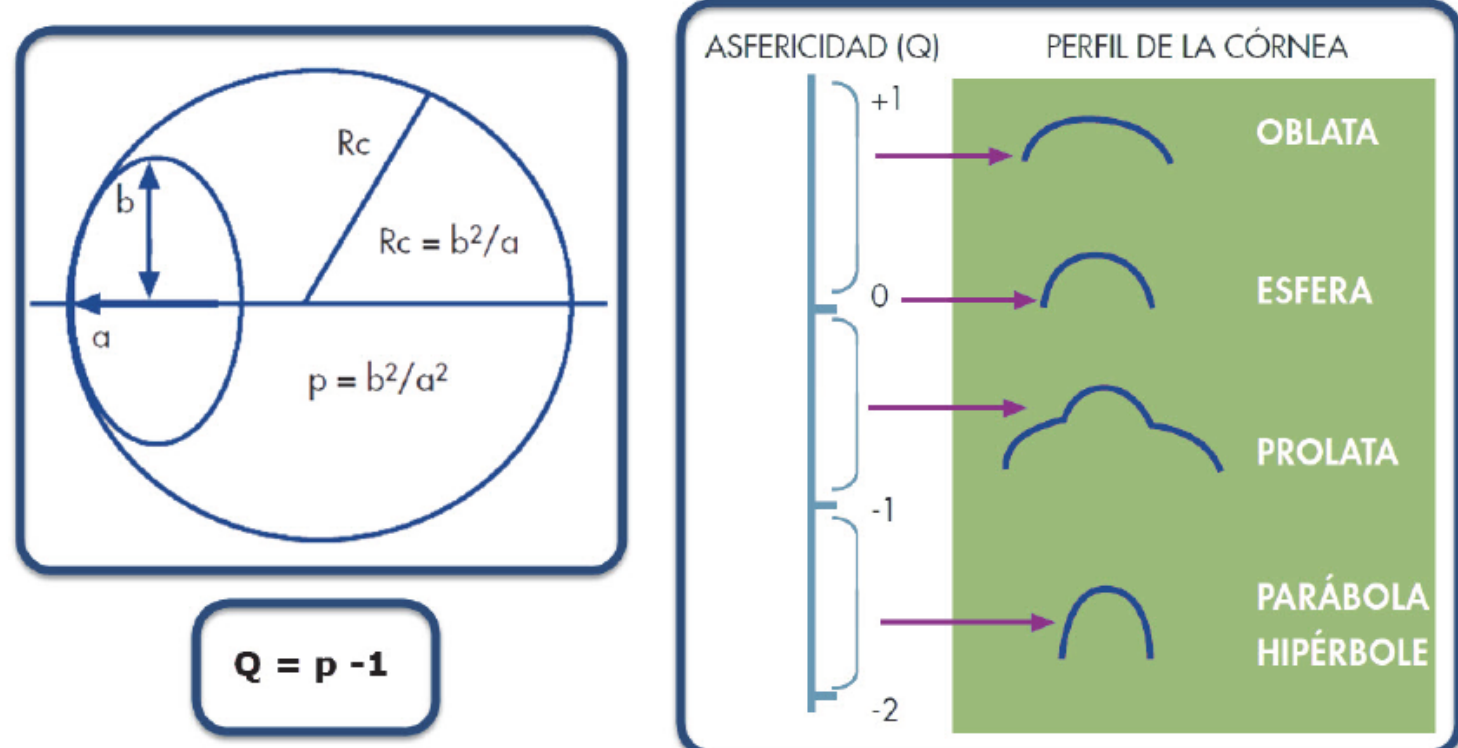

Figura 2.24 Asfericidad Corneal

En la literatura científica el término más utilizado para caracterizar la morfología corneal es la asfericidad (Q). En ojos normales, el valor numérico de la asfericidad de la cara anterior varía entre los valores de -0.29 a -0.13 (Dubbelman et al., 2002; YebraPimentel et al., 2004; Ho et al., 2008), y para la cara posterior varía entre los valores 0.34 a -0.38 (Dubbelman et al., 2002; Piñero et al., 2010a), lo que pone de manifiesto que ambas superficies presentan una caracterización morfológica de naturaleza prolata.

Por otro lado, respecto al concepto de asfericidad ha de puntualizarse que este valor cambia en función de la región corneal objeto de análisis, de forma que la morfología 
de una misma córnea puede presentar diferentes valores de asfericidad. Es por ello que resulta de gran interés para la comunicad oftalmológica definir un proceso de caracterización morfológica de la superficie corneal que integre las modificaciones que puede experimentar su morfología a lo largo de sus diferentes regiones corneales.

En la superficie corneal existen cuatro regiones o zonas geográficas que abarcan desde el ápex corneal hasta el limbo (Figura 2.25) (Montalbán, 2013):

- Región Central: esta región comprende los $3 \mathrm{~mm}$ centrales de la córnea, siendo la zona más esférica y con mayor repercusión corneal.

- Región paracentral o periférica: esta región comprende desde los $3 \mathrm{~mm}$ hasta los $8 \mathrm{~mm}$ del centro, siendo en esta zona donde la córnea empieza a aplanarse de forma progresiva.

- Región periférica: esta región comprende desde los $8 \mathrm{~mm}$ hasta los $11 \mathrm{~mm}$ del centro, siendo una zona más plana y esférica.

- Región del limbo: esta región comprende el anillo de los $12 \mathrm{~mm}$ desde el centro, siendo la zona de transición desde el cierre de la córnea hacia la esclera.

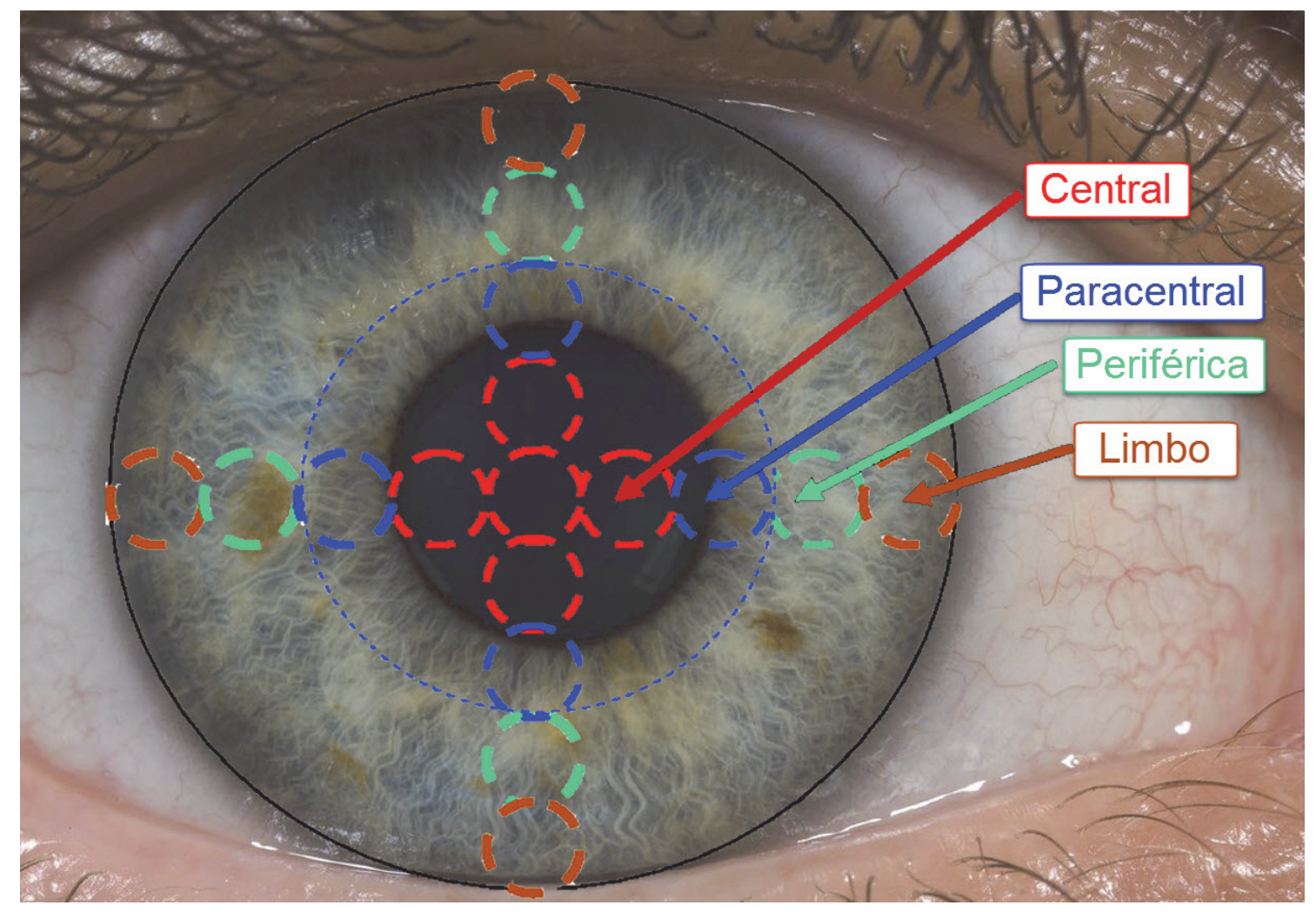

Figura 2.25 Regiones corneales

\subsubsection{Instrumentos para la caracterización de la morfología corneal}

La ubicación de la córnea en la anatomía humana le proporciona unas propiedades ópticas óptimas, ya que es en esta región donde la transición entre la interfase aire- 
córnea provoca la mayor variación del índice de refracción (n) del sistema óptico ocular. Es por ello que a lo largo de toda la historia ha habido una evolución en el desarrollo de las técnicas de diagnóstico clínico (Figura 1.6) que permitan una caracterización morfológica precisa de la forma corneal y la posibilidad de poder cuantificar la repercusión óptica de las alteraciones morfológicas sobre la calidad visual del paciente (Montalbán, 2013).

Las primeras caracterizaciones morfológicas para el diagnóstico clínico fueron realizadas por simple observación del aspecto externo de la superficie ocular (GüemezSandoval y Güemez-Sandoval, 2009), pero no fue hasta principios del siglo XVII, donde el oftalmólogo Scheiner propuso el primer instrumento para caracterizar la morfología corneal: este trata de comparar la imagen de reflexión generada sobre la superficie de la cara anterior de la córnea con diferentes esferas calibradas (Gutmark y Guyton, 2010; Montalbán, 2013). A partir de este primer intento se han desarrollado diversos instrumentos basados en diferentes tecnologías hasta llegar a la actualidad.

En este subcapítulo se revisa desde el primer instrumento utilizado para la caracterización de la morfología corneal, el oftalmómetro, pasando por el queratoscopio, hasta el videoqueratoscopio o topógrafo corneal actual. De forma adicional, se dedica un subcapítulo al topógrafo corneal Sirius (CSO, Italia) por ser el topógrafo utilizado en esta tesis para la caracterización morfológica de las superficies corneales.

\subsection{Oftalmómetro}

El oftalmómetro (Figura 2.26), o también conocido con el nombre de queratómetro, fue diseñado por el Oftalmólogo Helmhotz (Nover, 1982) a mediados del siglo XIX. Este diseño se basa en la propiedad óptica de la córnea de poder actuar como un espejo convexo al reflejar la luz que incide de forma directa sobre ésta para posteriormente analizar estas imágenes que sirven como técnica de caracterización de la morfología corneal (Montalbán, 2013).

El principio de Helmhotz se basa en proyectar 4 puntos no alineados ubicados en un anillo sobre la superficie de la cara anterior, obteniéndose a partir de las imágenes generadas los radios corneales, los cuales pueden ser interpretados mediante una expresión matemática en parámetros ópticos. Estos equipos, basados en el principio anteriormente descrito, se siguen utilizando en la actualidad. Sin embargo, tienen algunas limitaciones debido a su diseño (Montalbán, 2013):

- Presentan una medición sobre los $3 \mathrm{~mm}$ de la región central, por lo que cubre solamente el $6 \%$ de la superficie corneal total, obviando qué ocurre en el resto de la superficie corneal.

- El principio de estos equipos está basado en que la superficie corneal se asemeja perfectamente a un conjunto geométrico definido por una esfera-cilindro, lo cual actualmente está demostrado que no es así, sino que en función del escenario de análisis, ya sea sano o patológico, la morfología de la superficie 
corneal es distinta, es decir, tal y como se ha comentado anteriormente, esta presenta una geometría oblata o prolata.

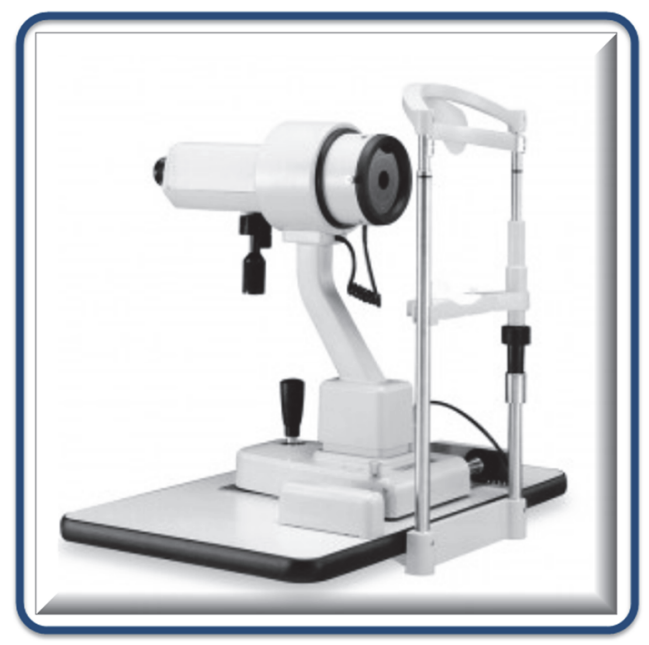

Figura 2.26 Oftalmómetro

\subsection{Queratoscopio}

El queratoscopio (Figura 2.27) fue inventado en 1847 por el oftalmólogo Goode (Nover, 1982) al analizar de forma lateral el reflejo de un objeto luminoso con una geometría cuadrada, el cual es proyectado sobre la superficie de la cara anterior de la córnea.

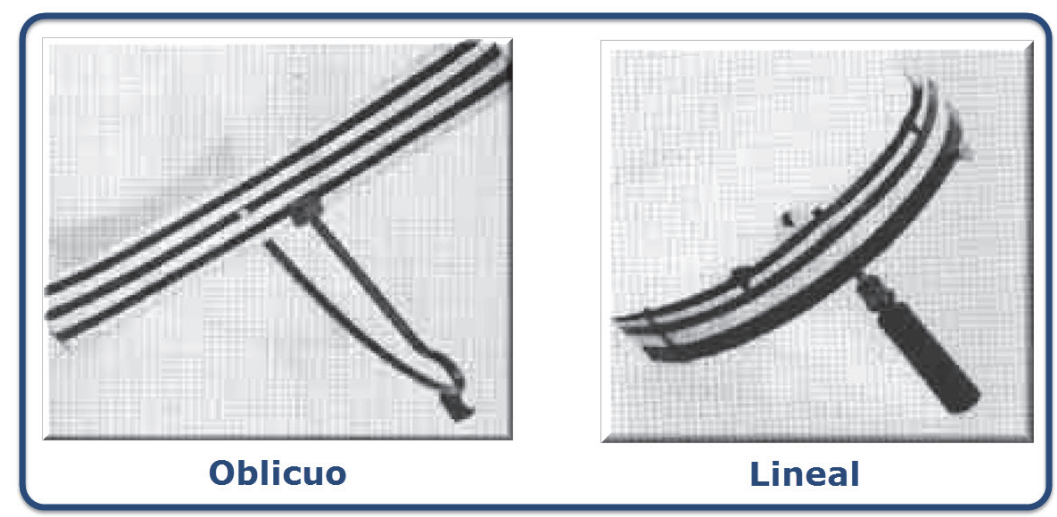

Figura 2.27 Queratoscopio

Sin embargo, el desarrollo de este equipo como herramienta de diagnóstico clínico fue descrito en 1880 por el médico oftalmólogo Antonio Plácido da Costa, quien desarrolló una variante de éste que permite realizar una mensuración precisa de la superficie corneal anterior mediante la proyección sobre la córnea de una placa circular sostenida por un mango. Esta placa (Figura 2.28) contiene un conjunto de anillos concéntricos de dimensiones conocidas y un orificio en su parte central a partir del cual el médico puede ver la imagen catóptrica reflejada en la superficie corneal de un paciente ubicado de espaldas respecto a la luz de incidencia (Montalbán, 2013). 


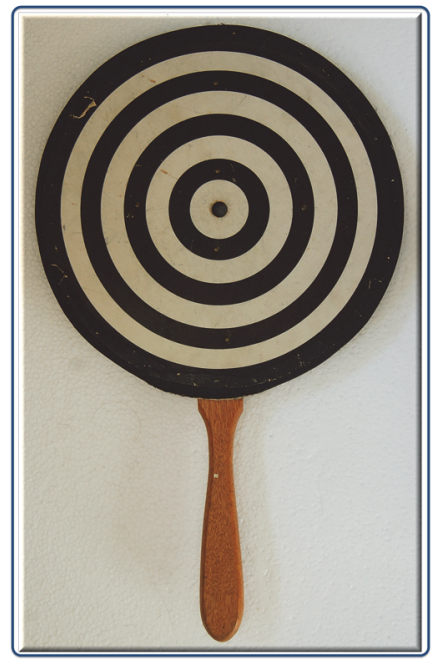

Figura 2.28 Disco de Plácido

La imagen de los anillos concéntricos obtenidos por medio de la luz reflejada fue fotografiada por Plácido a partir de una variante del queratoscopio, el equipo denominado fotoqueratoscopio (Figura 2.29). La interpretación cuantitativa de los datos aportados por el fotoqueratoscopio fue realizada a finales del siglo XIX por el oftalmólogo Gullstrand, quien propuso el primer modelo óptico humano preciso de la córnea humana (Sulek, 1967; Timoney y Breathnach, 2013).

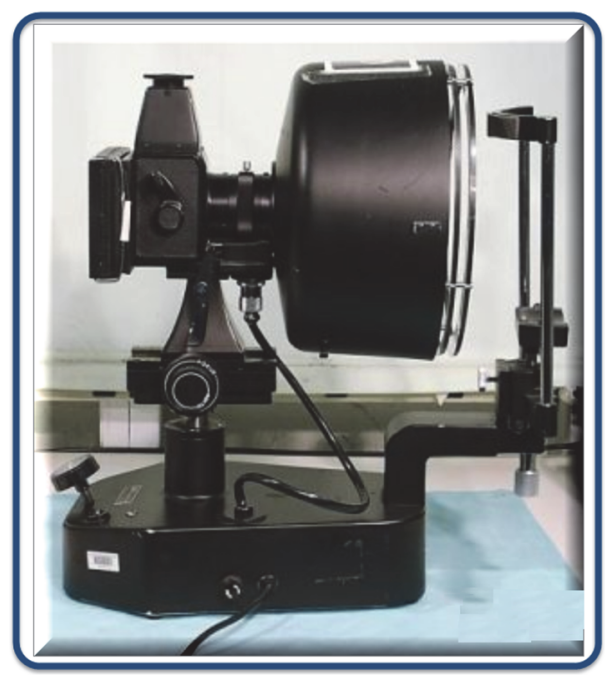

Figura 2.29 Fotoqueratoscopio

Esta interpretación cuantitativa viene establecida por la separación espacial existente entre los anillos concéntricos proyectados sobre la superficie corneal con respecto a los anillos concéntricos de referencia. En un escenario natural los anillos están más separados por lo que un paciente presenta un poder óptico óptimo, mientras que en un escenario patológico los anillos están más juntos al existir un mayor grado de curvatura de la superficie corneal, por lo que el paciente presenta una pérdida de poder óptico (Montalbán, 2013). 


\subsection{Videoqueratoscopio}

El videoqueratoscopio (Figura 2.30), más comúnmente conocido con el nombre de topógrafo corneal, es un instrumento que utiliza la topografía corneal para el diagnóstico clínico de patologías corneales mediante la caracterización morfológica de la córnea, utilizando para ello técnicas de tratamiento de imágenes (Montalbán, 2013).

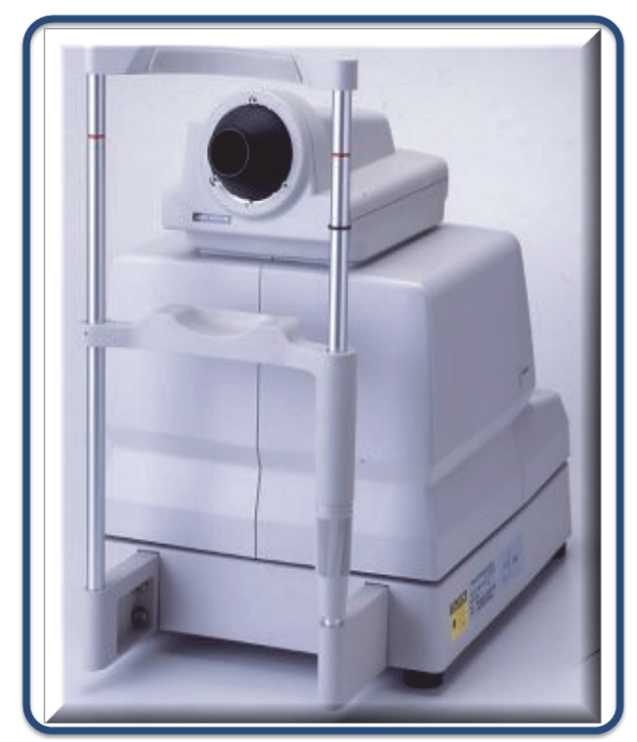

Figura 2.30 Videoqueratoscopio

La topografía corneal es una técnica exploratoria no invasiva que permite analizar tanto de forma cualitativa como cuantitativa la morfología de la córnea, siendo capaz de identificar patrones normalizados y descartar alteraciones potencialmente devastadoras para la visión derivados de los trastornos patológicos ectásicos (Maldonado et al., 2008; Ambrósio et al., 2011; Piñero et al., 2012; Piñero, 2013; Ambrósio et al., 2013).

Actualmente, los topógrafos corneales están basados en dos tecnologías (Montalbán, 2013): i) los sistemas basados en la reflexión de la luz sobre la córnea y ii) los sistemas basados en la proyección de una hendidura de luz sobre la córnea. Ambas tecnologías proporcionan diferentes mapas topográficos de la superficie corneal anterior, posterior y paquimétricos, así como unos índices resumen para el seguimiento y la valoración clínica de las topografías corneales.

\subsection{Sistemas basados en la reflexión de la luz sobre la córnea}

Estos topógrafos corneales se basan en la aplicación de las leyes de la óptica de los espejos convexos a un diseño en el que unos anillos concéntricos de alto contraste, y de tamaño y espaciado conocidos, son reflejados por la película lagrimal de la superficie de la cara anterior de la córnea. La imagen generada es capturada mediante una cámara digital durante una corta fracción de segundo y es procesada mediante medios informáticos identificando los bordes de cada anillo concéntrico. A partir de este momento el software realiza la reconstrucción de la curvatura corneal de toda la región 
sobre la que se dispongan datos mediante un algoritmo propio de cada topógrafo. Ha de señalarse que la exactitud y precisión de los datos de cada topógrafo dependen de varios factores ya comentados en el capítulo anterior, además de la propia eficacia del algoritmo de reconstrucción (Montalbán, 2013).

Por otro lado, los algoritmos de reconstrucción que asumen una geometría esférica son más inexactos en la determinación de la altura y del radio de curvatura instantáneo. Esta imprecisión es mayor cuanto más se aleja la morfología de la córnea en estudio de una esfera (Koch et al., 1989; Roberts, 1994).

Los algoritmos llamados arc-step reconstruyen la curvatura trazando una secuencia de arcos de punto a punto desde el vértice corneal hasta la periferia. Este método ha demostrado ser más exacto para el cálculo de la altura corneal, con un error inferior a $0.25 \mu$ en los $3 \mathrm{~mm}$ centrales, e inferior a $1 \mu$ para el resto de toda la córnea (Sicam et al., 2007). Esta precisión es importante especialmente en córneas anómalas, como las que presentan la patología ectásica (Maldonado et al., 2008).

La pendiente de cada punto medido se convierte a radio de curvatura mediante una fórmula matemática donde el centro de curvatura corresponde a la esfera que mejor se ajusta a la curvatura local. Si el centro de dicha esfera no está localizado sobre el eje óptico se obtiene el radio de curvatura instantáneo o tangencial; por lo contrario, si el centro de dicha esfera es forzado a localizarse en el eje óptico, se obtiene el radio de curvatura axial o sagital. Aplicando la fórmula paraxial de superficies esféricas y el índice queratométrico estándar (1.3375) se obtiene una potencia axial o instantánea en cada punto (Kaschke et al., 2014). A partir de la curvatura medida por el topógrafo, también puede calcularse la altura de cada punto respecto de un plano de referencia, si bien como ya se ha señalado, la precisión es mayor en algoritmos arc-step donde, matemáticamente, al medir la pendiente se obtiene simultáneamente la elevación de cada punto (Kaschke et al., 2014).

Por un lado, los datos queratométricos obtenidos en la región corneal son presentados de forma cuantitativa o cualitativa mediante una completa secuencia de mapas escalados de colores, donde se pueden apreciar (Montalbán, 2013) (Figura 2.31):

- Colores fríos, que corresponden a curvaturas planas y elevaciones por debajo de la esfera de referencia. Se trata de colores azules o violetas.

- Colores templados, que corresponden a curvaturas medias y elevaciones iguales a las esferas de referencia. Se trata de colores verdes o amarillos.

- Colores cálidos, que corresponden a curvaturas altas y valores de elevación por encima de la esfera de referencia.

Por otro lado, en función del tamaño del anillo del Disco de Plácido existen dos opciones comerciales del topógrafo corneal (Montalbán, 2013):

- Topógrafo corneal basado en Discos de Plácido con anillos de gran diámetro. Estos dispositivos son menos susceptibles del error extrínseco relacionado con 
la desalineación entre examinador-equipo-paciente debido a que trabaja a una distancia. Sin embargo, y debido a esta distancia, pierden puntos representativos de la región corneal objeto de la topografía por la sombra que la nariz y las pestañas pueden provocar sobre la morfología facial de los pacientes.

- Topógrafo corneal basado en Discos de Plácido con anillos de pequeño diámetro. Estos dispositivos son más susceptibles del error intrínseco relacionado con la alineación y desenfoque entre el examinador-equipopaciente debido a que trabaja a distancias muy próximas al ojo humano. Sin embargo, mitiga la perdida de información que la sombra de la nariz y las pestañas pueden provocar sobre la morfología facial de los pacientes.

En otro orden de cosas, además de las opciones comerciales comentadas, esta tecnología es fuente de errores en la primera etapa del proceso, la que corresponde al proceso de adquisición y tratamiento de los datos: son los denominados errores intrínsecos y extrínsecos, los cuales han sido descritos en el capítulo anterior.

Asimismo, estos topógrafos presentan otra limitación derivada de su diseño respecto a la utilización de algoritmos internos de reconstrucción, los cuales no tienen la capacidad de caracterizar la morfología corneal de la córnea cuanto ésta presenta elevados niveles de irregularidad (Rand et al., 1997). 


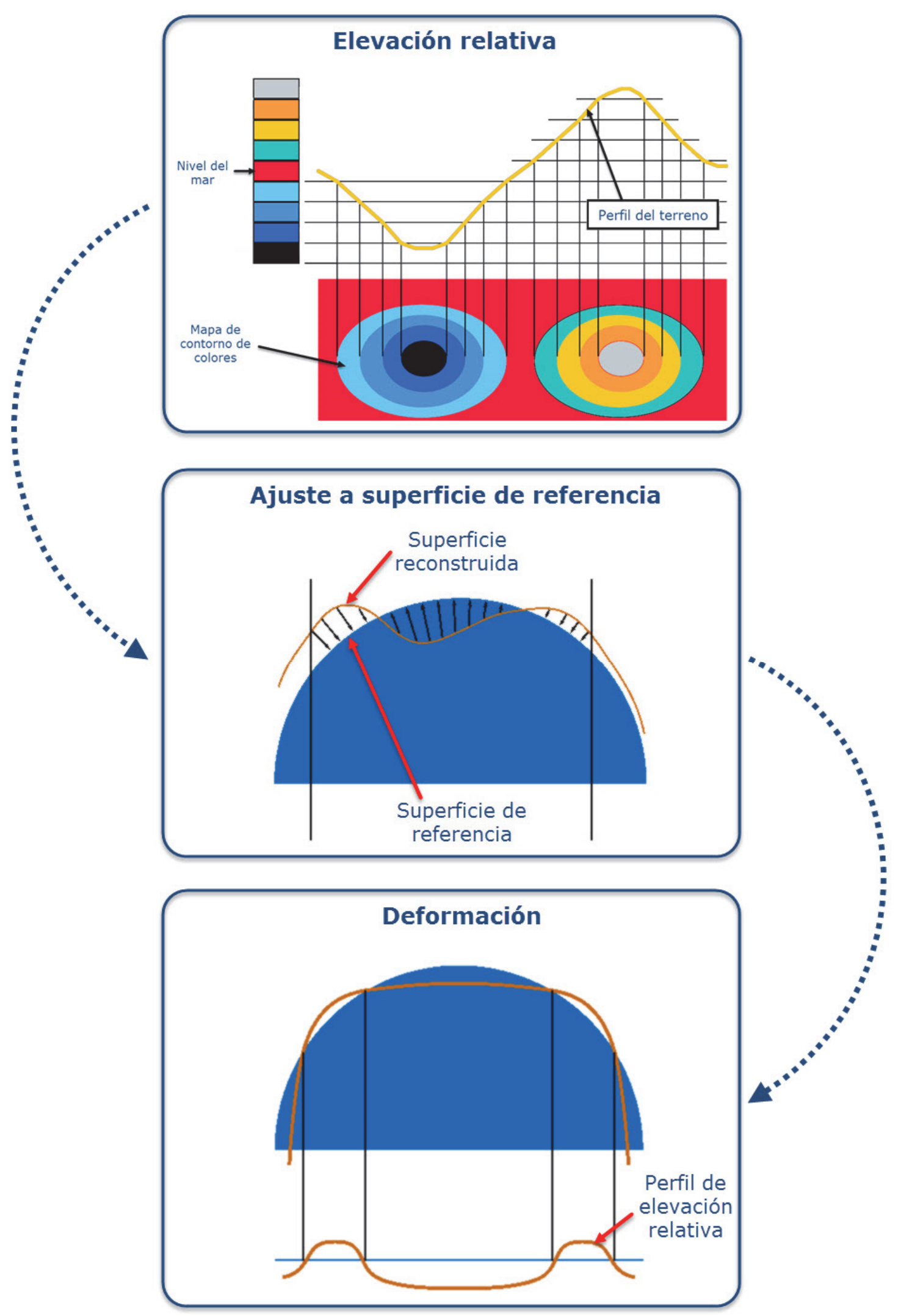

Figura 2.31 Topografía corneal 


\subsection{Sistemas basados en la proyección de una hendidura de luz sobre la córnea}

Los equipos basados en esta tecnología permiten obtener imágenes de secciones corneales, pudiendo fotografiar simultáneamente las caras anterior y posterior de la córnea, así como obtener un mapa topográfico. Esto es posible al poder fotografiar en sección una estructura transparente como la córnea gracias al principio de dispersión de Rayleigh que experimenta la luz al ser dispersada por las moléculas y las partículas constituyentes de un medio. La dispersión es mayor para longitudes de onda corta, razón por la que la luz azul es más eficaz para este propósito (Karpecki, 2006) (Figura 2.32).

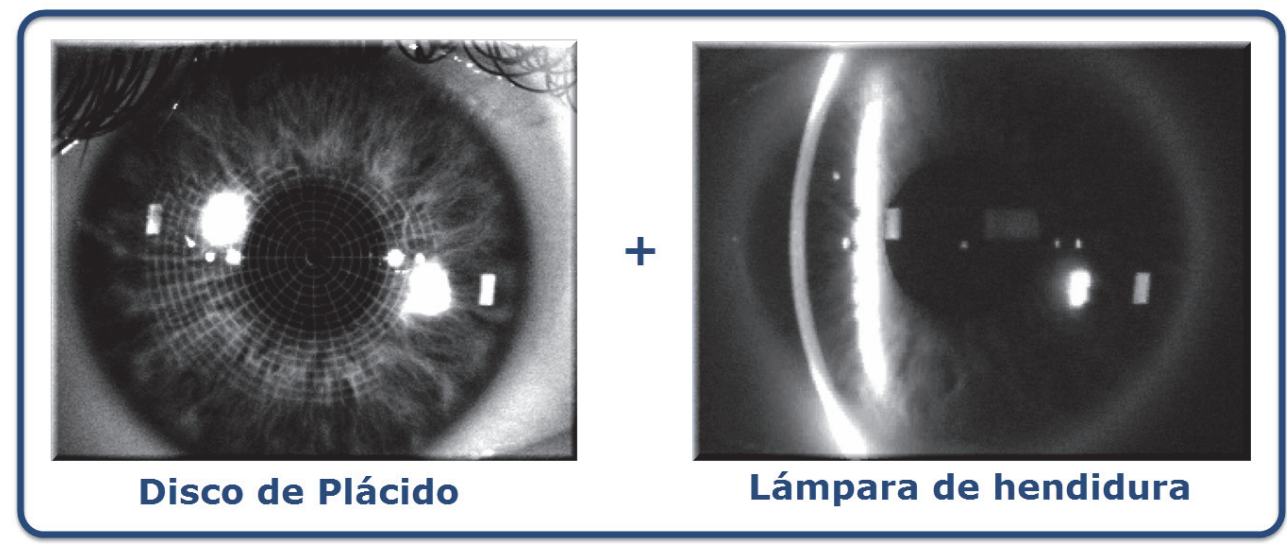

Figura 2.32 Integración de tecnologías: sistema basado en la proyección de una hendidura de luz

A diferencia de los topógrafos anteriores, estas máquinas miden directamente la elevación de los puntos de estudio y a partir de ahí, por diferenciación, se calcula la pendiente, la curvatura y la paquimetría. Además, una ventaja importante a la hora de medir un cono avanzado es que la medición no va a estar condicionada por la calidad de la película lagrimal, a diferencia de los topógrafos basados exclusivamente en los Discos de Plácido, pudiendo así ofrecer un mapeo más exacto.

La gran ventaja de estos equipos es que permiten una valoración global de la córnea anterior y posterior (elevación y curvatura), paquimetría, ACD y ángulo camerular, por lo que todos los aspectos morfológicos del queratocono pueden ser medidos.

La desventaja fundamental de estas máquinas es el tiempo de adquisición de los datos, el cual es superior a 1 segundo, por lo que pueden ocurrir imprecisiones en la medición de la altura (z), lo que da lugar a errores de curvatura significativos en el área paraxial.

Por otra parte, estos equipos pueden ser de dos formas en función de la disposición espacial del sistema de captura fotográfica: sistemas basados en el principio de fotografía estándar y sistemas basados en el principio de fotografía Scheimpflug. 


\subsection{1 Sistemas basados en el principio de fotografía estándar}

Estos sistemas se basan en el principio de la fotografía estándar o normal, es decir se define en una cámara la profundidad de campo sobre el plano del motivo cuando las prolongaciones imaginarias de éste, las del objetivo y las de la imagen no coinciden en ningún punto, es decir, las prolongaciones imaginarias de los tres componentes son paralelas (Figura 2.33) (Merklinger, 1993).

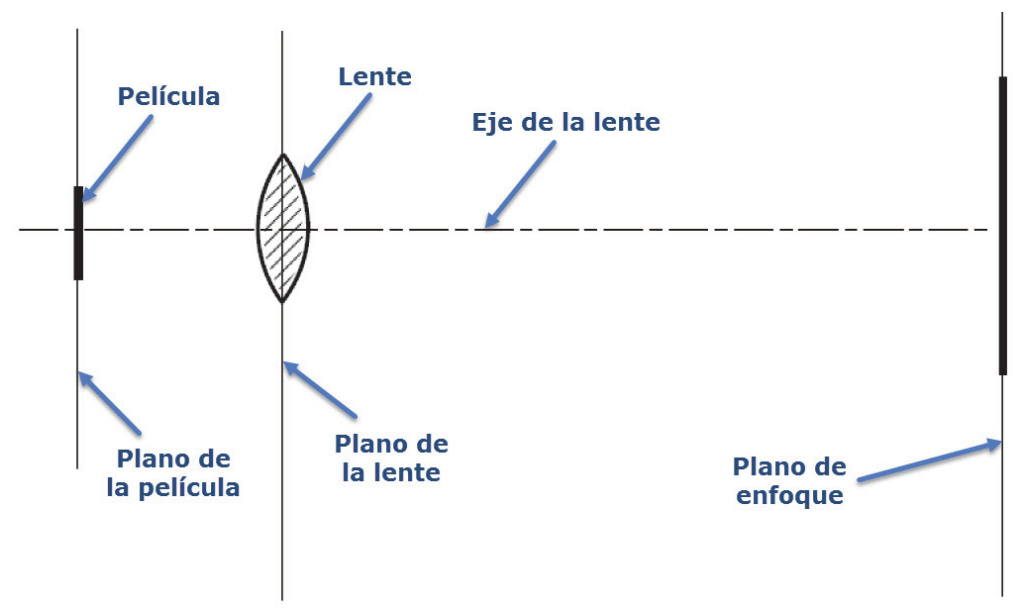

Figura 2.33 Principio de fotografía estándar

El problema de este principio (Figura 2.34) es que cuando utilizamos una cámara normal, si el sujeto no está situado en paralelo al plano de la imagen, solo queda enfocada una pequeña región (Merklinger, 1993).

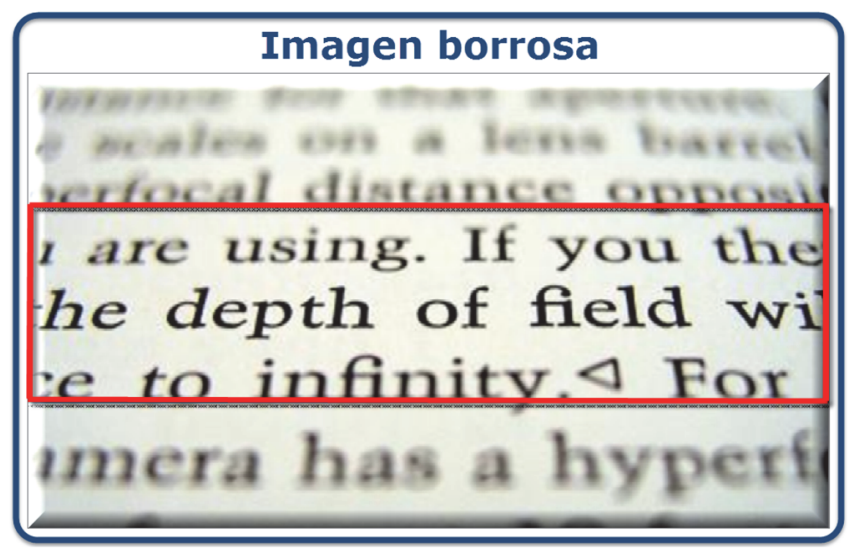

Figura 2.34 Defectos visuales en la fotografía estándar

El sistema comercial más importante es el Orbscan (Bausch \& Lomb Incorporated, USA) (Figura 2.35), el cual se basa en la proyección de una hendidura de luz sobre la córnea, realizando un barrido vertical de limbo a limbo mediante la proyección de 40 hendiduras de luz (20 desde cada lado) y con una angulación de 45 grados durante un período de tiempo de 1.5 segundos. La información de las 40 imágenes capturadas se combina con la obtenida de la imagen especular de un Disco de Plácido proyectado simultáneamente (Montalbán, 2013). 


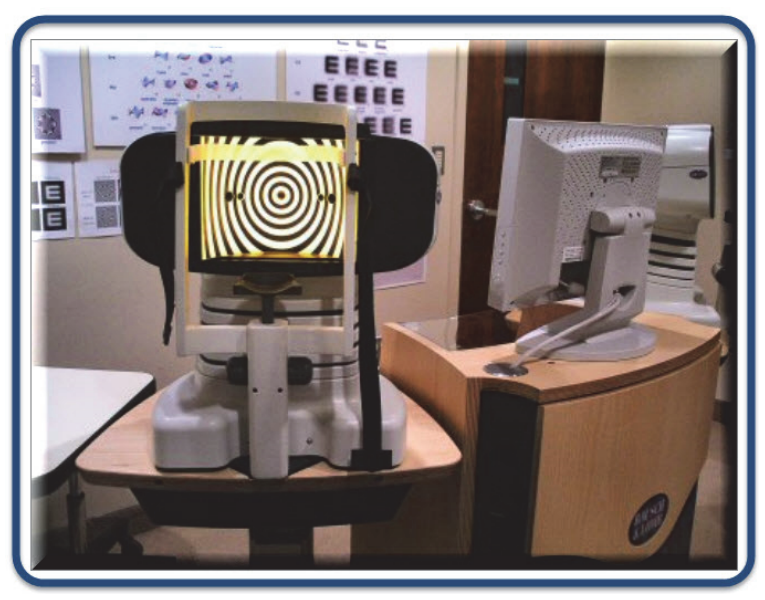

Figura 2.35 Orbscan

Con esta tecnología se miden 9600 puntos en total, 240 puntos por cada hendidura de luz, lo que permite obtener diferentes mapas de la superficie corneal anterior, posterior y de tipo paquimétrico.

Este equipo fue el primer dispositivo comercial que realizó una caracterización de la superficie corneal posterior de manera no invasiva, por lo que fue utilizado como una herramienta muy útil de diagnóstico clínico de la patología ectásica bilateral, concretamente el queratocono.

Además, el sistema dispone de un "eye tracker" para compensar los movimientos oculares producidos durante el proceso de adquisición de imágenes.

Sin embargo, este equipo presenta las siguientes limitaciones (Montalbán, 2013):

- Precisa un elevado tiempo de adquisición de los datos de medida, por lo que puede influir en dicho proceso la débil estabilidad de la película lagrimal (Maldonado et al., 2006a).

- Presenta problemas de repetibilidad respecto la medición de la superficie de la cara posterior de la córnea (Nawa et al., 2005; Cheng et al., 2007).

\subsection{Sistemas basados en el principio de fotografía Scheimpflug}

Este sistema se basa en el principio de fotografía desarrollado por Theodor Scheimpflug a principios del siglo XX, el cual a través de una cámara fotográfica de gran formato consigue la máxima profundidad de campo en el plano del objeto cuando las prolongaciones imaginarias de éste, del plano del objeto y del plano de la imagen coinciden en el espacio en un punto en común (Merklinger, 1993) (Figura 2.36). 


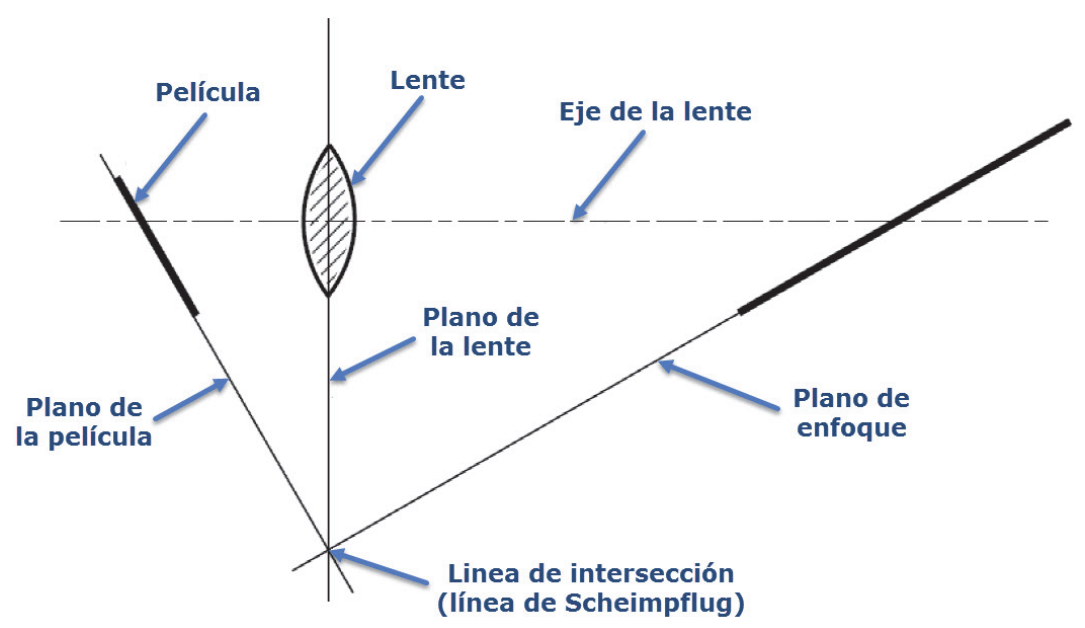

Figura 2.36 Principio de fotografía Scheimpflug

En el campo de la oftalmología esta regla geométrica se basa en la captura de la imagen a fotografiar de la córnea desde un ángulo oblicuo, donde el plano de la lente, de la película y del enfoque no son paralelos, sino que siguen el principio fotográfico de Scheimpflug y se intersectan en un punto en el espacio, con lo que se consigue un incremento de la profundidad de la foto, lo que se traduce ópticamente en una mayor región de enfoque y en una mejora de la nitidez de la imagen. Además, la distorsión de la imagen producida queda compensada por el software del equipo (Merklinger, 1993).

Actualmente existen tres equipos comerciales basados en este principio (Montalbán, 2013):

- Equipo Pentacam (Oculus, USA). Este sistema (Figura 2.37) utiliza dos cámaras fotográficas, una fija posicionada en el centro para controlar la fijación de la córnea basada en el principio de fotografía estándar, y otra cámara móvil basada en el principio de fotografía Scheimpflug y posicionada en una rueda que gira para capturar las imágenes de la proyección de una hendidura de luz sobre la córnea. Esta técnica proyecta 50 hendiduras de luz durante una rotación entre $0^{\circ}$ a $180^{\circ}$ alrededor del ojo durante un período de tiempo inferior a dos segundos.

La información de las 50 imágenes capturadas es combinada con la obtenida de la imagen especular de un Disco de Plácido proyectado de forma simultánea. El sistema genera 500 puntos de medida por cada imagen de hendidura de luz, obteniendo un total de 25000 puntos de alturas normalizadas que son utilizados para crear una imagen tridimensional del segmento anterior del ojo humano.

Este equipo realiza mediciones bastante precisas en la región central y paracentral. Sin embargo, conforme nos desplazamos hacia la región periférica se produce un desalineamiento involuntario del equipo que se traduce en una pérdida de precisión, cuantificada ésta entre 20-30 $\mu \mathrm{m}$ sobre los valores de precisión (Kawamorita et al., 2012). 


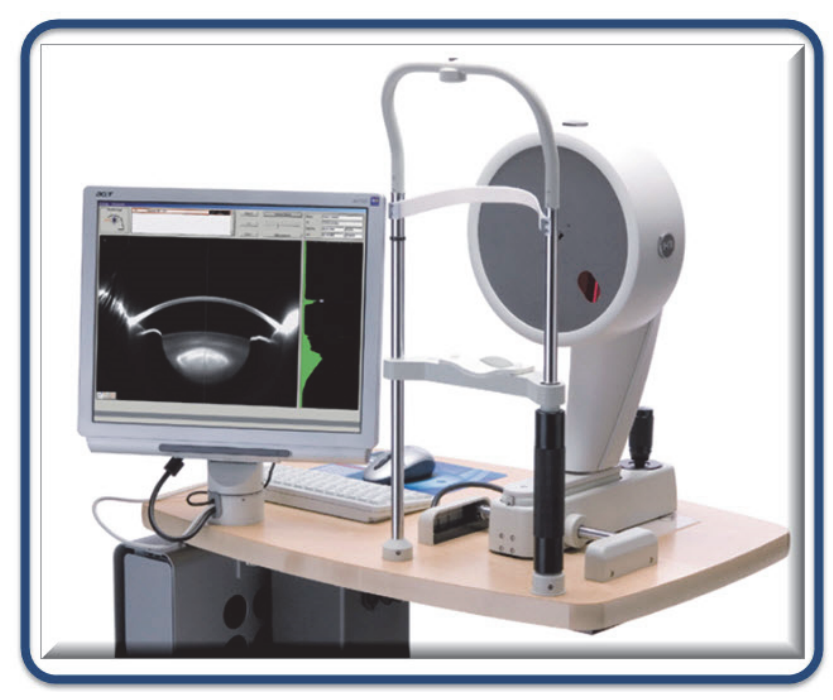

Figura 2.37 Pentacam

- Equipo Galilei (Ziemer, Suiza). Este sistema (Figura 2.38) utiliza dos cámaras fotográficas basadas en el principio de fotografía Scheimpflug combinados con un disco de Plácido.

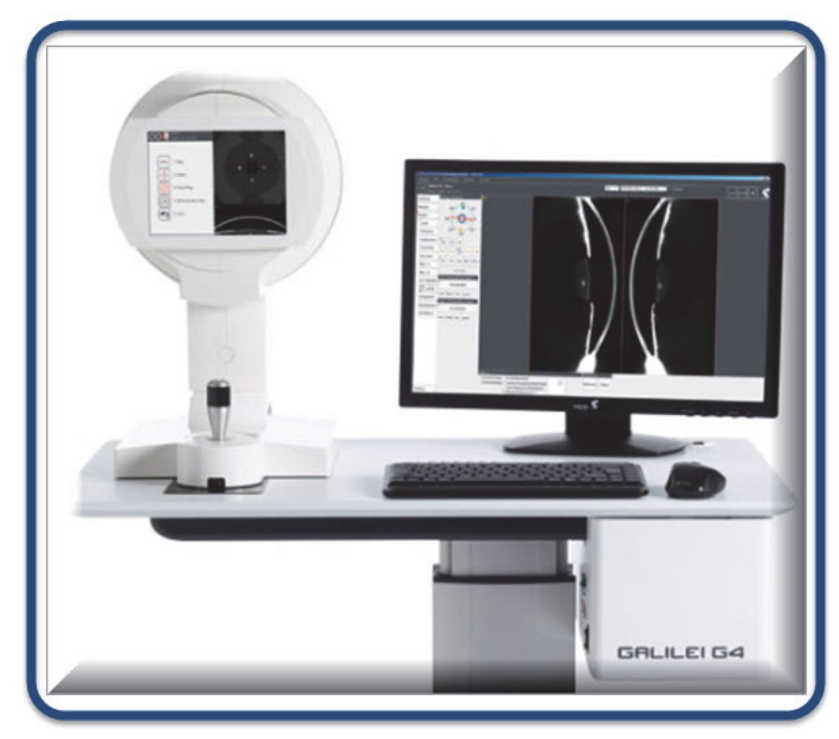

Figura 2.38 Galilei

El equipo es capaz de generar en torno a 120000 puntos de información sobre la morfología de la córnea. Además, al utilizar dos cámaras rotatorias presenta la ventaja frente al equipo Pentacam (Oculus, USA) de que minimiza el error de desalineamiento involuntario en la región periférica corneal; de esta forma se reduce la pérdida de imprecisión a la hora de la adquisición de los datos en dicha región (Roberts y Züger, 2006).

Sin embargo, este equipo presenta limitaciones, como son: i) baja repetibilidad de las mediciones realizadas en la superficie de la cara anterior y posterior de la córnea, y ii) tiempo elevado de adquisición de medidas al actuar a la vez las dos 
cámaras rotatorias, por lo que el proceso de adquisición de datos también puede verse afectado por la estabilidad de la película lagrimal.

- Equipo Sirius (CSO, Italia). Este sistema (Figura 2.39) ha sido utilizado en la presente tesis para la caracterización de la morfología de las superficies anterior y posterior de la córnea y es objeto de una descripción en el siguiente subcapítulo.

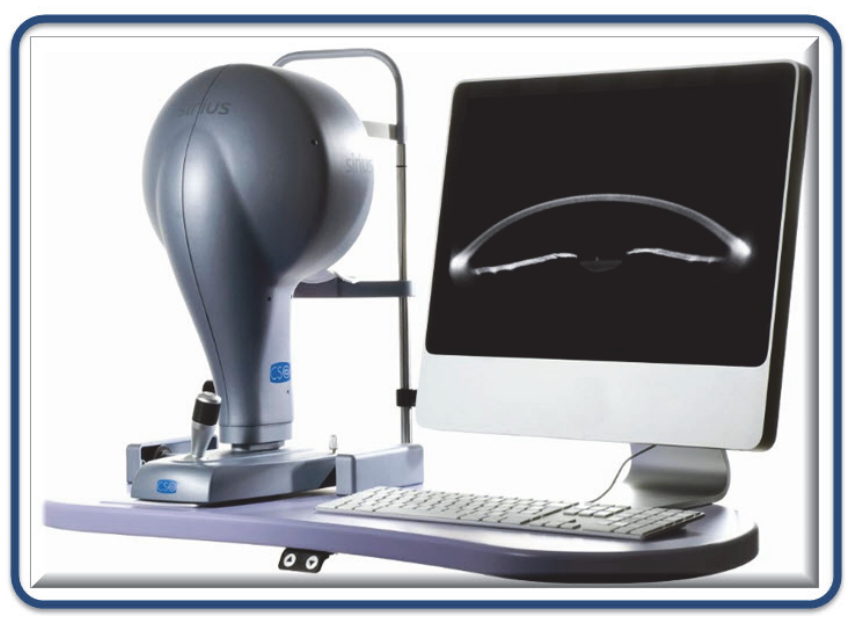

Figura 2.39 Sirius

\subsection{2.1 Equipo Sirius}

Este sistema utiliza la combinación de dos tecnologías (Figura 2.40) (Montalbán, 2013):

- La topografía de la superficie anterior de la córnea con un Disco de Plácido. Se trata de la reconstrucción de la superficie corneal de la cara anterior de la córnea basada en el principio de reflexión de la luz a partir de la imagen especular del Disco de Plácido. De esta forma, el sistema permite obtener información sobre las variaciones de la curvatura corneal utilizando la técnica Ray-Tracing o trazado de rayos.

La técnica Ray-Tracing fue descubierta por Descartes en 1673 en un tratado sobre geometría óptica (Hollasch, 1994). Esta técnica se basa en la emisión de una serie de rayos a partir de una fuente de luz conocida, y su rastreo en el momento en el que éstos son interceptados por un objeto en un determinado escenario; por lo tanto, crea imágenes que están basadas en las leyes de la física sobre los principios de la reflexión y de la refracción óptica. Gracias a estos principios se tiene la posibilidad de inducir el rayo de luz sobre los materiales tipo espejo o transparentes, así como poder trabajar con superficies curvas y sombras dentro del escenario seleccionado.

Además, es una técnica muy utilizada en el campo de la generación de gráficos tridimensionales por ordenador (Verma y Walia, 2010; Djeu et al., 2011; Hatka y Haindl, 2011). 
En el ámbito de la oftalmología, para cada punto de cada meridiano (Figura 2.41) se efectúa el proceso Ray-Tracing, que teniendo en cuenta las posiciones del Disco de Plácido (por su construcción), y conociendo las distancias de los puntos del plano de la imagen del eje, es decir, la posición de los anillos generados por la reflexión, se obtiene información de la superficie normal de la córnea (Figura 2.42). Esta superficie puede ser de forma oblata o prolata en función de un escenario natural o patológico, cumpliendo en ambos casos con la Ley de Snell para la reflexión (Drosdoff y Widom, 2005).

A partir de aquí, para la reconstrucción de la superficie corneal se dan una serie de pasos organizados que describen el proceso a seguir, con el fin de dar solución al problema de conocer la morfología de la superficie corneal. Concretamente se utiliza un algoritmo de reconstrucción Arc-Step; se trata de un proceso iterativo el cual no ignora los datos obtenidos del paso precedente (step i-1) para obtener los datos del proceso actual (step i) (Goldberg y Tarjan, 2014).
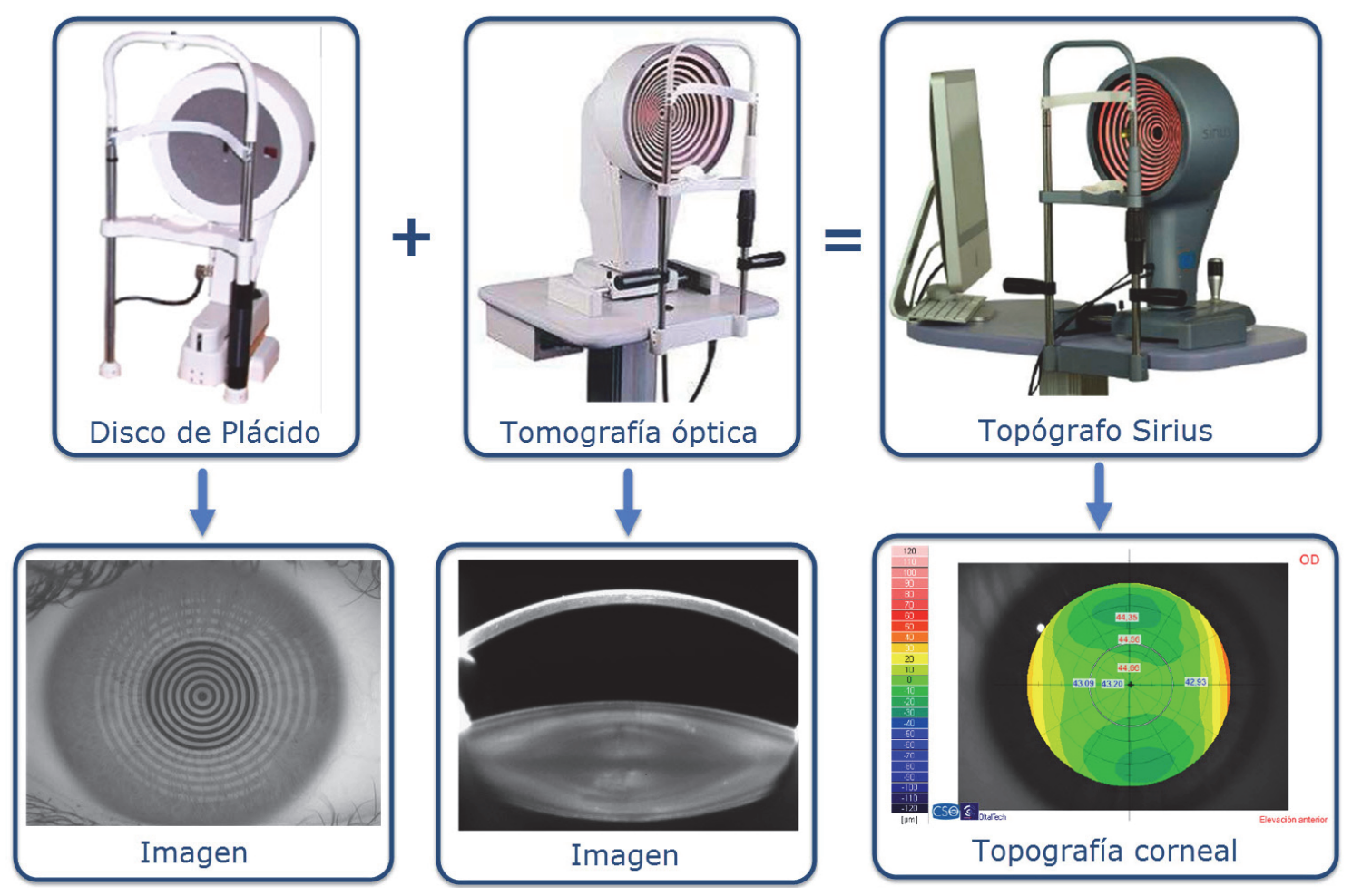

Figura 2.40 Integración tecnologías en el topógrafo corneal Sirius 


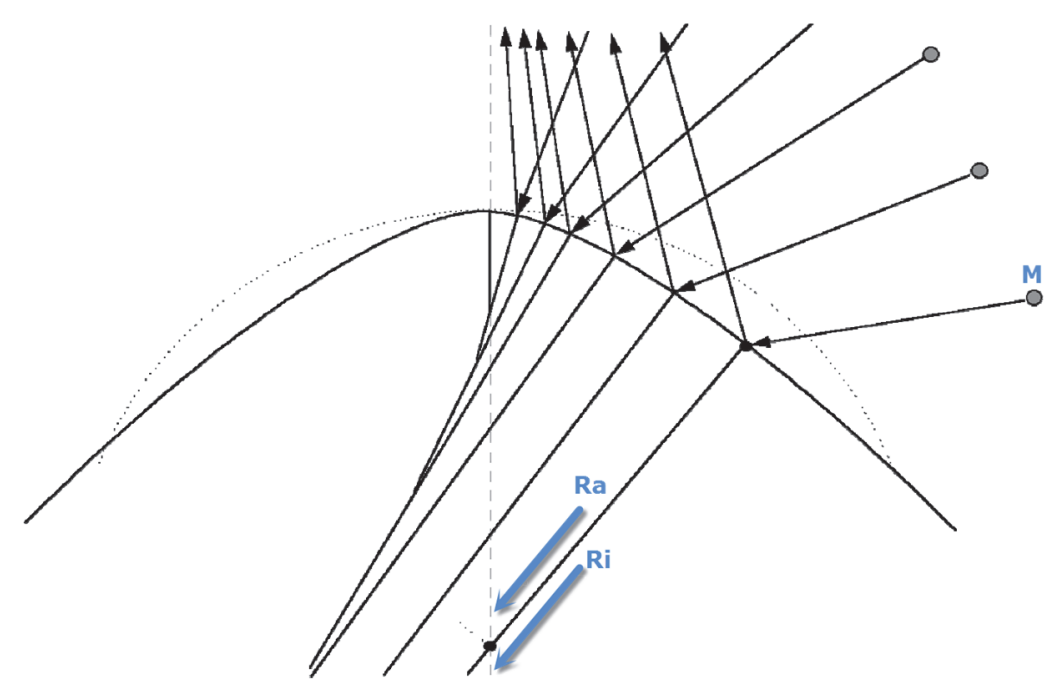

Figura 2.41 Algoritmo arc-step

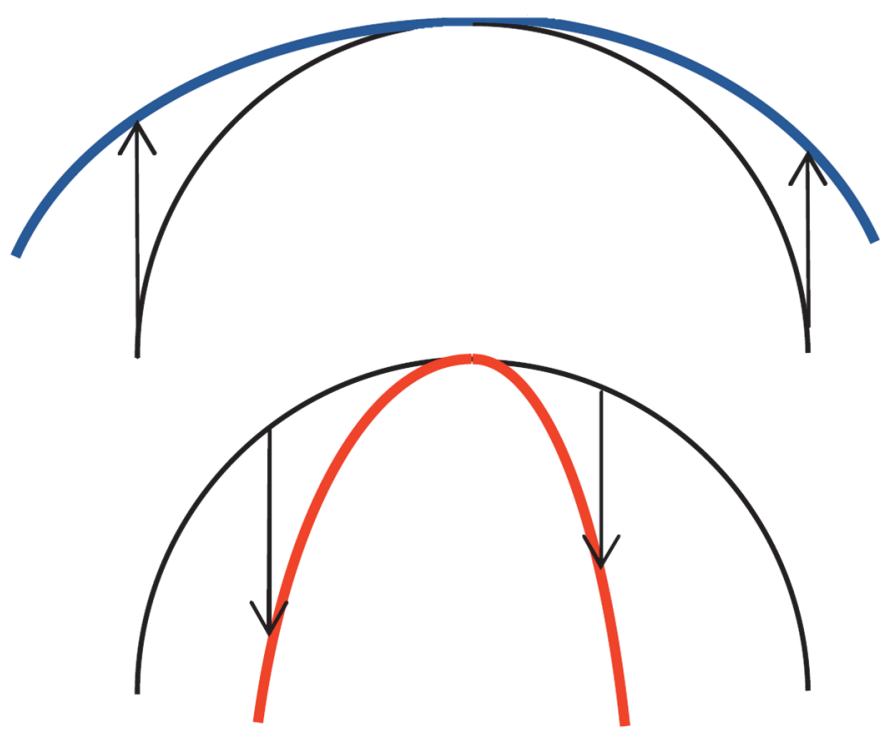

Figura 2.42 Arcos meridianos topográficos respecto a superficie de referencia SMA

- Tomografía óptica fundamentada en el principio fotográfico Scheimpflug. Se trata de la reconstrucción de la córnea en un entorno tridimensional a partir de los datos de elevación de las superficies anterior/posterior de la córnea.

El principio Scheimpflug es una fórmula matemática que explica la orientación del plano óptico de enfoque de una cámara cuando el plano de la lente no es paralelo al plano de la imagen (Figura 2.36), y en base a esta disposición espacial (en el campo de la oftalmología) el principio corrige la borrosidad (Figura 2.34) pero no corrige la deformación de la imagen (Figura 2.43), la cual es compensada por el software del equipo de medida. 


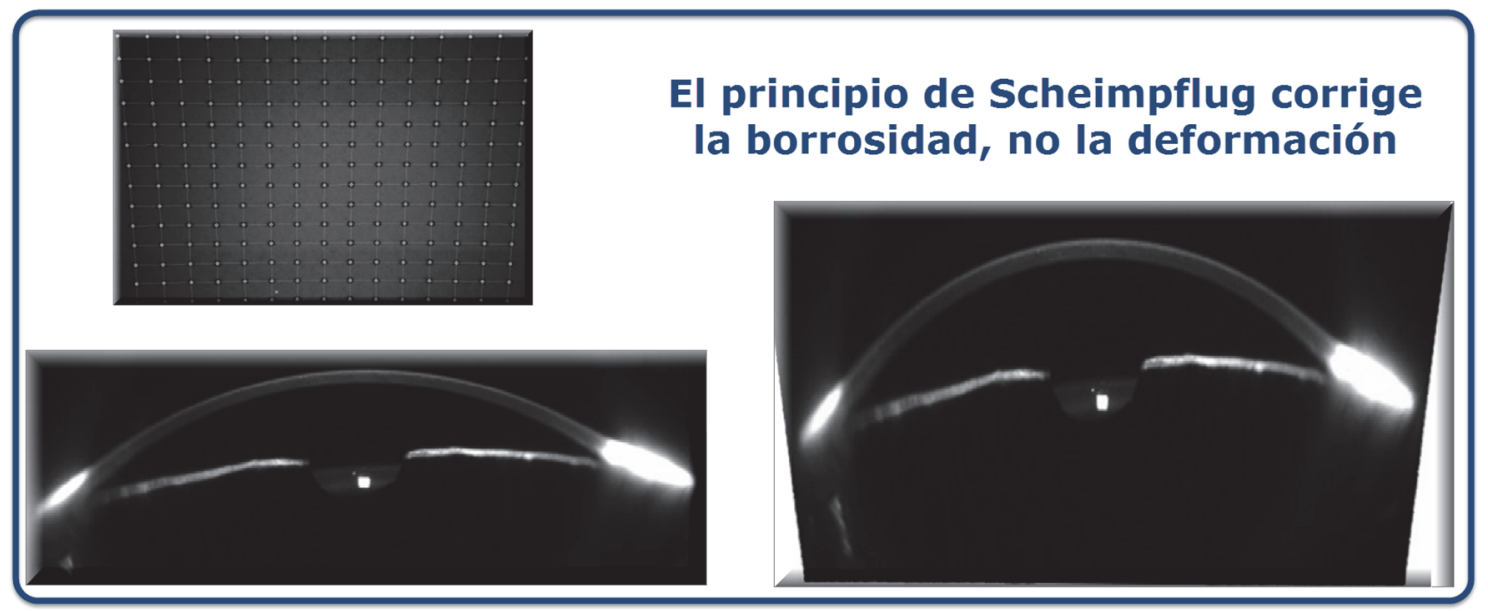

Figura 2.43 Borrosidad/Deformación en el principio de fotografía Scheimpflug

La cámara del equipo Sirius (CSO, Italia) basada en este principio, rota espacialmente hasta cubrir la región frontal de la córnea (Figura 2.44). El sistema de rotación está constituido por la cámara más un foco de iluminación que gira a la vez con el objeto de obtener imágenes de las secciones de la córnea, permitiendo una medición tridimensional de la cámara anterior y de sus estructuras (Figura 2.45).

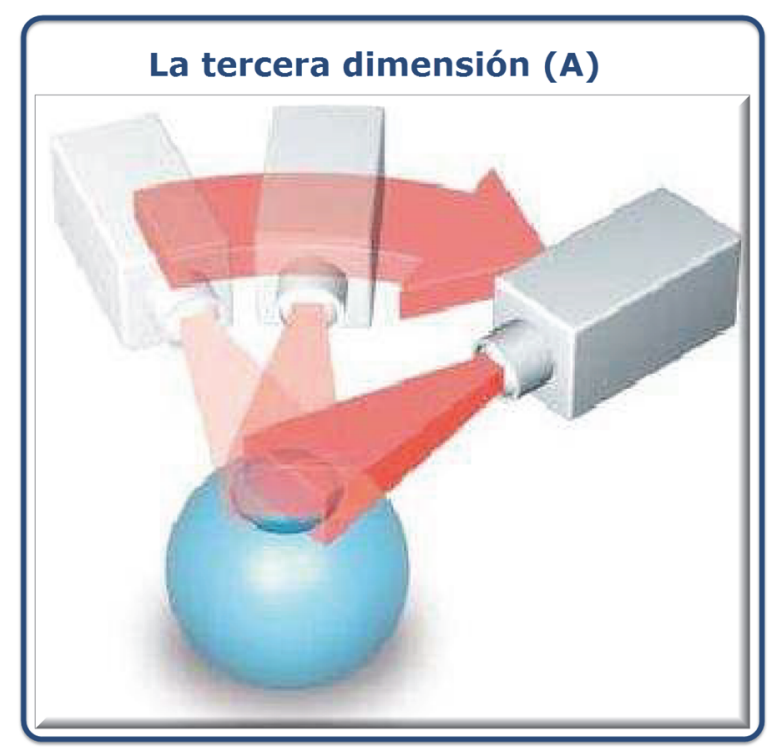

Figura 2.44 Tercera Dimensión (A). Rotación de la cámara fotográfica sobre el globo ocular

Por lo tanto, la combinación de esta doble tecnología, permite al equipo Sirius (CSO, Italia) proyectar 25 hendiduras de luz durante una rotación entre $0^{\circ}$ y $180^{\circ}$ alrededor de la córnea durante un segundo. La información de las 25 imágenes capturadas es combinada con la imagen especular de los 22 anillos de un Disco de Plácido proyectado de forma simultánea, obteniéndose un total de 35632 puntos representativos de la morfología de la superficie de la cara anterior de la córnea y unos 30000 puntos de la superficie de la cara posterior de la córnea, ambos en modo de alta resolución. 


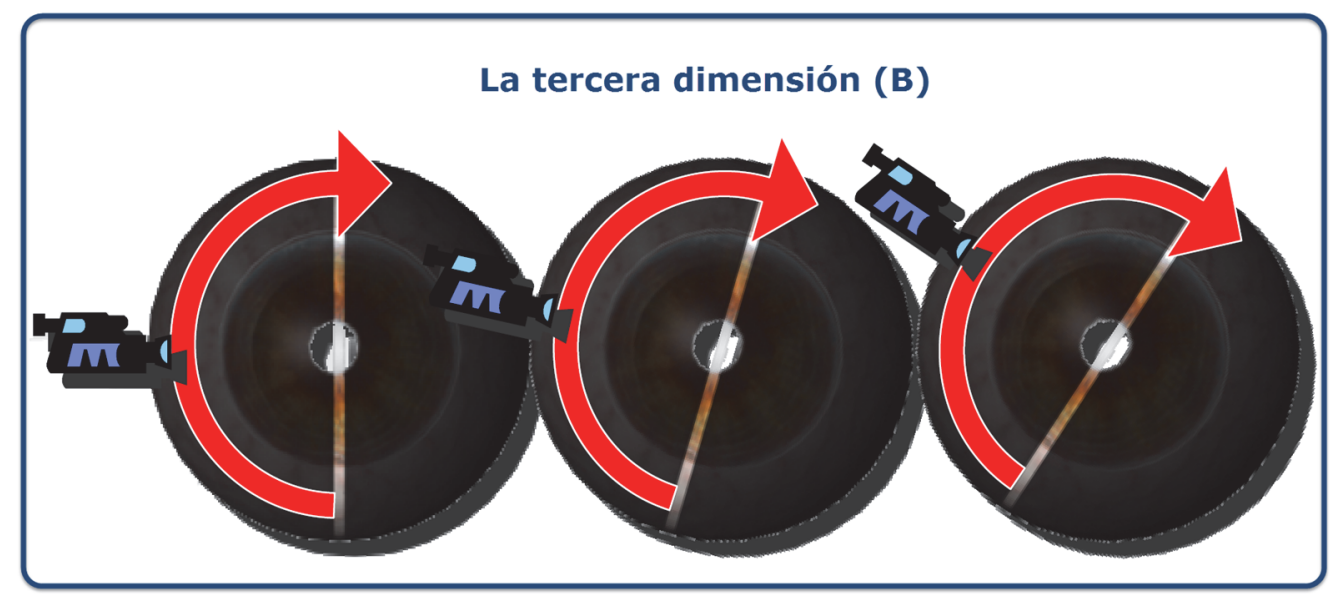

Figura 2.45 Tercera Dimensión (B). Rotación de la cámara fotográfica sobre la córnea

Además, la integración de la doble tecnología presenta las siguientes ventajas:

- Análisis de toda la región corneal con una elevada resolución y precisión en los términos de elevación, curvatura y potencia de toda la córnea.

- Caracterización de la morfología corneal en córneas que presentan un elevado grado de irregularidad en su superficie debido a un grado severo de Queratocono.

- Repetibilidad en las mediciones realizadas en la cara anterior y posterior de la córnea.

\subsection{2.2 Conclusiones}

Los tres equipos comerciales, Pentacam (Oculus, USA), Galilei (Ziemer, Suiza) y Sirius (CSO, Italia), basados en el principio de fotografía Scheimpflug, ofrecen medidas repetibles de la morfología corneal en comparación con otras tecnologías. Sin embargo, el grado de concordancia entre las medidas anatómicas que ofrece cada uno de ellos es cuestionable (Saloutti et al., 2009; Svini et al., 2011; Nasser et al., 2012; Montalbán, 2013; Hernandez-Camarena et al., 2014).

Los equipos Pentacam (Oculus, USA) y Galilei (Ziemer, Suiza) precisan de un elevado tiempo para la rotación y adquisición simultánea de los datos para la medida de la morfología corneal, en comparación con el equipo Sirius (CSO, Italia), de forma que la precisión de la medida puede verse influenciada por la estabilidad de la película lagrimal durante dicho proceso (Montalbán, 2013). Por este motivo en la presente tesis se ha utilizado como equipo de medida el topógrafo Sirius (CSO, Italia).

\subsubsection{La córnea en un escenario patológico clínico. El queratocono}

El queratocono es la patología ectásica bilateral objeto de diagnóstico en la presente tesis doctoral. Por ello en este subcapítulo se describe la literalidad del concepto clínico del queratocono y su influencia en la morfología de la arquitectura corneal. Para ello se describen los diferentes mapas de la superficie corneal que actualmente aportan los topógrafos corneales, así como los índices de caracterización morfológica basados en 
sistemas cuantitativos de detección univariante y multivariante. Por último, se realiza una descripción de las clasificaciones del queratocono clínico en función del grado de severidad, haciendo un especial hincapié en la clasificación de Amsler-Krumeich por ser la utilizada en la presente tesis doctoral.

\subsection{Queratocono}

La patología ectásica bilateral denominada queratocono provoca una pérdida del espesor en la córnea de forma progresiva. Este cambio morfológico en la arquitectura corneal se manifiesta en forma de protusión, presentando ésta una geometría de tipo cónico, lo que provoca la aparición de un astigmatismo irregular o de una pérdida de calidad visual en los pacientes (Montalbán, 2013).

Esta protusión crea un adelgazamiento que afecta a los tejidos que forman parte de la arquitectura corneal. Ésta se produce de forma progresiva conforme avanza el grado de severidad de la enfermedad, provocando además unos cambios morfológicos conforme a un patrón característico relacionado con el debilitamiento estructural de los tejidos que conforman la córnea (Figura 2.11).

En la literatura científica existen numerosas publicaciones que utilizan técnicas de topografía corneal para representar patrones topográficos característicos de la enfermedad (Kennedy et al., 1986; Rabinowitz y MacDonnell, 1989; Wilson et al., 1991; Rabinowitz, 1998; Auffarth et al., 2000; Montalbán, 2013) (Figura 2.46).

Una de las principales características morfológicas que presenta la arquitectura corneal relacionadas con esta patología es el encurvamiento focal que sufre la superficie de la cara anterior corneal. Esta protusión se manifiesta de forma más frecuente, concretamente en el $72 \%$ de los casos, en la región paracentral y aproximadamente el $25 \%$ de los casos se localiza en la región central. Por lo tanto, el $97 \%$ de los casos con queratocono queda localizado para un radio desde $r=0 \mathrm{~mm}$ hasta $\mathrm{r}=4 \mathrm{~mm}$, comprendiendo las regiones central y paracentral de la córnea (Wilson et al., 1991). La presencia de la protusión en la región periférica se considera inusual (Prisant et al., 1997; Weed et al., 2005) (Figura 2.47). 


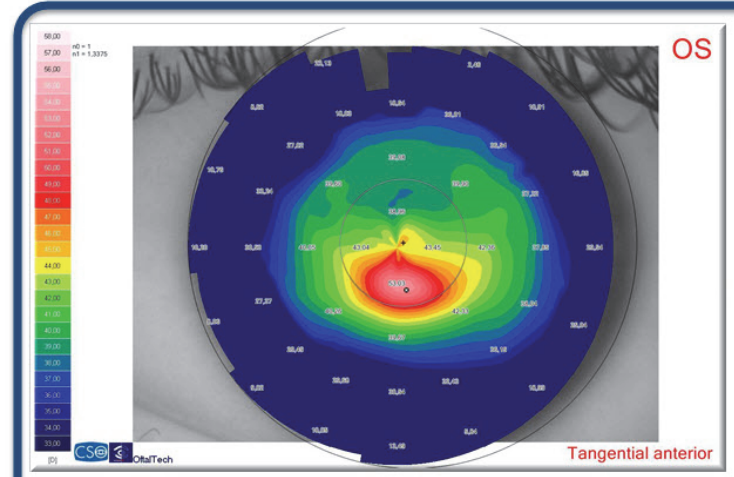

Grado I

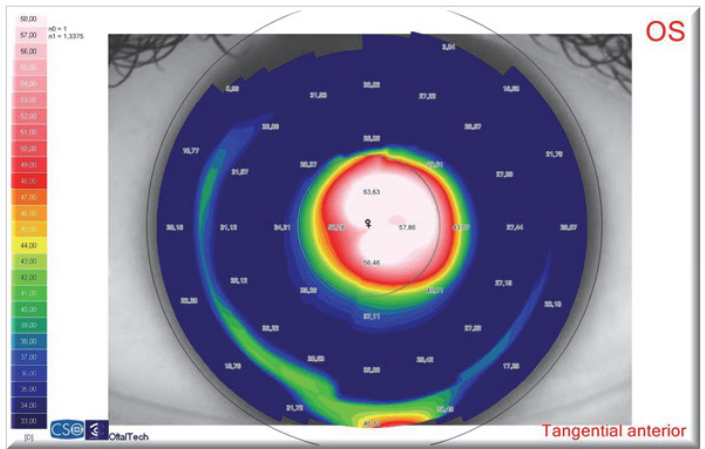

Grado III

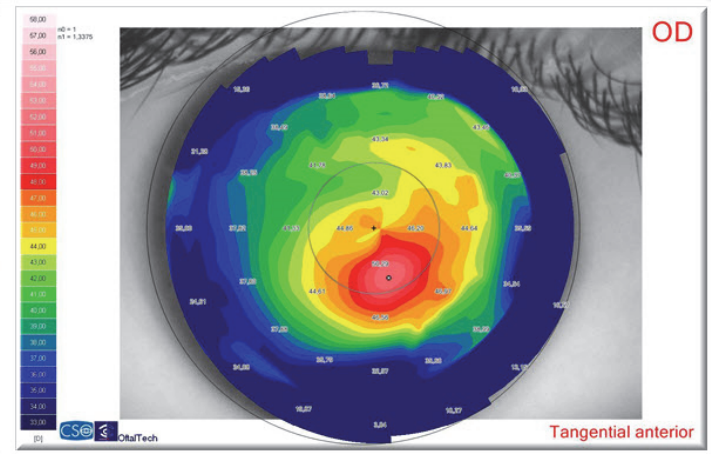

Grado II

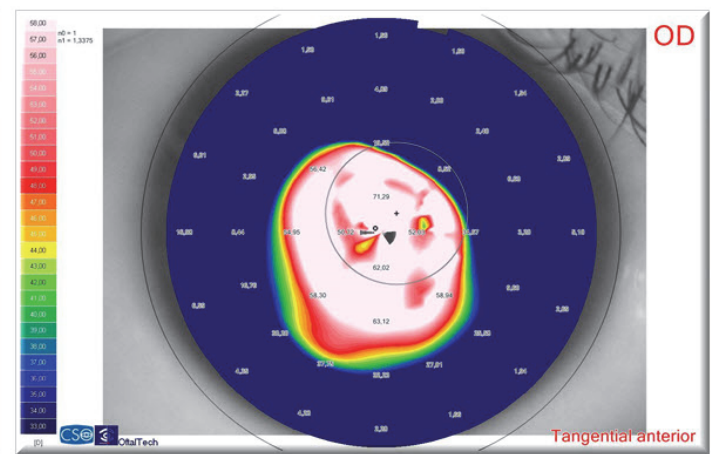

Grado VI

Figura 2.46 Patrones topográficos característicos del queratocono

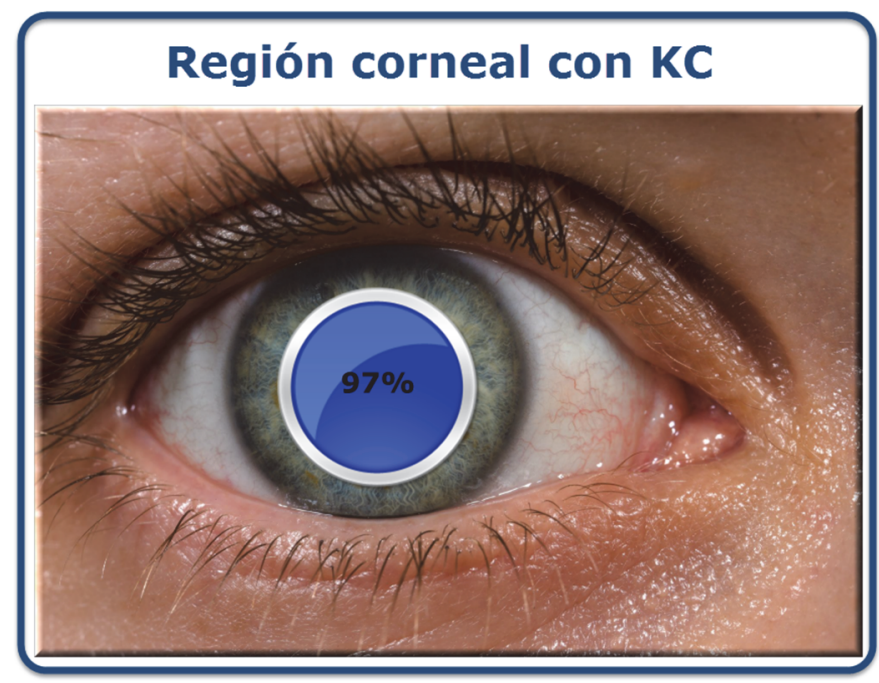

Figura 2.47 Incidencia del queratocono sobre las regiones corneales

El aumento de la curvatura que produce el queratocono en la morfología corneal debido al debilitamiento de los tejidos que forman parte de su arquitectura no solo afecta a la superficie de la cara anterior, sino también a la superficie de la cara posterior, inclusive en queratoconos incipientes o tempranos (Schlegel et al., 2008; Montalbán, 2013). Por ello el conocimiento del comportamiento geométrico de la superficie posterior de la córnea resulta de interés en el campo de la oftalmología para 
el diagnóstico precoz del queratocono (Smolek y Klyce, 1997; Tomidokoro et al., 2000; Wolffsohn et al., 2012) (Figura 1.4).

Por otro lado, los pacientes con queratocono presentan un astigmatismo distinto con respecto a los pacientes sanos. Las córneas en un escenario sano adquieren una configuración geométrica en forma de pajarita bastante simétrica. Sin embargo, en un escenario patológico el astigmatismo adquiere una configuración geométrica en forma de pajarita asimétrica, con una angulación diagonal entre los hemimeridianos inferior y superior que no existe en las córneas sanas (Rabinowitz et al., 1996; Montalbán, 2013) (Figura 2.48).

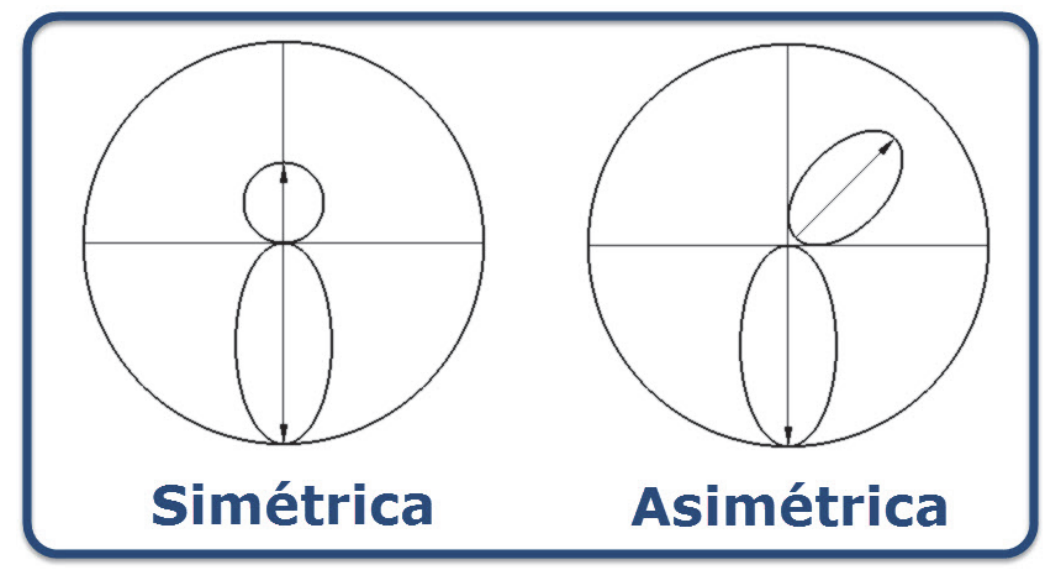

Figura 2.48 Patrones topográficos. Pajaritas

Por otra parte, existe otro elemento diferenciador de la córnea queratocónica; se trata de un parámetro que caracteriza la naturaleza de la curva cónica o asfericidad. En este escenario se produce una variación de la asfericidad en las superficies corneales anterior/posterior hacia valores negativos, es decir, la córnea sana presenta respecto a ambas superficies un comportamiento geométrico de elipse más prolata (Piñero et al., 2010a; Savini et al., 2011a-b). En base a todo esto, la curvatura de la morfología de una cornea patológica es mayor en la región central que en la región periférica, de forma que presenta un tendencia en su comportamiento hacia una parábola más que hacia una elipse prolata, y por ello el valor de la asfericidad aumenta en los grados más avanzados del queratocono (Montalbán, 2013).

Además de todo lo anteriormente comentado, los topógrafos corneales presentan diferentes mapas para representar las medidas que caracterizan la superficie corneal de la córnea queratocónica, pero previa a la descripción de estos mapas es fundamental considerar la dimensión o escala con el fin de decidir cuál es la mejor escala a adoptar en la valoración del examen topográfico para obtener la máxima información desde el punto de vista clínico. Existen dos tipos de escalas (Buey Salas y Peris Martínez):

a) Escala absoluta: se confiere todo el rango dióptrico que el topógrafo puede medir a una escala de colores, por lo que se pierde sensibilidad ante pequeños cambios. 
b) Escala relativa: se ajusta el rango dióptrico de medida a la córnea a analizar. De esta manera es sensible a pequeños cambios, por lo que esta escala es más apropiada para un análisis personalizado de la morfología corneal (Wilson et al., 1993; Smolek et al., 2002; Maldonado et al., 2008; Piñero et al., 2012).

Los mapas que actualmente proporcionan los equipos topográficos son:

Mapas de curvatura. Aportan información sobre la curvatura de la superficie corneal en cada punto de la córnea. Pueden ser, mapa sagital o axial y mapa tangencial o instantáneo.

- Mapa sagital: este mapa adopta como criterio que la superficie de la córnea es una esfera; de esta forma el algoritmo de la curvatura sagital reconstruye la superficie corneal mediante radios de curvatura local de esferas cuyos centros están todos situados en el eje óptico (Figura 2.49).

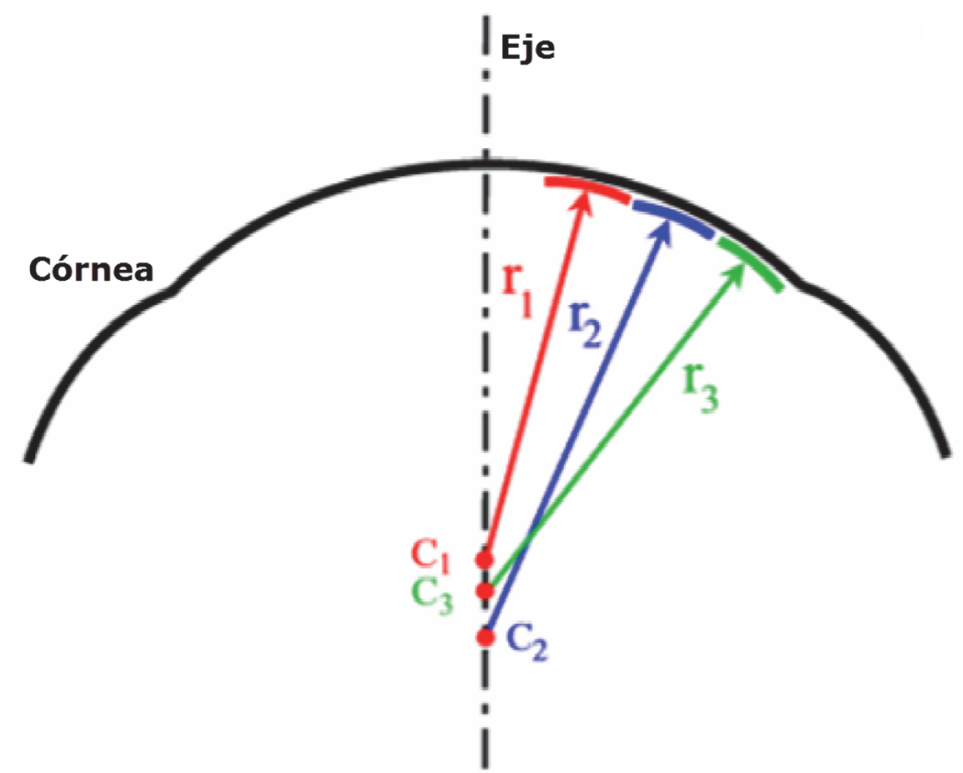

Figura 2.49 Algoritmo geométrico de reconstrucción de un mapa sagital de la córnea

Sin embargo, este paradigma de reconstrucción es erróneo, debido a que se cumple en aproximaciones paraxiales, $y$ tal $y$ como se ha indicado anteriormente la superficie de la córnea presenta una geometría más asférica (elipse prolata). Por lo tanto, los datos cuantitativos aportados por este mapa son imprecisos (Ambrósio et al., 2011; Piñero et al., 2012; Buey Salas y Peris Martínez, 2014).

Según lo descrito, este mapa resulta útil para una valoración de índole cualitativa o a través de los colores (Figura 2.50), dado que los contornos geométricos de la córnea los suaviza y de esta forma su interpretación por parte de personal menos experimentado resulta más asequible (Buey Salas y Peris Martínez, 2014). 


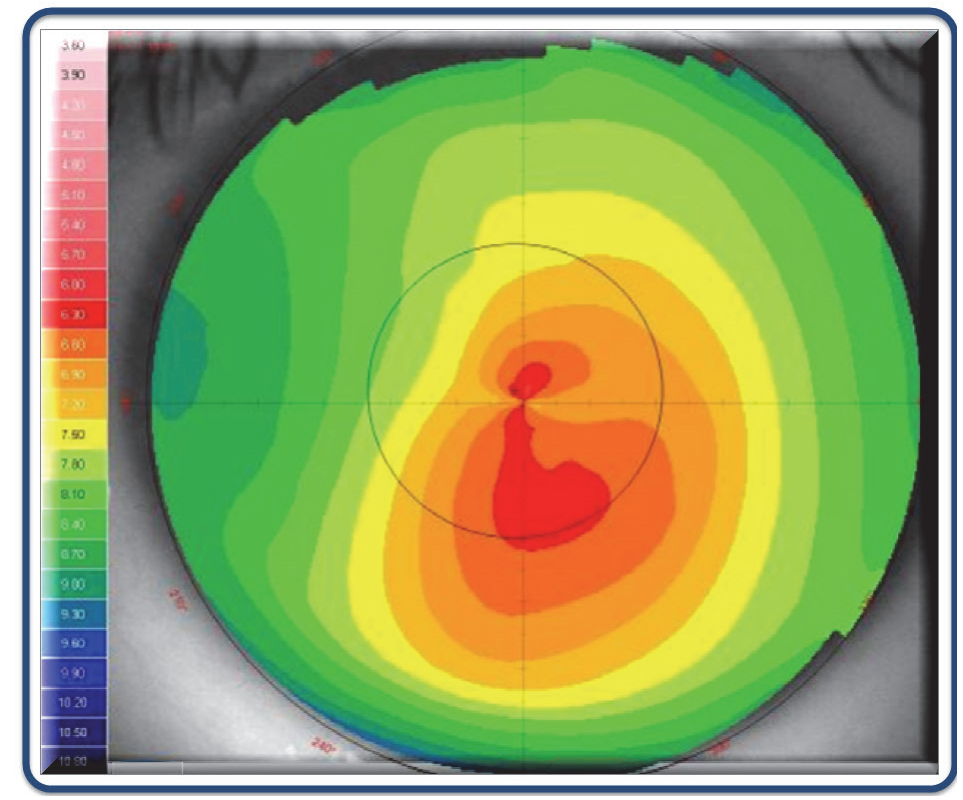

Figura 2.50 Mapa sagital de la córnea

- Mapa Tangencial. Este mapa no asume que la morfología de la córnea es esférica, y por ello el algoritmo de la curvatura tangencial reconstruye la superficie corneal mediante radios de curvaturas locales de esferas con el centro no vinculado al eje óptico. Este mapa representa con mayor exactitud la curvatura de la región periférica corneal, ya que a nivel local se considera la esfera que mejor se ajusta a la curvatura focal, sin que ésta deba estar obligatoriamente situada en el eje óptico tal y como ocurre en los mapas axiales (Figura 2.51) (Buey Salas y Peris Martínez, 2014).

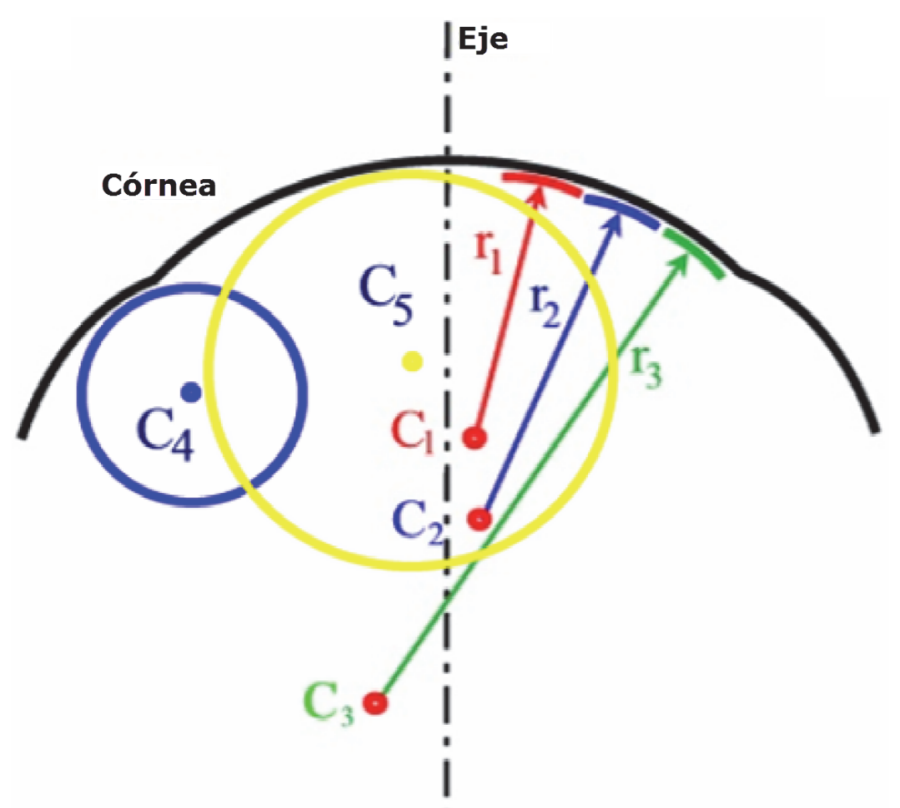

Figura 2.51 Algoritmo geométrico de reconstrucción de un mapa tangencial de la córnea 
Este mapa presenta una elevada sensibilidad a los datos obtenidos, por lo que lo hacen idóneo para monitorizar la forma cónica de la patología ectásica. Sin embargo es menos intuitivo que el axial y por lo tanto su interpretación puede resultar más compleja (Figura 2.52).

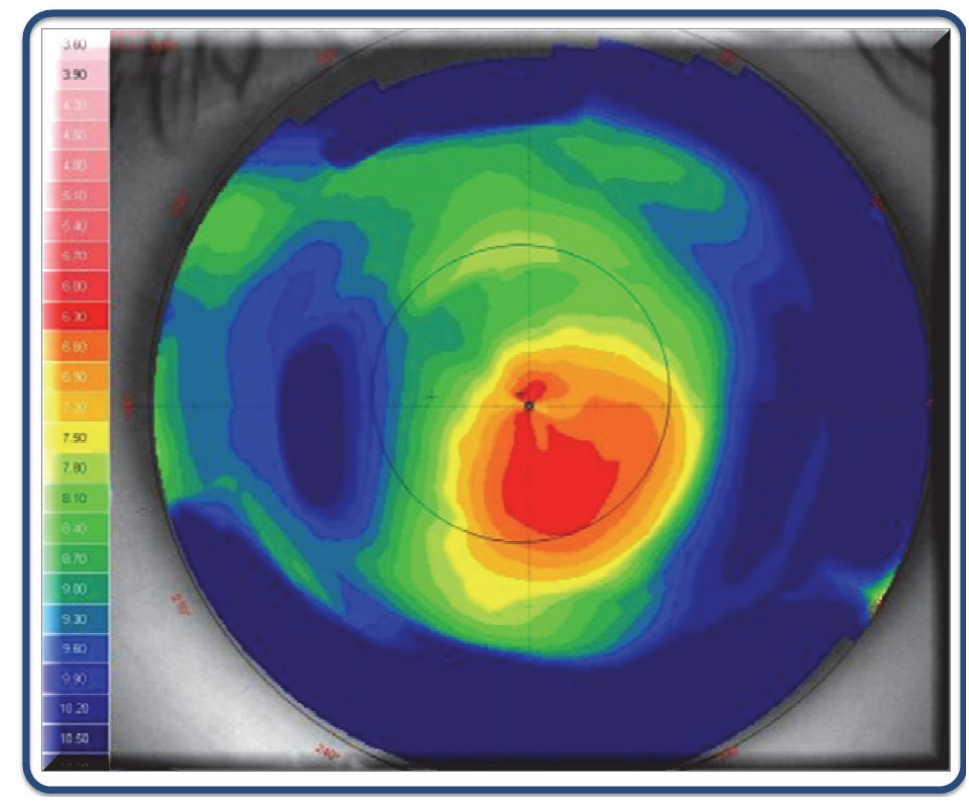

Figura 2.52 Mapa tangencial de la córnea

En resumen, ambos mapas de curvatura proporcionan datos medidos directamente por los topógrafos corneales sobre los pacientes. Sin embargo el mapa sagital ofrece una reconstrucción de la superficie corneal con menos detalle que el mapa tangencial, ya que este mapa es fuertemente dependiente del eje del instrumento o del centro del radio de las esferas, lo que puede provocar errores de centraje. Por otro lado, el estudio morfológico de la córnea con el mapa sagital finaliza cuanto más se aleja del eje queratoscopico. Sin embargo, y debido a la insensibilidad de éste con respecto al sistema de referencia, hace que su uso sea más adecuado para el análisis de la curvatura en región periférica.

Mapas de elevación. Estos mapas no presentan los datos medidos directamente por el topógrafo corneal, sino que son obtenidos por comparación de la superficie reconstruida de la cara anterior o posterior de la córnea con respecto a una superficie que mejor se ajuste (Figura 2.53), normalmente una esfera, toroide o elipsoide de revolución o no-revolución. La diferencia entre ambas superficies la proporcionan unos datos de altimetría que corresponden a los mapas de elevación (Figura 2.54) (Chan et al., 1995; Szcoztka et al., 1998; Montalbán, 2013). 


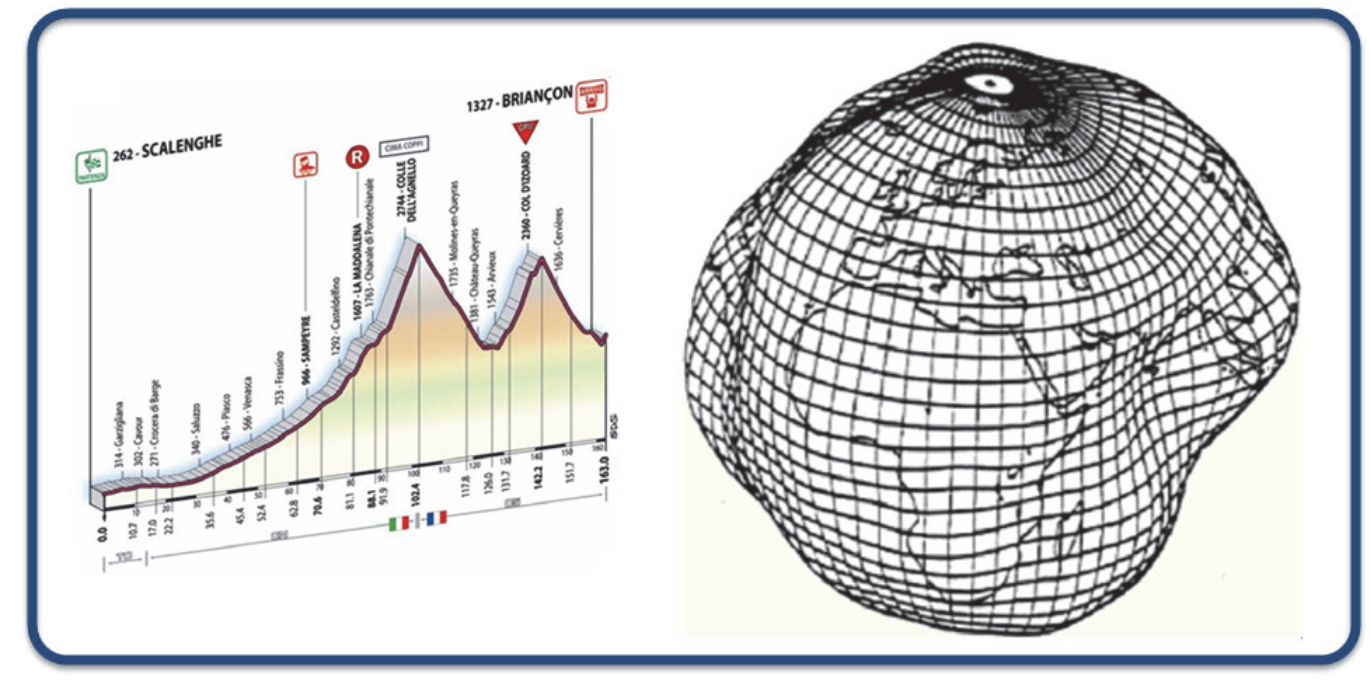

Figura 2.53 Mapa de elevación altimétrica. Concepto

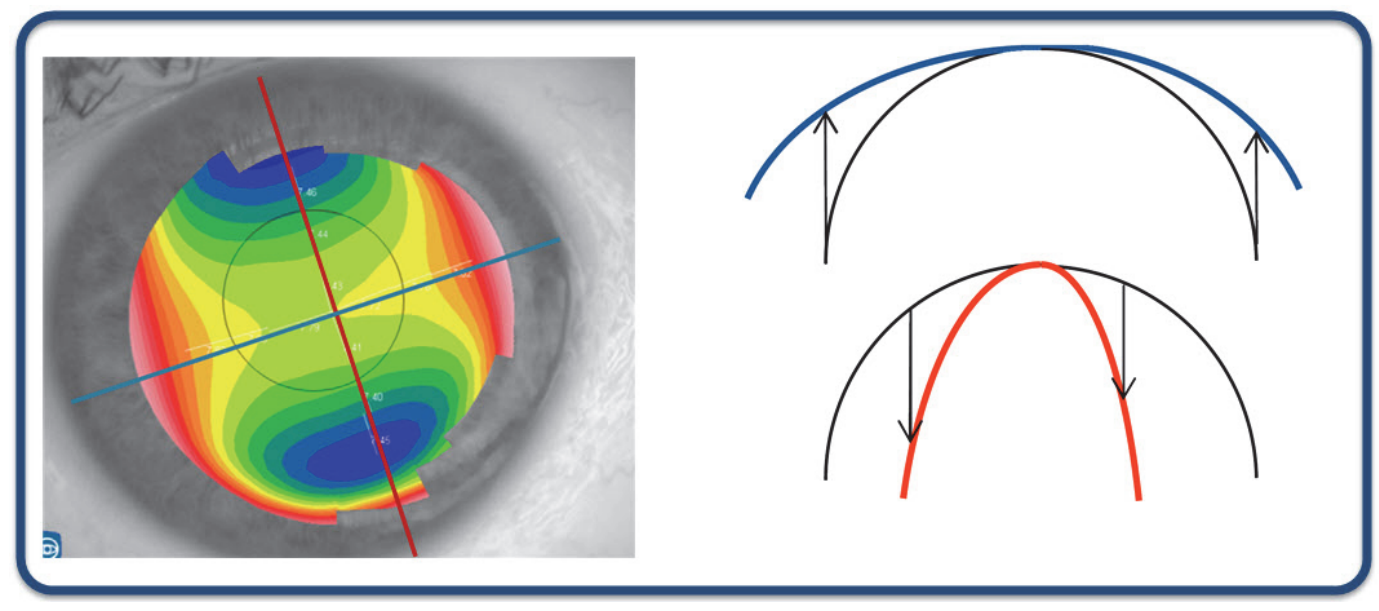

Figura 2.54 Mapa de elevación altimétrica corneal. Concepto

Por otro lado, las dimensiones típicas de la superficie de referencia están en torno a los $8 \mathrm{~mm}$ de diámetro. De esta forma se evitan escenarios que puedan influir en el proceso de adquisición de datos, como por ejemplo sombras generadas por las pestañas (Buey Salas y Peris Martínez, 2014). Estos mapas presentan las siguientes ventajas:

- Los datos que aportan están en unidades dimensionales de $\mu \mathrm{m}$, por lo tanto, son datos muy exactos y presentan una elevada sensibilidad frente a pequeñas alteraciones que la morfología corneal pudiera presentar como consecuencia del queratocono (Piñero et al., 2012).

- Los topógrafos corneales permiten seleccionar la superficie que mejor se ajuste a la córnea para realizar el mapa de elevación altimétrica, lo que se traduce en un aumento de la sensibilidad del diagnóstico clínico.

En este tipo de mapas resulta de interés conocer la elevación del ápex corneal (Khachikian y Belin, 2009), del punto de mínimo espesor (Khachikian y Belin, 2009) y la elevación del centro de la región central (De Sanctis et al., 2008); todos estos datos respecto a la cara anterior y la cara posterior de la córnea. 
El conocimiento de todos los parámetros anteriormente referenciados respecto la superficie de la cara posterior resulta de interés para el diagnóstico clínico del queratocono al ser una superficie que no está alterada o modificada por tratamientos invasivos como la fotoablación con láser excímer, por escenarios patológicos como la generación del colgajo corneal o por el efecto hiperplástico del epitelio corneal (Maldonado et al., 2006a; De Sanctis et al., 2008; Khachikian y Belin, 2009; Piñero et al., 2012; Buey Salas y Peris Martínez, 2014).

Mapa de grosor. Estos mapas no presentan datos medidos directamente por el topógrafo corneal, sino que inicialmente han de ser reconstruidas las superficies corneales anterior y posterior, y a continuación por diferencias entre ambos proceder a reconstruir este mapa (Figura 2.55).

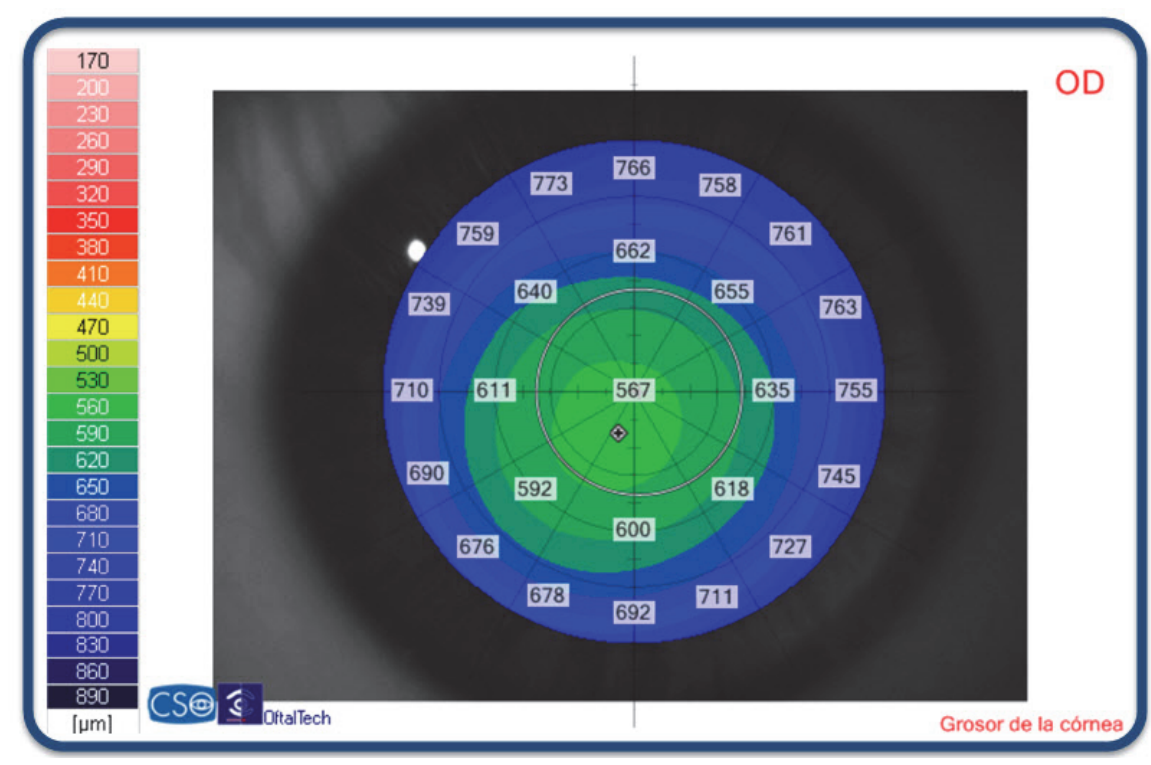

Figura 2.55 Mapa de grosor de la córnea

Con este tipo de mapa resulta de interés conocer el punto de menor espesor y su posición respecto el centro de la córnea, ya que este punto es clave para el mantenimiento y configuración de la estructura corneal (Emre et al., 2007; Alió et al., 2011), así como para conocer el adelgazamiento progresivo que sufre éste y su zona de influencia cuando avanza el grado de severidad del queratocono (Montalbán, 2013).

En la literatura científica existen trabajos que valoran el perfil paquimétrico desde el centro hacia la periferia en función de los diámetros corneales. Dicho perfil presenta un cambio más abrupto en un escenario patológico que en un escenario sano (Saad y Gatinel, 2010; Ambrosio et al., 2011b).

Mapa 3D. Estos mapas se construyen una vez las superficies anterior y posterior de la córnea ha sido reconstruidas, y a partir de éstas se genera el mapa en tres dimensiones (Figura 2.56). 


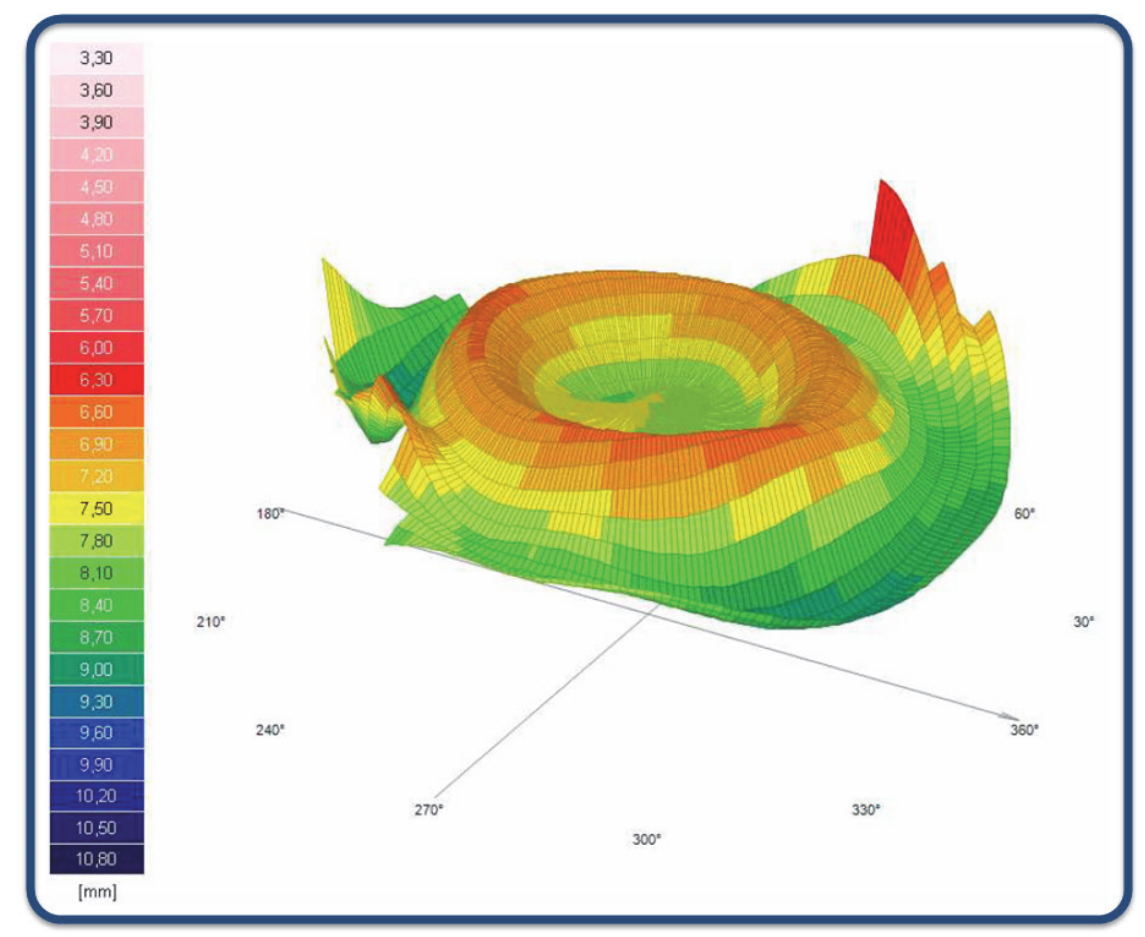

Figura 2.56 Mapa 3D de la superficie corneal anterior, equipo Sirius (CSO, Italia)

Otra forma de poder analizar la morfología corneal es a través del volumen corneal; se trata de realizar comparaciones entre el volumen que presenta la córnea en un escenario sano y en otro patológico (Ambrosio et al., 2006; Alió et al., 2011).

En resumen, la morfología que presenta la arquitectura de las superficies corneales en un escenario patológico frente a un escenario sano le confiere una geometría más prolata, inclusive de tipo paraboloide para los grados más avanzados del queratocono. Es por ello que las córneas patológicas presentan menor espesor en la región central y paracentral que las córneas sanas, observándose un incremento abrupto del espesor corneal y del volumen desde el punto de mínimo espesor hasta la región periférica de la córnea (Ambrosio et al., 2006; Montalbán, 2013).

\subsubsection{2 Índices de valoración de la irregularidad en la superficie corneal}

El desarrollo de nuevas tecnologías en el ámbito de la oftalmología permite mejorar la capacidad de diagnóstico clínico a raíz de un análisis preciso de la forma corneal y de la posibilidad de cuantificar la calidad visual de los pacientes. Además, estas tecnologías han incrementado y mejorado la sensibilidad y especificidad de la evaluación y diagnóstico de la córnea queratocónica (Albertazzi, 2010). El diagnóstico del queratocono ha adquirido una importancia en los últimos años por dos motivos fundamentales:

- La necesidad de contraindicar la práctica de técnicas de cirugía refractiva corneal que pueden acelerar la evolución del queratocono (Seiler y Quurke, 2000; Binder et al., 2005). En este caso, es fundamental extremar la sensibilidad del proceso de diagnóstico aún a costa de sacrificar especificidad, cuya única 
consecuencia negativa sería contraindicar una cirugía refractiva a un candidato apto.

- La posibilidad de emplear terapias que puedan frenar o retrasar el grado de severidad del queratocono, como el cross-linking (Wollensak et al., 2003) o la implantación de los anillos intraestromales (Colin et al., 2000; Torquetti et al., 2014). En este caso, es fundamental asegurar la especificidad de cara a evitar tratamientos innecesarios en ojos sanos.

Los diferentes métodos de análisis basados en índices de valoración de la irregularidad en la superficie corneal disponibles en la práctica clínica intentan diagnosticar la presencia de la patología del queratocono a partir de la detección cualitativa y cuantitativa de esta deformación en la córnea. Si bien con los métodos que vamos a referenciar no se alcanza una exactitud de diagnóstico del $100 \%$ de forma individual (positivos reales + negativos reales/ número de casos), la suma de todos ellos sí permiten al médico oftalmólogo una exactitud de diagnóstico del 100\%. Estos índices de valoración son obtenidos a partir de la topografía corneal; de ahí que numerosos estudios clínicos hayan propuesto determinados valores de corte para discriminar córneas normales de queratocónicas, y a su vez estudiar los diferentes grados severidad de queratocono (Albertazzi, 2010). Sin embargo, el principal problema reside en el hecho de que cada índice de valoración descrito tiene un alto grado de especificidad para el equipo con el que se ha desarrollado, de forma que no puede ser fácilmente extrapolable a otros; inclusive en algunos casos, los resultados obtenidos de dichos equipos no coinciden con las formulas publicadas (Mahmoud et al., 2006; Albertazzi, 2010).

Por todas las razones anteriormente expuestas resulta de interés conocer los sistemas cuantitativos de detección univariante y multivariante empleados, ya que permiten comprender las principales características topográficas del queratocono y aplicar este conocimiento en la valoración de cada topografía de forma individual.

\subsection{Sistemas cuantitativos de detección univariante}

Los sistemas cuantitativos de detección univariante son unos sistemas que se centran en el análisis de un único índice del paciente. Éstos pueden ser:

Coeficiente de Asfericidad. Es un índice que describe la medida en la que cambia la curvatura de la córnea desde la región central hasta la región periférica. El valor depende del diámetro en estudio por lo que hay que indicarlo al expresar un determinado índice. La sección de la córnea normal es una elipse prolata, con un valor Q promedio en torno a -0.20 con una desviación típica estándar de 0.12 (Tabla 2.1) (Carney et al., 1997; Calossi, 2003), lo que significa que la córnea es más curva en el centro que en la periferia. En el queratocono el valor de $Q$ se hace más negativo, es decir, la región central y paracentral es más curva respecto a la región periférica en una medida mayor que la habitual. Sin embargo, cuanto más periférica sea la protusión cónica, puede ocurrir que el valor de Q en los 4 o $5 \mathrm{~mm}$ de diámetro central presente una geometría oblata $(Q>0)$. En base a los valores anteriormente descritos el coeficiente 
de asfericidad no es muy específico para el diagnóstico del queratocono y hay que valorarlo en su relación con la posición del ápex del cono.

Valor Inferior-superior (I-S). Este índice se define como la diferencia en potencia entre cinco puntos del hemisferio inferior y otros cinco puntos del hemisferio superior de la región corneal, situados a $3 \mathrm{~mm}$ del vértice corneal en intervalos espaciales de $30^{\circ}$ (Rabinowitz y McDonell, 1989; Maeda et al., 1994; Albertazzi, 2010; Montalbán, 2013).

SimK (Queratometría simulada). Aporta información sobre el poder dióptrico de los meridianos más planos y más curvos en la denominada región útil del topógrafo (anillos para diámetros comprendidos entre 3 y $9 \mathrm{~mm}$ ). Numéricamente se expresa como K1 y K2; además la diferencia entre ambos valores aporta un valor cuantitativo del astigmatismo corneal (Smolek y Klyce, 1997; Montalbán, 2013).

K Central. Corresponde al valor promedio de la potencia corneal para los anillos de diámetro 2, 3 y 4 mm (Maeda et al., 1995; Montalbán, 2013).

ACP (Average corneal power). Este índice indica un valor promedio de potencia en varios puntos de la región corneal prepupular o central (Maeda et al., 1995; Albertazzi, 2010).

EffRP (Effective refractive power). Índice que promedia la potencia en el área central de $3 \mathrm{~mm}$ de diámetro. Considera el efecto Styles-Crawford (Holladay, 1997; Albertazzi, 2010).

AK (Apex curvature). Corresponde a un índice que aporta un valor de la curvatura instantánea en el ápex corneal (Albertazzi, 2010).

SAI (Surface asymmetry index). Es un índice que indica un valor promedio de las diferencias en potencia entre los puntos situados espacialmente a $180^{\circ}$ de 128 meridianos equidistantes (Dingeldein et al., 1989; Albertazzi, 2010; Montalbán, 2013).

SRI (Surface Regularity index). Es un descriptor de la regularidad local en un área central de diámetro $4.5 \mathrm{~mm}$ (comprende los 10 anillos centrales de los Discos de Plácido). Cuantifica las diferencias en gradientes de potencias entre los sucesivos pares de anillos en 256 semimeridianos equidistantes (Wilson y Klyce, 1991; Albertazzi, 2010; Montalbán, 2013).

DSI (Different sector index). Es un índice que cuantifica la diferencia en potencia media entre sectores de $45^{\circ}$ con la mayor y menor potencia (Albertazzi, 2010; Montalbán, 2013).

OSI (Opposite sector index). Se trata de otro índice que indica en términos de potencia media la diferencia entre sectores de $45^{\circ}$ opuestos (Albertazzi, 2010; Montalbán, 2013). 
IAI (Irregular astigmatism index). Se trata de una medida de las variables dióptricas a lo largo de cada semimeridiano, normalizada por la potencia media de la córnea y el número de puntos medidos (Maeda et al., 1995; Montalbán, 2013).

CIM (Corneal Irregularity Measurement). Es un índice numérico que representa el grado de irregularidad que presenta la morfología de la superficie de la córnea, de tal forma que cuantifica la desviación estándar entre la superficie corneal y la superficie de referencia de mejor ajuste, en este caso una superficie tórica. Valores elevados de este índice indican una mayor probabilidad de que la córnea presente una patología relacionada con una anomalía morfológica (Montalbán, 2013).

AA (Analysed area). Es la razón del área de datos interpolados por el área circunscrita por el anillo más periférico (Maeda et al., 1995; Albertazzi, 2010; Montalbán, 2013).

CSI (Centre Surround index). Es un índice que cuantifica la diferencia en potencia media entre la zona central de diámetro $3 \mathrm{~mm}$ y un anillo medio-periférico comprendido entre los $3 \mathrm{~mm}$ y los 6 mm (Maeda et al., 1995; Albertazzi, 2010; Montalbán, 2013).

CU (Corneal uniformity index). Corresponde a un índice que cuantifica la uniformidad de la distorsión en los $3 \mathrm{~mm}$ centrales. Se expresa en porcentaje, es decir, un valor del $100 \%$ indica que la córnea tiene una uniformidad perfecta (Holladay, 1997).

PCA (Predicted corneal acuity). Cuantifica, en unidades Snellen, la calidad óptica en los 3 mm de diámetro central de la córnea en un rango de 20/10 a 20/200 (Albertazzi, 2010).

SRAX (Skew of steepest radial axes). Mide la angulación entre el semimeridiano más curvo superior y el semimeridiano más curvo inferior. El semimeridiano más curvo de cada hemisferio se determina promediando las potencias de los anillos a $5 \mathrm{~mm}$ y 16 $\mathrm{mm}$ de diámetro. El ángulo más pequeño entre estos semimeridianos es sustraído de $180^{\circ}$; los resultados en grados es el índice SRAX (Albertazzi, 2010; Montalbán, 2013).

TI (Topographic irregularity). Es el root mean square (RMS) de la diferencia entre los datos topográficos reales y una superficie geométrica de referencia; en este caso un esferocilindro de mejor ajuste a la superficie corneal de estudio (Albertazzi, 2010).

Calossi-Foggi ACG (Apex curvature gradient). Se trata de un índice que cuantifica la diferencia media por unidad de distancia de la potencia corneal relativa a la potencia apical (Albertazzi, 2010).

Calossi-Foggi SI (Superior-Inferior Index). Es un índice de asimetría vertical similar al valor I-S, pero éste indica la diferencia en términos de potencia media entre el área superior y un área inferior (Albertazzi, 2010). 
Irregularidad de superficie Orbscan. Es un coeficiente que se calcula a partir de las desviaciones estándar de la curvatura media y del astigmatismo medio en las zonas comprendidas entre los anillos centrales de $3 \mathrm{~mm}$ y $5 \mathrm{~mm}$ (Albertazzi, 2010).

\subsection{Sistemas cuantitativos de detección multivariante}

Los sistemas cuantitativos de detección multivariante son unos sistemas que se basan en el análisis simultáneo de varios índices de diagnóstico de un paciente. Con el desarrollo de nuevas tecnologías, éstas proporcionan algoritmos basados en la combinación de varios índices que cuantifican, en términos de alturas normalizadas o de potencia, la irregularidad de la superficie corneal facilitando el diagnóstico del queratocono. Cada equipo topográfico utiliza un algoritmo propio, el cual posee un diseño específico para ese equipo, por lo que el oftalmólogo debe conocer la sensibilidad y especificidad de cada software (Albertazzi, 2010). Los sistemas de detección multivariante son:

Índice de Rabinowitz y McDonell. Se trata de uno de los primeros índices multivariantes basado en la combinación de los valores numéricos aportados por los índices I-S, el valor de $\mathrm{K}$ central y la diferencia del $\mathrm{K}$ central entre ambos ojos del paciente, de forma que este sistema multivariante combina la información obtenida de los valores de curvatura central con los de la asimetría ínfero-superior que pueden aparecer tanto en la región central como en la periférica (Rabinowitz y McDonell, 1989; Montalbán, 2013).

PathFinder Corneal Analysis. Es un sistema que utiliza tres índices diferentes, concretamente el índice CIM, el índice de asfericidad y el índice de queratometría torácica media, para la detección de las alteraciones morfológicas que presentan las topografías corneales (Abad et al., 2007; Montalbán, 2013).

KPI (Keratoconus prediction index). Se trata de un índice calculado por la combinación de 8 índices topográficos utilizando una función discriminante lineal; estos índices son: Sim K1, Sim K2, SAI, DSI, OSI, CSI, IAI y AA (Albertazzi, 2010).

KCI (Keratoconus Index). Se trata de un método también denominado en el campo de la oftalmología como método Klyce-Maeda. Este método trata de discriminar una córnea sana de una córnea queratocónica, y también de diferenciar entre los queratoconos que se desarrollan en la región central y en las regiones periféricas. El método multivariante KPI, junto con los índices DSI, OSI, GSI y Sim K2 fueron implementados en un algoritmo computacional experto basado en un árbol de decisión binaria (Albertazzi, 2010; Montalbán, 2013).

KSI (keratoconus severity index). También denominado en el campo de la oftalmología como el método de Smolek-Klyce. Este sistema multivariante calcula el grado de severidad del queratocono, pudiendo discernir entre una córnea sana, una córnea con sospecha de queratocono incipiente y una córnea con queratocono. El algoritmo utilizado está basado en una red neuronal con 10 índices topográficos como entrada (Smolek y Klyce, 1997). 
KISA\%. Se calcula a partir de cuatro índices: K central, AST (astigmatismo SIM K1-K2), valor I-S y SRAX. Es un índice muy eficaz en la identificación del queratocono, pero puede presentar una cifra significativa de falsos negativos en el diagnóstico del queratocono clínico e incipiente, lo que puede ser un riesgo importante en su uso como herramienta de screening en cirugía refractiva (Rabinowitz y Rasheed, 1999; Albertazzi, 2010; Montalbán, 2013).

Método Chastang. Combina los índices SDSD y Asph elaborando un árbol de decisión primaria. Este método no es válido para definir el grado o severidad del queratocono, por lo que los casos incipientes o tempranos no son identificados (Chastang et al., 2000; Albertazzi, 2010).

\subsection{Conclusiones}

En la literatura científica no existe ningún índice de valoración de la irregularidad de la superficie corneal, basado en sistemas cuantitativos de detección univariante o multivariante, que proporcione unos parámetros clínicos para el diagnóstico del queratocono con un $100 \%$ de sensibilidad y especificidad. Por otra parte, una combinación de toda la información aportada por estos índices, basados en diferentes exámenes clínicos, resulta esencial para el correcto diagnóstico del queratocono por parte del médico oftalmólogo. Sin embargo, estos índices son aportados por unos equipos topográficos presentando una elevada especificidad para cada equipo para el cuál ha sido desarrollado, y el modelo propuesto no es fácilmente extrapolable a otros equipos topográficos. Es por ello que en este escenario de exploración morfológica resulta de interés para la comunidad oftalmológica proponer una nueva técnica de diagnóstico clínico de la patología ectásica bilateral denominada queratocono, basado en un sistema cuantitativo de detección multivariante a partir de unos índices de valoración de la irregularidad de la superficie corneal fundamentados en parámetros geométricos, de forma que el procedimiento definido para su cálculo no sea específico de un topógrafo corneal en particular, sino que pueda ser utilizado, junto con otros topógrafos comerciales, como una herramienta de diagnóstico clínico dentro del concepto de Análisis integral de la córnea, de tal forma que el conjunto de datos obtenidos por todos los índices de valoración permitan al médico oftalmólogo poder emitir un juicio clínico lo más veraz posible para el diagnóstico de la enfermedad.

\subsection{Queratocono clínico: clasificación}

La patología ectásica bilateral, denominada queratocono es una enfermedad con un rango muy variable de afección clínica, desde tan solo un leve astigmatismo irregular hasta un adelgazamiento con una protusión severa, acompañados de una grave disminución de la calidad o agudeza visual del paciente que requiere un tratamiento mediante técnicas invasivas o no (Rabinowitz, 1998; Albertazzi, 2010).

Disponer de clasificaciones estandarizadas y reproducibles del queratocono clínico es importante por tres motivos (Albertazzi, 2010): 
- Los últimos avances técnicos en la cirugía refractiva ha popularizado esta técnica como una técnica invasiva de corrección y de mejora de la calidad visual de los pacientes. Anteriormente, era suficiente con diagnosticar el queratocono clínico, pero con el uso de la cirugía refractiva corneal ésta requiere de la detección y de la exclusión de la formas incipientes o tempranas del queratocono, ya que éstas pueden suponer un factor de riesgo de ectasia importante después de operaciones por láser como el Lasik (Randleman, 2006) o como la queratectomía fotorrefractiva (Malaceze et al., 2006). Este interés en el diagnóstico del queratocono ha impulsado el desarrollo de índices cuantitativos y de programas de diagnóstico clínico basados en los datos aportados por las topografías corneales. A pesar de todos estos avances el diagnóstico clínico del queratocono al $100 \%$ de fiabilidad sigue siendo todavía un desafío (Sonmez et al., 2007; Piñero, 2014).

- Las nuevas técnicas terapéuticas invasivas de corrección de la patología, como son los anillos intracorneales (Colin et al., 2000) o el crosslinking (Wollensak et al., 2003), requieren de un sistema de clasificación de la gravedad de la enfermedad que sea estandarizado y reproducible, tanto para la valoración de la patología como para su seguimiento y su posterior evaluación tras tratamiento correctivo (Rosen, 2007).

- Los estudios genéticos del queratocono requieren de la medición de la severidad del queratocono en una escala numérica. Se considera que el queratocono es un rasgo genético complejo de evolución variable. La genética estadística utiliza métodos para correlacionar la similaridad genética con la similaridad fenotópica o clínica; estos fenotipos pueden clasificarse como variables decotómicas (afectado versus no afectado) o como un índice de severidad de la enfermedad. Si esta clasificación se utiliza para buscar los genes del queratocono, se necesita una clasificación válida y fácil, y con una buena correlación en la parte clínica, lo que requiere que la escala que se emplee utilice un rango de características fenotópicas del queratocono lo suficientemente amplio para abarcar desde el escenario natural o sano hasta el escenario patológico más grave (McMahon et al., 2006).

\subsection{Alteraciones ectásicas corneales: clasificación}

Antes de establecer la clasificación del queratocono clínico es necesario indicar que el queratocono es la patología más frecuente dentro del grupo de las degeneraciones o alteraciones ectásicas corneales (Binder et al., 2005). Esta denominación incluye a las patologías degenerativas o distróficas en las que se produce un adelgazamiento progresivo con modificación en la curvatura de la córnea, lo que genera una protusión de la misma en ausencia de un proceso inflamatorio. Existen otras patologías dentro de este grupo, como son la degeneración marginal pelúcida (Figura 2.57) y el queratoglobo (Figura 2.58), que junto con el queratocono pueden presentar variaciones en la expresión fenotópica del mismo mecanismo patogénico con diferente localización de la ectasia en función de la zona adelgazada (Albertazzi, 2010). Esto implicaría la existencia de casos atípicos de queratocono, con formas más globulares o más 
periféricas de lo habitual, controversias sobre el diagnóstico o casos con un tipo de degeneración en un ojo y otra diferente en el contralateral (Barraquer et al., 2004; Erlan, 2007; Lee et al., 2007).

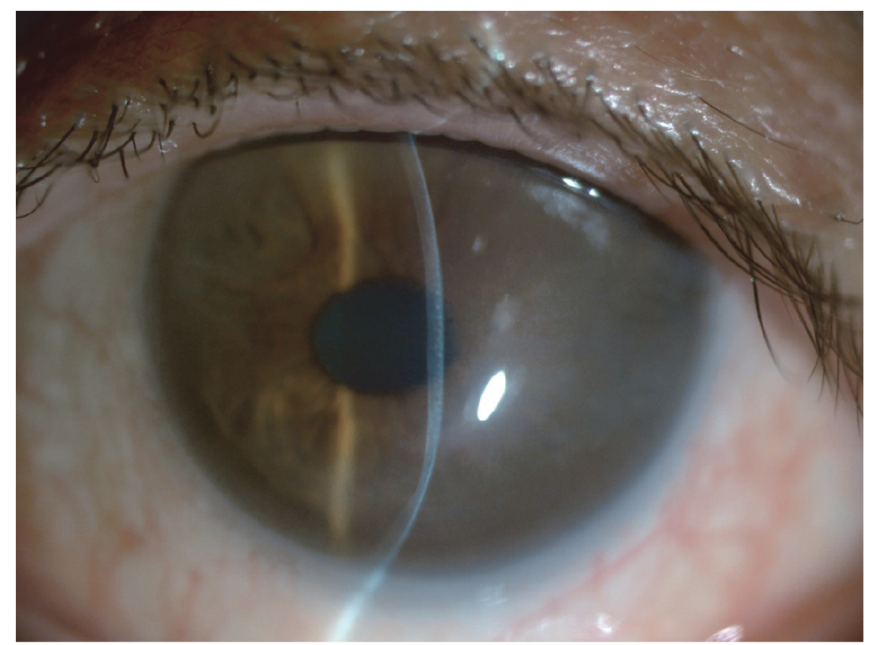

Figura 2.57 Degeneración marginal pelúcida

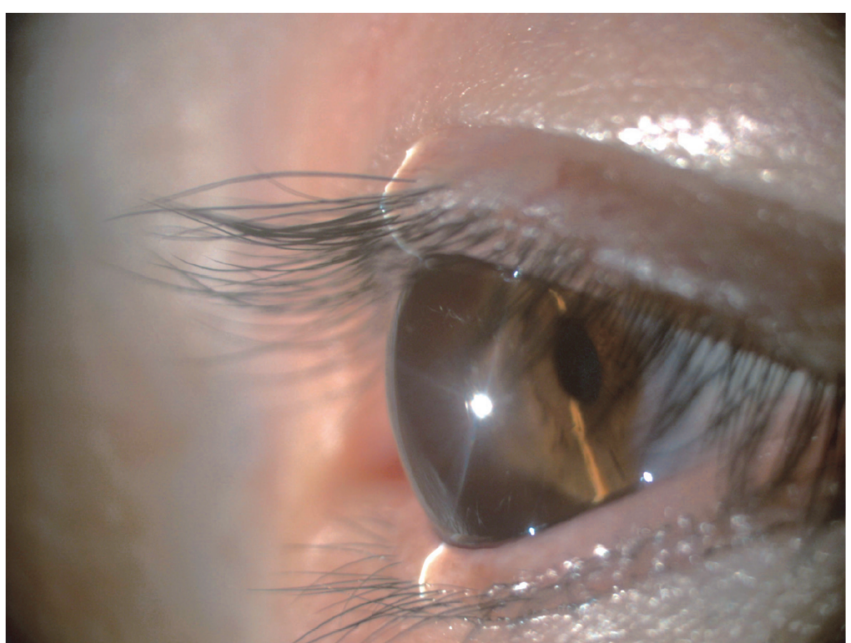

Figura 2.58 Queratoglobo

Las ectasias corneales pueden clasificarse:

Clasificación según su origen. La ectasia puede producirse de un modo natural (queratocono, queratoglobo, degeneración marginal pelúcida) o iatrogénica (ectasias tras una cirugía refractiva) (Binder et al., 2005).

Clasificación según su configuración. En función de su configuración principal pueden ser:

- Ectasia corneal axial (central o paracentral): queratocono, iatrogénica.

- Ectasia corneal generalizada: queratoglobo.

- Ectasia corneal periférica: degeneración marginal pelúcida. 
Así pues, el queratocono es una ectasia corneal bilateral natural axial (central o paracentral).

\subsection{Nomenclatura}

Dentro de la práctica clínica existen condiciones diferenciadas sobre el concepto del queratocono, y por ello deben ser definidas desde el punto de vista de la nomenclatura. Así pues en la literatura científica nos encontramos con los términos (Albertazzi, 2010):

Queratocono Clínico o Queratocono. Este término designa la entidad en la cual la córnea adquiere una protusión o forma cónica como resultado de un adelgazamiento progresivo no inflamatorio, asociada con procesos de cicatrización corneal (Rabinowitz, 1998; Rabinowitz, 2004). Su diagnóstico es clínico, basado en la combinación de signos clínicos y de datos de naturaleza cualitativa y cuantitativa aportados por los topógrafos corneales. Este término indica que la enfermedad ya se manifiesta desde su grado más leve (estados iniciales) hasta sus grados más severos (estados avanzados). Esta nomenclatura corresponde a la patología que es diagnosticada en la presente tesis basada en índices de caracterización geométrica obtenidos a partir de un modelo virtual de la córnea patológica.

Queratocono frustre, temprano o subclínico. Este término designa la situación inversa a la del queratocono, se trata de una entidad en la que la córnea presenta una topografía anormal, pero en la que no están presentes ninguno de los signos clínicos de la enfermedad, ni existen otras causas, como traumatismos o lentes de contacto, que puedan explicar el patrón topográfico alterado (Amsler, 1961). Esta nomenclatura no es utilizada en la presente tesis.

Pseudoqueratocono. Este término se emplea para referirse a la situación en la que nos encontramos con alteraciones topográficas que coinciden a las encontradas en el queratocono clínico o subclínico, pero que tienen un origen diferente a los de la patología queratocónica. Éste puede ser debido al moldeado por lentes de contacto, traumatismo, errores de captura topográfica, frotamiento ocular, queratopatía punteda, cirugía previa, adelgazamiento corneal inflamatorio y/o secreción meibomiana excesiva (Montalbán, 2013). Cualesquiera de ellos puede generar patrones topográficos iguales a los del queratocono, pero estas causas han de ser consideraras como elemento fundamental en el diagnóstico diferencial de la patología. Esta nomenclatura no es utilizada en la presente tesis.

\subsection{Clasificación clínica}

Existen diferentes clasificaciones del queratocono clínico, algunas de ellas evalúan de forma aislada un único parámetro como la queratometría (Zadnik et al., 1998), la morfología (Perry et al., 1980) o la paquimetría (Avitabile et al., 1997; Reinstein et al., 2011) con aplicaciones limitadas al considerar una sola característica de la enfermedad.

Las clasificaciones más útiles empleadas desde el punto de vista clínico son las que tienen en cuenta una combinación de distintos signos del queratocono, como la 
clasificación adoptada en la presente tesis denominada Amsler-Krumich (Kamiya et al., 2014), la clasificación de Ferrara-Amsler (Albertazzi, 2010), la denominada de Amsler modificada por aberrometría (Alió y Shabayek, 2006) o finalmente la denominada CLEK (Hom y Bruce, 2006), especialmente adecuada para la realización de estudios genéticos del queratocono. En todas ellas se describe el grado de avance o severidad de la enfermedad en base a unos estadios.

En el presente trabajo se describe una clasificación a nivel morfológico y la clasificación utilizada en esta tesis doctoral.

Clasificación Morfológica. Esta clasificación describe varios subtipos de queratocono por tamaño y forma del cono (Perry et al., 1980) en función del análisis topográfico realizado sobre la superficie corneal (Perry et al., 1980). Estos pueden ser (Montalbán, 2013):

- Pezón. El análisis de la topografía corneal presenta un cono de aproximadamente $5 \mathrm{~mm}$ de diámetro que afecta a menos del $50 \%$ de la región corneal. Adquiere una morfología de forma redondeada y curva, presentando el resto de la superficie corneal su forma natural. El ápex se localiza en la región central o paracentral, aunque a veces puede desplazarse inferonasalmente (Figura 2.15).

- Oval. El análisis de la topografía corneal presenta un cono de tamaño mayor al pezón y afecta a uno o dos cuadrantes, localizándose generalmente en el área inferotemporal. Adquiere una morfología de tipo elipsoide (Figura 2.16).

- Globo. Esta morfología cubre prácticamente toda la región corneal al presentar una extensión mayor a los $6 \mathrm{~mm}$ de diámetro. Su morfología se caracteriza por un adelgazamiento generalizado (Figura 2.59).

- Astigmatismo. Esta caracterización presenta una protusión cónica caracterizada por un astigmatismo en pajarita vertical con una asimetría inferosuperior, con frecuencia más curva en la zona superior por lo que afecta a menos de un $50 \%$ de la región corneal (Figura 2.60).

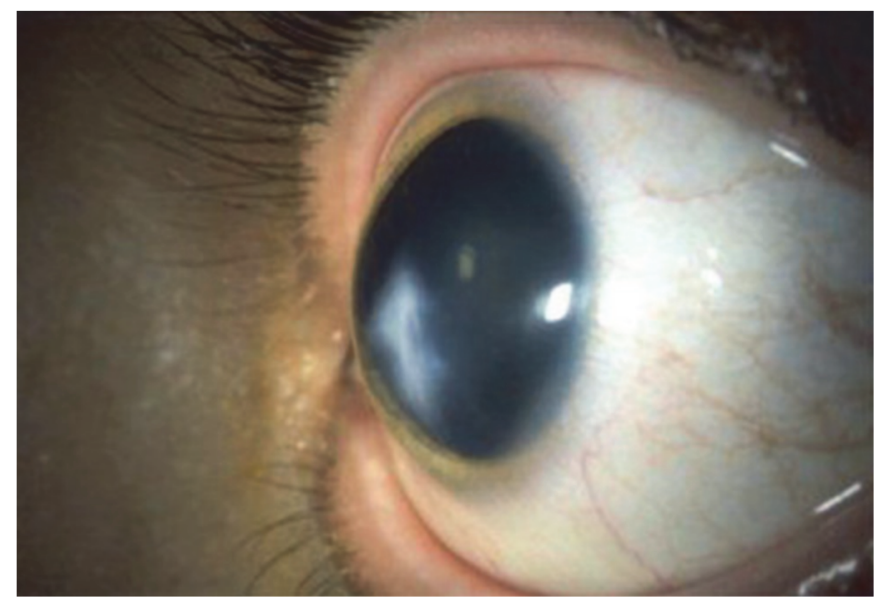

Figura 2.59 Córnea tipo globo 


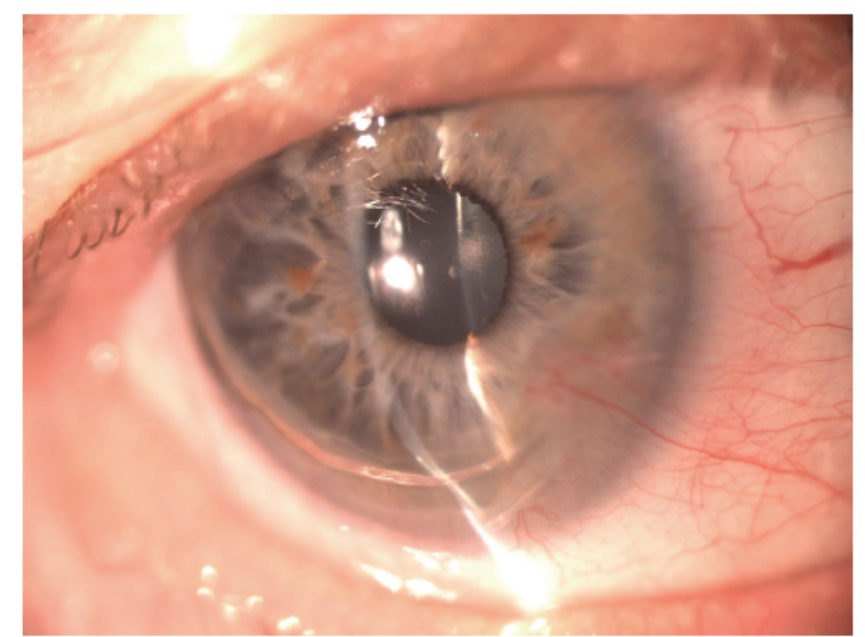

Figura 2.60 Córnea con astigmatismo debido a la patología del queratocono

Esta clasificación basada en la forma del cono sirve sobre todo para describir la extensión del cono y clasificar el queratocono en base a la forma de éste, pero no ofrece información sobre la severidad de la patología corneal.

Clasificación de Amsler-Krumeich. Esta clasificación es la utilizada en este trabajo de investigación; se trata de la clasificación más generalizada utilizada para la graduación de la severidad del queratocono, y para ello se combina la información obtenida del análisis clínico del defecto refractivo del paciente con las lecturas queratométricas de valores de curvatura del cono, con valores de paquimetría y con los signos clínicos encontrados durante la exploración del paciente (Montalbán, 2013).

Esta clasificación define cuatro estadios (Tabla 2.2) en función del grado de severidad del queratocono. Puede ocurrir que determinados casos de queratocono solapen valores de los estadios propuestos en la clasificación, en cuyo caso se debe clasificar la patología en aquel estadio o grado que mayor número de criterios cumpla.

$\begin{array}{ccccc}\text { Estadio } & \begin{array}{c}\text { Miopía y/o } \\ \text { astigmatismo } \\ \text { inducido (D) } \\ \text { Hasta-5D }\end{array} & \begin{array}{c}\text { Valores de } \\ \text { queratometría } \\ \text { central media (D) } \\ \text { I }\end{array} & \begin{array}{c}\text { Paquimetría } \\ \text { mínima }(\mu \mathrm{m})\end{array} & \begin{array}{c}\text { Otros signos, } \\ \text { cicatrices, } \\ \text { encorvamiento } \\ \text { Ausencia de } \\ \text { cicatrices y } \\ \text { encorvamiento }\end{array} \\ \text { III } & \text { Entre-5D }-8 \mathrm{D} & \leq 53 \mathrm{D} & >53 \mu \mathrm{m} & \begin{array}{c}\text { Ausencia de } \\ \text { cicatrices }\end{array} \\ \text { III } & \text { Entre-8D y-10 D } & >53 \mathrm{D} & \begin{array}{c}\text { Entre } 300 \mu \mathrm{m} \mathrm{y} 400 \\ \mu \mathrm{m}\end{array} & \begin{array}{c}\text { Ausencia de } \\ \text { cicatrices }\end{array} \\ \text { IV } & \text { Refracción no } & >55 \mathrm{D} & \leq 200 \mu \mathrm{m} & \begin{array}{c}\text { Cicatrices corneales } \\ \text { centrales }\end{array}\end{array}$

Tabla 2.2 Clasificación del queratocono clínico según Amsler-Krumeich, adaptada de Montalbán (2013).

\subsection{Conclusiones}

Dentro de las patologías ectásicas corneales el queratocono es la patología ectásica más importante. Además, en el ámbito clínico el término queratocono puede tener varias 
afecciones en función del grado de manifestación de la patología corneal, siendo el queratocono clínico el utilizado en el presente trabajo de tesis, que es cuando se manifiesta la enfermedad y es diagnosticada a partir de una combinación de índices aportados por los topógrafos corneales. Además, el queratocono desde su estado o grado de manifestación leve al más severo puede ser clasificado en base al grado de severidad. En la literatura científica existen varias clasificaciones, siendo la clasificación de Amsler-Krumeich la utilizada en la presente tesis por ser la clasificación del queratocono más utilizada en el campo de la oftalmología.

\subsubsection{Conclusiones}

El queratocono es la patología ectásica bilateral más importante. Los actuales métodos de diagnóstico clínico del queratocono están basados en sistemas cuantitativos de detección multivariante, los cuales combinan los valores numéricos aportados por las variables de curvatura y de medición de la irregularidad morfológica de la superficie corneal. El desarrollo de nuevas tecnologías, sobre todo la combinación de una doble tecnología basada en la integración, por un lado de una imagen especular obtenida por reflexión de los Discos de Plácido, y por otro lado por la proyección de una hendidura de luz fotografiada en base al principio de dispersión de la luz de Raylehg, introduce nuevas variables como son los mapas paquimétricos o valores de volumen corneal.

El principal problema que plantean estos sistemas es que están basados en unos índices los cuales han sido desarrollados para unos topógrafos corneales en concreto, por lo que presentan un alto grado de especificidad hacia estos equipos, y no son fácilmente implementables con otros equipos, aun estando basados en la misma tecnología. Por otro lado, uno de los campos de la ciencia que no ha sido desarrollado para el diagnóstico clínico del queratocono en base a la alteración morfológica que produce en la arquitectura corneal es la geometría descriptiva. En la literatura científica solamente consta la existencia de dos trabajos de caracterización geométrica en 2D (Ramos-López et al., 2011 y 2013) y un trabajo de caracterización geométrica en 3D (Cavas-Martínez et al., 2014) autor de esta tesis doctoral.

En base a todo lo anteriormente expuesto, esta tesis doctoral plantea un nuevo concepto de diagnóstico clínico de la principal ectasia corneal, la denominada como queratocono, basado en unos índices descriptivos de la irregularidad de la superficie corneal anterior y posterior, fundamentados éstos en unos parámetros geométricos descriptivos aplicados al modelo de córnea generado en un entorno virtual, de forma que éstos permitan establecer un criterio objetivo, cuantificable y con una elevada sensibilidad y especificidad de caracterización de dicha alteración morfológica.

Además, estos parámetros geométricos son compatibles con cualquier modelo de córnea virtual generado a partir de los datos de altimetría normalizados en bruto, obtenidos en la primera etapa de los topógrafos corneales basados en la combinación de la doble tecnología Disco de Plácido más principio de fotografía Scheimpflug, y por lo tanto independientes de los diferentes topógrafos corneales existentes en el mercado. 


\subsection{Diseño Geométrico Asistido por Ordenador}

El Diseño Geométrico Asistido por Ordenador (DGAO) se ha convertido en una importante herramienta para una amplia variedad de aplicaciones en diversos campos de la ingeniería, como en el ámbito de la mecánica, la producción, la bioingeniería, etc.

Los aviones, los satélites, los automóviles, etc., son productos que durante su diseño y fabricación requieren de la modelización de superficies complejas. Es por ello que en estos ámbitos industriales se focalizan los principales beneficios de la investigación desarrollada de forma simultánea entre las ciencias matemáticas y la ingeniería gráfica.

Como resultado de todo esto, los objetos físicos han sido sustituidos por modelos sólidos virtuales, lo que se traduce en la fabricación de productos comerciales más baratos, ya que los modelos virtuales son más fáciles de analizar y modificar que los primeros modelos desarrollados en un entorno físico (Dimas y Briassoulis, 1999).

\subsubsection{Concepto de modelización}

El modelado geométrico puede diferir en el planteamiento de la representación matemática de una entidad geométrica. Una importante distinción es entre las representaciones implícitas y las representaciones paramétricas.

- Una superficie paramétrica adquiere la forma:

$$
x(s, t)=[x(s, t), y(s, t), z(s, t)]^{T}
$$

Por lo tanto, es esencialmente una asignación de un dominio $D \subset R^{2} a R^{3}$.

De manera análoga, una curva paramétrica es una asignación de $D \subset R^{2} a R^{3}$.

Las curvas de Bézier, Splines, B-Splines, Cónicas y líneas y superficies NURBS son las representaciones paramétricas más importantes.

Una curva de Bézier es definida mediante un polígono de control con un número determinado de puntos de control en función del grado. A partir de la idea anterior se introduce el concepto de curva definida a trozos, la cual incorpora unos puntos o nodos, los cuales son una serie de valores de la curva que sirven para su definición; este nuevo enfoque corresponde al concepto de línea Spline. A su vez, estas mismas funciones pueden ser denominadas como B-Spline cuando son representadas a partir del polígono de Boor. Si además las curvas poseen un término racional, éstas se denominan curvas cónicas y corresponden a las denominadas como parábolas, elipses, etc.

Por otro lado, las líneas NURBS representan una generalización natural de las funciones B-Spline con un término racional, es decir, combinan las propiedades 
de las funciones B-Spline con las de las curvas cónicas. Así mismo, las superficies NURBS son una extensión de las líneas NURBS en dos direcciones, es decir, una forma apropiada de la generalización del producto tensorial BSpline y de las curvas de Bézier (Dimas y Briassoulis, 1999).

- Las superficies implícitas se definen como el contorno cero de una función de valor escalar, es decir, el conjunto de puntos $[\mathrm{x}, \mathrm{y}, \mathrm{t}]^{\mathrm{T}}$ que satisface:

$$
f(x, y, z)=0
$$

Las curvas implícitas se definen como la intersección de dos superficies implícitas, es decir, sus ecuaciones son:

$$
f_{1}(x, y, z)=f_{2}(x, y, z)=0
$$

Por otra parte, a veces pueden ser utilizadas otras representaciones geométricas como por ejemplo las representaciones explícitas; sin embargo, las representaciones paramétricas e implícitas son las predominantes en los ámbitos académico, industrial y comercial (Dimas y Briassoulis, 1999).

Los sistemas de modelado geométrico también pueden diferir en su concepto o enfoque. Históricamente ha habido tres diferentes tipos de sistema de modelado geométrico en base al concepto o el enfoque de partida: modelado de malla, modelado de superficies y modelado de sólidos.

Los primeros modelos fueron de mallas, los cuales fueron creados con la ayuda de los ordenadores. Se trata del empleo de líneas rectas, de cónicas o de sencillas curvas Spline las cuales se utilizan para representar los límites del objeto para ser modelado. Sin embargo, la falta de información explícita sobre la superficie a modelar puede conducir a modelos ambiguos, incompletos o incluso imposibles de fabricar, ya que pueden no corresponder a ningún objeto 3D físico (Goldman, 1987). Estos problemas de representación obligan a buscar otros sistemas de modelado más completos; en consecuencia, los sistemas mallados dieron paso a los sistemas de modelado de superficies y de sólidos (Dimas y Briassoulis, 1999).

Los modelos de superficies se utilizan de forma explícita para describir un objeto a partir del modelado de su superficie. Por lo tanto, con este modelado pueden ser modeladas formas más complejas que con el modelado de malla.

Por definición, un sólido es un objeto 3D bien definido tanto interiormente como exteriormente, y separado por un límite bidimensional (2D). Se han desarrollado muchas técnicas para generar y almacenar modelos geométricos que están representados como sólidos, como son las denominadas en inglés Constructive Solid Geometry (CSG) y Boundary Representation (B-rep) (Dimas y Briassoulis, 1999).

En la literatura científica existen diversos trabajos que describen procedimientos de modelado de sólidos (Requicha y Voelcker, 1982; Requicha y Voelcker, 1983), así como 
estudios sobre las ventajas y desventajas de tales modelados solidos (Requicha y Rossignac, 1992; Dimas y Briassoulis, 1999). Los primeros sistemas de modelado de sólidos están basados en semi-espacios de naturaleza planar y cuadrática, como por ejemplo la esfera, el cilindro, etc.. Sin embargo, estos sistemas no son válidos para el modelado de superficies de forma libre, requiriéndose para estas unos sistemas de modelado con mayores grados de libertad (Bajaj y Ihm, 1992; Menon, 1993; Bajaj et al., 1993; Dahmen y Thamm-Schaar, 1993; Middleditch y Dimas, 1994; Menon et al., 1994; Dimas y Briassoulis, 1999).

Por otra parte, desde el punto de vista de las técnicas utilizadas para el modelado geométrico existen dos enfoques básicos: por un lado la denominada interpolación transfinita y por otro lado la denominada aproximación e interpolación discreta.

Respecto a la interpolación transfinita, una superficie está construida de tal manera que pasa a través de un conjunto de curvas. El concepto de diseño transversal es un ejemplo de un método basado en esta técnica (Woodward, 1987). Y con respecto a la aproximación discreta o interpolación, se trata de una técnica donde una superficie se aproxima a un conjunto dado de puntos espaciales.

Por otra parte, y en función de cómo puede afectar un cambio a la generación de una curva o superficie a partir del conjunto de los datos espaciales, podemos distinguir entre dos métodos de reconstrucción, los denominados métodos globales y los métodos locales.

En los métodos globales, un cambio en los datos de partida afecta a toda la superficie, mientras que en los métodos locales el cambio solo afecta a la superficie a nivel local. En la primera categoría, es decir en los globales, corresponden a las superficies como la de Gordon o las superficies polinomiales de Bézier (Dimas y Briassoulis, 1999). Sin embargo, si manejamos un denso conjunto de datos espaciales, el grado de ajuste requerido a la superficie polinomial con respecto estos datos es alta, lo que implica que la superficie resultante sea irrazonablemente complicada para posteriores modificaciones adicionales.

Por lo tanto, los diseñadores están más interesados en los métodos locales donde un cambio en los datos espaciales solo afecta a la curva o la superficie a nivel local, concretamente en la región próxima al cambio de los datos. Los métodos locales generan polinomios triangulares definidos a trozos o bipolinomiales para construir la superficie deseada. Además tales métodos incluyen funciones a trozos como son las de Bézier, B-splines, B-Splines racionales, curvas y superficies NURBS (Dimas y Briassoulis, 1999).

Por lo general, existe una aproximación poliédrica o poligonal inicial del objeto deseado en términos de una triangulación o de una rejilla rectangular en los denominados puntos de control (Schumaker, 1993). El polígono o poliedro primitivo es suavizado por partes, utilizando unos tensores de naturaleza triangular o rectangular, mediante el uso de los denominados parches. Para las superficies de Bézier, han de 
cumplirse las condiciones de suavidad de la curva entre los parches adyacentes (Gregory, 1982; Degen, 1990), pero para las funciones B-Spline o las NURBS, esta condición de suavidad de la función viene definida sin ninguna condición especial (Dimas y Briassoulis, 1999).

\subsubsection{Historia del Diseño Geométrico Asistido por Ordenador}

El término Diseño Geométrico Asistido por Ordenador (DGAO) fue acuñado por R. Barnhill y R. Riesenfeld en 1974 cuando organizaron una conferencia sobre tecnologías de diseño geométrico en la Universidad de Utah. En esta conferencia se reunieron investigadores de EEUU y Europa, pudiendo ser considerado como el primer evento en este campo (Dimas y Briassoulis, 1999; Farin et al., 2002).

A partir de aquí, nació el primer libro de referencia sobre el DGAO, el denominado "Computational Geometry for Design and Manufacture" escrito por Faux y M. Pratt (1979), y la primera publicación académica de referencia denominada "Computer Aided Geometric Design", fundada en 1984 por R. Barnhill y W. Boehm (Farin et al., 2002).

\subsubsection{Reseña histórica del DGAO, desde las primeras curvas hasta la tecnología actual}

Se tiene constancia de que el primer uso de las curvas en el ámbito de la fabricación data de los inicios de la época romana para la construcción de un barco. Las cuadernas de los barcos estaban hechas por un tablón de madera que salía desde la quilla. Éstas se realizaban basándose en plantillas las cuales podían ser reutilizadas varias veces; por lo tanto, la geometría básica de un navío podía ser guardada y no tenía que volver a ser redibujada cada vez que fuese necesario. Estas técnicas fueron perfeccionadas por los venecianos desde el siglo XIII hasta el siglo XVI. La forma de las cuadernas del barco estaban definidas en términos de tangentes continuas de arcos circulares o NURBS, tal y como se les conoce actualmente en el lenguaje de la técnica (Farin et al., 2002).

El casco del barco era obtenido modificando la forma de las cuadernas a lo largo de la quilla. Dado que en aquella época no existían dibujos que definiesen el casco del barco, este concepto es una de las primeras manifestaciones de lo que hoy en día definimos como las tensiones en la superficie de un producto sólido. Además esta idea se hizo muy popular en la Inglaterra del siglo XVII. En este escenario surgió el concepto clásico de Spline, que corresponde al de una viga de madera la cual se usaba para dibujar curvas suavizadas. La primera mención de un Spline fue en 1752 (Duchon, 1977). Esta conexión en la construcción de barcos fue el primer uso de la geometría constructiva para definir las formas libres (Farin et al., 2002). En la actualidad, estas técnicas han sido ampliamente utilizadas en el campo de la ingeniería naval (Narli y Sarioz, 1998; Farin et al., 2002; Chung et al., 2004; Dong y Chen, 2014).

En la historia del DGAO existe otra fecha clave, concretamente en el campo de la aeronaútica, ya que en 1944 el ingeniero Liming escribió un libro titulado "Analytical Geometry with Application to Aircraft" (Farin et al., 2002). Liming trabajó para la 
compañía aérea llamada North América durante la segunda guerra mundial, compañía que fabricó los conocidos aviones de combate de guerra denominados Mustang. En su libro, Limming combinó por primera vez los métodos clásicos de trazados geométricos con las técnicas basadas en herramientas computacionales. Para ello empleó las secciones de las cónicas en el diseño de los aviones, al igual que se hizo anteriormente en la industria de construcción naval. Tradicionalmente, estas construcciones se diseñaban en las mesas de los diseñadores a partir de los planos, lo que puede ser interpretado como una definición básica del producto. Sin embargo, Liming se dio cuenta de que existía una alternativa más eficiente: guardar un diseño en términos de números, en lugar de curvas geométricas trazadas manualmente sobre los planos, y por lo tanto, él reinterpretó el método clásico del diseño de producto a un nuevo concepto de diseño basado en algoritmos numéricos. La principal ventaja de este nuevo enfoque es que los números se pueden almacenar en tablas las cuales no pueden dar lugar a interpretaciones individuales de los dibujos. El trabajo de Liming fue muy influyente en los años 50, cuando se adoptó este método por las compañías que diseñaban aviones en los Estados Unidos.

Otro investigador que también estuvo involucrado en la transición del diseño de los aviones hacia la computación fue Coons, quien más tarde ganó fama por su trabajo en el MIT (Farin et al., 2002).

Por otra parte, la aparición en los años 50 del control numérico $(\mathrm{CN})$ influyó de forma notable en el desarrollo del DGAO. Los primeros ordenadores eran capaces de generar instrucciones numéricas, las cuales eran usadas por las fresadoras para la producción de los moldes y de las estampadoras para las láminas de metal. Para este propósito, en el Instituto Tecnológico de Masachuses (MIT) se desarrolló el lenguaje de programación APT; pero existía un problema, todo lo relevante a la información era almacenado en forma de planos, y no estaba claro cómo transmitir esta información a los ordenadores, que eran los responsables de dirigir la fresadora. Al principio se planteó como primera solución la digitalización de los puntos fuera de los planos y de los ajustes a las curvas usando técnicas familiares como la interpolación de Lagrange; sin embargo, esta idea no funcionó. Por ello se necesitaban nuevos conceptos sobre los planos para los ordenadores.

En Francia, de Casteljau y Bézier fueron más lejos en la tarea de permitir a los diseñadores abandonar todos los procesos de planos manuales (Farin et al., 2002).

En los EEUU, por un lado Ferguson en Boeing y por otro lado Coons en el MIT, proveyeron de nuevas técnicas alternativas. Además, General Motors (GM) desarrolló su primer sistema CAD/CAM, el DAC-I (Design Augmented by Computer), que usaba técnicas de las curvas y de las superficies desarrolladas en GM por investigadores tales como C. de Boor y W. Gordon (Farin et al., 2002).

En el Reino Unido, Forrest comenzó su trabajo con curvas y superficies después de que Coons le expusiese sus ideas. Su tesis doctoral, realizada en la Universidad de 
Cambridge incluye un trabajo sobre la clasificación de las formas cúbicas, cúbicas racionales y de generalización del área de Coons (Farin et al., 2002).

Por otra parte, Sabin trabajó para la empresa de aviación inglesa Bristish Aircraft, donde desarrolló un trabajo fundamental en el desarrollo del sistema CAD, el denominado "Numerical Master Geometry". También desarrolló una gran cantidad de algoritmos que más tarde fueron reutilizados para conseguir la continuidad geométrica y los tensores de las Splines (Farin, et al., 2002).

Todos los anteriores desarrollos tuvieron lugar en los años 60 y 70 de forma aislada, hasta que empezó a ver una confluencia de las diferentes ideas de las investigaciones, culminando con la creación de una nueva disciplina denominada DGAO.

Sin la aparición de los ordenadores, el DGAO no habría nacido. Al principio, el principal uso de los ordenadores no era para calcular formas geométricas complejas, sino simplemente generar la información necesaria para poder controlar las fresadoras de mecanizado. Esta información era normalmente registrada en una cinta perforada por un cuadro principal del ordenador. Esta cinta era entonces transferida a la unidad de control de la fresadora (Farin et al., 2002).

El principal interés de un diseñador no estaba en la fresadora en sí, dado que era más bien un plotter de curvas el cual podía mostrar gráficamente y de forma rápida los conceptos al diseñador. Los primeros trazadores de curvas eran de igual o mayor tamaño que una mesa de billar, algo que era normal ya que la mayoría de los dibujos para la gran mayoría de piezas de automoción eran producidos a escala. El trazado o diseño era tan importante que prácticamente todo CAD tenía por objetivo la producción de dibujos (Farin et al., 2002).

Antes de la aparición de estos sistemas, estas tareas triviales de modificación consumían una gran cantidad de tiempo. Por ejemplo, el producir una nueva vista del mallado de un objeto complejo con respecto de otras vistas ya existentes llevaba al diseñador una semana o más. Esta actividad usando ordenadores era solo cuestión de unos segundos.

El hito en el hardware respecto a las pantallas fue el uso de los CRTs o Terminales de rayos Catódicos, que provocaron el desuso de los oscilógrafos, los cuales fueron usados para varias aplicaciones científicas. Los CRTs (que actualmente no se usan para aplicaciones CAD) mostraban una imagen "dibujando" las curvas en la pantalla (Farin et al., 2002).

Otra evolución de la tecnología se debe a la aparición de los sistemas interactivos. El primer sistema gráfico interactivo fue inventado por I. Sutherland en el MIT en 1963 (Farin et al., 2002).

En 1959 la compañía francesa de automoción Citroën contrató a un joven matemático con el propósito de resolver algunos de los problemas teóricos que surgían del reto de 
pasar los planos al ordenador. El matemático era Paul de Faget de Casteljau, quien comenzó a desarrollar un sistema el cual, en un principio tenía como objetivo el diseño de las curvas y superficies en lugar de centrarse en la reproducción de los planos ya existentes. Casteljau adoptó el uso de los polinomios de Bernstein para su definición de las curvas y las superficies desde el mismo comienzo; a este conjunto es lo que ahora se conoce como el algoritmo de Casteljau (Farin et al., 2002).

El éxito de estos conocimientos fue el uso de los polígonos de control, una técnica que no había sido utilizada antes, en lugar de definir una curva o una superficie a través de puntos en ella misma. Los polígonos de control usan puntos cerca de ellas, y en lugar de cambiar la curva o superficie directamente, se cambia el polígono de control de tal forma que la curva o la superficie la continúa de una manera muy intuitiva (Farin et al., 2002).

El trabajo de De Casteljau se mantuvo en secreto por Citroën durante un largo periodo de tiempo. La primera mención pública del algoritmo (aunque no se mencionaba al inventor) fue realizada por Boehm, quien fue el primero en reconocer a Casteljau por su trabajo a la comunidad científica, al descubrir las técnicas en los artículos de Casteljau, acuñó el término de "De Casteljau algorithm" a finales de los 70 (Farin et al., 2002).

En la industria del automóvil, además de los avances en DGAO realizados por Citroën, su competidor Renault, ubicado también en Paris, revolucionó la geometría de superficies. Fue al inicio de los años 60 donde Pierre Bézier encabezó el departamento de diseño y se dio cuenta de la necesidad de la representación por ordenador de las partes mecánicas. Los esfuerzos de Bézier estuvieron influenciados por el conocimiento de los desarrollos similares en Citroën, pero procedió de una manera independiente. La idea inicial de Bézier fue representar una curva básica como la intersección de dos cilindros elípticos, los dos cilindros estaban definidos dentro de un paralelepípedo, así que las transformaciones afines de este paralelepípedo resultarían transformaciones afines de la curva. Más tarde, Bézier pasó a formulaciones polinómicas de este concepto inicial y también lo extendió a otros polinomios de grados más altos. El resultado acabó siendo idéntico al de las curvas de Casteljau; la única diferencia era que las matemáticas utilizadas eran diferentes (Farin et al., 2002).

El trabajo de Bézier fue extensamente publicado, y pronto llamó la atención de Forrest, quién se dio cuenta de que las curvas de Bézier podían ser expresadas en términos de los polinomios de Bernstein, de la misma forma que Casteljau los había usado desde finales de los 50. El artículo de Forres sobre las curvas de Bézier fue muy influyente y ayudó a popularizar las curvas de Bézier de forma considerable (Farin et al., 2012).

El sistema UNISURF de CAD/CAM de Rénault estaba basado por completo en las curvas y superficies de Bézier. Esto influyó en la compañía de diseño aeronáutico francesa Dassault, quién había construido un sistema denominado EVE, para más tarde, evolucionar ese sistema al conocido hoy en día con el nombre de CATIA (en inglés, Computer Aided Three-dimensional Interactive Application) (Farin et al, 2002). 
Bézier también invento un método para deformar ensamblajes completos de superficies, incrustándolos en un cubo y luego deformándolos usando la denominada tri-variación de los "cubos de Bézier". De Casteljau se retiró de Citroën en 1989 y se dedicó a las publicaciones, Bézier falleció en Paris en 1999 (Farin et al., 2002).

\subsubsection{Fundamento teórico de las funciones B-Spline y NURBS}

En este subcapítulo se definen las funciones B-Spline y el comportamiento de las NURBS tanto de forma univariable, es decir se analiza el comportamiento de las variables de forma individual, como de forma bivariable, es decir se estudia las relaciones que hay entre las variables tomadas de dos en dos.

\subsubsection{Fundamento teórico de las funciones B-Spline}

Una curva B-Spline se define a partir de unas características: su grado, su polígono de control y por una secuencia de nudos.

Dado que la curva B-Spline está formada por diversos segmentos de naturaleza polinómica, el grado de la línea debe ser el mismo grado que tiene cada uno de los segmentos, siendo el orden de la curva el grado más uno.

El polígono de control se define como un conjunto definido de puntos en el espacio, donde algunos de ellos pueden estar repetidos, de tal forma que la curva B-Spline pasará por el primer y por el último punto de control del conjunto, y se aproximará de forma suave al resto de puntos.

La secuencia de nudos está constituida por un conjunto listado de números reales en forma no decreciente en el intervalo [0,1], donde el valor numérico del primer nudo será 0 y del último nudo será 1 ; además si un mismo valor numérico está repetido $\mathrm{r}$ veces, se dice que posee una multiplicidad $r$. La presencia de diferentes multiplicidades implicará distintas propiedades con respecto al punto de control que corresponden a cada nudo en particular. En concreto, una multiplicidad igual al orden supondrá que la curva interpole al punto correspondiente. El primer y el último nodo de la secuencia listada tendrán una multiplicidad igual al orden para asegurar la interpolación de los puntos extremos. Para definir y evaluar una curva de esta naturaleza puede ser utilizado el siguiente algoritmo.

Siendo $u=\left\{u_{0}, u_{1}, \ldots, u_{i}, u_{i+1}, \ldots, u_{m}\right\}$ una secuencia de números reales no decreciente (se denomina a $U$ un vector de nudo), la siguiente expresión define la curva normalizada B-Spline en función del grado de $p$ de forma recursiva.

$$
N_{i}^{p}(u)=\frac{u-u_{i}}{u_{i+p}-u_{i}} N_{i}^{p-1}(u)+\frac{u_{i+p+1}-u}{u_{i+p+1}-u_{i+1}} N_{i+1}^{p-1}(u)
$$


donde

$$
N_{i}^{o}(u)=\left\{\begin{array}{c}
1, \text { if } u_{i} \leq u \leq u_{i+1} \\
0, \text { otro }
\end{array}\right.
$$

El intervalo $\left[u_{i}, u_{i+1}\right]$ es llamado intervalo del nudo i-ésimo. Un vector del nudo es no periódico si los primeros y los últimos nudos se repiten con una multiplicidad $p+1$, i.e $U=\left\{u_{0}, \ldots, u_{0}, \ldots, u_{p+1}, \ldots, u_{m-p-1},\right\}$. Para la mayoría de las aplicaciones prácticas, $u_{0}=0$ y $u_{m}=1$.

A los nudos $u_{p+1}, \ldots, u_{m-p-1}$ se les llama nudos internos.

Además, a un vector del nudo se le denomina uniforme si los nudos están igualmente espaciados, es decir, existe un número real positivo $U=h$ tal que $u_{i+1}-u_{i}=h, p \leq$ $i \leq m-p-1$.. De lo contrario, el vector del nudo no es uniforme. Los vectores del nudo no uniformes ofrecen una mayor flexibilidad para diversas aplicaciones de diseño (Faroki y Hinds, 1985; Piegl y Tiller, 1987; Dimas y Briassoulis, 1999).

Las funciones B-spline son una generalización natural de funciones de Bézier:

$$
B_{i}^{p}(u)=\left(\begin{array}{c}
p \\
i
\end{array}\right) u^{i}(1-u)^{p-i}
$$

para el vector del nudo sin nudos internos, es decir, $U=\{0, \ldots, 0,1, \ldots, 1$,$\} , donde los 0$ y 1 son repetidos $\mathrm{p}+1$ veces.

\subsubsection{Fundamento teórico de las NURBS univariables}

Una NURBS es una función B-Spline con un término racional, por lo tanto las expresiones consideradas para evaluar NURBS son equivalentes a las de evaluación de una B-Spline, incorporando a ésta unos pesos $w_{i}$ con su correspondiente evaluación de forma recursiva; además, si ambas funciones operan con los puntos en coordenadas homogéneas $\left(E^{4}\right)$, las ecuaciones de ambas funciones son idénticas.

En el caso de funciones NURBS univariables, donde se analiza el comportamiento de las variables de la función de forma individual, se pueden definir como:

$$
R_{i}^{p}(u)=\frac{w_{i} N_{i}^{p}(u)}{\sum_{j=0}^{n} w_{j} N_{j}^{p}(u)}
$$

donde $w_{i}$ son $n+1(=m-p)$ pesos reales positivos. También cuenta que si todos los pesos son iguales, es decir, $w_{i}=w$, para $i=1, \ldots, n$, las funciones de base racionales se transforman a B-Spline. Por lo tanto, son generalizaciones de las funciones B-Splines. Ciertamente, 


$$
R_{i}^{p}(u)=\left\{\begin{array}{c}
N_{i}^{p}(u), \text { si } w_{i}=w, i=1, \ldots, n \\
B_{i}^{p}(u), \text { si } w_{i}=w, i=1, \ldots, n, U=\{0, \ldots, 0,1, \ldots, 1\}
\end{array}\right.
$$

donde los 0 y 1 en $U$ se repiten $p+1$ veces.

Las propiedades de $R_{i}$ provienen de las funciones B-Spline normalizadas. En particular, tenemos (Dimas y Briassoulis, 1999):

- No-negatividad: $R_{i}(u) \geq 0$.

- Partición de la unidad: $\sum_{i=0}^{n} R_{i}^{p}(u)=1$.

- No negatividad y la partición de la unidad significa que $0 \leq R_{i}(u) \leq 1$.

- Apoyo local: Para $u \notin\left[u_{i}, u_{i+p+1}\right], R_{i}(u)$. En otras palabras, $R_{i}(u)$ es "activo" (no nulo) solamente en el intervalo $\left[u_{i}, u_{i+p+1}\right]$, es decir, desde el nudo $u_{i}$ en adelante.

- Diferenciabilidad: Si la multiplicidad de un nudo es $k$, entonces la función de base es $p-k$ veces diferenciable con continuidad en este nudo. Es infinitamente diferenciable con continuidad en el interior de un lapso de nudo.

- Para $p>0, R_{i}(u)$ tiene exactamente un valor máximo en $\left[u_{i}, u_{i+p+1}\right]$ (donde es distinto de cero).

- Con respecto a la influencia de los pesos de la forma de las funciones de base, se puede probar fácilmente que:

$$
\begin{aligned}
& \text { Para } w_{i}=0, R_{i}(u)=0 . \\
& \text { Para } w_{j} \rightarrow \infty, R_{i}(u) \rightarrow 1, \text { si } j=i \text { y } R_{i}(u) \rightarrow 0, \text { si } j \neq i
\end{aligned}
$$

\subsubsection{Fundamento teórico de las NURBS bivariables}

Estas funciones están fundamentadas en el concepto anteriormente descrito respecto las NURBS univariables, pero en este caso, para las funciones NURBS bivariables se considera que para definir una superficie racional B-Spline se utilizan las funciones de base B-Spline de grado $(p, q)$ :

$$
R_{i j}^{p, q}(u, v)=\frac{w_{i} N_{i}^{p}(u) N_{j}^{q}(v)}{\sum_{r=s}^{k} \sum_{j=0}^{n} w_{r s} N_{j}^{p}(u) N_{j}^{q}(v)}
$$

Naturalmente, en este caso se utilizan dos vectores en el nudo $\mathrm{U}, \mathrm{V}$ asociado con $N_{i}^{p}(u)$ y $N_{i}^{q}(v)$. Las líneas de los nudos $u=u_{r}, r=0, \ldots, k, v=v_{s}, s=0, \ldots, n$ forman una rejilla rectangular en el dominio de parámetro $[0,1]^{2}$ (Dimas y Briassoulis, 1999).

Tal y como ha sido comentado anteriormente, cuando todos los pesos $w_{i}$ son iguales, las funciones de base bivariables NURBS son una generalización apropiada del producto tensorial de las funciones de base B-Spline y Bézier (Dimas y Briassoulis, 1999). 
Las propiedades de las funciones de base racionales univariables también sirven para las funciones de base racionales bivariables (Dimas y Briassoulis, 1999):

- No-negatividad: $R_{i j}(u, v) \geq 0$.

- Partición de la unidad: $\sum_{i=0}^{n} \sum_{j}^{n} R_{i, j}^{p, q}(u, v)=1$.

- No negatividad y la partición de la unidad significa que $0 \leq R_{i j}(u, v) \leq 1$.

- Apoyo local: Para $(u, v) \notin\left[u_{i}, u_{i+p+1}\right] \times\left[v_{i}, v_{i+p+1}\right], R_{i j}(u, v)=0$.

- Efecto interruptor on-off: en un lapso de nudo $\left[u_{i-1}, u_{i}\right] \times\left[v_{j-1}, v_{j}\right]$, las únicas funciones de base activas son $R_{r, s}(u, v), i-p-1 \leq r \leq i-1, j-q-1 \leq s \leq j-$ 1. Cuando los parámetros se mueven en un intervalo cercano, una función de base se "apaga" (se convierte en nula) y otra es "encendida" (se convierte en no nula).

- Diferenciabilidad: Si la multiplicidad de un nudo en la dirección $\mathrm{u}(\mathrm{v})$ es $k$, entonces la función de base es $p-k$ veces diferenciable con continuidad en este nudo. Es infinitamente diferenciable con continuidad en el interior de un lapso de nudo.

- Para $p, q>0, R_{i j}(u)$ tiene exactamente un valor máximo en $\left[u_{i}, u_{i+p+1}\right] \times$ $\left[v_{i}, v_{i+p+1}\right]$ (donde es distinto de cero).

- Con respecto a la influencia de los pesos de la forma de las funciones de base, se puede probar fácilmente que:

$$
\begin{aligned}
& \text { Para } w_{i j}=0, R_{i j}(u, v)=0 . \\
& \text { Para } w_{i j} \rightarrow \infty, R_{r, s}^{p, q}(u, v)= \begin{cases}1, & s i(r, s)=(i, j) \\
0, & s i(r, s) \neq(i, j)\end{cases}
\end{aligned}
$$

- Para puntos fijos $(\mathrm{u}, \mathrm{v})$, el aumento de un peso $w_{i j}$ aumenta la respectiva función de base $R_{i j}$ mientras que el resto de las funciones de base disminuyen.

\subsubsection{Curvas y superficies generadas a partir de NURBS}

En este subcapítulo se presentan las NURBS, así como las ventajas y desventajas de éstas.

\subsubsection{Concepto}

La extensión de las expresiones de las curvas NURBS en dos direcciones permite generar las superficies NURBS, quedando éstas definidas a partir del producto tensorial de las dos líneas curvas.

Estas superficies se definen mediante el grado y la secuencia listada de nodos en cada una de las direcciones u y v. Ha de indicarse que tanto el grado de la superficie como el número de nudos no tienen por qué coincidir para las direcciones u y v. Los puntos de control serán una cuadrícula en el espacio que en general tendrá diferente número de puntos según cada una de las direcciones consideradas. 
Un modelo geométrico en el espacio 3D proyectado en un espacio cuatri-dimensional de tipo Euclidiano (4D) puede ser usado para definir las superficies NURBS (Piegl, 1991).

Los puntos en $E^{4}$ son de la forma $[x, y, z, 1]^{T}$. Los puntos en un espacio 3D $[x, y, z]^{T}$ pueden ser insertados en $E^{4}$ como $[x, y, z, 1]^{T}$. Por ejemplo, el hiperplano $w=1$ es considerado una copia del espacio 3D (Dimas y Briassoulis, 1999).

Una superficie NURBS es una proyección en perspectiva en el espacio 3D de un producto tensorial de superficie de la función B-Spline sobre el hiperplano $w=1$.

Esta perspectiva se define como:

$$
M([x, y, z, w])=\left\{\begin{array}{l}
{[x / w, y / w, z / w], \text { si } w \neq 0} \\
\text { apunta al infinito, si } w=0
\end{array}\right.
$$

Se debe de tener en cuenta que todos los $[w x, w y, w z, w]^{T}$ puntos trazan a $[x, y, z]^{T}$, y así el conjunto de todos los puntos $[w x, w y, w z, w]^{T}$ se denominan coordenadas homogéneas de la forma homogénea $[x, y, z]^{T}$.

Dado un conjunto de puntos de control 3D $P_{i j}=\left[x_{i j}, y_{i j}, z_{i j}\right]^{T}, i=0, \ldots, k, j=0, \ldots, n, \mathrm{y}$ un conjunto de pesos $w_{i j}, i=0, \ldots, k, j=0, \ldots, n$, asociados con los puntos de control, puede ser definida una superficie NURBS (Dimas y Briassoulis, 1999).

Para este propósito utilizamos unas coordenadas homogéneas para definir los puntos $4 \mathrm{D}{ }^{h} P_{i j}=\left[w_{i j} x_{i j}, w_{i j} y_{i j}, w_{i j} z_{i j}, w_{i j}\right]^{T}, i=0, \ldots, k, j=0, \ldots, n$. Por lo tanto, podemos construir una superficie no racional B-Spline en espacio 4D.

$$
N(u, v)=\sum_{i=0}^{k} \sum_{j=0}^{n}{ }^{h} P_{i j} N_{i}^{p}(u) N_{j}^{q}(v), 0 \leq u, v \leq 1
$$

donde, y sin pérdida de generalidad, se ha asumido que los vectores de nudo son de la forma:

$$
U=\left\{0, \ldots, 0, u_{p+1}, \ldots, u_{m-p-1}, 1, \ldots, 1\right\}
$$

La superficie NURBS $R^{p, q}(u, v)$ de grado $(\mathrm{p}, \mathrm{q})$ es entonces definida como un mapa perspectivo:

$$
R^{p, q}(u, v)=M(N(u, v))=\frac{\sum_{i=0}^{k} \sum_{j=0}^{n} w_{i j} \boldsymbol{P}_{i j} N_{i}^{p}(u) N_{j}^{q}(v)}{\sum_{i=0}^{k} \sum_{j=0}^{n} w_{i j} N_{i}^{p}(u) N_{j}^{q}(v)}
$$


o de forma más compacta:

$$
R^{p, q}(u, v)=\sum_{i=0}^{k} \sum_{j=0}^{n} P_{i j} R_{i j}^{p, q}(u, v)
$$

El exponente será eliminado cuando esté claro que el grado de la superficie es (p, q). Al interpolador lineal por tramos en los puntos de control $P_{i j}$ se le conoce como polígono de control de la superficie (Dimas y Briassoulis, 1999).

Se debe de tener en cuenta que cuando todos los pesos son iguales, la superficie definida por la ecuación (2.18) se convierte en una superficie B-spline. Si los pesos no son iguales y no hay nudos interiores, las superficies definidas por la ecuación (2.18) se convierten en superficies racionales de Bézier. La ecuación (2.16) se puede utilizar para evaluar eficientemente la superficie NURBS (Deboor, 1991; Dimas y Briassoulis, 1999).

Del mismo modo, una curva NURBS se define como un mapa en perspectiva del espacio 4D para el espacio 3D o desde el espacio 3D al espacio 2D.

El grado $p$, el número de nudos $(=m+1)$ y el número de puntos de control $(=n+1)$ están relacionados por la fórmula: $m=n+p+1$. Naturalmente, si los pesos son todos iguales, las funciones de base NURBS $R_{i}^{p}(u)$ (definida por la ecuación 2.12) se transforman a funciones de base B-Spline y la curva se convierte en una curva B-Spline

$$
C(u)=\sum_{i=0}^{n} P_{i} R_{i}^{p}(u), 0 \leq u \leq 1
$$

Las propiedades más importantes de las superficies NURBS son (Dimas y Briassoulis, 1999):

- Generalización: Cuando todos los pesos son iguales, la superficie definida por la ecuación (2.18) se convierte en una superficie B-Spline. Si los pesos no son iguales y no hay nudos interiores, las superficies NURBS se convierten en superficies racionales Bézier.

- Para un valor de parámetro fijo $v=a$ y un valor de $u$ variando de $[0,1], R(u, a)$ es una curva NURBS de grado $p$ con pesos

$$
w_{i}=\sum_{j=0}^{n} w_{i j} N_{j}^{q}(a)
$$

y puntos de control

$$
P_{i}=\sum_{j=0}^{n} \frac{w_{i j} N_{j}^{q}(a)}{w_{i}} P_{i j}=\sum_{j=0}^{n} P_{i j} R_{j}^{q}(a)
$$

- Las superficies NURBS interpolan los 4 puntos de control de los extremos $P_{00}, P_{0 n}, P_{k 0}, P_{k n}$. 
- Las derivadas en los extremos son las mismas que las derivadas de las curvas de límite $R(0, v), R(1, v), R(u, 0)$ en sus extremos.

- Diferenciabilidad: poseen las mismas propiedades diferenciables que en las funciones base.

- Las funciones de base cambian los puntos de control de encendido y apagado.

- Propiedad de casco convexo fuerte: Si $(u, v) \in\left[u_{i}, u_{i+1}\right] \times\left[u_{j}, u_{j+1}\right]$ entonces $\mathrm{R}(\mathrm{u}, \mathrm{v})$ está en el casco convexo de los puntos de control $P_{r s}, r=i-p, \ldots, i, s=$ $j-q, \ldots j$.

- Localidad: Un movimiento del punto de control $P_{i j}$ afecta a la superficie sólo en el intervalo $\left[u_{i}, u_{i+p+1}\right] \times\left[u_{j}, u_{j+q+1}\right]$.

- Afinidad e invariancia proyectiva: Una superficie NURBS es afín y proyectivamente invariante, es decir, la transformación de la superficie por un afín o transformación perspectiva es equivalente a la transformación de los puntos de control.

- $\quad$ El aumento de un peso $w_{i j}$ aproxima la superficie hacia el punto de control $P_{i j}$ (Piegl, 1986, Dimas y Briassoulis, 1999).

Una propiedad importante de las curvas NURBS es que las superficies no parecen compartir la propiedad de variación decreciente (Prautzsch, 1985; Dimas y Briassoulis, 1999). Otra característica a considerar es que la mayoría de las operaciones a realizar sobre las superficies NURBS pueden realizarse primero en un sentido de los considerados, obteniendo un resultado como línea y posteriormente aplicar la misma operación sobre el otro sentido. De esta forma se minimiza el problema de operar sobre una superficie al problema de operar sobre un conjunto de líneas.

\subsubsection{Ventajas y desventajas de las NURBS}

Las NURBS son muy populares en el mundo académico y en el ámbito comercial del modelado geométrico. De hecho, ofrecen varias ventajas que las hacen atractivas para aplicaciones de diseño industrial (Dimas y Briassoulis, 1999):

- Son más generales que las superficies de Bézier, las curvas B-Spline y que los productos tensoriales de superficies.

- La evaluación es sencilla, rápida y computacionalmente estable.

- Ofrecen una representación matemática común para superficies de forma libre y formas de análisis de uso común como son superficies cuadráticas, superficies extruidas y superficies de revolución y paralelismo.

- Poseen afinidad (rotación, escalado, traslación) y paralelismo. También son invariantes bajo transformaciones de deformación.

- Su morfología es fácil de cambiar a través de la manipulación de puntos de control, pesos y nudos. 
- Ofrecen una amplia gama de herramientas para diseñar y analizar la información de forma en función del grado de elevación, división, inserción de nudos, eliminación de nudos y refinamiento de nudos.

Algunas de las desventajas de NURBS sobre representaciones tradicionales son (Dimas y Briassoulis, 1999):

- Una mala elección de los pesos puede conducir a una mala parametrización de la curva/superficie.

- Es necesario una elevada densidad de puntos para definir las formas tradicionales, tales como un círculo o una esfera.

- Algunos algoritmos son numéricamente inestables (por ejemplo mapeo inverso de los puntos).

- Algunos algoritmos funcionan mejor con otras formas que con NURBS, por ejemplo, el cálculo de la curva de intersección de dos superficies.

\subsubsection{Diseño de una superficie con forma libre}

Las NURBS pueden ser utilizadas para representar superficies cuadráticas, superficies regladas y superficies de revolución. Sin embargo, el poder real de las NURBS recae en su capacidad para modelar curvas y superficies complejas de formas libres.

Las técnicas para el modelado de curvas y superficies complejas a partir de NURBS se pueden clasificar en: interpolación y aproximación.

\subsubsection{Interpolación}

A partir de las técnicas de interpolación, una curva o una superficie libre puede ser construida pasando por los datos espaciales dados. Cuando los datos dados son puntos, se trata de una interpolación denominada discreta. Sin embargo, puede ser que se tenga que construir una superficie que interpola un conjunto de curvas, en cuyo caso estamos realizando una interpolación transfinita.

La interpolación de un conjunto de puntos con una superficie NURBS puede ser formulada de la manera siguiente: Dado un conjunto de puntos de $Q_{i}, i=0, \ldots, l$, una parametrización inicial y una distribución en forma de nudo, encontrar una superficie de interpolación ajustada a los datos espaciales dados. Más precisamente, encontrar los puntos de control $P_{i j}$ y los pesos $w_{i j}$ de una superficie NURBS R(u, v) de tal manera que:

$$
Q_{r}=R\left(u_{r}, v_{r}\right)=\sum_{i=0}^{k} \sum_{j=0}^{n} P_{i j} R_{i j}^{p, q}\left(w_{i j} ; u_{r}, v_{r}\right), 0 \leq r \leq l=(k+1)(n+1)
$$

La resolución de la ecuación (2.23) requiere la solución de un sistema no-lineal de ecuaciones debido a la presencia de unos pesos desconocidos. Sin embargo, algunos 
autores (Ma y Kruth, 1998; Dimas y Briassoulis, 1999) muestran cómo resolver esta ecuación (2.23) en dos etapas de forma lineal.

La formulación del problema de una curva análoga es similar.

La interpolación de curvas de secciones transversales es un ejemplo de interpolación transfinita, tales datos se producen generalmente en aplicaciones médicas, como por ejemplo en la tomografía (Woodward, 1988; Dimas y Briassoulis, 1999).

El método de interpolación no es utilizado en este trabajo de investigación debido a que se procede a la reconstrucción de las superficies corneales a partir de los datos obtenidos por el algoritmo de visión, en la denominada etapa I del procedimiento de reconstrucción que utilizan los topógrafos corneales. Una interpolación de los datos implica un sesgado de éstos, y dada la elevada sensibilidad que se desea que tenga el modelo virtual generado, la interpolación puede dar lugar a que el modelo generado no detecte las pequeñas irregularidades que se puedan manifestar en la morfología corneal, sobre todo en los grados más leves del queratocono.

\subsubsection{Aproximación}

En los métodos de aproximación, una superficie o curva se aproxima lo más ajustadamente posible a una nube de puntos espaciales. Esta técnica es especialmente útil a partir de los datos espaciales obtenidos de un dispositivo de escaneado.

La formulación matemática de un problema de aproximación es la ecuación (2.23), aquí el número de puntos espaciales digitalizados es mayor que los puntos de control y que los pesos. Aunque esto es un problema de optimización no lineal, varios autores muestran cómo construir las ecuaciones del planteamiento de la minimización del problema, que luego las resuelven en dos pasos lineales: primero para el cálculo de los pesos y posteriormente para el cálculo de los puntos de control de la superficie NURBS (Ma y Kruth, 1998; Dimas y Briassoulis, 1999).

La aproximación es análoga a la ecuación (2.23), y la parametrización de los puntos medidos viene dada por:

$$
Q_{i} \sum_{i=0}^{k} \sum_{j=0}^{n} w_{r s} N_{r}^{p}\left(u_{i}\right) N_{s}^{q}\left(v_{i}\right)=\sum_{i=0}^{k} \sum_{j=0}^{n} w_{r s} N_{r}^{p}\left(u_{i}\right) N_{s}^{q}\left(v_{i}\right) P_{r s}
$$

donde $0 \leq 1 \leq l$ (l es el número total de puntos de medición) o en forma de matriz:

$$
\begin{aligned}
& N \cdot P_{x}=Q_{x} \cdot N \cdot w \\
& N \cdot P_{y}=Q_{y} \cdot N \cdot w \\
& N \cdot P_{z}=Q_{z} \cdot N \cdot w
\end{aligned}
$$

$Q_{x}, Q_{y}, Q_{z}$, son vectores que contienen las coordenadas de los puntos medidos, y: 


$$
\begin{gathered}
N=\left[N_{i j}\right]=\left[N_{i}^{p}\right]^{T} \cdot\left[N_{j}^{q}\right] \\
w=\left[w_{00}, \ldots, w_{0 n}, w_{10}, \ldots, w_{1 n}, \ldots w_{k 0}, \ldots, w_{k 0}, \ldots, w_{k n}\right]^{T} \\
P_{x}=\left[w_{00} x_{00}, \ldots, w_{0 n}, x_{0 n}, \ldots, w_{k 0} x_{k 0}, \ldots w_{k n} x_{k n}\right]^{T} \\
P_{y}=\left[w_{00} y_{00}, \ldots, w_{0 n}, y_{0 n}, \ldots, w_{k 0} y_{k 0}, \ldots w_{k n} y_{k n}\right]^{T} \\
P_{z}=\left[w_{00} z_{00}, \ldots, w_{0 n}, z_{0 n}, \ldots, w_{k 0} z_{k 0}, \ldots w_{k n} z_{k n}\right]^{T}
\end{gathered}
$$

Además, la ecuación (2.25) se puede escribir en forma matricial

$$
\left[\begin{array}{cccc}
N & 0 & 0 & -Q_{x} \cdot N \\
0 & N & 0 & -Q_{y} \cdot N \\
0 & 0 & N & -Q_{z} \cdot N
\end{array}\right]_{3(\times 4(k+1)(n+1)} \quad\left[\begin{array}{c}
P_{x} \\
P_{y} \\
P_{z} \\
w
\end{array}\right]=\left[\begin{array}{l}
0 \\
0 \\
0 \\
0
\end{array}\right]
$$

Se puede demostrar que los pesos pueden ser aislados de los puntos de control en un sistema de la forma $M w=0$, donde $M$ es una matriz no negativa simétrica de dimensión $(\mathrm{K}+1) \times(\mathrm{n}+1)$. Una vez los pesos se calculan, la ecuación (2.25) puede ser utilizada para calcular los puntos de control desconocidos. Este método producirá soluciones interpoladoras si el rango es $(M)<(K+1) \cdot(n+1)$.

Alternativamente, una superficie B-Spline (en lugar de una NURBS) puede ser construida por este procedimiento, y luego ser utilizada como una aproximación inicial al objeto o como una superficie de base para la parametrización de los puntos de medición (Ma y Kruth, 1998; Dimas y Briassoulis, 1999). 
Materiales y métodos 
El presente trabajo de investigación propone un nuevo procedimiento de generación de un modelo sólido personalizado 3D de una córnea in vivo, utilizando herramientas de DGAO, además, sobre el modelo virtual obtenido van a ser definidos unos índices descriptivos de la irregularidad de la superficie corneal anterior y posterior basados en unas variables geométricas.

La validez del procedimiento de reconstrucción propuesto, así como de los nuevos índices de caracterización geométrica, requiere la realización de un ensayo clínico sobre una muestra de sujetos con ojos sanos y sobre otra muestra con sujetos de ojos diagnosticados con diferentes grados de severidad del queratocono.

Es por ello, que en este capítulo se describe inicialmente el estudio clínico y de exploración morfológica realizado sobre un grupo de control de ojos sanos y sobre otro grupo de control de ojos enfermos. Posteriormente se realiza una descripción detallada del procedimiento de reconstrucción y de generación del modelo sólido de la córnea, así como de los nuevos índices de caracterización geométrica de la morfología de la arquitectura corneal. Y por último, se describe la estadística que va a ser utilizada para validar los índices como unos nuevos índices de diagnóstico del queratocono.

\subsection{Sujetos}

En el presente estudio han participado un total de 131 sujetos, diferenciados en dos grupos: por un lado los sujetos pertenecientes al grupo de pacientes sanos y por otro lado, los sujetos pertenecientes al grupo de pacientes diagnosticados con la patología del queratocono.

En los siguientes subcapítulos se realiza una descripción del tipo de estudio realizado en la presente tesis doctoral, de los criterios de inclusión y exclusión de los sujetos considerados en ambos grupos de control, del protocolo de información seguido con respecto los pacientes y del historial clínico y de exploración morfológica de cada paciente.

\subsubsection{Tipo de estudio}

Se trata de un estudio descriptivo en el que se detallan las características geométricas de la córnea de una muestra, y retrospectivo de cohortes, ya que en el mismo se emplean datos preexistentes de pacientes, seleccionados en función de su patología, sexo y edad, debidamente anonimizados y cedidos por Vissum Corporación S.L. para su estudio en base al convenio marco firmado el 13 de junio de 2013 entre la clínica oftalmológica y la Universidad Politécnica de Cartagena.

\subsubsection{Selección de la muestra}

Los sujetos pertenecientes al grupo de control de ojos sanos y los pertenecientes al grupo de control de ojos diagnosticados con queratocono fueron seleccionados de la consulta del Segmento Anterior de Vissum Corporación (Alicante). 
El estudio fue aprobado por el comité ético local de Vissum Corporación (Alicante) y realizado de acuerdo con las normas éticas definidas en la Declaración de Helsinki de 1964 (www.wma.net).

Los participantes en el estudio firmaron un consentimiento informado en el cual se detallan los ítems del trabajo a desarrollar y las pruebas que incluían en el protocolo de exploración clínica, tanto para los ojos de los pacientes sanos como para los ojos de los pacientes diagnosticados con queratocono clínico.

De igual forma, los pacientes fueron informados de la posibilidad de poder abandonar el ensayo clínico en cualquier instante, sin necesidad de informar del motivo del abandono, y todo esto sin que pudiera suponer una perdida en la calidad de su atención clínica por parte de la clínica Vissum Corporación (Alicante).

El estudio fue realizado sobre la comparación de dos grupos:

- Pacientes con ojos sanos: grupo formado por 90 ojos de 90 pacientes con un rango de edad comprendido entre los 7 y los 66 años (37.49 \pm 15.11 años); la composición del grupo fue de $49 \%$ de hombres y $51 \%$ de mujeres en la muestra, el 50\% de ojos derechos y el 50\% de ojos izquierdos.

Como criterios de inclusión de pacientes en este grupo se adoptó no padecer ninguna patología crónica o enfermedades sistomáticas que contraindiquen el ensayo.

Como criterios de exclusión de pacientes en este grupo se adoptó:

- Presencia de alguna patología ocular o corneal, como la patología del ojo seco, o antecedentes del glaucoma, queratitis hipértica, o infección corneal concamicante.

- La presencia de cicatrización corneal debido a factores externos detectados en la exploración biomicroscópica.

- Cirugía ocular previa.

- Enfermedades autoinmunes de base.

- Antecedentes de retraso en el crecimiento del epitelio corneal.

- Pacientes con ojos diagnosticados con queratocono: grupo formado por 41 ojos de 41 pacientes, con un rango de edad comprendido entre los 14 y los 65 años (34.75 \pm 10.84 años); la composición del grupo fue de $63.9 \%$ de hombres y $36.1 \%$ de mujeres en la muestra, el $62.3 \%$ de ojos derechos y el $37.7 \%$ de ojos izquierdos. 
Como criterios de inclusión de pacientes en este grupo se adoptó:

- Criterio de Rabinowitz (Rabinowitz, 1998): se basa en la presencia en la topografía corneal de un encurvamiento localizado en una zona específica de la región corneal, normalmente central o paracentral y/o identificación de una forma geométrica en forma de pajarita topográfica asimétrica, con o sin angulación, entre los principales meridianos corneales (Montalbán, 2013).

- Presencia de signos biomicroscópicos, los cuales comprenden un afinamiento y protusión de la córnea en la región central o paracentral identificados a partir de una minuciosa exploración realizada por la lámpara de hendidura (Albertazzi, 2010). Los signos biomicroscópicos son el adelgazamiento estromal, anillo de Fleischer, estrías de Vogt, cicatrices corneales en el estroma anterior y protusión del ápex en la región central (Rabinowitz, 1998; Rabinowitz y McDonnel, 1989; Piñero et al., 2010a).

- Valoración del grado de severidad del queratocono siguiendo la clasificación de Amsler-Krumeich (Alió y Shabayek, 2006; Piñero et al., 2010a; Vega-Estrada et al., 2013).

Como criterios de exclusión de pacientes en este grupo se adoptó:

- Presencia de alguna patología ocular o corneal, como la patología del ojo seco, o antecedentes del glaucoma, queratitis hipértica, o infección corneal concamicante.

- La presencia de cicatrización corneal debido a factores externos detectados en la exploración biomicroscópica.

- Cirugía ocular previa.

- Enfermedades autoinmunes de base.

- Antecedentes de retraso en el crecimiento del epitelio corneal.

Por otra parte, el protocolo de medida para ambos grupos adoptó como criterio incluir un solo ojo para cada paciente de forma aleatoria, siguiendo una secuencia dicotómica numérica entre 0 y 1 creada mediante un software específico a fin de evitar la interferencia de la potencial correlación que pudiera existir entre los ojos de una misma persona (Montalbán, 2013).

\subsubsection{Historial Clínico y exploración morfológica}

El protocolo de exploración clínica realizado a los sujetos incluidos en el presente estudio consta de un análisis de su historial clínico y una minuciosa exploración morfológica. 


\subsubsection{Historial Clínico}

Este análisis consiste en la adquisición de los datos de naturaleza epimediológica, como la edad, el género y la raza, así como un cuestionario basado en preguntas sobre la existencia de antecedentes familiares con esta patología, o cuestiones sobre antecedentes personales oftalmológicos como posibles tratamientos previos, $\mathrm{o}$ traumatismos oculares, cirugías previas, etc., con el fin de descartar la presencia de cualquier criterio previo de exclusión del estudio clínico.

Así mismo, se interrogó al paciente sobre la presencia de patologías sistemáticas que de alguna forma pudieran influir en la exploración oftalmológica, como enfermedades respiratorias, enfermedades cardiovasculares, hipertensión arterial, etc., así como tratamientos actuales o pasados.

\subsubsection{Exploración morfológica}

La exploración morfológica realizada a todos los sujetos incluyó un exhaustivo y completo examen ocular en donde se emplearon diferentes pruebas para valorar el estado de salud de los ojos estudiados. Todas estas exploraciones morfológicas fueron realizadas por un mismo examinador experimentado perteneciente a Vissum Corporación S.L., realizando tres medidas consecutivas sobre los ojos de los pacientes estudiados:

- Agudeza visual: se valoró la capacidad del ojo para reconocer detalles en un test. En el presente trabajo se midió la capacidad visual sin corregir o corregida (utilizando para la corrección unas gafas con la graduación pertinente), utilizando los optotipos de Snellen. Para el análisis de refracción se emplearon métodos objetivos y subjetivos. El objetivo se realizó empleando retinoscopia, y el subjetivo utilizando unas gafas de prueba y una caja de lentes.

- Tonometría de Goldman: mediante la misma se midió la presión intraocular (PIO), estimando la fuerza necesaria para aplanar un área de la córnea de 3.06 mm de diámetro.

- Biometría ocular: a través de esta prueba se calculó la medida de la longitud axial del globo ocular.

- Análisis topográfico corneal con el topógrafo Sirius (CSO, Italia): el topógrafo corneal Sirius (CSO, Italia) se caracteriza por presentar una buena repetitibilidad en la toma de medidas (Wang et al., 2012; Montalbán, 2013), y debido a la importancia de los datos aportados por este equipo para la realización de la presente tesis doctoral, también fueron realizadas tres medidas consecutivas de la córnea por un examinador experimentado para cada paciente perteneciente a los grupos de control.

El topógrafo corneal utilizado en este estudio utiliza el software Phoenix v1.2 (CSO, Italia), el cual permite exportar la medida realizada en tres formatos:

- CTV: formato específico para el software CTView. 
- XYZ: formato de archivo de texto que contiene las coordenadas cartesianas de captura xyz en una sola columna.

- CSV: archivo en formato Excel que contiene las coordenadas polares de captura xyz, permitiendo representar datos en forma de tabla donde los valores incluidos en las columnas van separados por comas y los valores de las filas por saltos de línea.

De los tres posibles formatos de exportación se seleccionó el formato csv, por presentar éste una distribución en filas y columnas más sencilla de interpretar y utilizar durante el estudio. Respecto a las tres medidas realizadas por el topógrafo, se seleccionó la medida correspondiente a la topografía corneal más completa, es decir, la topografía que aportó un mayor número de datos respecto las superficies de la cara anterior y posterior de la córnea.

\subsection{Metodología}

El procedimiento de diagnóstico presentado en esta tesis consta de dos etapas principales claramente diferenciadas (Figura 3.1): i) por un lado, a partir de la información proporcionada por el topógrafo corneal se lleva a cabo la reconstrucción geométrica 3D de la córnea, y ii) por otro lado, se realiza el cálculo de determinadas variables geométricas sobre el modelo obtenido que van a permitir clasificar la córnea analizada dentro un grupo de control $u$ otro.
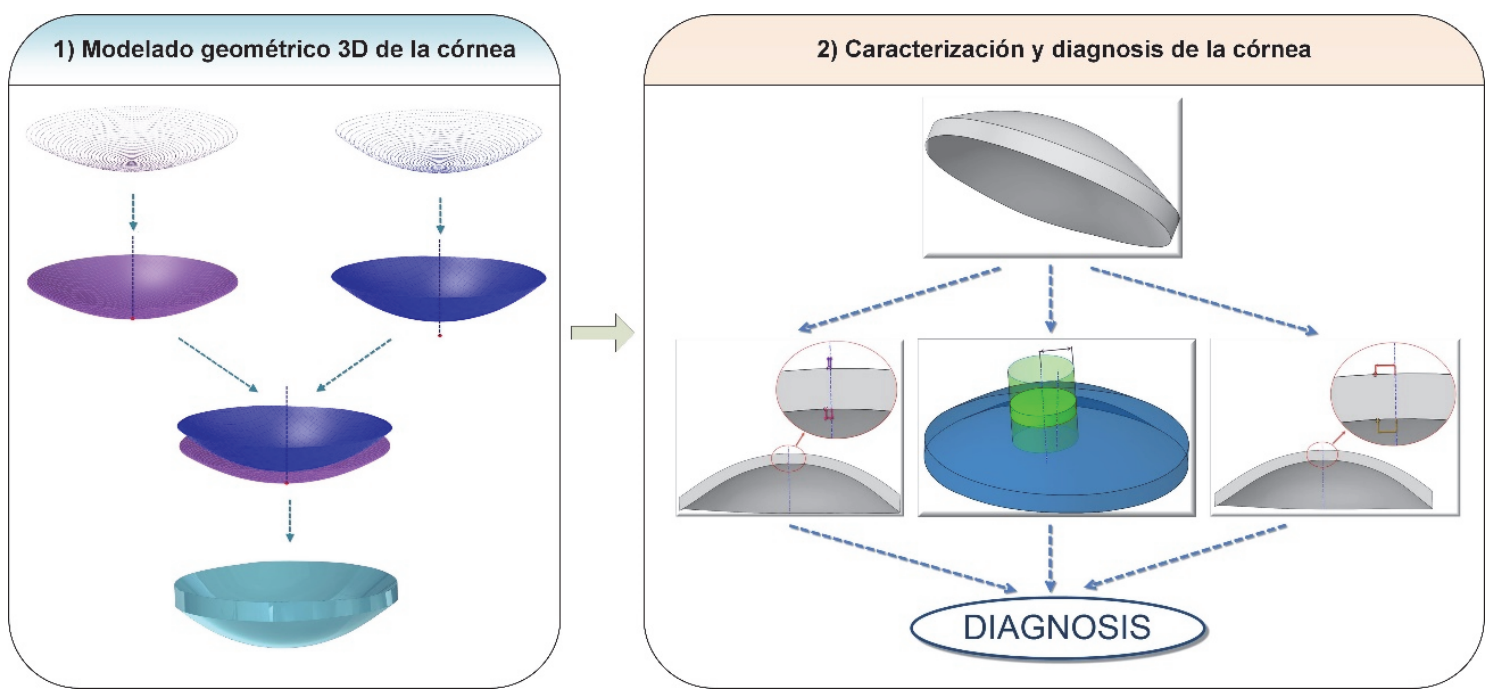

Figura 3.1 Etapas principales para el procedimiento de diagnóstico

\subsubsection{Reconstrucción geométrica $3 \mathrm{D}$ de la córnea}

El proceso de reconstrucción geométrica de la córnea se divide a su vez en varias etapas (Figura 3.2): i) Obtención de la nube de puntos representativa de las superficies de la córnea, ii) Reconstrucción geométrica de las superficies corneales, y iii) Generación del modelo sólido representativo de la córnea. 


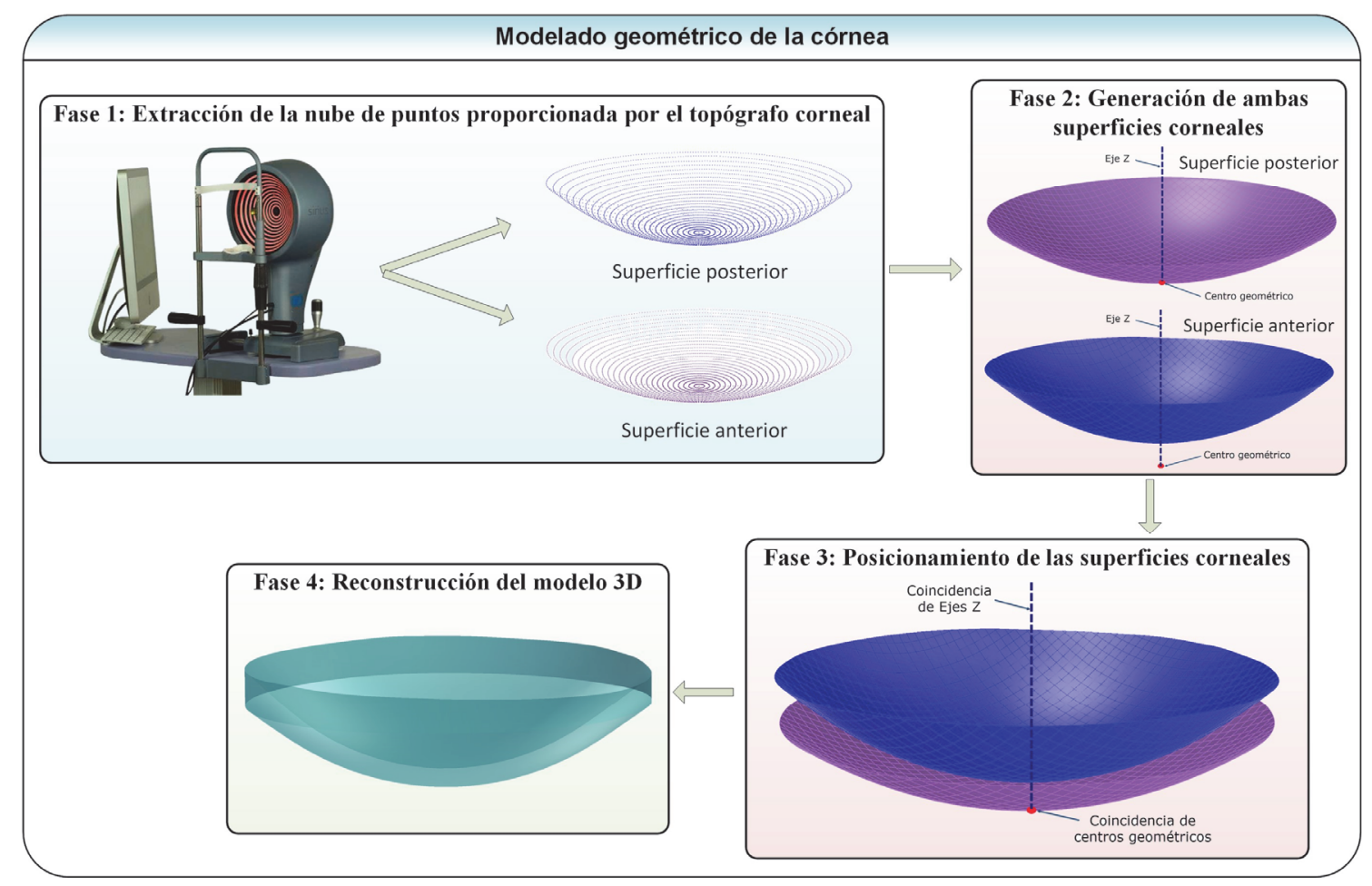

Figura 3.2 Esquema del procedimiento de reconstrucción geométrica 3D de la córnea

\subsubsection{Obtención de la nube de puntos}

El proceso de reconstrucción propuesto está basado en la generación de una superficie a partir de la geometría que presenta una nube de puntos en un sistema de coordenadas tridimensionales en el espacio, normalmente en formato de coordenadas cartesianas. Esta técnica de reconstrucción geométrica no es nueva en el ámbito de la ingeniería biomédica, habiendo sido utilizada ya con éxito en la reconstrucción de otras partes del cuerpo humano (Ding et al., 2010; Duan et al., 2012).

La reconstrucción de la nube de puntos de la geometría de las superficies de la cara anterior y posterior de la córnea fue obtenida mediante el topógrafo corneal Sirius (CSO, Italia).

Para ello se obtuvo inicialmente un fichero CSV para cada paciente del estudio, conteniendo cada fichero la siguiente información:

- Radios de los anillos de los Discos de Plácido (en mm). Esta medida comprende un total de 31 valores de radio tomados en intervalos de $0.2 \mathrm{~mm}$ y que cubren toda la región corneal, es decir, desde $r=0 \mathrm{~mm}$ hasta $\mathrm{r}=6 \mathrm{~mm}$.

- Datos altimétricos en bruto de elevación anterior (en $\mu \mathrm{m})$. Se trata de una matriz de elevaciones formada por 31 filas correspondientes a los 31 radios de los anillos de los Discos de Plácido, y por 256 columnas correspondientes a los 256 puntos que el topógrafo mide para cada anillo. En total la matriz aporta 7936 puntos de altimetría representativos de la superficie de la cara anterior de la córnea. 
- Datos altimétricos en bruto de elevación posterior (en $\mu \mathrm{m})$. Se trata de una matriz de elevaciones formada por 31 filas correspondientes a los 31 radios de los anillos de los Discos de Plácido, y por 256 columnas correspondientes a los 256 puntos que pueden ser medidos por cada anillo. En total la matriz aporta 7936 puntos de altimetría representativos de la superficie de la cara posterior de la córnea.

- Datos de grosor corneal (en $\mu \mathrm{m})$. Se trata de una matriz formada por 31 filas correspondientes a los 31 radios de los anillos de los Discos de Plácido, y por 256 columnas correspondientes a los 256 puntos que pueden ser medidos por cada anillo. En total la matriz aporta 7936 puntos de grosor corneal obtenido por diferencia entre los datos altimétricos en bruto de elevación anterior y los datos altimétricos en bruto de elevación posterior.

- Información adicional como mapas sagitales anterior/posterior de la córnea, mapas tangenciales y mapas de refracción, los cuales no son de interés para el estudio realizado en la presente tesis doctoral.

El topógrafo corneal Sirius (CSO, Italia) puede proporcionar los datos en bruto en forma de puntos espaciales que conforman las superficies corneales anterior y posterior, indicando las coordenadas de cada punto escaneado. Estos datos son proporcionados por el algoritmo de visión del topógrafo corneal al combinar, por un lado una imagen especular de un Disco de Plácido obtenido por reflexión sobre la superficie corneal, y por otro lado la imagen obtenida por la proyección de una hendidura de luz sobre la misma superficie corneal. Así pues los datos espaciales obtenidos son la información más fiable que se puede usar para el modelado geométrico, ya que no han sido manipulados o procesados por ningún algoritmo software interno del equipo (Ramos-López et al., 2011). Por este motivo, el procedimiento descrito en esta tesis emplea solamente datos en bruto.

Sin embargo, los datos proporcionados por el topógrafo en el fichero CSV están representados en formato polar, donde cada fila representa un círculo o anillo en el mapa, y cada columna representa un semi-meridiano, proporcionando 256 puntos para cada uno de los radios de la córnea (desde $\mathrm{r}=0$ hasta $6 \mathrm{~mm}$ en intervalos de $0.2 \mathrm{~mm}$ ) (Figura 3.3). Así pues, cada i-ésima fila muestrea un mapa sobre un círculo de radio $i^{*} 0.2 \mathrm{~mm}$ y cada j-ésima columna muestrea un mapa sobre un semi-meridiano en la dirección $j^{*} 360 / 256^{\circ}$, por lo que cada valor $\mathrm{Z}$ de la matriz [i, j] representa el punto $\mathrm{P}$ $\left(i^{*} 0.2, j^{*} 360 / 256^{\circ}\right)$ en coordenadas polares.

Con el fin de poder convertir los datos proporcionados por el CSV en formato polar a una nube de puntos en formato cartesiano $(X, Y, Z)$ representativa de ambas superficies corneales anterior y posterior, se implementó una macro en el software Microsoft Excel que permitió esta conversión de forma totalmente automatizada para cada fichero CSV de los pacientes estudiados, generándose dos nuevos ficheros: un fichero CSV para la cara anterior y otro fichero CSV para la cara posterior (Figura 3.4). 
Durante el proceso de conversión se pudo comprobar que no todos los puntos proporcionados por el fichero CSV representaban correctamente las superficies corneales anterior y posterior, ya que se detectaron algunos puntos cuyo valor en altura aparecía con el valor $Z=-1000$, lo que mostraba que el punto no había sido escaneado correctamente.

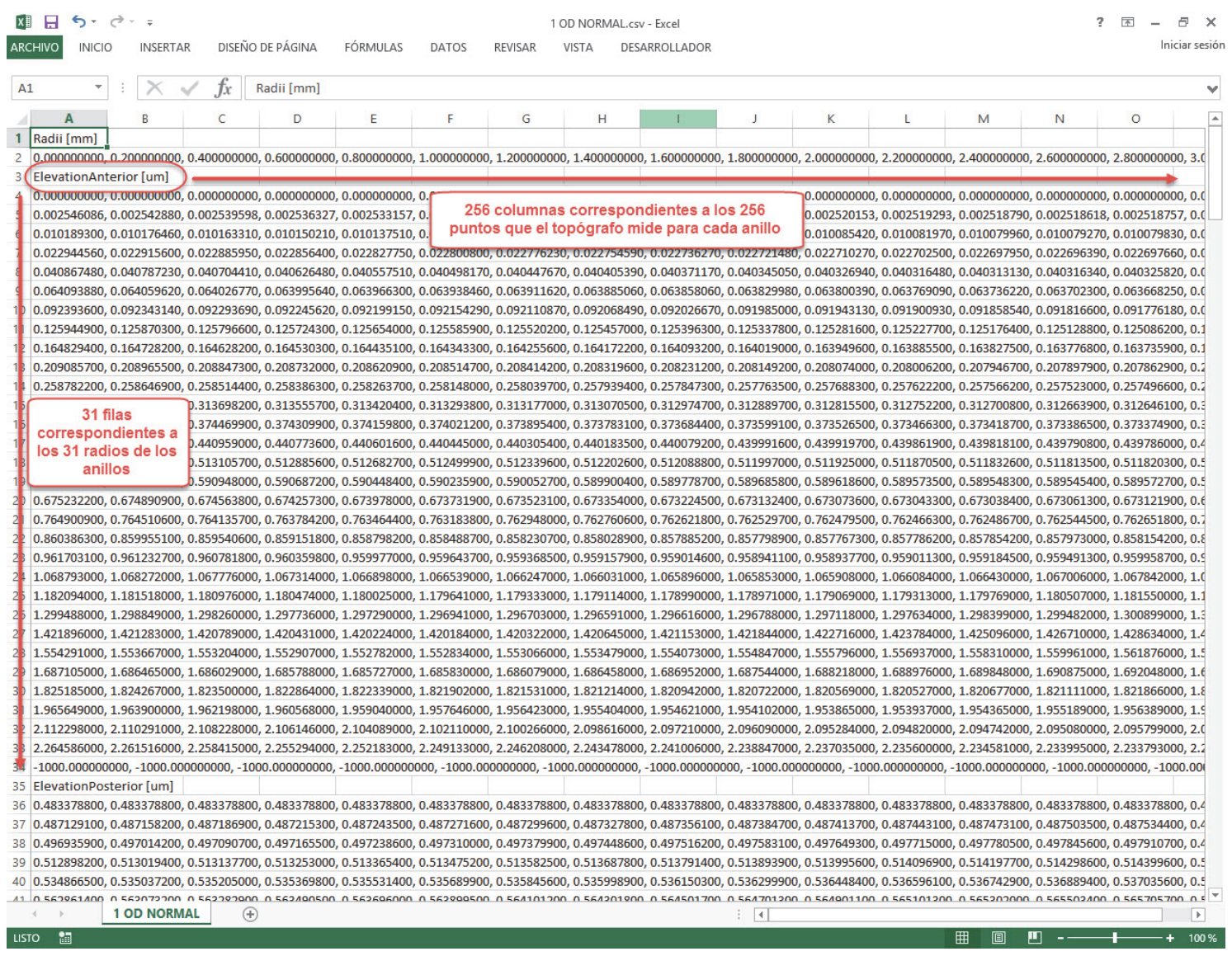

Figura 3.3 Representación de los datos en formato polar en el fichero CSV proporcionado por el topógrafo corneal Sirius 


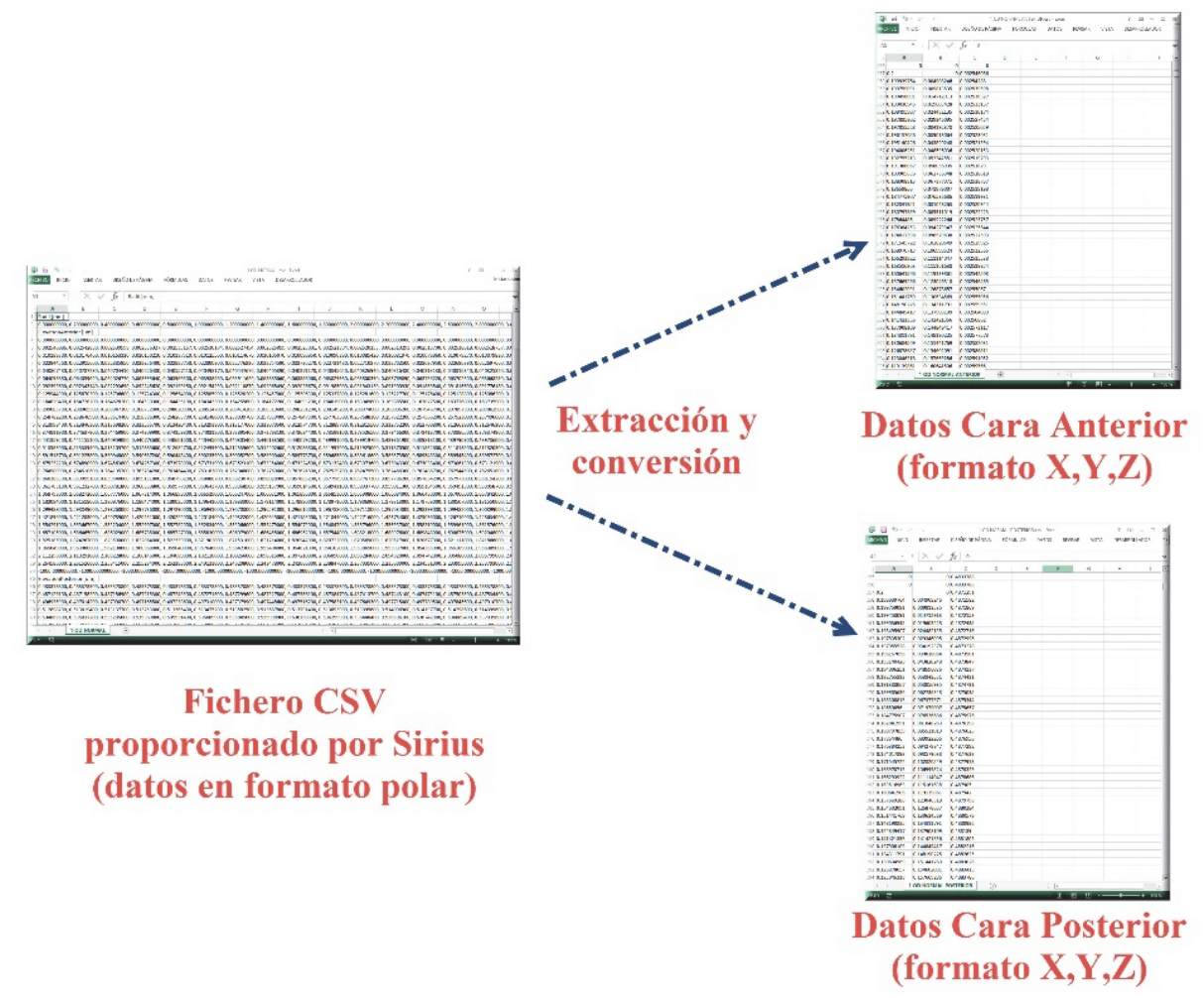

Figura 3.4 Extracción y conversión de datos a partir del fichero CSV proporcionado por el topógrafo corneal Sirius

Este hecho demuestra algo que ya se sabía previamente, y es que el topógrafo corneal Sirius (CSO, Italia) presenta una baja densidad de datos en la zona geográfica de la córnea denominada región periférica (radio entre $4 \mathrm{~mm}$ y $5.5 \mathrm{~mm}$ ) y en el limbo (radio de $6 \mathrm{~mm}$ ) como consecuencia del tiempo empleado para la rotación y la adquisición de los datos.

Esta pérdida de rendimiento del dispositivo está causada por la presencia de factores extrínsecos del paciente durante el proceso de medida, como la estabilidad de la película lagrimal, o una obstrucción del campo visual por las pestañas o por una apertura palpebral insuficiente en el momento de toma de datos. Esto condujo al desarrollo de un procedimiento de reconstrucción geométrica que comprendiera únicamente la superficie corneal desde su centro geométrico $(\mathrm{r}=0 \mathrm{~mm})$ hasta el principio de la denominada región periférica $(\mathrm{r}=4 \mathrm{~mm})$, lo que viene justificado principalmente por los siguientes motivos:

- Principio geométrico. El topógrafo corneal Sirius permite obtener todos los puntos que conforman la geometría de la córnea en la región definida para la reconstrucción ( $\mathrm{r}=0$ a $4 \mathrm{~mm}$ ). Concretamente, se obtuvieron 10752 puntos espaciales correspondientes a ambas superficies corneales anterior y posterior (5376 puntos para cada una) para cada paciente de la población objeto de estudio, incluyendo tanto casos de córneas sanas como enfermas.

- Principio clínico. Se considera que la superficie corneal definida para el estudio $(\mathrm{r}=0$ a $4 \mathrm{~mm})$ presenta una mayor información sobre la morfología corneal tanto 
para ojos sanos como para ojos enfermos. Esta región incluye tanto la denominada zona central ( $\mathrm{r}=0$ a $2 \mathrm{~mm}$ ), que corresponde a la zona más esférica y con mayor repercusión visual y concentra el $25 \%$ de los casos de queratocono, como la denominada zona paracentral ( $\mathrm{r}=2$ a $4 \mathrm{~mm}$ ), que corresponde a la zona donde empieza a aplanarse la córnea y que concentra el $72 \%$ de los casos de queratocono (Wilson et al., 1991). En total la región objeto de reconstrucción geométrica ( $\mathrm{r}=0$ a $4 \mathrm{~mm}$ ) presenta niveles de irregularidad en su morfología corneal tanto de la cara anterior como de la cara posterior y engloba al $97 \%$ de los casos de queratocono.

Así pues, una vez obtenida la nube de puntos representativa de ambas superficies corneales desde $\mathrm{r}=0 \mathrm{~mm}$ hasta $\mathrm{r}=4 \mathrm{~mm}$, el siguiente paso es importar dicha nube de puntos en un software que nos permita reconstruir con gran fiabilidad y precisión dichas superficies.

\subsubsection{Reconstrucción geométrica de las superficies corneales}

La nube de puntos representativa de la geometría de la córnea es importada posteriormente mediante un software de reconstrucción de superficies denominado Rhinoceros ${ }^{\circledR}$ v5.0, importando los dos ficheros CSV creados en la etapa anterior para cada superficie corneal (Figura 3.5). Este software utiliza un modelo matemático para generar superficies basándose en non-uniform rational B-spline (NURBS) (Piegl \& Tiller, 1997), donde la superficie generada a partir de esos puntos espaciales se caracteriza por presentar una evolución en dos direcciones paramétricas u y v. Además, este tipo de superficies son invariantes bajo transformaciones afines, o de perspectiva, proporcionando flexibilidad para diseñar una gran variedad de superficies con un bajo consumo computacional en comparación con otros métodos.

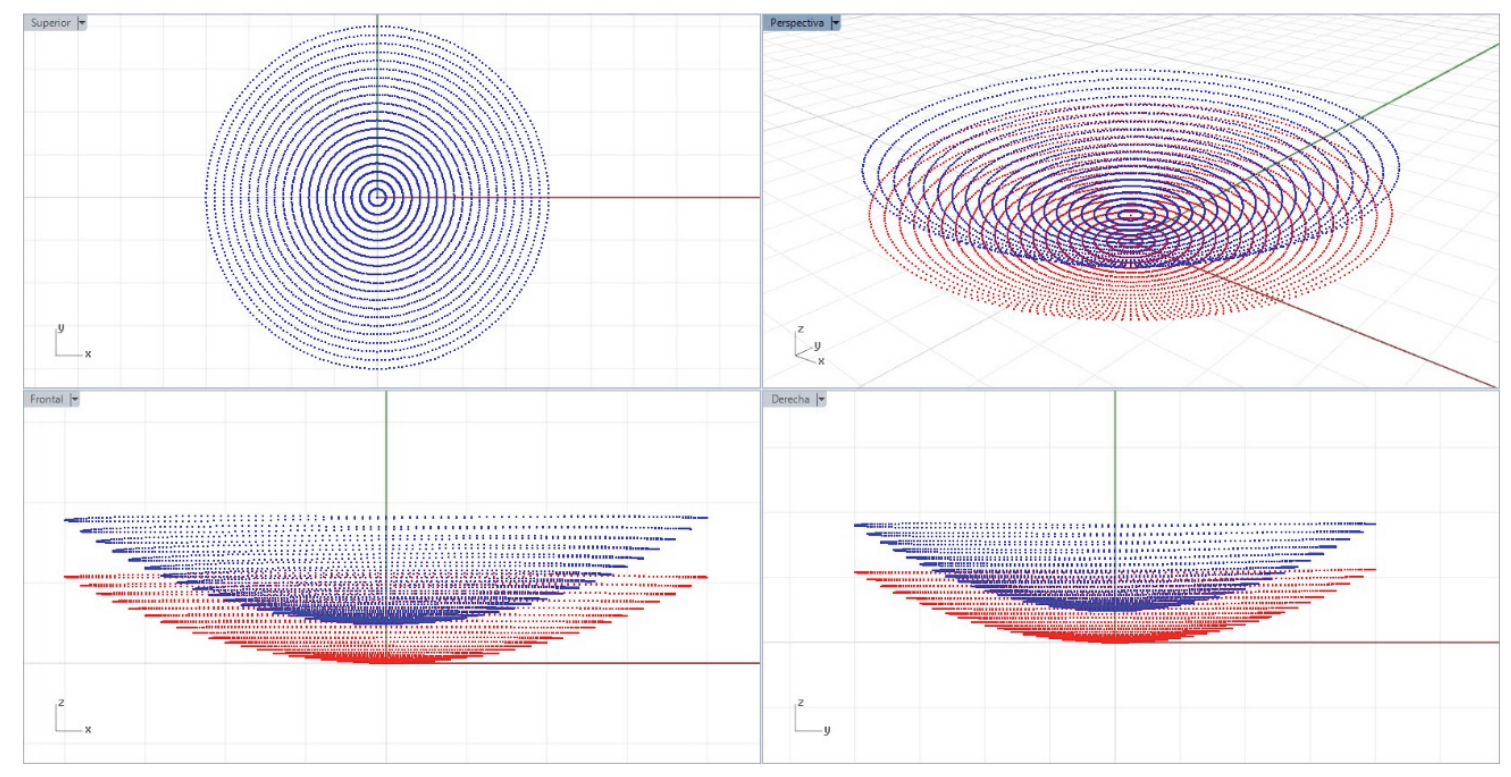

Figura 3.5 Importación de las nubes de puntos correspondientes a ambas superficies corneales 


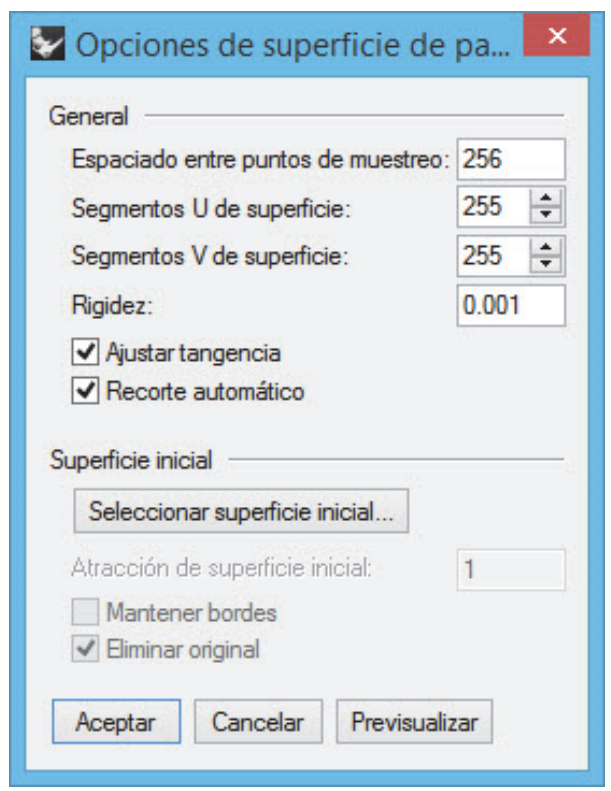

Figura 3.6 Configuración de la función "Parche" para reconstrucción de superficies

De entre las diversas funciones de las que dispone el software, la función de reconstrucción de superficie denominada "Parche" es la que produce un mejor ajuste a la nube de puntos proporcionada. Se trata de una función de reconstrucción que ajusta una superficie mediante curvas, mallas, objetos puntuales y nubes de puntos previamente proporcionadas (Cheng, 2014). Para el caso concreto de esta investigación, esta función trata de minimizar la distancia nominal entre la nube de puntos espaciales y la superficie solución. Para ello, se configuró (Figura 3.6) fijando el espaciado entre puntos de muestreo a 256 (número de puntos por cada anillo de datos), se definieron 255 segmentos de superficie para ambas direcciones U y V (el número máximo de segmentos que el software permite), y la rigidez de la superficie solución a $10^{-3} \mathrm{~mm}$, parámetro que proporciona información acerca de cuánto puede deformarse el plano de mejor ajuste de forma que se garantice que contiene a los puntos de entrada.

Una vez aplicada la función de reconstrucción "Parche" sobre las nubes de puntos de ambas superficies corneales se obtuvieron dos superficies similares a las mostradas en la Figura 3.7. Tal y como se puede apreciar en dicha figura, se genera una superficie rectangular que se ajusta a la nube de puntos proporcionada para cada cara de la córnea, por lo que se hace necesario recortar dicha superficie al área de estudio donde se poseen puntos escaneados de la córnea (desde $r=0 \mathrm{~mm}$ hasta $\mathrm{r}=4 \mathrm{~mm}$ ). Esto se consigue colocando un cilindro de radio $\mathrm{r}=4 \mathrm{~mm}$ y de una altura determinada con su eje $\mathrm{Z}$ coincidente con el de ambas superficies (Figura 3.8). Posteriormente se realiza el recorte de ambas superficies corneales utilizando el cilindro creado, obteniéndose así las superficies definitivas correspondientes a ambas caras de la córnea con radio $\mathrm{r}=4$ mm (Figura 3.9). 


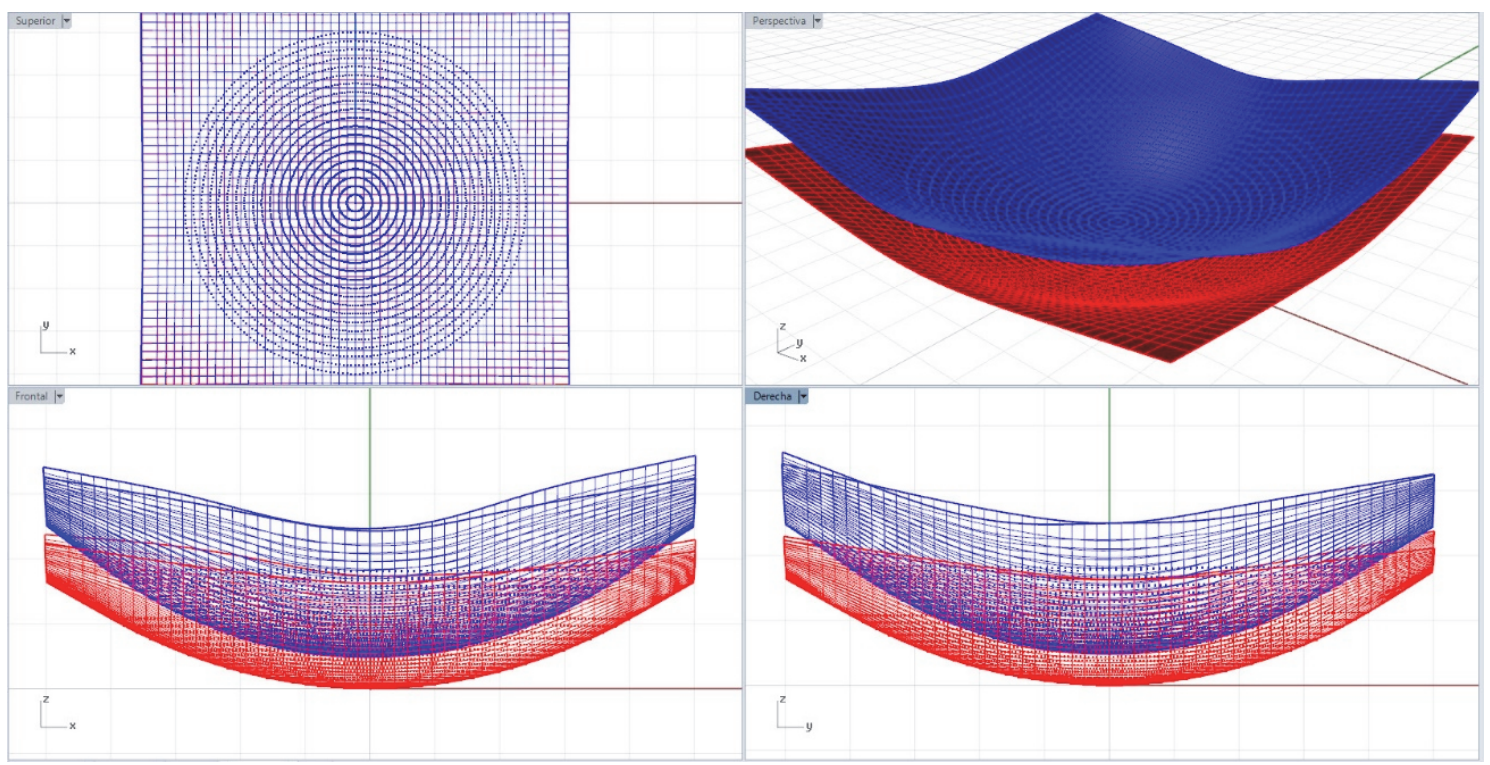

Figura 3.7 Resultado tras aplicar la función "Parche" sobre las nubes de puntos de ambas superficies corneales

Para comprobar la desviación existente entre la superficie finalmente reconstruida y la nube de puntos empleada para su generación existe una función en el software Rhinoceros ${ }^{\circledR}$ denominada "Desviación de nube de puntos" que nos permite calcular el valor promedio del error de distancia para la superficie solución respecto la nube de puntos empleada para su generación.

Esto puede observarse en la Figura 3.10a, donde se representa la vista superior de la nube de puntos de la cara anterior de una córnea sana y se obtiene un error de distancia promedio de $7.23 \times 10^{-6} \pm 1.536 \times 10^{-5} \mathrm{~mm}$ (media \pm desviación standard).

En el caso de la Figura 3.10b. se muestra el error de desviación para la cara anterior de una córnea con queratocono en estado avanzado, obteniéndose en este caso un error de distancia promedio de $3.54 \times 10^{-4} \pm 6.36 \times 10^{-4} \mathrm{~mm}$ (media \pm desviación standard).

En ambas figuras se configuraron los mismos valores de umbral para considerar los puntos como válidos o como no válidos, fijando $10^{-3} \mathrm{~mm}$ para los puntos no válidos (en rojo) y $10^{-4} \mathrm{~mm}$ para los puntos válidos (en azul). Estas figuras muestran a su vez cómo los puntos se distribuyen en anillos circulares perfectos con radios desde $\mathrm{r}=0 \mathrm{~mm}$ hasta $\mathrm{r}=4 \mathrm{~mm}$ en intervalos de $0.2 \mathrm{~mm}$. Esto se debe, tal y como se ha mencionado previamente, a la conversión de los datos proporcionados por el topógrafo corneal en formato polar a formato cartesiano $[X, Y, Z]$. 


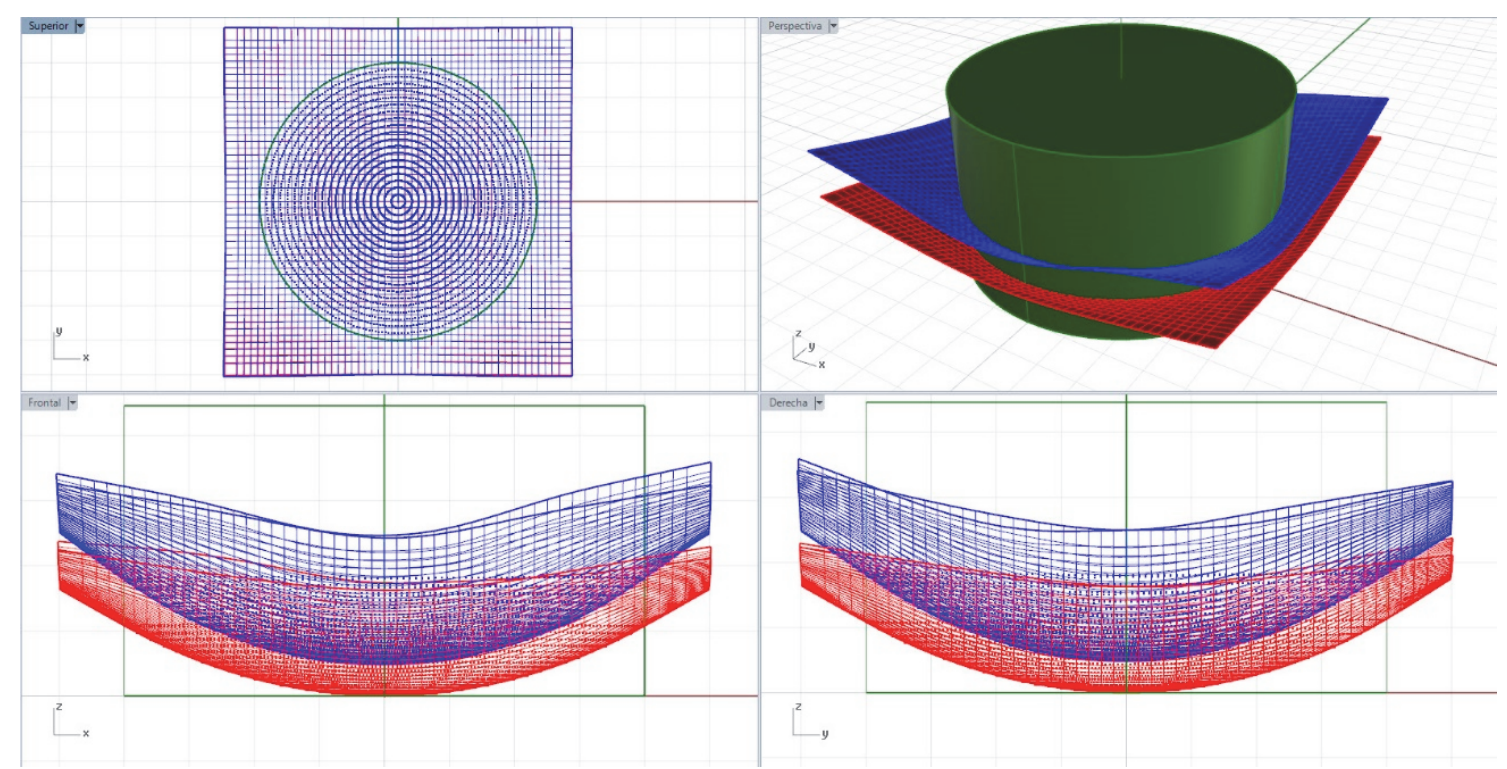

Figura 3.8 Posicionamiento de un cilindro de radio $r=4 \mathrm{~mm}$ para recortar las superficies generadas por la función "Parche"

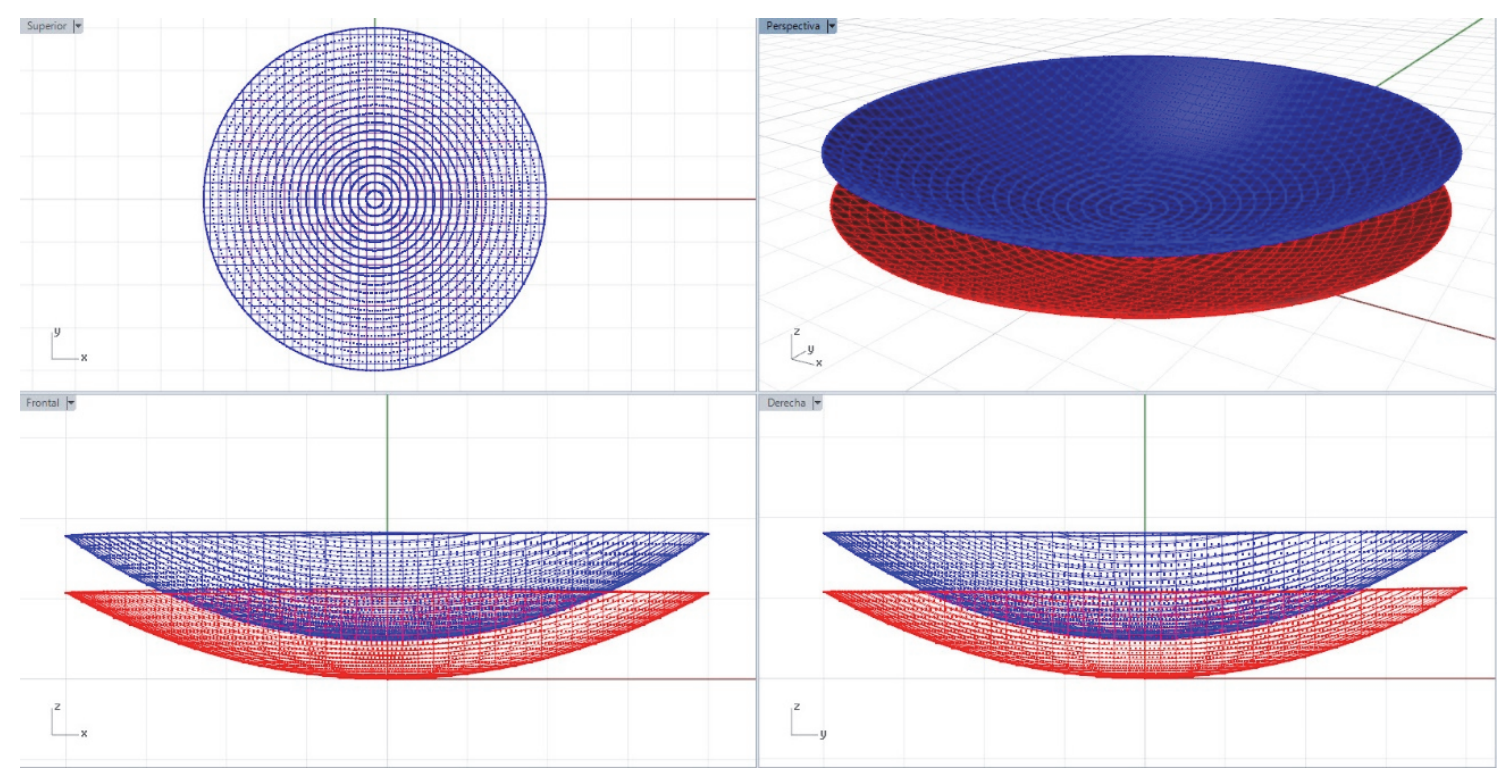

Figura 3.9 Superficies definitivas tras aplicar el recorte con el cilindro a las superficies generadas con la función "Parche" 


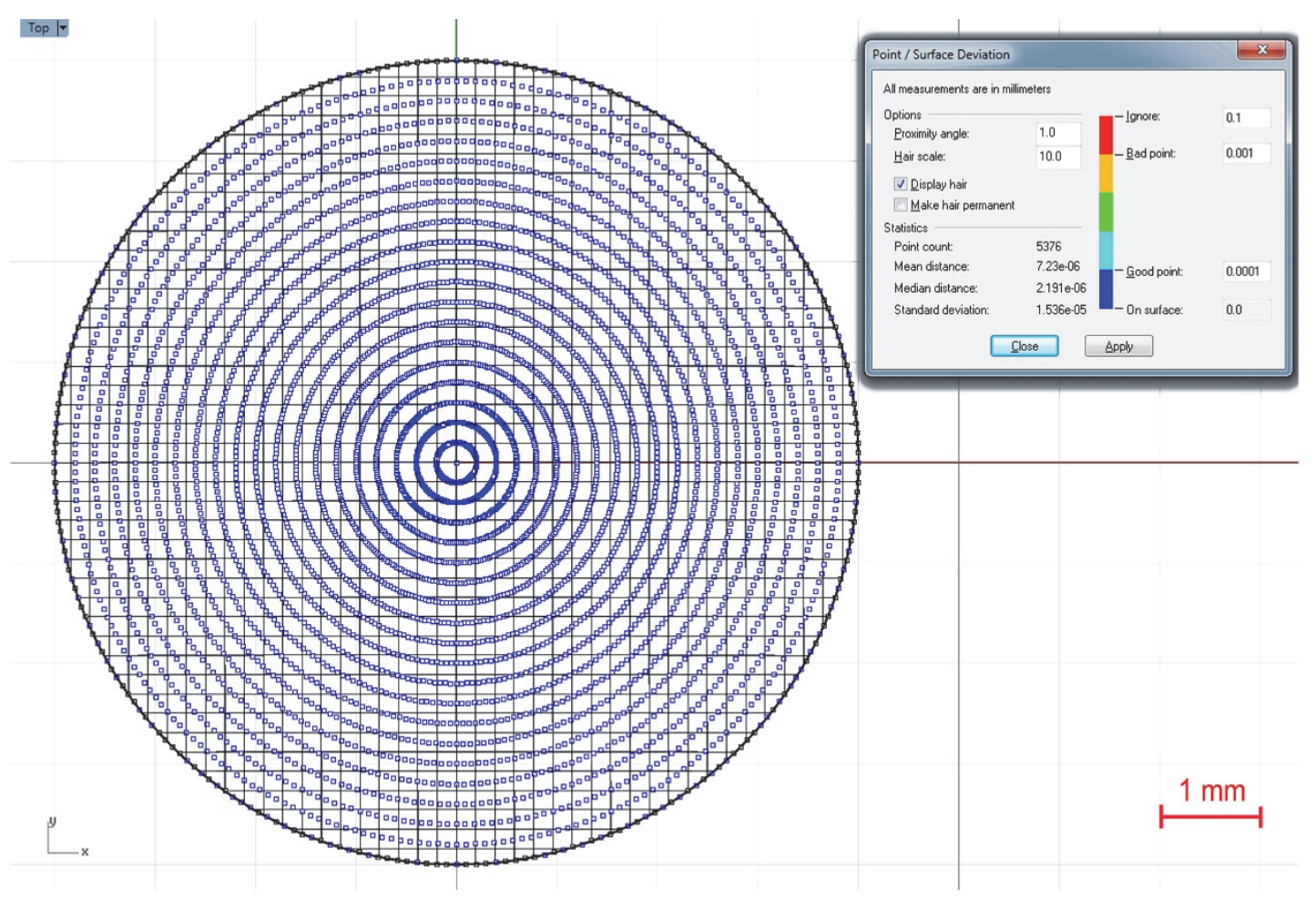

a)

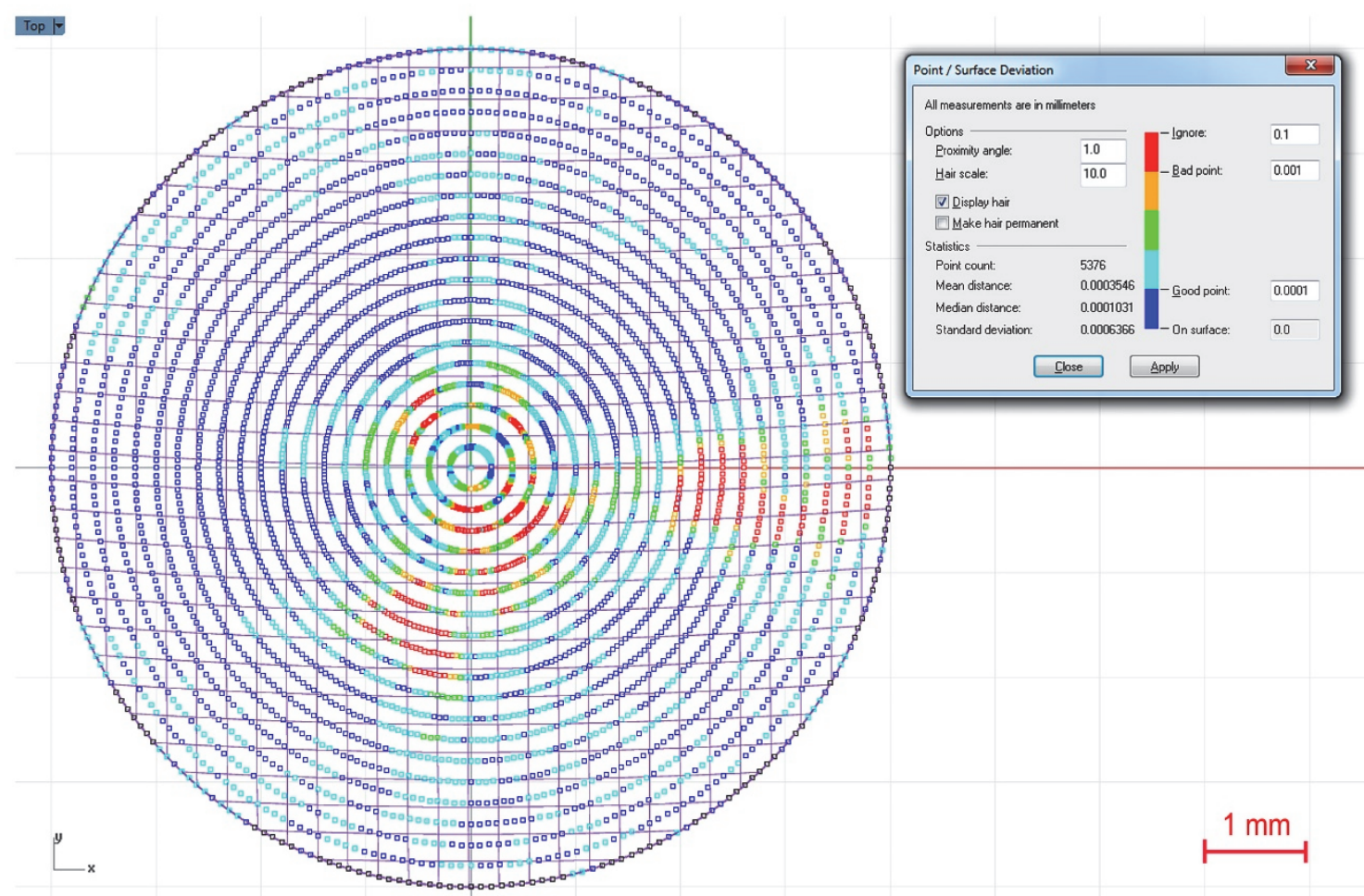

b)

Figura 3.10 Análisis de la desviación punto-superficie para la reconstrucción de la cara anterior de: a) una córnea sana, b) una córnea con queratocono en estado avanzado 
Mediante el procedimiento descrito se generaron las superficies de la cara anterior y la cara posterior de la córnea, quedando éstas acopladas por su centro geométrico respecto el eje Z (Figura 3.9). Posteriormente, se obtuvo la superficie perimetral (superficie de unión entre ambas caras en la dirección del eje Z), usando para el ello el cilindro con $\mathrm{r}=4 \mathrm{~mm}$ creado anteriormente para el recorte (Figura 3.11). Finalmente se unieron las tres superficies conformando una única superficie que comprende el objeto de estudio.

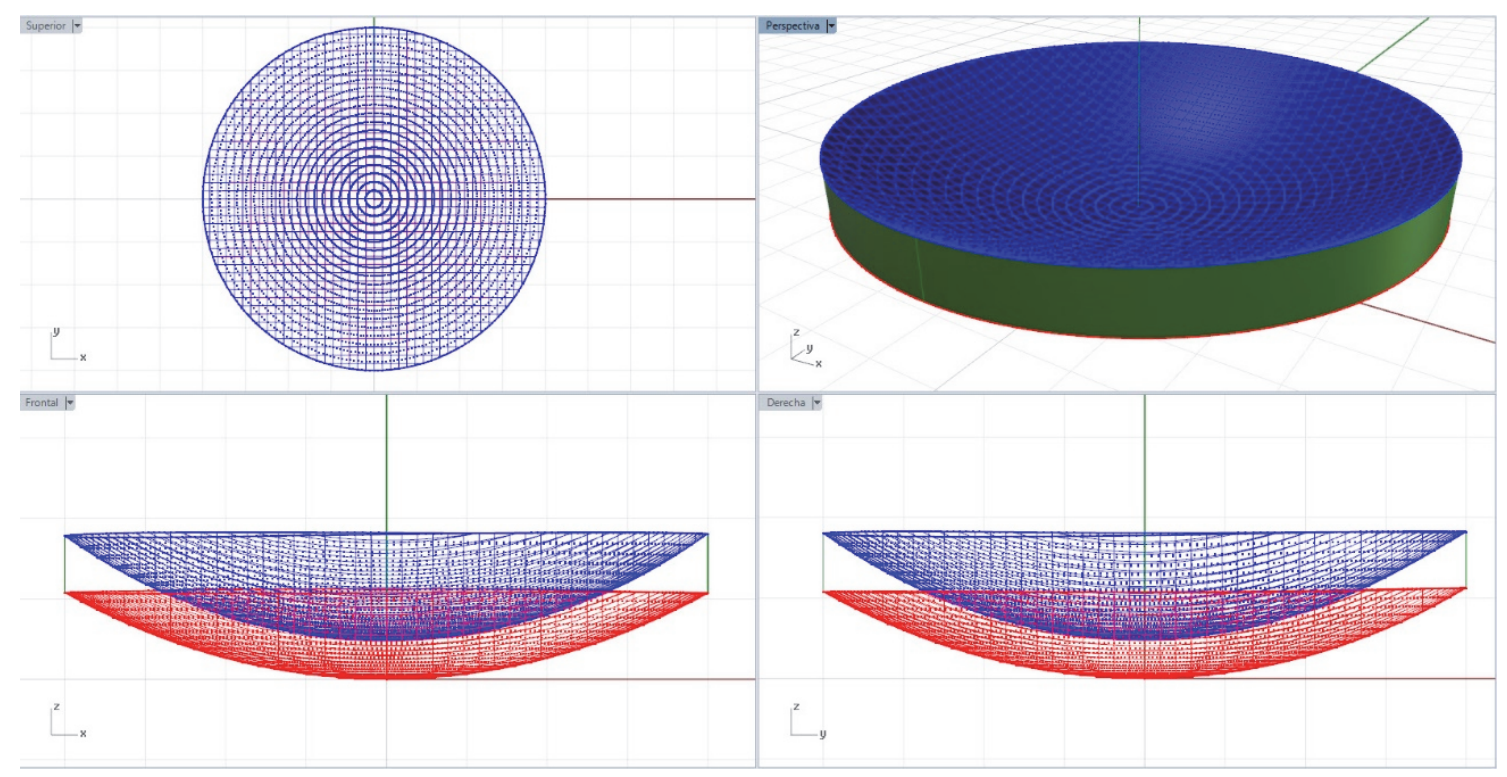

Figura 3.11 Creación de la superficie perimetral y unión de las tres superficies en una única

\subsubsection{Generación del modelo sólido de la córnea}

La superficie obtenida mediante Rhinoceros ${ }^{\circledR}$ fue posteriormente importada usando el software de modelado sólido SolidWorks ${ }^{\circledR}$ v2014, el cual permitió generar el modelo sólido representativo de la geometría real y personalizada de la córnea (Figura 3.12). Teniendo en cuenta todos los aspectos anteriormente mencionados acerca de los datos empleados para la reconstrucción del modelo, es importante recordar que los modelos sólidos se reconstruyeron hasta un radio de $4 \mathrm{~mm}$. De esta forma, cualquier caso de estudio en el cual los datos proporcionados por el topógrafo corneal Sirius tuviera algún punto erróneo (mal capturado) hasta el radio $\mathrm{r}=4 \mathrm{~mm}$ fue descartado del estudio.
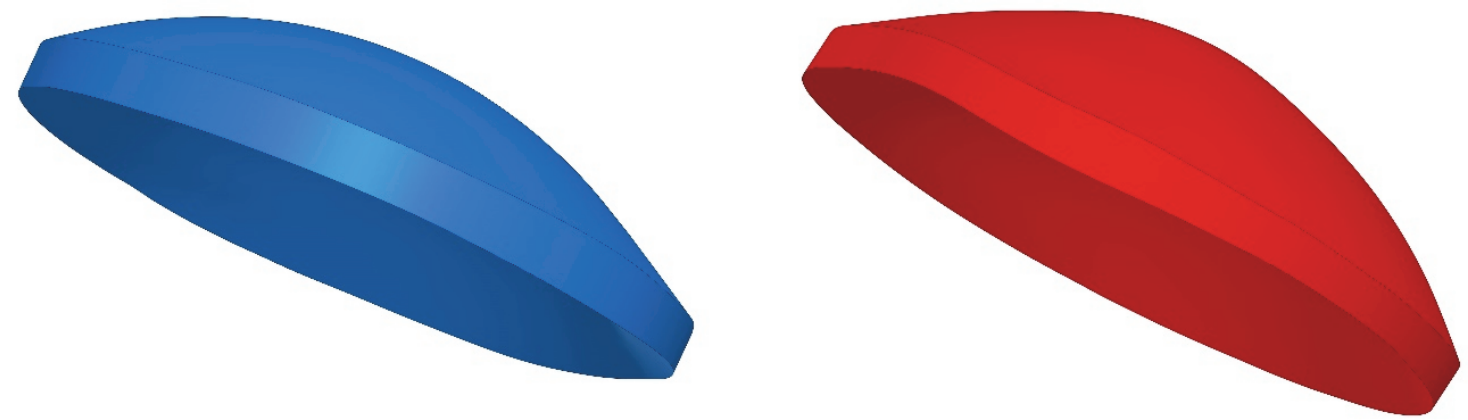

Figura 3.12 Modelos sólidos 3D de una córnea sana (en azul) y una córnea con queratocono (en rojo) generados mediante el software Solidworks ${ }^{\circledR}$ 


\subsubsection{Caracterización y diagnosis de la córnea}

Una vez obtenido el modelo sólido 3D de la córnea objeto de estudio, se realiza sobre dicho modelo el cálculo de determinadas variables geométricas que van a permitir caracterizar la córnea analizada y diagnosticar si se trata de una córnea sana o por el contrario, presenta algún grado de la ectasia corneal definida como queratocono.

A continuación se describen todas las variables geométricas calculadas de forma detallada.

\subsubsection{Volumen corneal total}

Se define la variable "Volumen total corneal" (en $\mathrm{mm}^{3}$ ) como el volumen comprendido entre las superficies anterior, posterior y perimetral del modelo sólido generado de la córnea (Figura 3.12).

\subsubsection{2Área de la superficie corneal anterior}

Se define la variable "Área de la superficie corneal anterior" (en $\mathrm{mm}^{2}$ ) como el área ocupada por la superficie corneal anterior/exterior. La Figura 3.13 muestra esta variable (en color verde) tanto para una córnea sana (en color azul) como para una córnea con queratocono (en color rojo).
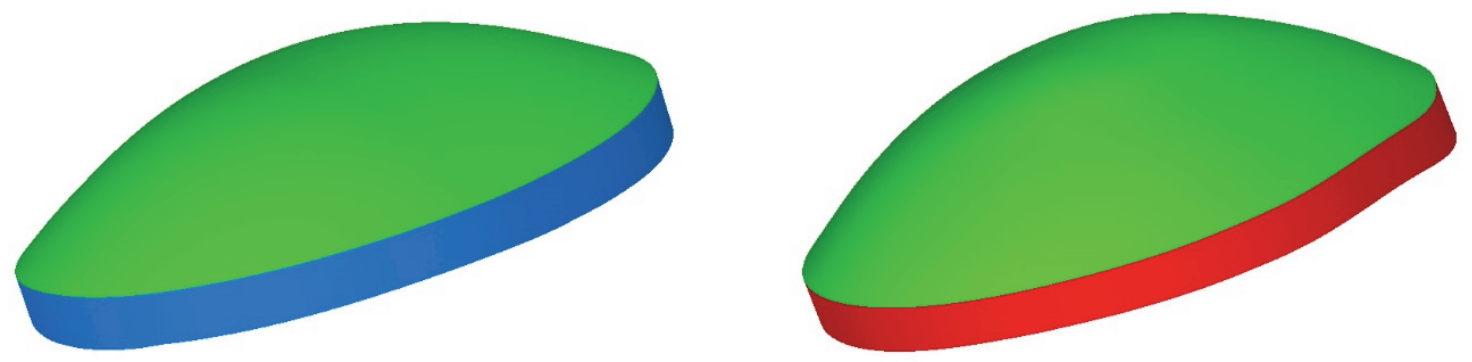

Figura 3.13 Área de la superficie corneal anterior (en verde) calculada en una córnea sana (en azul) y en una córnea con queratocono (en rojo)

\subsubsection{3 Área de la superficie corneal posterior}

Se define la variable "Área de la superficie corneal posterior" (en $\mathrm{mm}^{2}$ ) como el área ocupada por la superficie corneal posterior/interior. La Figura 3.14 muestra esta variable (en color verde) tanto para una córnea sana (en color azul) como para una córnea con queratocono (en color rojo).
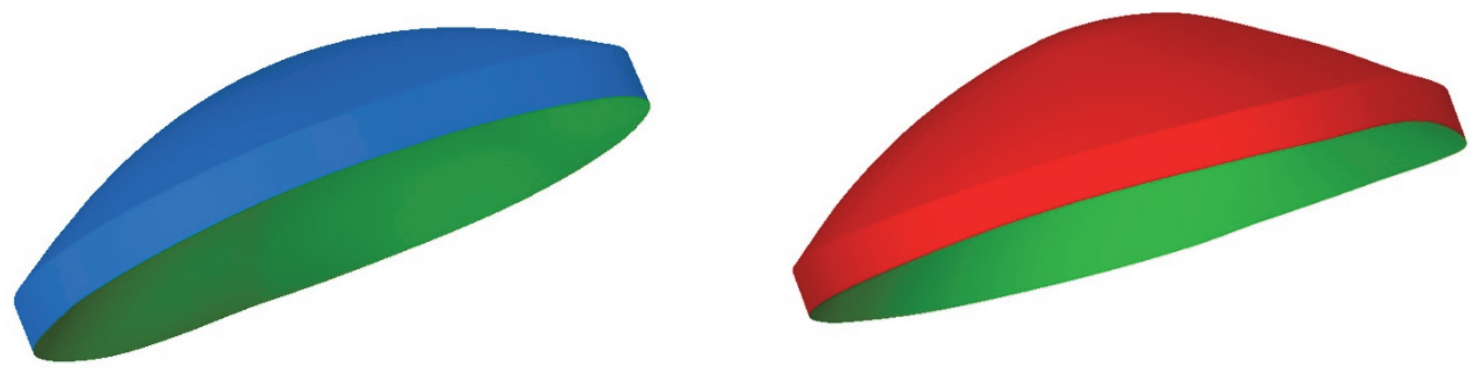

Figura 3.14 Área de la superficie corneal posterior (en verde) calculada en una córnea sana (en azul) y en una córnea con queratocono (en rojo) 


\subsubsection{4Área de la superficie corneal total}

Se define la variable "Área de la superficie corneal total" (en $\mathrm{mm}^{2}$ ) como la suma del área que comprende las superficies corneales anterior, posterior y perimetral del modelo sólido generado.

\subsubsection{5 Área del plano sagital que pasa por el ápex}

Se define la variable "Área del plano sagital que pasa por el ápex" (en $\mathrm{mm}^{2}$ ) como el área de la córnea comprendida en el plano sagital que pasa por el eje $Z$ y el punto de mayor altura (ápex) de la superficie anterior de la córnea. En la Figura 3.15 se muestra esta variable (en color verde) tras realizar un corte tridimensional de la córnea por el plano sagital que pasa por el eje $\mathrm{Z}$ y por el ápex de la cara anterior, tanto para una córnea sana (en azul) como para una córnea con queratocono (en rojo).
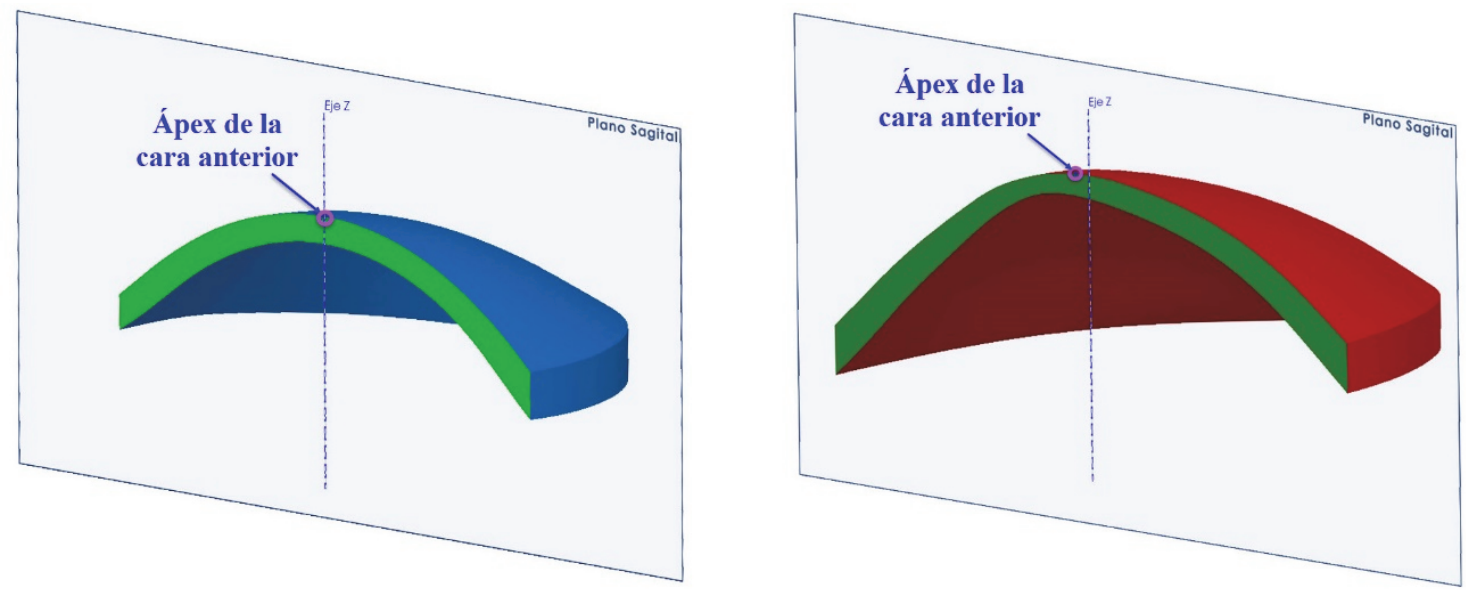

Figura 3.15 Área del plano sagital que pasa por el ápex anterior (en verde) calculada en una córnea sana (en azul) y en una córnea con queratocono (en rojo)

\subsubsection{Desviación del ápex anterior}

Se define la variable "Desviación del ápex anterior" (en $\mathrm{mm}$ ) como la distancia desde el eje $\mathrm{Z}$ al punto de mayor altura (ápex) de la superficie corneal anterior (Figura 3.16).

\subsubsection{Desviación del ápex posterior}

Se define la variable "Desviación del ápex posterior" (en $\mathrm{mm}$ ) como la distancia desde el eje $\mathrm{Z}$ al punto de mayor altura (ápex) de la superficie corneal posterior (Figura 3.17). 

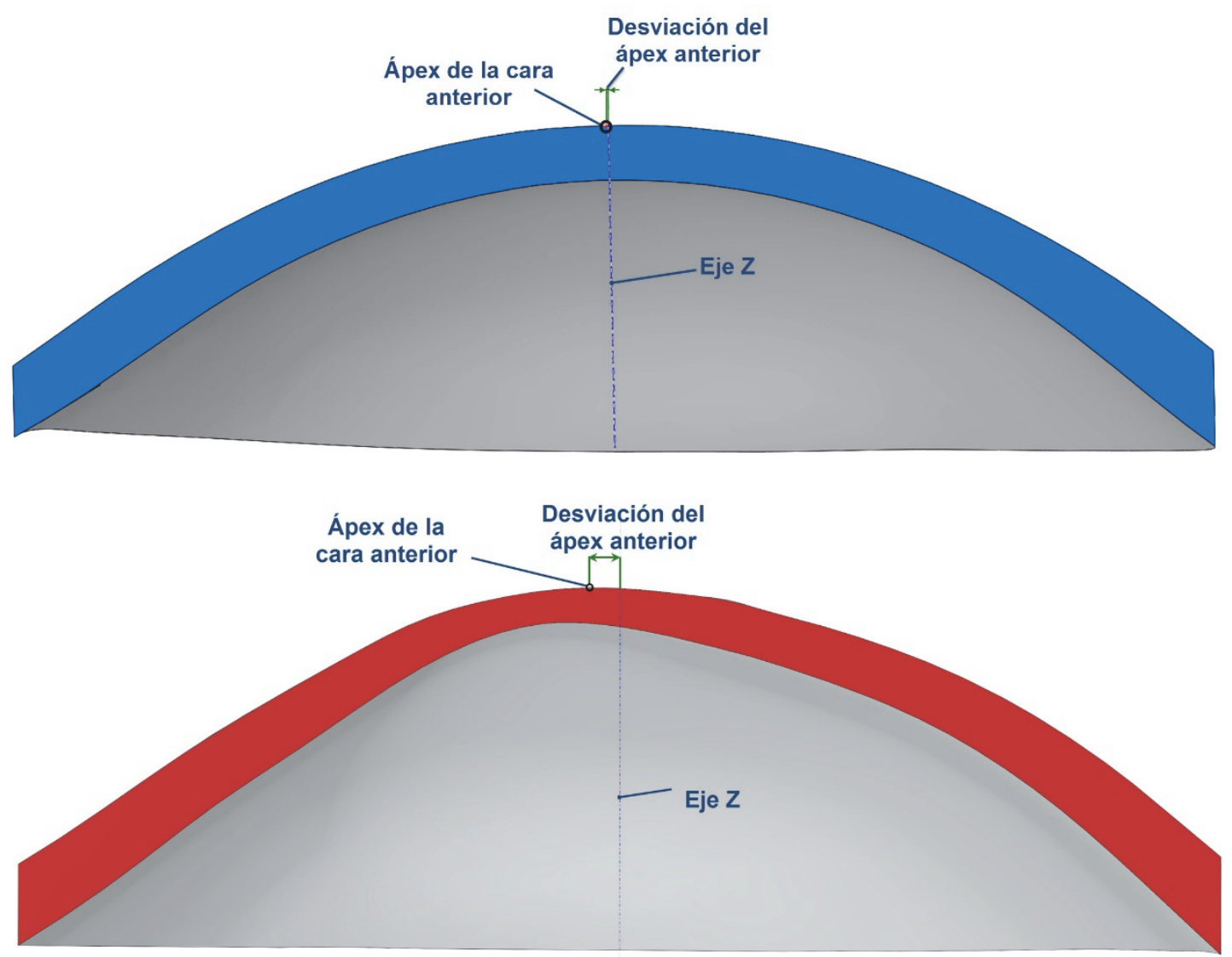

Figura 3.16 Desviación del ápex anterior calculada para una córnea sana (en azul) y para una córnea con queratocono (en rojo)
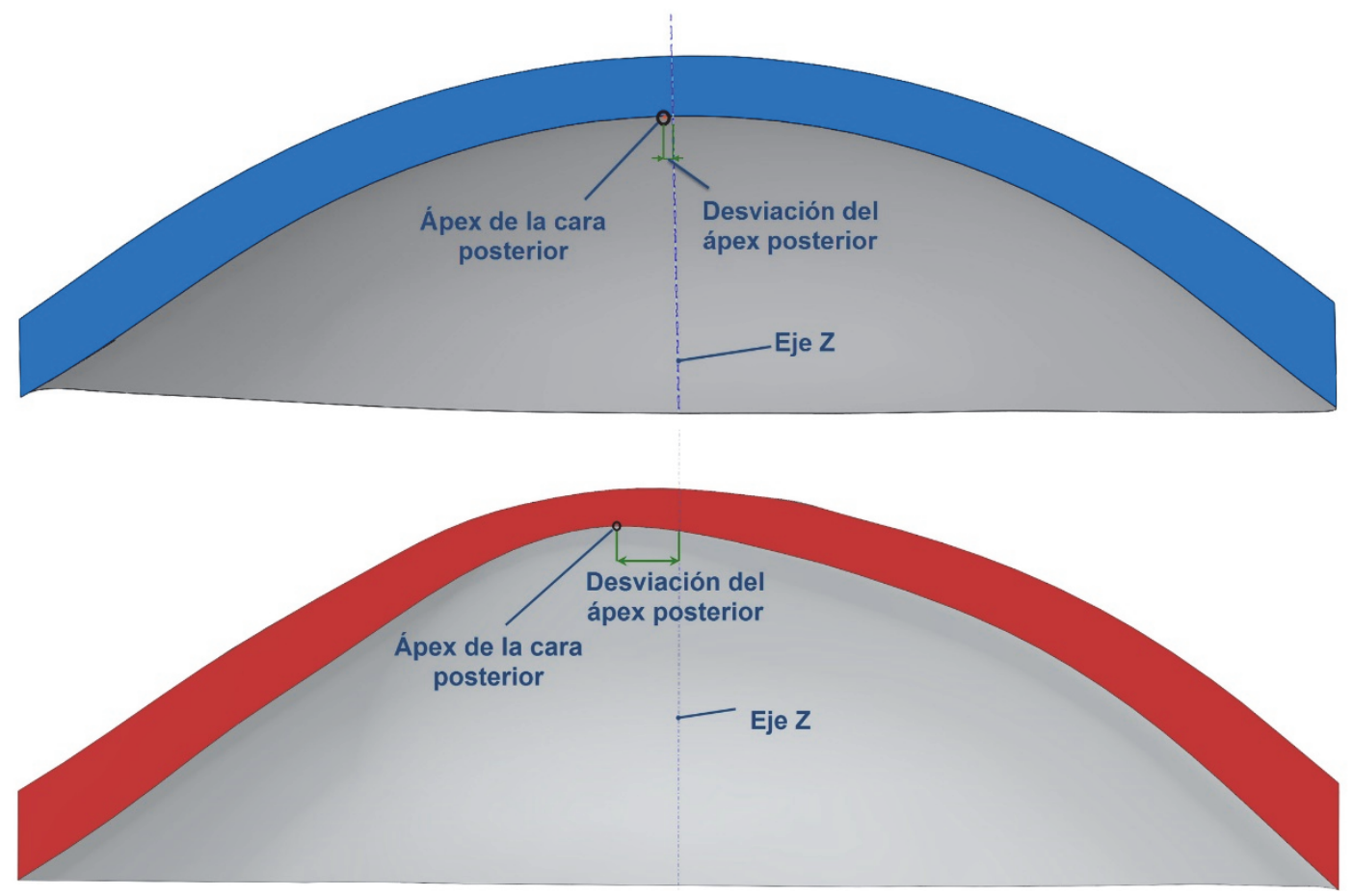

Figura 3.17 Desviación del ápex posterior calculada para una córnea sana (en azul) y para una córnea con queratocono (en rojo) 


\subsubsection{8Área del plano sagital que pasa por el punto de mínimo espesor anterior}

Se define la variable "Área del plano sagital que pasa por el punto de mínimo espesor" $\left(\right.$ en $\mathrm{mm}^{2}$ ) como el área de la córnea comprendida en el plano sagital que pasa por el eje Z y el punto de mínimo espesor (máxima curvatura) de la cara anterior de la córnea. En la Figura 3.18 se muestra esta variable (en color verde) tras realizar un corte tridimensional de la córnea por el plano sagital que pasa por el eje $\mathrm{Z}$ y por el punto de mínimo espesor de la cara anterior, tanto para una córnea sana (en azul) como para una córnea con queratocono (en rojo).
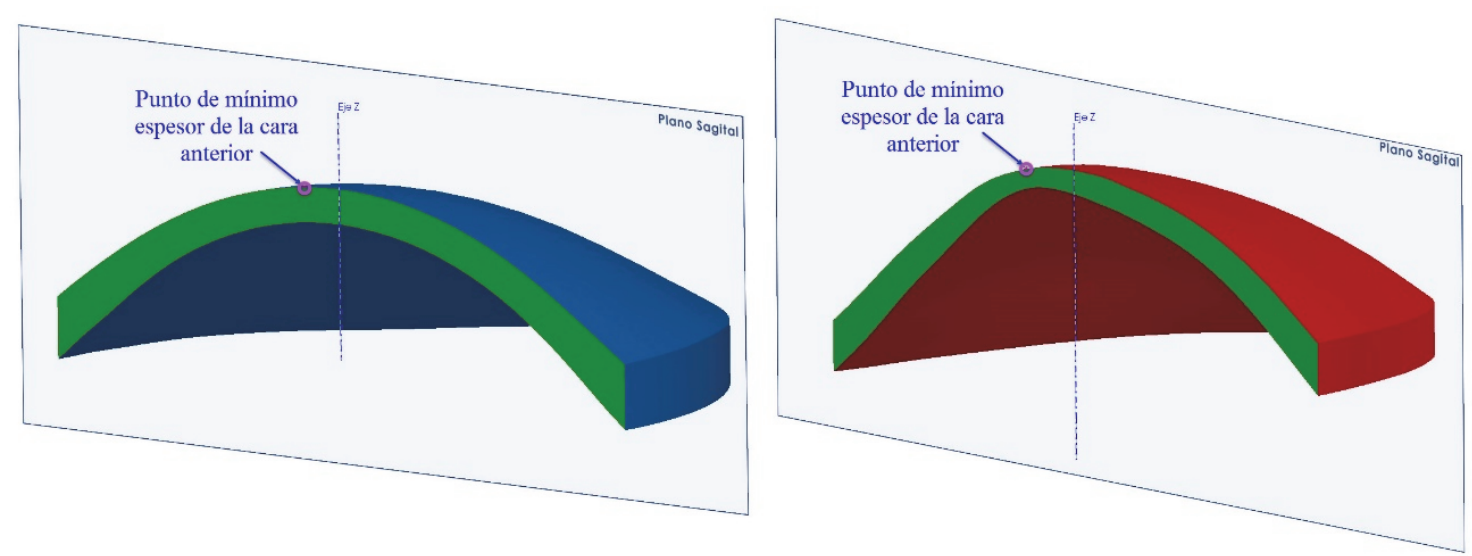

Figura 3.18 Área del plano sagital que pasa por el punto de mínimo espesor anterior (en verde) calculada en una córnea sana (en azul) y en una córnea con queratocono (en rojo)

\subsubsection{Desviación del punto de mínimo espesor anterior}

Se define la variable "Desviación del punto de mínimo espesor anterior" (en $\mathrm{mm}$ ) como la distancia desde el eje $\mathrm{Z}$ al punto de mínimo espesor (máxima curvatura) de la superficie corneal anterior (Figura 3.19).

\subsubsection{Desviación del punto de mínimo espesor posterior}

Se define la variable "Desviación del punto de mínimo espesor posterior" (en $\mathrm{mm}$ ) como la distancia desde el eje $\mathrm{Z}$ al punto de mínimo espesor (máxima curvatura) de la superficie corneal posterior (Figura 3.20). 

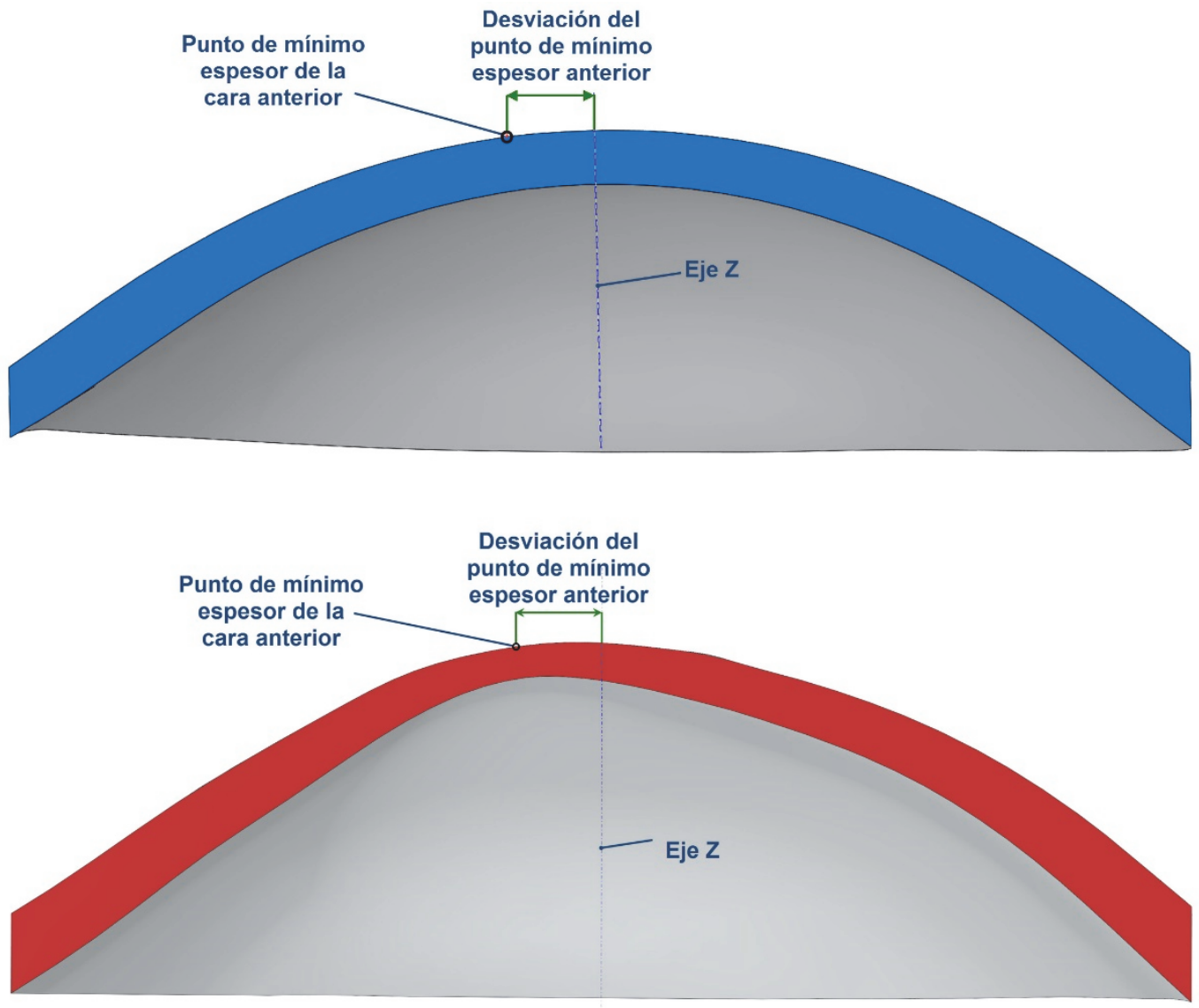

Figura 3.19 Desviación del punto de mínimo espesor anterior calculada para una córnea sana (en azul) y para una córnea con queratocono (en rojo)
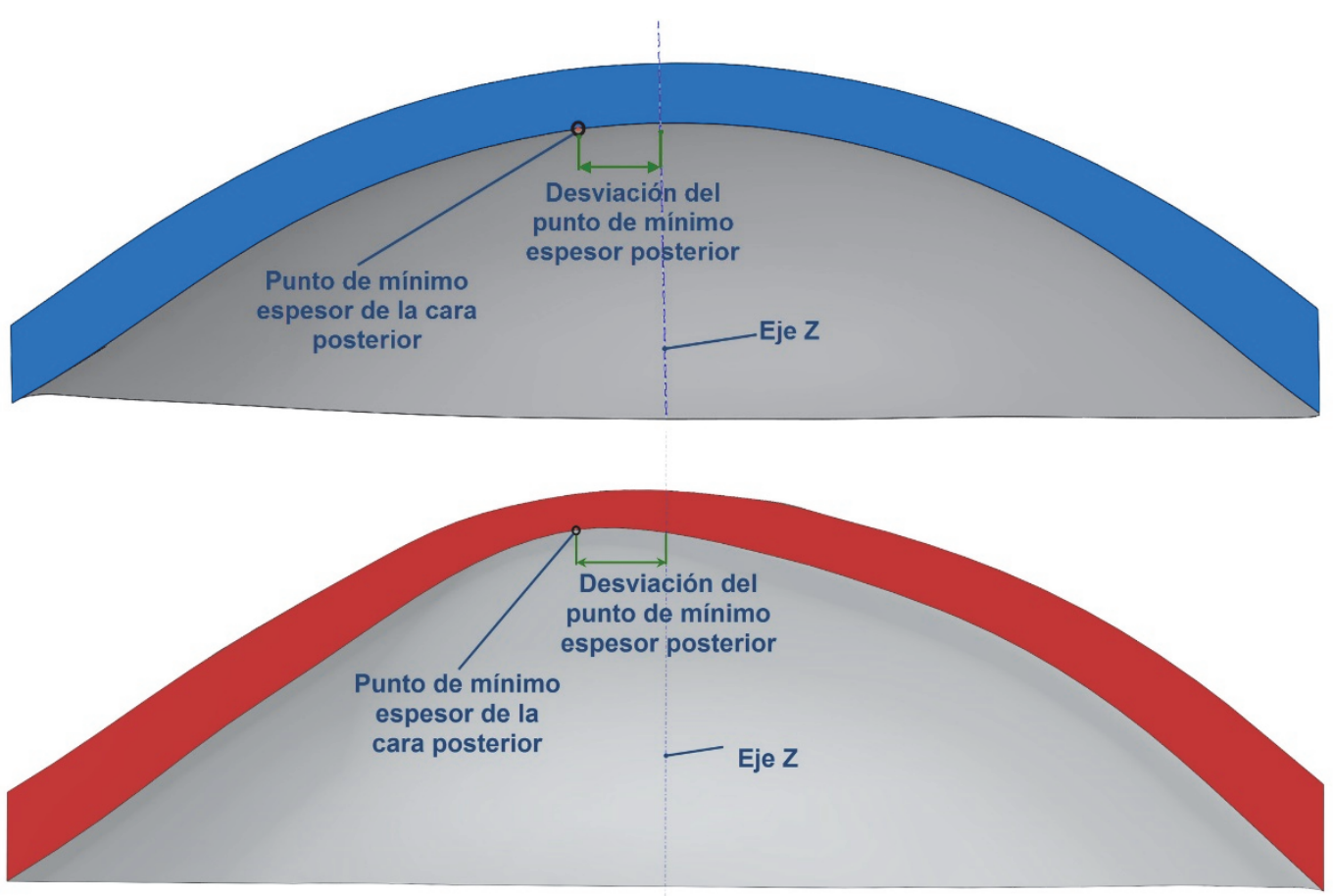

Figura 3.20 Desviación del punto de mínimo espesor posterior calculada para una córnea sana (en azul) y para una córnea con queratocono (en rojo) 


\subsubsection{Centro de masas}

Se define la variable "Centro de masas" (en mm) como la posición del centro de masas expresado en coordenadas cartesianas X, Y, Z.

\subsubsection{Desviación Neta el centro de masas XY}

Se define la variable "Desviación Neta del centro de masas en $X Y$ " (en mm) como el módulo proyectivo XY del centro de masas.

\subsubsection{Volumen cilíndrico corneal $R-x$}

Se define la variable "Volumen cilíndrico corneal $\mathrm{R}-\mathrm{x}$ " (en $\mathrm{mm}^{3}$ ) como el volumen de la intersección en 3D entre el modelo sólido de la córnea generado y un cilindro de radio $\mathrm{r}=\mathrm{x} \mathrm{mm}$ cuyo eje pasa por los puntos de mínimo espesor (máxima curvatura) de las superficies corneales anterior y posterior (Figura 3.21). Para este estudio se emplearon los radios 0.5, 1.0, 1.5 y $2.0 \mathrm{~mm}$. En la Figura 3.22 se muestra el cálculo de estos radios tanto para una córnea sana (en azul) como para una córnea con queratocono (en rojo).

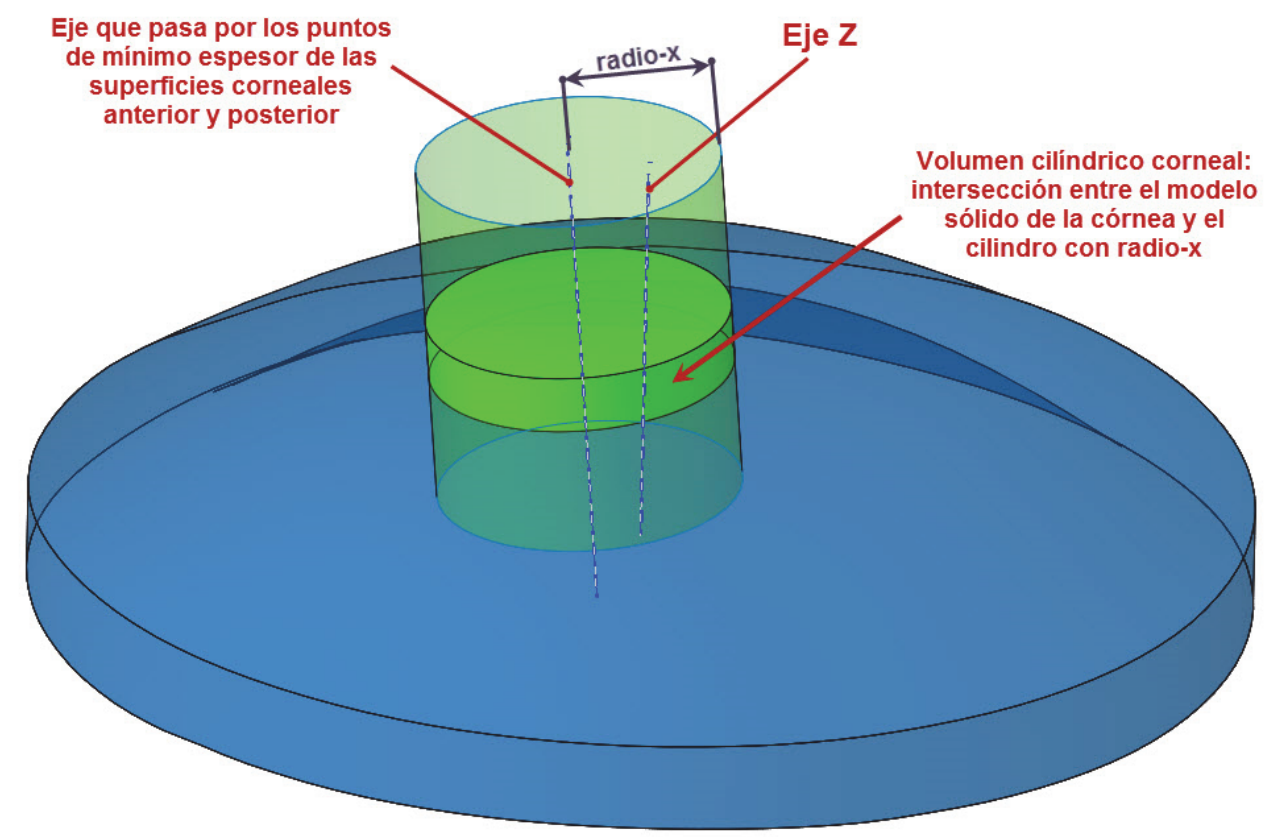

Figura 3.21 Procedimiento para el cálculo del volumen cilíndrico corneal $\mathrm{R}-\mathrm{x}$ 


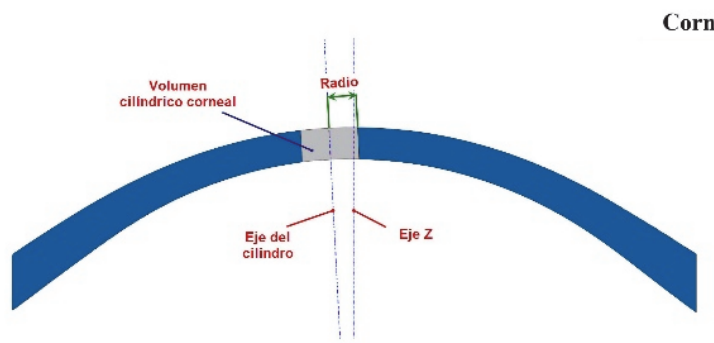

Radio $=0,5 \mathrm{~mm}$

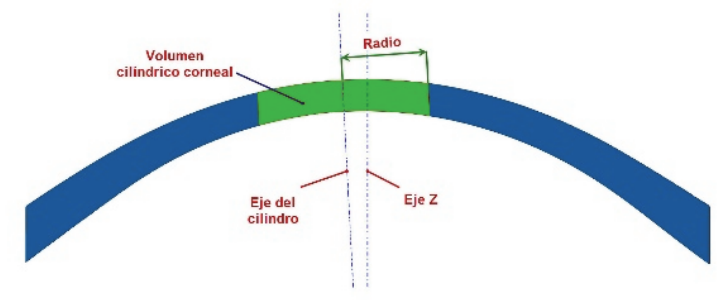

Radio $=1,5 \mathrm{~mm}$

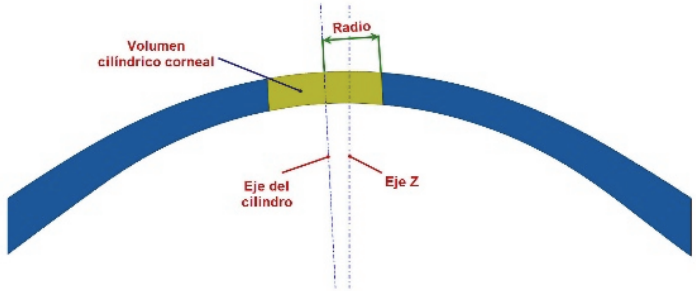

Radio $=1 \mathrm{~mm}$

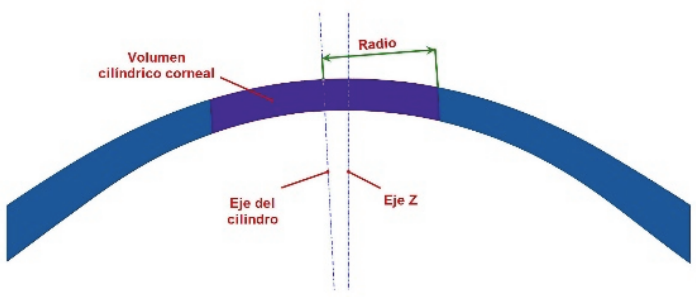

Radio $=2 \mathrm{~mm}$

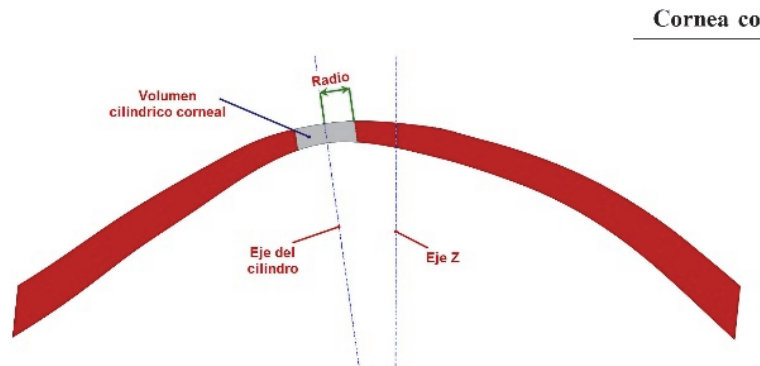

Radio $=0,5 \mathrm{~mm}$

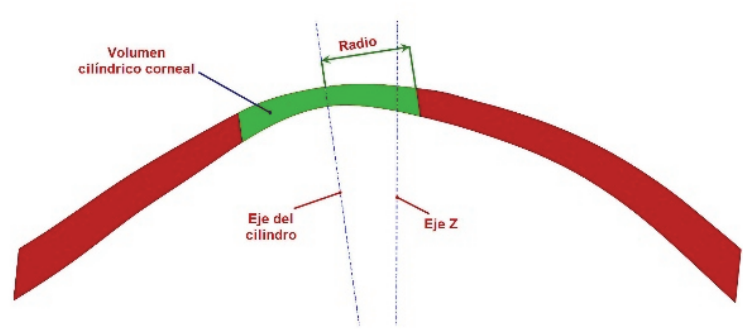

Radio $=1,5 \mathrm{~mm}$

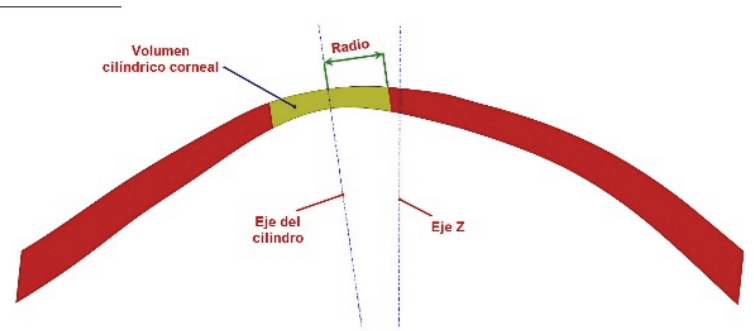

Radio $=1 \mathrm{~mm}$

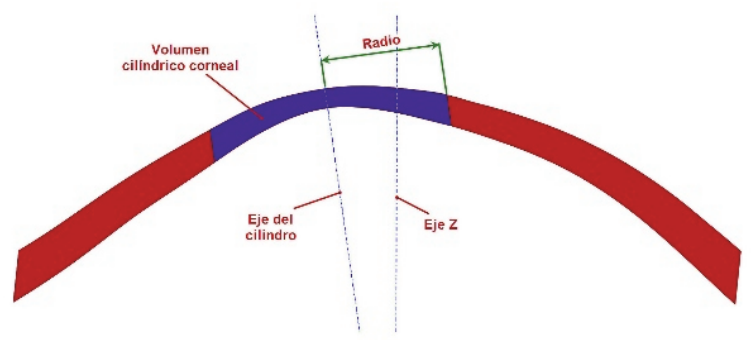

Radio $=2 \mathrm{~mm}$

Figura 3.22 Representación esquemática de las diferencias de los volúmenes cilíndrico corneales con radio $0.5,1.0,1.5$ y $2.0 \mathrm{~mm}$ para una córnea sana (en azul) y una córnea con queratocono (en rojo). 


\subsection{Análisis Estadístico}

Se utilizó un test de Kolmogorov-Smirnov para evaluar el tipo de distribución de la muestra. Posteriormente y en función del tipo de distribución (dependiendo de la normalidad), se empleó una prueba de $t$ de Student o un test de U-Mann Whitney Wilcoxon para datos no pareados, con el objetivo de describir las diferencias entre el grupo de ojos sanos y el grupo de ojos con queratocono respecto a todas las variables estudiadas. Un test adicional de Kruskal-Wallis ha sido utilizado para describir diferencias entre los diferentes grupos en función de la progresión de la enfermedad (acorde a la clasificación por estadios establecida a través del sistema de evaluación de Amsler- Krumeich). Las comparaciones por pares se realizaron con el procedimiento de Dunn con una corrección de Bonferroni para comparaciones múltiples.

Finalmente, se realizó un análisis de la curva ROC (acrónimo de Receiver Operating Characteristic, en castellano Característica Operativa del Receptor) con el fin de obtener la precisión de las diferentes mediciones (sensibilidad y especificidad). Con este procedimiento se consigue identificar los positivos verdaderos y reducir al mínimo el número de falsos positivos. Para ello se ha elaborado una representación gráfica de la curva de la función sensibilidad frente a (1 - especificidad), estableciendo un sistema clasificador binario según se varía el umbral de discriminación. Así, un área con un valor de 1 representaría la prueba más precisa, mientras que un área de 0.5 representa una prueba sin valor (clasificación debida al azar). Cuanto mayor es la proximidad de la curva a la izquierda y más alto su valor en el eje y durante el recorrido, más precisa será la prueba.

Todos los análisis estadísticos mencionados se realizaron utilizando el paquete estadístico GraphPad Prism 6 y el software SPSS 17.0. 
Resultados 
Del total de 131 pacientes incluidos en el estudio, 90 estaban incluidos en el grupo de ojos sanos (con una edad de 7 a 66 años) y 41 personas presentaban diagnóstico clínico de queratocono (entre 14 y 66 años) en sus diferentes grados de afectación (51.2\% en el estadio I, $36.6 \%$ en el estadio II y un $12.2 \%$ en los estadios extremos III y IV).

La mayoría de las variables modeladas muestran en el grupo de personas enfermas diferencias respecto al grupo de ojos normales, en la mayoría de los casos acorde al grado de desarrollo de la enfermedad. Así, se puede comprobar que los descriptivos básicos difieren en el volumen total de la córnea, el área de la cara anterior y posterior, el área del ápex en el plano sagital y el área del plano sagital en el punto de mínimo espesor, no siendo tan marcada la diferencia en el área total (Figura 4.1). De la misma forma, el análisis de las diferentes desviaciones difiere (Figura 4.2), así como los volúmenes de los cilindros corneales con distinto radio (Figura 4.3).

La Tabla 4.1 recoge el análisis estadístico de estas diferencias, como las observadas en el volumen corneal total (mayor en los ojos normales, $\mathrm{p}<0.000$ ) o las superficies corneales anterior y posterior son también significativamente diferentes (menores en sujetos sanos, $\mathrm{p}<0.000$ ). Este mismo patrón de diferencias se mantiene para el plano sagital en el ápex y el plano sagital en el punto de mínimo espesor (mayor en ojos sanos, $\mathrm{p}<0.000$ ), en las desviaciones anterior y posterior del ápex (mayores en los ojos con queratocono, $\mathrm{p}<0.000$ ) y también en las desviaciones del punto de mínimo espesor anterior y posterior (mayor en los ojos con queratocono, $\mathrm{p}<0.01$ ). Desde un punto de vista estadístico, los centros de masas no son variables que permitan diferenciar el grupo de ojos enfermos respecto al grupo de ojos sanos, no observándose ninguna diferencia significativa entre los centros de masas de ambos grupos en $\mathrm{x}, \mathrm{y} \mathrm{o} \mathrm{z}$, así como en la desviación neta del centro de masas en $\mathrm{x}, \mathrm{y}$. De la misma forma, el área total de la córnea no muestra diferencias estadísticamente significativas entre ojos sanos y enfermos.

La Figura 4.1 muestra un diagrama de caja y bigotes que representa la distribución de los descriptivos básicos en las variables de volumen total y áreas de la córnea (mediana, P10, P25, P75, P90 y valores atípicos), en función de los cuatro grupos establecidos, ojos sanos y estadios de la enfermedad, agrupando en 2 los casos extremos (estadios III-IV). El área de la cara anterior y de la cara posterior aumentan en función de la progresión de la enfermedad, con diferencias marcadas en cada uno de los grupos; el área total es similar para toda la muestra; y el volumen total, el área del plano sagital y el área en el plano sagital en el punto de mínimo espesor es mayor en los ojos sanos, si bien no hay diferencias muy evidentes entre los distintos estadios agrupados.

Nótese la existencia de valores atípicos en todos los grupos y variables estudiadas, a excepción del grupo que aglutina los casos de estadio más avanzado, algo que se mantiene en la descripción por grupos de todos los índices analizados (debido probablemente al tamaño reducido del mismo). 


\begin{tabular}{|c|c|c|c|}
\hline Medida & $\begin{array}{l}\text { Grupo Normal } \\
\quad \mathrm{n}=90 \\
\text { Media }(95 \% \mathrm{CI})\end{array}$ & $\begin{array}{l}\text { Grupo Queratocono } \\
\qquad \mathrm{n}=41 \\
\text { Media }(95 \% \mathrm{CI})\end{array}$ & p (test estadístico) \\
\hline Volumen corneal total $\left[\mathrm{mm}^{3}\right]$ & $25.81(25.47-26.14)$ & $23.42(22.81-24.03)$ & 0.000 (Mann-Whitney) \\
\hline $\begin{array}{l}\text { Área de la superficie de la cara } \\
\text { anterior de la córnea }\left[\mathrm{mm}^{2}\right]\end{array}$ & $43.08(43.04-43.11)$ & $43.39(43.30-43.40)$ & 0.000 (Mann-Whitney) \\
\hline $\begin{array}{l}\text { Área de la superficie de la cara } \\
\text { posterior de la córnea }\left[\mathrm{mm}^{2}\right]\end{array}$ & $44.24(44.18-44.30)$ & $44.73(44.57-44.89)$ & 0.000 (Mann-Whitney) \\
\hline $\begin{array}{l}\text { Área de la superficie total de la } \\
\text { córnea }\left[\mathrm{mm}^{2}\right]\end{array}$ & 103.93 (103.67-104.20) & 103.59 (103.13-104.05) & 0.169 (Mann-Whitney) \\
\hline $\begin{array}{l}\text { Área del plano sagital en el } \\
\text { ápex }\left[\mathrm{mm}^{2}\right]\end{array}$ & $4.33(4.27-4.39)$ & $3.90(3.80-4.00)$ & 0.000 (Mann-Whitney) \\
\hline $\begin{array}{l}\text { Área del plano sagital en el } \\
\text { punto de mínimo espesor } \\
{\left[\mathrm{mm}^{2}\right]}\end{array}$ & $4.32(4.26-4.38)$ & $3.88(3.78-3.99)$ & 0.000 (t-test) \\
\hline $\begin{array}{l}\text { Desviación del ápex anterior } \\
{[\mathrm{mm}]}\end{array}$ & $0.0003(0.0001-0.0006)$ & $0.0083(0.0048-0.0118)$ & 0.000 (Mann-Whitney) \\
\hline $\begin{array}{l}\text { Desviación del ápex posterior } \\
{[\mathrm{mm}]}\end{array}$ & $0.0768(0.063-0.0905)$ & $0.1886(0.1587-0.2185)$ & 0.000 (Mann-Whitney) \\
\hline Centro de masas en $X$ [mm] & $0.044(0.0409-0.0478)$ & $0.0415(0.0331-0.0499)$ & 0.341 (t-test) \\
\hline Centro de masas en $Y$ [mm] & $0.034(0.0304-0.0375)$ & $0.0364(0.0279-0.0449)$ & 0.964 (Mann-Whitney) \\
\hline $\begin{array}{l}\text { Desviación neta del centro de } \\
\text { masas en } X Y[\mathrm{~mm}]\end{array}$ & $0.0577(0.0538-0.0616)$ & $0.0606(0.0517-0.0694)$ & 0.132 (t-test) \\
\hline Centro de masas en $\mathrm{Z}$ [mm] & $0.771(0.766-0.776)$ & $0.785(0.771-0.800)$ & 0.156 (Mann-Whitney) \\
\hline $\begin{array}{l}\text { Desviación del punto de } \\
\text { mínimo espesor anterior }[\mathrm{mm}]\end{array}$ & $0.864(0.812-0.917)$ & $1.031(0.901-1.161)$ & 0.010 (Mann-Whitney) \\
\hline $\begin{array}{l}\text { Desviación del punto de } \\
\text { mínimo espesor posterior } \\
{[\mathrm{mm}]}\end{array}$ & $0.800(0.749-0.851)$ & $0.958(0.835-1.081)$ & 0.009 (Mann-Whitney) \\
\hline
\end{tabular}

Tabla 4.1 Descriptivos básicos (media e IC 95\%) y diferencias entre grupos en las variables modeladas

La Figura 4.2 representa la distribución de los descriptivos básicos en las variables de desviación del ápex anterior, desviación del ápex posterior, del punto de mínimo espeso anterior y del punto de mínimo espesor posterior (mediana, P10, P25, P75, P90 y valores atípicos). Nótese el comportamiento de la desviación del ápex anterior, mínima en el caso de los sujetos sanos y más acentuada en el grupo con la patología más desarrollada. La desviación del ápex posterior es menos marcada, y ambas desviaciones del punto de mínimo espesor no presentan una diferenciación tan evidente. En este conjunto de variables destacan los valores atípicos que se pueden observar en el grupo de ojos sanos. 


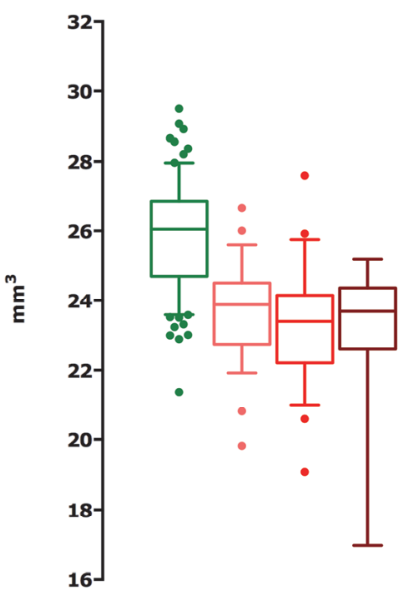

Volumen total de la cómea

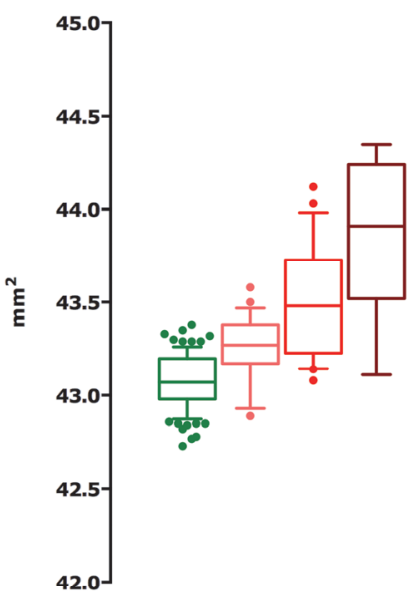

Área de la cara anterio

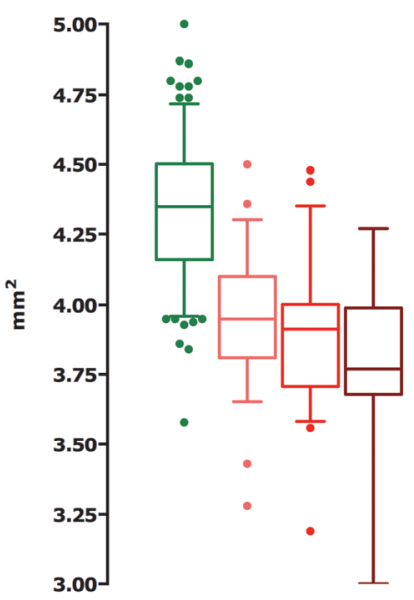

Área del ápex en el plano sagita

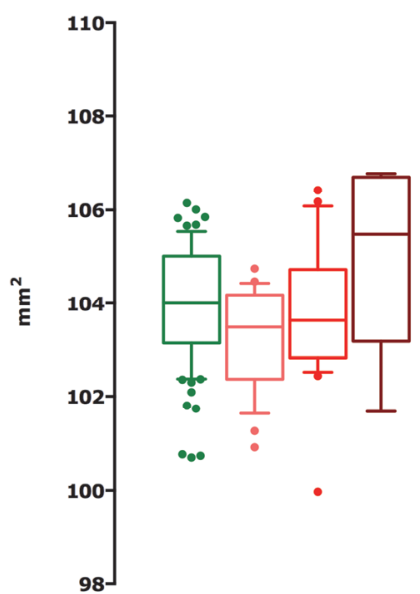

Área total

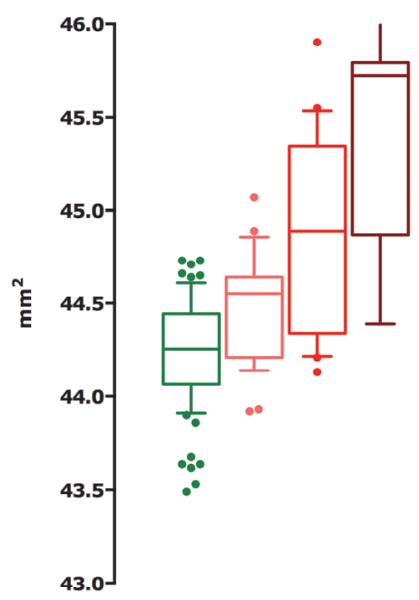

Área de la cara posterior

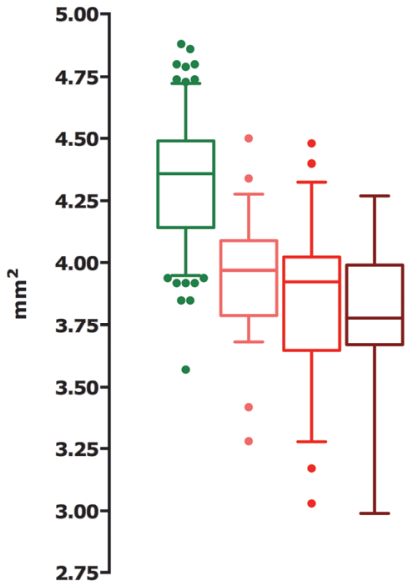

Área del plano sagital en el punto de mínimo espesor

-Normal — Estadío I — Estadío II — Estadío III-IV

Figura 4.1 Diagramas de caja y bigotes (P10-90) con los valores de volumen total y las diferentes áreas modeladas en función de cada grupo (escala Amsler- Krumeich) 


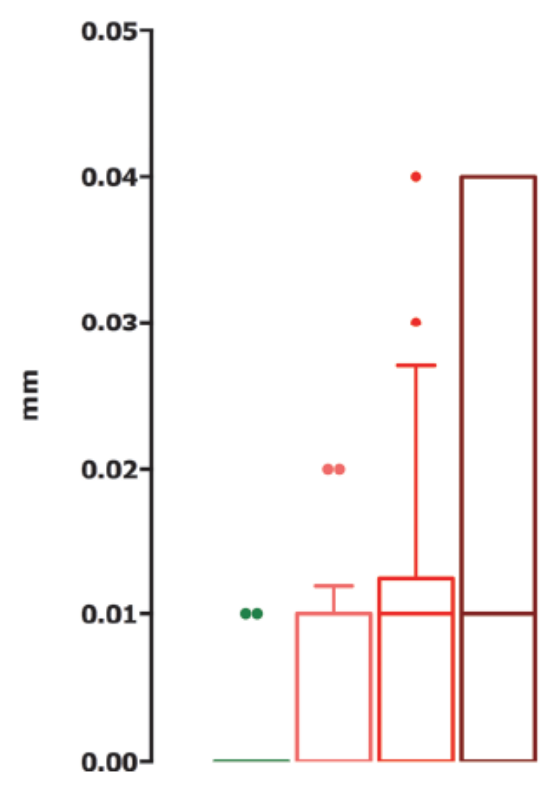

Desviación del ápex anterior

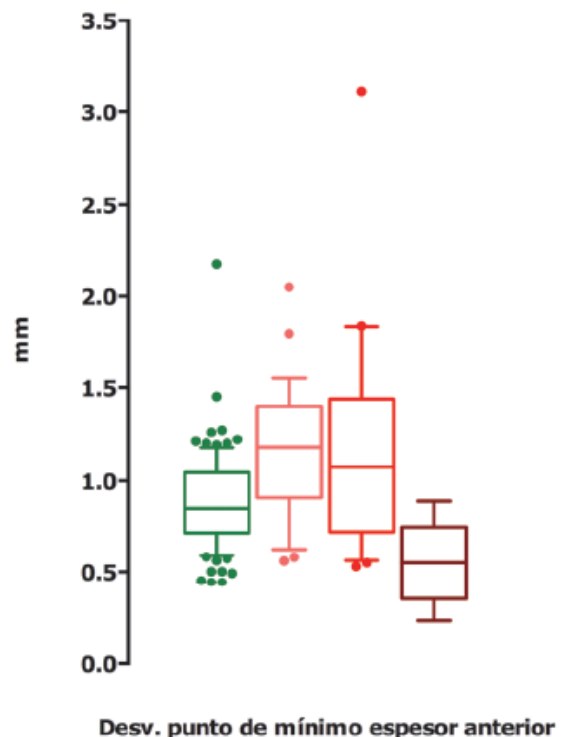

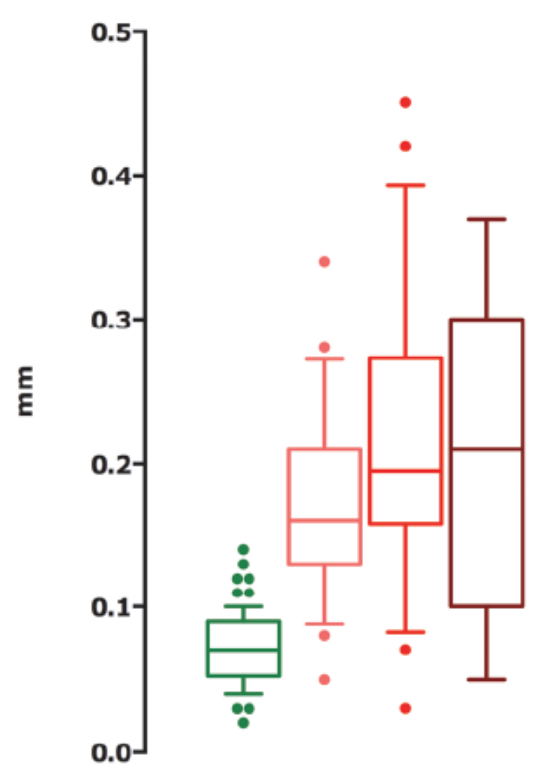

Desviación del ápex posterior

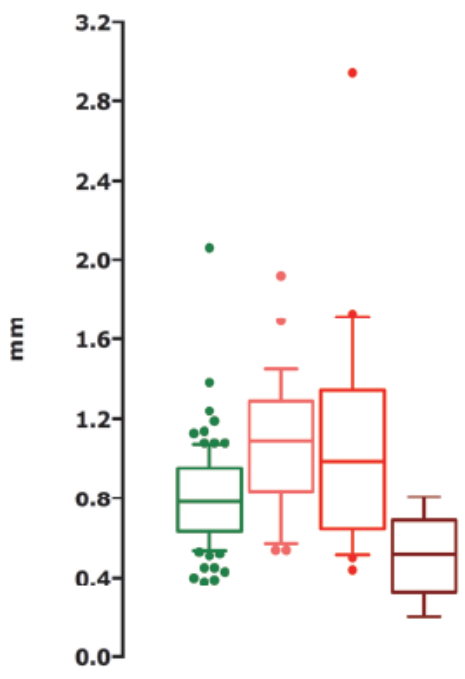

Desv. punto de mínimo espesor posterior

—Normal —Estadío I — Estadío II —Estadío III-IV

Figura 4.2 Diagramas de caja y bigotes (P10-90) con los valores las diferentes desviaciones en función de cada grupo (escala Amsler- Krumeich).

La Figura 4.3 representa la distribución de los descriptivos básicos en los centros de masas $x, y, z$ y la desviación neta en xy (mediana, P10, P25, P75, P90 y valores atípicos), a excepción del comportamiento del grupo que aglutina los estadios III y IV. 

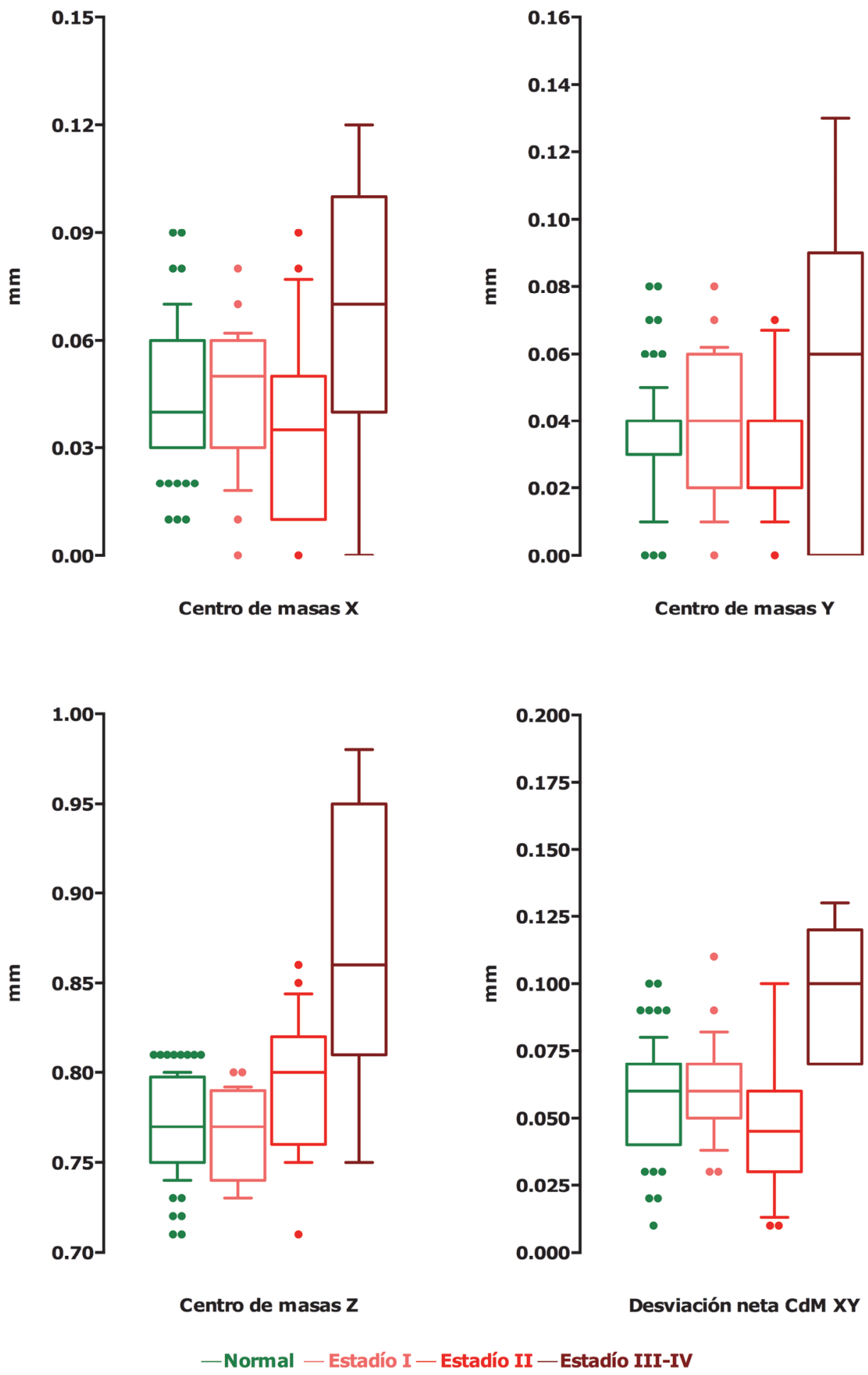

Figura 4.3 Diagramas de caja y bigotes (P10-90) con los valores de posición de los centros de masas en función de cada grupo (escala Amsler- Krumeich)

Los volúmenes de los cilindros corneales, descritos en la Figura 4.4, muestran una distribución diferenciada de tamaño en función de la progresión de la enfermedad, 
disminuyendo conforme aumenta la severidad de la patología y constituyendo los índices que mejor discriminan a los sujetos en función del estado de salud.

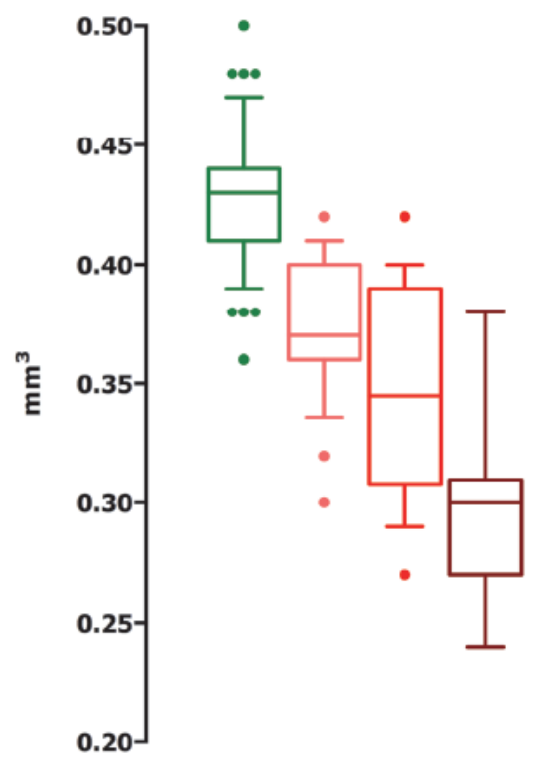

Volumen del cilindro corneal $r=0.5$

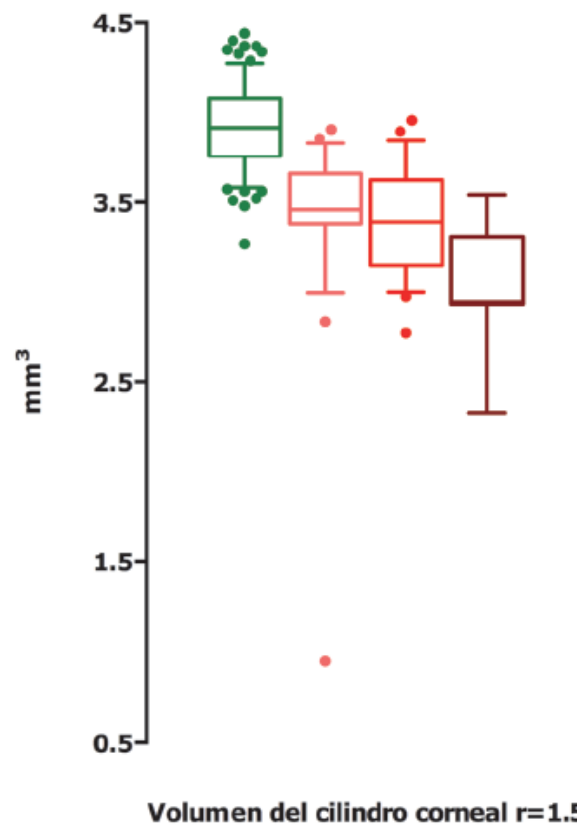

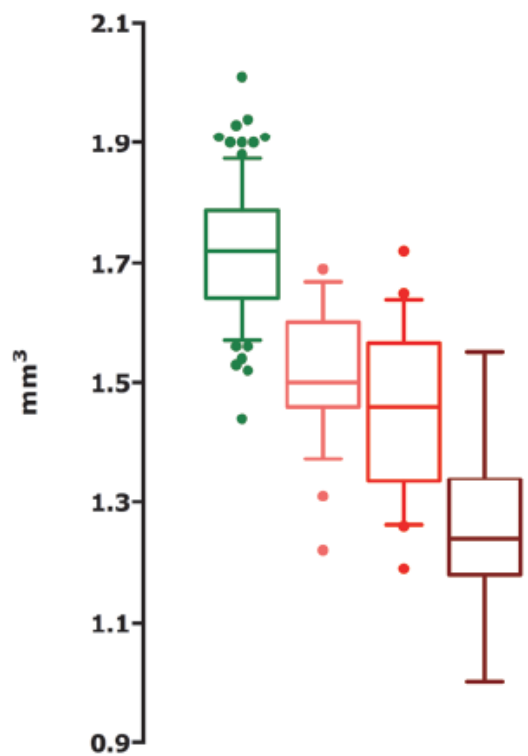

Volumen del cilindro corneal $r=1$

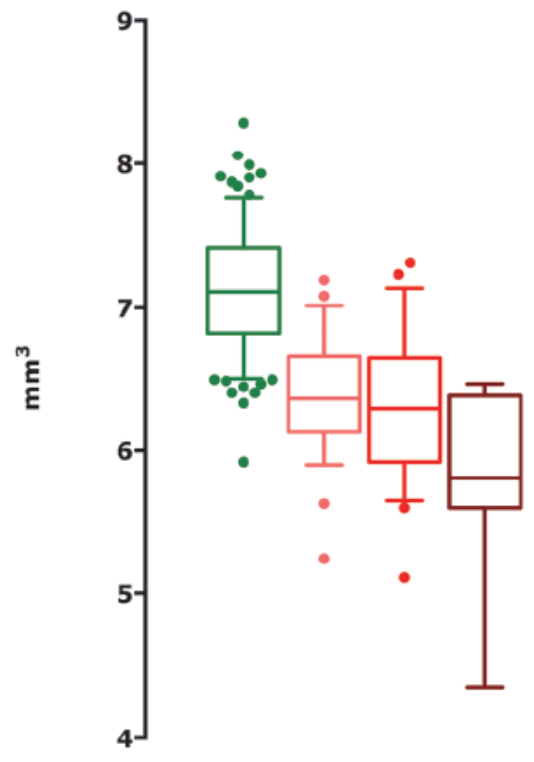

Volumen del cilindro corneal $r=2$

—Normal — Estadío I — Estadío II —Estadío III-IV

Figura 4.4 Diagramas de caja y bigotes (P10-90) con los valores del volumen de los diferentes cilindros corneales en función de cada grupo (escala Amsler- Krumeich) 
Adicionalmente, la Figura 4.5 muestra las diferencias más detalladas entre el grupo de córneas normales y el grupo de córnea con queratocono en los volúmenes cilíndricos usando diferente radio (máxima curvatura en 0.5, 1.0, 1.5 y $2.0 \mathrm{~mm}$ desde el eje que pasa a través del punto de mínimo espesor). Se muestra la diferencia entre un ojo sano (Figura 4.5a-d) y un ojo con queratocono (Figura 4.5e-h).

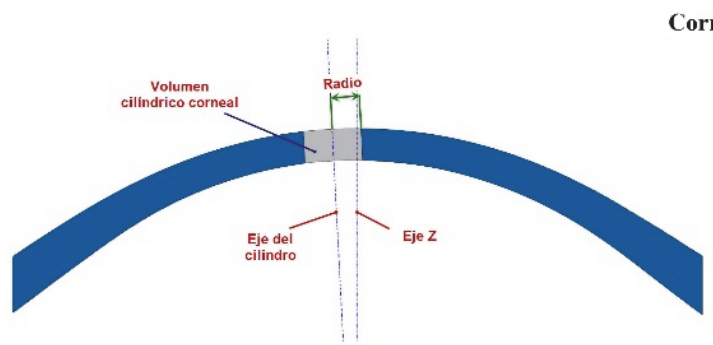

Radio $=0,5 \mathrm{~mm}$

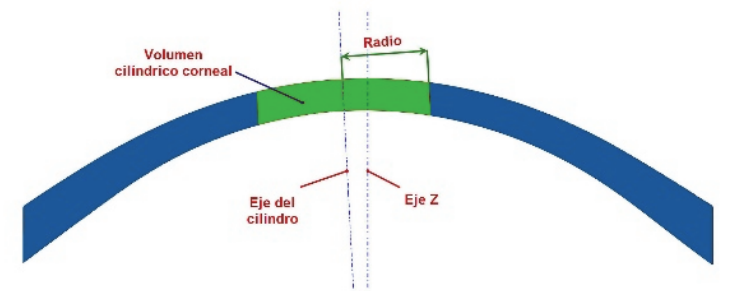

Radio $=1,5 \mathrm{~mm}$

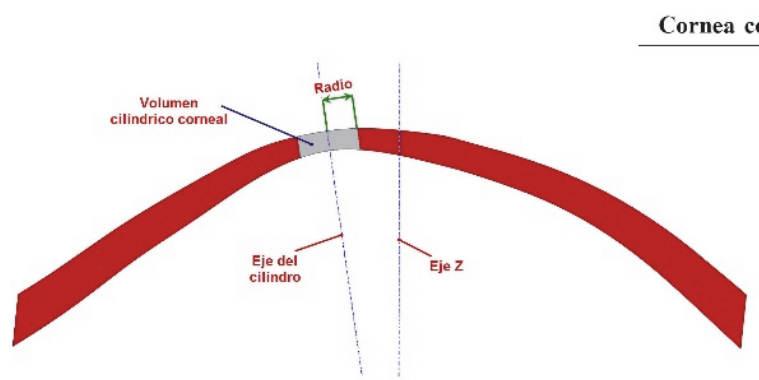

Radio $=0,5 \mathrm{~mm}$

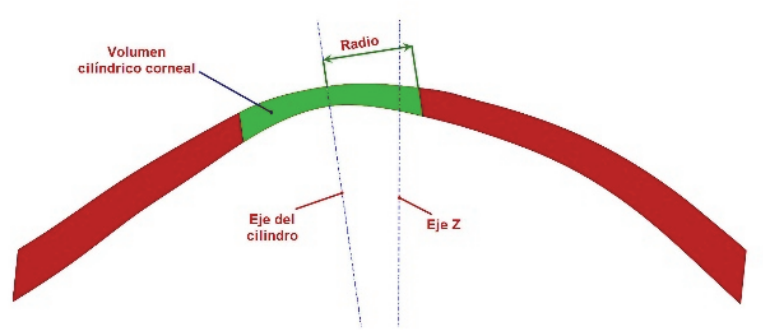

Radio $=1,5 \mathrm{~mm}$

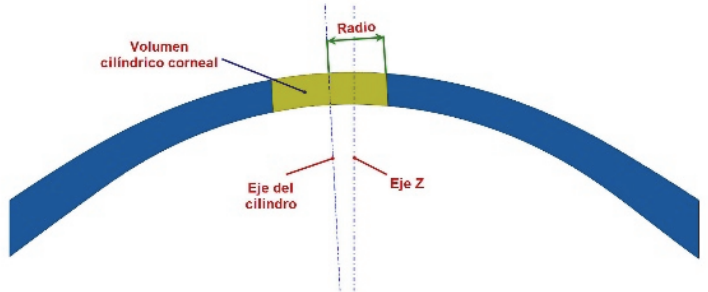

Radio $=1 \mathrm{~mm}$

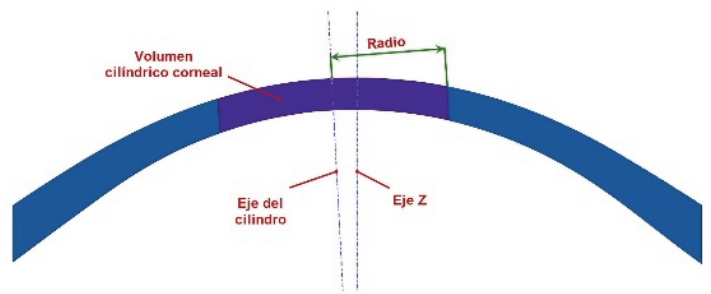

Radio $=2 \mathrm{~mm}$

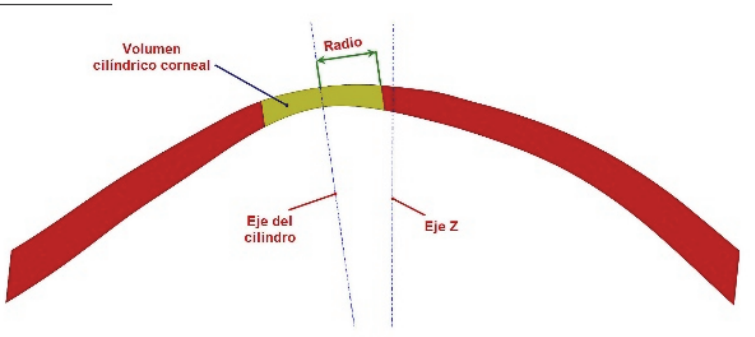

Radio $=1 \mathrm{~mm}$

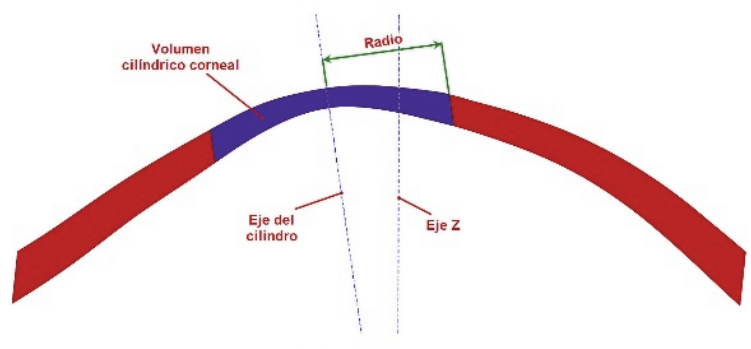

Radio $=2 \mathrm{~mm}$

Figura 4.5 Representación esquemática de la diferencia en los volúmenes de los cilindros corneales con radio $0.5,1.0,1.5$ y 2.0 entre córneas normales (A-D) y córneas con queratocono $(\mathrm{E}-\mathrm{H})$ 
Se encontraron diferencias estadísticamente significativas para todas estas variables geométricas que permiten diferenciar los ojos con queratocono (Tabla 4.2).

\begin{tabular}{|c|c|c|c|c|}
\hline \multirow[t]{2}{*}{$\begin{array}{l}\text { Volumen cilíndrico } \\
\text { corneal }\left(\mathrm{mm}^{3}\right) \text { con radio } \\
x(\mathrm{~mm})\end{array}$} & $\begin{array}{l}\text { Grupo normal. } n=90 ; \\
\text { fig. } 7 \mathrm{a}-\mathrm{d}\end{array}$ & $\begin{array}{l}\text { Grupo queratocono. } n=41 ; \\
\text { fig. } 7 \mathrm{~b}-\mathrm{h}\end{array}$ & & \\
\hline & Media \pm DT & Media \pm DT & z & $\mathrm{p}$ \\
\hline $\mathrm{r}=0.5$ & $0.46 \pm 0.29$ & $0.35 \pm 0.041$ & -8.280 & 0.000 \\
\hline$r=1$ & $1.71 \pm 0.11$ & $1.46 \pm 0.15$ & -7.980 & 0.000 \\
\hline $\mathrm{r}=1.5$ & $3.91 \pm 0.24$ & $3.33 \pm 0.50$ & -7.650 & 0.000 \\
\hline$r=2$ & $7.10 \pm 0.44$ & $6.26 \pm 0.57$ & -7.211 & 0.000 \\
\hline
\end{tabular}

Tabla 4.2 Diferencias entre el grupo normal (Figs. 7a-d) versus el grupo de queratocono

(Figs. $7 e-h$ en el volumen cilíndrico corneal de radio $0.5,1.0,1.5$ y $2.0 \mathrm{~mm}$ (media y desviación típica; U-Mann-Whitney-Wilcoxon test)

Los resultados acordes a la severidad del queratocono se muestran en la Tabla 4.3, donde se pueden observar las comparaciones agrupando los ojos enfermos en función de la severidad de la enfermedad acorde al sistema de clasificación de AmslerKrumeich. Sólo el área de la superficie corneal total y los centros de masas en $x$ e $y$ no son capaces de discriminar los subgrupos de ojos enfermos de los ojos sanos, siendo el resto de variables analizadas estadísticamente diferentes entre grupos (de $\mathrm{p}<0.000$ a p $<0.013$ ). Para el centro de masas en z y la desviación neta del centro de masas en $x y$, se puede observar que el grupo de estadio avanzado (III-IV) se diferencia bien del resto, tal y como revela el análisis post hoc (método de Dunn con corrección de Bonferroni para comparaciones múltiples). Nótese que los tamaños del efecto calculados para cada estadio (respecto al grupo de ojos sanos) permiten definir el grado de cambio en las variables analizadas que supone la progresión de la enfermedad, mayor en el caso del grupo de estadio III-IV, donde es más evidente la progresión de la enfermedad. 


\begin{tabular}{|c|c|c|c|c|c|}
\hline & Normal & Estadio I & Estadio II & Estadio III-IV & $\begin{array}{l}\mathrm{p}(\mathrm{K}-\mathrm{Wallis} \\
\text { test) }\end{array}$ \\
\hline $\begin{array}{l}\text { Volumen total } \\
\text { de la córnea }\left[\mathrm{mm}^{3}\right]\end{array}$ & $\begin{array}{c}26.00 \\
{[21.37-29.50]}\end{array}$ & $\begin{array}{c}23.88 \\
{[19.82-26.66]}\end{array}$ & $\begin{array}{c}23.32 \\
{[19.09-27.60]}\end{array}$ & $\begin{array}{c}19.78 \\
{[16.97-22.60]}\end{array}$ & 0.000 \\
\hline (ES) & - & 1.19 & 1.42 & 3.35 & \\
\hline $\begin{array}{l}\text { Área de la cara anterior } \\
\text { de la córnea }\left[\mathrm{mm}^{2}\right]\end{array}$ & $\begin{array}{c}43.07 \\
{[42.73-43.38]}\end{array}$ & $\begin{array}{c}43.27 \\
{[42.89-43.58]}\end{array}$ & $\begin{array}{c}43.46 \\
{[43.14-44.12]}\end{array}$ & $\begin{array}{c}44.10 \\
{[43.86-44.35]}\end{array}$ & 0.000 \\
\hline (ES) & - & -1.18 & -1.70 & -4.85 & \\
\hline $\begin{array}{l}\text { Área de la cara } \\
\text { posterior de la córnea } \\
\text { área }\left[\mathrm{mm}^{2}\right]\end{array}$ & $\begin{array}{c}44.25 \\
{[43.49-44.90]}\end{array}$ & $\begin{array}{c}44.55 \\
{[43.93-45.07]}\end{array}$ & $\begin{array}{c}44.85 \\
{[44.21-45.90]}\end{array}$ & $\begin{array}{c}45.75 \\
{[45.72-45.78]}\end{array}$ & 0.000 \\
\hline (ES) & - & -0.99 & -1.54 & -4.18 & \\
\hline $\begin{array}{l}\text { Área total de la córnea } \\
{\left[\mathrm{mm}^{2}\right]}\end{array}$ & $\begin{array}{l}103.94 \\
{[100.6-} \\
106.15]\end{array}$ & $\begin{array}{c}103.59 \\
{[100.91-104-75]}\end{array}$ & $\begin{array}{c}103.71 \\
{[99.97-106.18]}\end{array}$ & $\begin{array}{c}103.58 \\
{[101.68-105.48]}\end{array}$ & 0.185 \\
\hline (ES) & - & 0.28 & 0.18 & 0.28 & \\
\hline $\begin{array}{l}\text { Área del plano sagital } \\
\text { en el ápex }\left[\mathrm{mm}^{2}\right]\end{array}$ & $\begin{array}{c}4.34 \\
{[3.58-5.00]}\end{array}$ & $3.94[3.28-4.50]$ & $3.91[3.19-4.48]$ & $3.35[3.00-3.70]$ & 0.000 \\
\hline (ES) & - & 1.30 & 1.37 & 3.25 & \\
\hline $\begin{array}{l}\text { Área del plano sagital } \\
\text { en el punto de mínimo } \\
\text { espesor }\left[\mathrm{mm}^{2}\right]\end{array}$ & $\begin{array}{c}4.35 \\
{[3.57-5.01]}\end{array}$ & $3.94[3.28-4.50]$ & $3.92[3.03-4.48]$ & 3.34 [2.99-3.69] & 0.000 \\
\hline (ES) & - & 1.33 & 1.28 & 3.29 & \\
\hline $\begin{array}{l}\text { Desviación del ápex } \\
\text { anterior [mm] }\end{array}$ & $\begin{array}{c}0.000 \\
{[0.000-0.007]}\end{array}$ & $\begin{array}{c}0.003 \\
{[0.000-0.016]}\end{array}$ & $\begin{array}{c}0.008 \\
{[0.000-0.041]}\end{array}$ & $\begin{array}{c}0.029 \\
{[0.014-0.044]}\end{array}$ & 0.000 \\
\hline (ES) & - & -1.12 & -1.41 & -5.93 & \\
\hline $\begin{array}{l}\text { Desviación del ápex } \\
\text { posterior [mm] }\end{array}$ & $\begin{array}{c}0.068 \\
{[0.024-0.650]}\end{array}$ & $\begin{array}{c}0.164 \\
{[0.054-0.339]}\end{array}$ & $\begin{array}{c}0.198 \\
{[0.032-0.453]}\end{array}$ & $\begin{array}{c}0.132 \\
{[0.054-0.209]}\end{array}$ & 0.000 \\
\hline (ES) & - & -1.25 & -1.44 & -0.97 & \\
\hline $\begin{array}{l}\text { Centro de masas } \\
\text { en } X[\mathrm{~mm}]\end{array}$ & $\begin{array}{c}0.044 \\
{[0.009-0.089]}\end{array}$ & $\begin{array}{c}0.042 \\
{[0.002-0.083]}\end{array}$ & $\begin{array}{c}0.030 \\
{[0.006-0.083]}\end{array}$ & $\begin{array}{c}0.059 \\
{[0.002-0.116]}\end{array}$ & 0.184 \\
\hline (ES) & - & 0.12 & 0.79 & -0.82 & \\
\hline $\begin{array}{l}\text { Centro de masas } \\
\text { en } Y[\mathrm{~mm}]\end{array}$ & $\begin{array}{c}0.032 \\
{[0.000-0.095]}\end{array}$ & $\begin{array}{c}0.036 \\
{[0.005-0.084]}\end{array}$ & $\begin{array}{c}0.021 \\
{[0.008-0.281]}\end{array}$ & $\begin{array}{c}0.065 \\
{[0.001-0.129]}\end{array}$ & 0.187 \\
\hline (ES) & - & -0.22 & 0.37 & -1.67 & \\
\hline $\begin{array}{l}\text { Desviación neta del } \\
\text { centro de masas en } X Y \\
\text { [mm] }\end{array}$ & $\begin{array}{c}0.056 \\
{[0.009-0.108]}\end{array}$ & $\begin{array}{c}0.059 \\
{[0.031-0.105]}\end{array}$ & $\begin{array}{c}0.042 \\
{[0.014-0.281]}\end{array}$ & $\begin{array}{c}0.123 \\
{[0.116-0.129]}\end{array}$ & 0.006 \\
\hline (ES) & - & -0.16 & 0.48 & -3.25 & \\
\hline $\begin{array}{l}\text { Centro de masas } \\
\text { en } Z \text { [mm] }\end{array}$ & $\begin{array}{c}0.770 \\
{[0.708-0.813]}\end{array}$ & $\begin{array}{c}0.771 \\
{[0.730-0.795]}\end{array}$ & $\begin{array}{c}0.799 \\
{[0.709-0.864]}\end{array}$ & $\begin{array}{c}0.839 \\
{[0.809-0.869]}\end{array}$ & 0.013 \\
\hline (ES) & - & -0.04 & -1.02 & -2.55 & \\
\hline $\begin{array}{l}\text { Desviación del punto de } \\
\text { mínimo espesor } \\
\text { anterior }[\mathrm{mm}]\end{array}$ & $\begin{array}{c}0.839 \\
{[0.438-2.171]}\end{array}$ & $\begin{array}{c}1.050 \\
{[0.558-2.051]}\end{array}$ & $\begin{array}{c}1.084 \\
{[0.527-3.107]}\end{array}$ & $\begin{array}{c}0.391 \\
{[0.233-0.549]}\end{array}$ & 0.001 \\
\hline (ES) & - & -0.71 & -0.69 & 1.72 & \\
\hline $\begin{array}{l}\text { Desviación del punto de } \\
\text { mínimo espesor } \\
\text { posterior [mm] }\end{array}$ & $\begin{array}{c}0.771 \\
{[0.375-2.059]}\end{array}$ & $\begin{array}{c}0.953 \\
{[0.536-1.924]}\end{array}$ & $\begin{array}{c}0.996 \\
{[0.444-2.941]}\end{array}$ & $\begin{array}{c}0.358 \\
{[0.197-0.519]}\end{array}$ & 0.000 \\
\hline (ES) & - & -0.65 & -0.67 & 1.66 & \\
\hline
\end{tabular}

Tabla 4.3 Comparativa entre grupos establecidos con la claslificación de Amsler- Krumeich; test de Kruskall-Wallis y tamaño del efecto (ES) ${ }^{1}$. 
${ }^{1}$ Comparando cada estadio de la enfermedad con el grupo normal; el tamaño del efecto fue calculado como sigue: $\mathrm{d}=\left(\overline{\boldsymbol{X}}_{1-} \overline{\boldsymbol{X}}_{\mathrm{n}}\right) / \sigma$, calculando $\overline{\boldsymbol{X}}_{1}$ para los ojos normales, $\overline{\boldsymbol{X}}_{\mathrm{n}}$ para cada estadio de los ojos enfermos, y siendo $\sigma$ una desviación típica combinada de los datos comparados.

El valor predictivo de las diferentes variables modeladas ha sido establecido a partir de un análisis ROC, calculándose los respectivos puntos de corte, la sensibilidad y la especificidad para cada una de las variables con un área bajo la curva de 0.7 (Tabla 4.4).

\begin{tabular}{|c|c|c|c|c|c|c|}
\hline Variable & Área & $\mathrm{p}$ & $\begin{array}{l}\text { Punto de } \\
\text { corte }\end{array}$ & $\begin{array}{c}\text { Sensibilidad } \\
(\%)\end{array}$ & $\begin{array}{c}\text { Especificidad } \\
(\%)\end{array}$ & IC $95 \%$ \\
\hline $\begin{array}{l}\text { Volumen total de } \\
\text { la córnea }\left[\mathrm{mm}^{3}\right]\end{array}$ & 0.153 & 1.000 & - & - & - & - \\
\hline $\begin{array}{l}\text { Área de la cara anterior } \\
\text { de la córnea }\left[\mathrm{mm}^{2}\right]\end{array}$ & 0.847 & 0.000 & 43.11 & 89 & 57 & $0.777-0.925$ \\
\hline $\begin{array}{l}\text { Área de la cara posterior } \\
\text { de la córnea área }\left[\mathrm{mm}^{2}\right]\end{array}$ & 0.807 & 0.000 & 44.2 & 91 & 44 & $0.726-0.889$ \\
\hline $\begin{array}{l}\text { Área total } \\
\text { de la córnea }\left[\mathrm{mm}^{2}\right]\end{array}$ & 0.430 & 0.171 & - & - & - & - \\
\hline $\begin{array}{l}\text { Área del plano sagital } \\
\text { en el ápex }\left[\mathrm{mm}^{2}\right]\end{array}$ & 0.872 & 0.000 & 4.275 & 91.07 & 63.54 & $0.814-0.930$ \\
\hline $\begin{array}{l}\text { Área del plano sagital en el } \\
\text { punto de mínimo espesor } \\
{\left[\mathrm{mm}^{2}\right]}\end{array}$ & 0.867 & 0.000 & 4.275 & 92.98 & 60 & $0.8082-0.925$ \\
\hline $\begin{array}{l}\text { Desviación del ápex anterior } \\
\text { [mm] }\end{array}$ & 0.735 & 0.000 & 0.0015 & 71.4 & 91.4 & $0.630-0.840$ \\
\hline $\begin{array}{l}\text { Desviación del ápex posterior } \\
\text { [mm] }\end{array}$ & 0.891 & 0.000 & 0.0855 & 91.1 & 72.9 & $0.814-0.967$ \\
\hline Centro de masas en $X[\mathrm{~mm}]$ & 0.444 & 0.168 & - & - & - & - \\
\hline Centro de masas en $\mathrm{Y}$ [mm] & 0.485 & 0.911 & - & - & - & - \\
\hline $\begin{array}{l}\text { Desviación neta del centro } \\
\text { de masas en } X Y[\mathrm{~mm}]\end{array}$ & 0.503 & 0.821 & - & - & - & - \\
\hline Centro de masas en $\mathrm{Z}$ [mm] & 0.567 & 0.159 & - & - & - & - \\
\hline $\begin{array}{l}\text { Desviación del punto de } \\
\text { mínimo espesor anterior }[\mathrm{mm}]\end{array}$ & 0.632 & 0.010 & - & - & - & - \\
\hline $\begin{array}{l}\text { Desviación del punto de } \\
\text { mínimo espesor posterior }[\mathrm{mm}]\end{array}$ & 0.634 & 0.009 & - & - & - & - \\
\hline $\begin{array}{l}\text { Volumen cilíndrico corneal } \\
\left(\mathrm{mm}^{3}\right) \text { con radio } 0.5(\mathrm{~mm})\end{array}$ & 0.945 & 0.000 & 0.405 & 92.8 & 78.13 & $0.912-0.977$ \\
\hline $\begin{array}{l}\text { Volumen cilíndrico corneal } \\
\left(\mathrm{mm}^{3}\right) \text { con radio } 1(\mathrm{~mm})\end{array}$ & 0.937 & 0.000 & 1.625 & 89.09 & 78.13 & $0.901-0.974$ \\
\hline $\begin{array}{l}\text { Volumen cilíndrico corneal } \\
\left(\mathrm{mm}^{3}\right) \text { con radio } 1.5(\mathrm{~mm})\end{array}$ & 0.919 & 0.000 & 3.720 & 89.09 & 78.13 & $0.875-0.962$ \\
\hline $\begin{array}{l}\text { Volumen cilíndrico corneal } \\
\left(\mathrm{mm}^{3}\right) \text { con radio } 2(\mathrm{~mm})\end{array}$ & 0.896 & 0.000 & 6.765 & 89.09 & 77.08 & $0.844-0.948$ \\
\hline
\end{tabular}

Tabla 4.4 Análisis ROC de la sensibilidad versus 1-especificidad en el diagnóstico para las variables estudiadas

Las variables que mejor permitieron discriminar entre el grupo de ojos sanos y el grupo de ojos enfermos fueron las siguientes (Figura 4.6): superficie de la cara anterior de la córnea $(\mathrm{p}<0.000)$; superficie de la cara posterior de la córnea $(\mathrm{p}<0.000)$; área del plano sagital en el ápex $(\mathrm{p}<0.000)$; área del plano sagital en el ápex en el punto de mínimo espesor $(\mathrm{p}<0.000)$; desviación del ápex anterior $(\mathrm{p}<0.000)$; desviación posterior 
del ápex ( $\mathrm{p}<0.000) ; y$ finalmente, los cuatro volúmenes cilíndricos en máxima curvatura en $0.5,1.0,1.5$ y $2.0 \mathrm{~mm}$ desde el eje que pasa a través del punto de mínimo espesor $(\mathrm{p}<0.000)$.
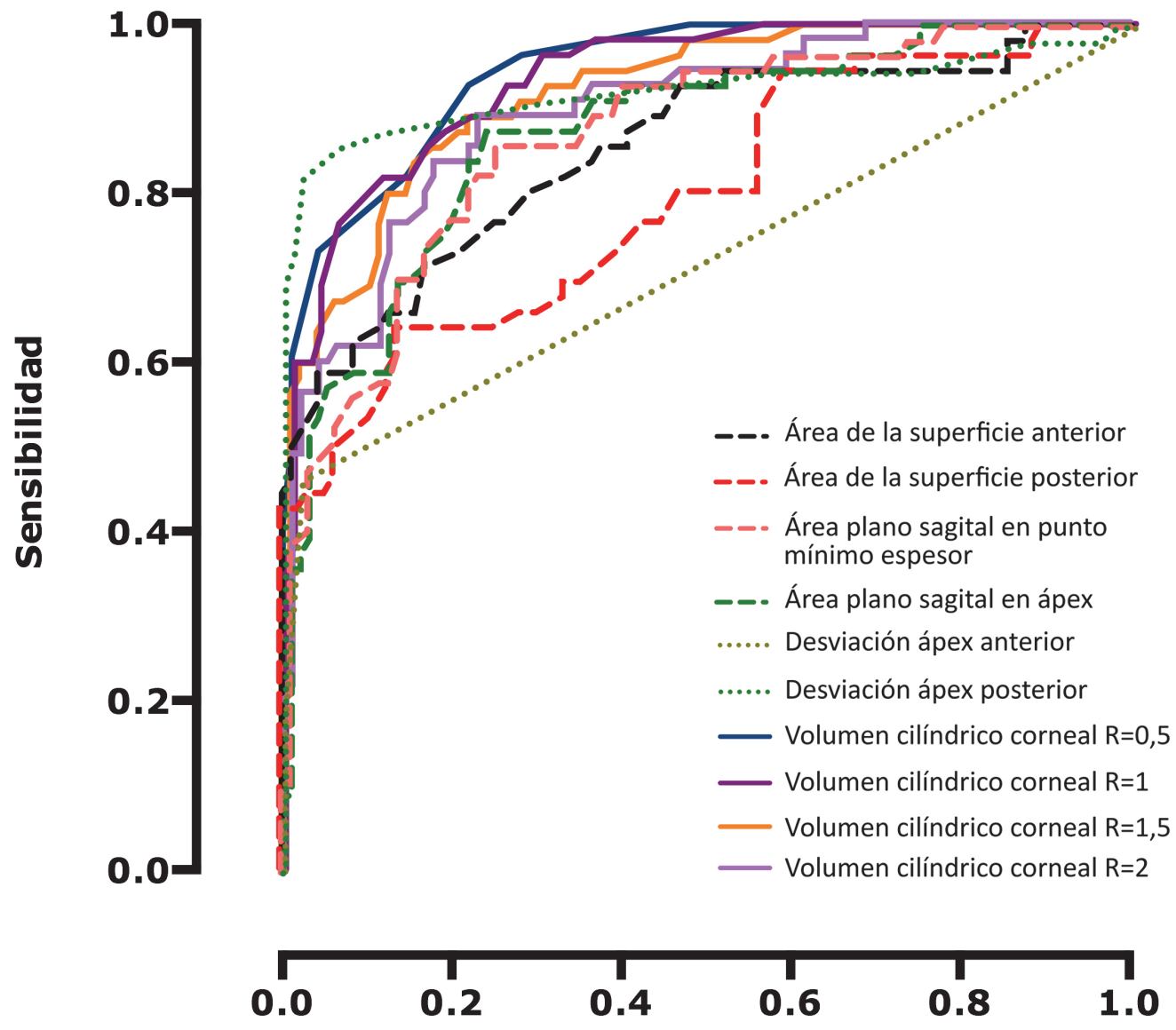

1 - Especificidad

Figura 4.6 Representación gráfica de la sensibilidad versus la especificidad de las variables con un área bajo la curva superior a 0.7 


\section{Discusión}


Esta tesis doctoral propone un nuevo procedimiento de reconstrucción y de generación de un modelo sólido personalizado de la córnea para pacientes in vivo en un entorno virtual. El nuevo modelo reproduce fidedignamente la arquitectura corneal tanto para córneas de pacientes sanos como para córneas de pacientes diagnosticados con queratocono.

El modelado de la córnea humana puede ser realizado desde dos puntos de vista distintos: por un lado el modelado basado en los denominados modelos genéricos, los cuales no son válidos para el diagnóstico clínico de las patologías corneales al no considerar las características individuales de cada paciente; y por otro lado, el modelado basado en los denominados modelos personalizados, los cuales son interesantes para el diagnóstico clínico de determinadas patologías corneales relacionadas con la modificación de la arquitectura corneal, ya que estos modelos no prescinden de las características individuales de cada paciente en particular; este último enfoque es el que ha sido empleado en este trabajo de investigación.

Los modelos personalizados pueden ser realizados a partir de dos técnicas distintas de caracterización: las técnicas basadas en tratamiento de imágenes y las técnicas basadas en topografía corneal. Las primeras plantean una baja fiabilidad en el proceso de adquisición y tratamiento de las imágenes, debido fundamentalmente a los errores durante el proceso de adquisición de los datos y a una incorrecta integración del binomio examinador-paciente (Wang et al., 2015). A raíz de estos errores, algunos autores proponen la interpolación de los datos para completar la reconstrucción del modelo personalizado, que puede ser realizada mediante el uso de un software específico (Ang et al., 2013) o bien empleando un software comercial (Garrido et al., 2014; Wang et al., 2015); no obstante esto implica un sesgo, y en consecuencia, una desvirtualización del modelo (Lohfeld et al., 2005). Las otras técnicas, basadas en las técnicas de topografía corneal, sí permiten obtener un conjunto completo de datos espaciales representativos de la morfología corneal sin la necesidad de realizar esa interpolación.

El modelo personalizado in vivo propuesto en esta tesis doctoral está generado solamente con los datos obtenidos por los equipos empleados para la medición (topógrafos), de forma que en ningún momento se recurre al proceso de interpolación de los datos que pueda generar un sesgo de la información de partida, y en consecuencia, una alteración de la morfología de la arquitectura corneal. La adopción de este criterio se debe a que uno de los principales objetivos de este trabajo de tesis es generar un modelo capaz de reproducir fidedignamente la superficie de la cara anterior y posterior de la córnea, con el fin de poder caracterizar ambas y proponer unos nuevos índices de diagnóstico clínico de la patología ectásica corneal más importante, el queratocono. Así, estos índices aplicados a la caracterización geométrica de la patología evidencian la alteración de la morfología corneal desde el estadio inicial o grado más leve, hasta el estadio más avanzado o grado más severo.

El Diseño Geométrico Asistido por Ordenador (DGAO), empleado en este trabajo para la obtención del modelo virtual, está siendo ampliamente utilizado en el campo de la 
bioingeniería para caracterizar estructuras biológicas mediante desarrollo de modelos virtuales con diferentes finalidades. Concretamente para el diagnóstico clínico y posterior tratamiento de patologías mediante técnicas invasivas o no (Lee et al., 2009; Almeida y Bártolo, 2013; Whu et al., 2015), el análisis del comportamiento de las estructuras biológicas en un escenario patológico mediante métodos numéricos (Brand et al., 2014; C IC, et al., 2014; Schmidt et al., 2015), análisis anatómicos con fines educativos mediante la generación de modelos virtuales 3D (Rocha et al., 2014) y la generación de modelos físicos de las estructuras biológicas utilizando la impresión en 3D (Schubert et al., 2014). Sin embargo, para conocimiento del autor del trabajo, no consta en la literatura científica la existencia previa en el campo de la Oftalmología de un modelo virtual personalizado in vivo de la córnea humana.

Uno de los aspectos característicos del modelo virtual propuesto en esta tesis doctoral es que ha sido generado a partir de dos etapas: una primera etapa, de reconstrucción fidedigna de las superficies de la cara anterior y posterior de la córnea a partir de conjunto discreto de puntos espaciales, y una segunda etapa, de generación del modelo sólido a partir de ambas superficies. Ambas etapas han sido desarrolladas utilizando herramientas basadas en DGAO. En trabajos previos, algunos autores proponen el uso del DGAO para generar solamente la superficie de la cara anterior de la córnea, a partir de puntos espaciales obtenidos por los datos aportados por los topógrafos corneales (Donnelly, 2008; Talu et al., 2011; Giovanzana, 2011), o bien realizan el modelo a partir de las imágenes realizadas a los cortes realizados a ojos de pollo ex vivo, utilizando técnicas de tratamiento de imágenes (Genest, 2010; Wong et al., 2012). Sin embargo, a diferencia del presente estudio, estos trabajos tienen como finalidad el análisis óptico a partir de la reconstrucción de la superficie anterior de la córnea, si bien la misma no resulta completa, dado que se desarrolla a partir de la interpolación de los datos obtenidos por los topógrafos, con el fin de generar una nube de puntos completa, para posteriormente reconstruir la superficie corneal utilizando la herramienta DGAO.

Así, el procedimiento de reconstrucción de las superficies corneales propuesto en esta tesis doctoral difiere del descrito por estos autores, ya que se han considerado exclusivamente los datos espaciales aportados por los topógrafos corneales, y esto aún a pesar de la dificultad para obtener una reconstrucción completa que comprenda todas las regiones de la córnea en un ambiente virtual, dada la baja densidad de los datos representativos de la superficie corneal posterior que pueden proporcionar estos equipos. En función de esta limitación, el procedimiento de reconstrucción en este trabajo comprende solamente la región corneal desde el centro $(\mathrm{r}=0 \mathrm{~mm}$, incluyendo la región central y paracentral) hasta el comienzo de la región periférica $(\mathrm{r}=4 \mathrm{~mm})$. La adopción de este criterio se basa en dos principios fundamentales:

- Uno geométrico, debido a que con la información que aporta el topógrafo corneal empleado se obtienen sobre la región corneal definida un total de 10752 puntos espaciales (5376 puntos por cara), representativos de la morfología de las superficies corneales anterior y posterior. 
- Otro clínico, debido a que la región corneal definida comprende el 97\% de los casos diagnosticados de queratocono (Wilson et al., 1991).

Otra de las peculiaridades del método empleado en este trabajo de investigación es el uso de un método zonal para la reconstrucción de la superficie corneal, dado que el estándar más utilizado en el campo de la Oftalmología está basado en el uso de los métodos de reconstrucción modales, más concretamente los basados en los desarrollos matemáticos de los polinomios de Zernike (ANSI, 2004; Klyce et al., 2004; Schneider, et al., 2009; Espinosa et al., 2010). El empleo de estos polinomios adolece de una serie de problemas que han sido discutidos ampliamente en la literatura científica, siendo el más importante la imprecisión del método en la evaluación de morfologías corneales anómalas, ya que impiden obtener una reconstrucción fidedigna en los casos de topografías complejas, que precisamente son las de mayor interés clínico (Smolek y Klyce, 2005; Carvalho, 2005; Ares y Rollo; 2006; Ramos-López et al., 2011).

Adicionalmente, una dificultad añadida en el empleo de Zernike es determinar la correcta estimación del número de polinomios a utilizar en la reconstrucción (Schwiegerling y Greivenkamp, 1989; Smolek y Klyce, 2005); si bien algunos autores han propuesto técnicas objetivas de estimación del número de coeficientes de expansión a considerar en el polinomio de reconstrucción, es importante señalar la complejidad computacional de las mismas (Iskander et al., 2008; Alkhaldi et al., 2009). Como alternativa a los polinomios de Zernike, diversos autores describen otros desarrollos matemáticos dentro de los métodos modales (Dai, 2006; Wang et al., 2007; Yoon et al., 2008; Ramos-López et al., 2011; Martinez-Finkelshtein et al., 2011; Okrasinski y Plociniczak, 2012; Plociniczak et al., 2014); no obstante, adolecen de los mismos problemas de Zernike o inclusive otros, como una elevada complejidad en el manejo de errores residuales, o la presentación de resultados controvertidos en algunos casos. Así, la propuesta de reconstrucción de las superficies corneales a partir de los denominados métodos zonales en esta tesis tiene como objeto solventar las dificultades asociadas a los métodos modales ya descritas, si bien su uso no es común en el ámbito de la Oftalmología. Para ello, se ha empleado funciones numéricamente estables, flexibles y que presentan una gran precisión en el ajuste, denominadas B-Splines (Pielg, 1991; Piegl y Tiller, 1997).

Las funciones B-Splines han sido utilizadas previamente con éxito en algunos trabajos para la caracterización de la superficie topográfica corneal (Turuwhenua y Henderson, 2004; Turuwhenua, 2008; Zhu et al., 2010; Zhu et al., 2011), en la caracterización del globo ocular (Xing y Wei, 2014), en el diseño de lentes ópticas para el tratamiento del queratocono (Rosenthal y Cotter, 1995) y en el diseño de una prótesis de superficie ocular para una patología corneal denominada queratoglobo (Mahadevan et al., 2014). Sin embargo, para conocimiento de los autores no consta su uso en la literatura científica como una función de reconstrucción de superficies corneales para la generación de un modelo virtual de la córnea humana.

Otro aspecto importante en la elaboración de estos modelos es el equipo utilizado, ya que existen diferentes topógrafos corneales que permiten la obtención de los puntos 
espaciales representativos de las superficies corneales. Estos equipos utilizan tecnologías diversas; por un lado están los basados en la reflexión de la luz sobre la córnea, los cuales presentan varias limitaciones, como las derivadas de su algoritmo de reconstrucción superficial, que presenta dificultades para caracterizar fidedignamente la morfología corneal, ampliamente discutido en la literatura (Rand et al., 1997). Por ello, el equipo empleado para este trabajo está basado en la proyección de una hendidura de luz sobre la córnea; estos equipos de hendidura integran una doble tecnología: la proyección de una hendidura de luz sobre la córnea y el principio fotográfico de Scheimpflug. La integración de la información que ofrecen presenta varias ventajas respecto a otras tecnologías: permiten el análisis de toda la región corneal con una elevada resolución y precisión en términos de elevación, curvatura y potencia de toda la córnea (Piñero, 2013), habilitan la caracterización de la morfología corneal en córneas que presentan un elevado grado de irregularidad en su superficie debido a un grado severo de queratocono (Montalbán, 2013), y presentan un grado excelente en términos de repetibilidad en las diferentes mediciones realizadas en la cara anterior y posterior de la córnea (Wang et al., 2012).

Las soluciones comerciales más empleadas son los equipos Pentacam (Oculus, USA), Galilei (Ziemer, Suiza) y Sirius (CSO, Italia), que ofrecen medidas repetibles de la morfología corneal. No obstante, hay autores que han descrito que el grado de concordancia entre las medidas anatómicas que ofrece cada uno de ellos es cuestionable (Saloutti et al., 2009; Savini et al., 2011a; Nasser et al., 2012; Montalbán, 2013; Hernandez-Camarena et al., 2014). A diferencia del equipo que ha sido utilizado para obtener los datos en este trabajo, el topógrafo Sirius (CSO, Italia), los equipos Pentacam (Oculus, USA) y Galilei (Ziemer, Suiza) precisan de un elevado tiempo para la rotación y adquisición simultánea de datos para la medida de la morfología corneal, en comparación con el equipo Sirius (CSO, Italia), de forma que la precisión de la medida puede verse influenciada por la estabilidad de la película lagrimal durante dicho proceso (Montalbán, 2013). La obtención de la topografía corneal utilizando el equipo Sirius (CSO, Italia) se realiza en dos etapas: en la primera se adquieren y tratan internamente los datos, y en la segunda se reconstruye la superficie corneal mediante métodos modales con un ajuste posterior a una superficie de referencia, que permite al aparato obtener por comparación entre ambas superficies el mapa topográfico corneal (con las dificultades de los métodos modales, anteriormente comentadas).

Los datos analizados en este trabajo son los obtenidos en la primera etapa descrita, utilizando para el modelo propuesto la metodología zonal a partir del conjunto discreto y finito de puntos representativos de la morfología corneal que ofrece el topógrafo, conocidos en la literatura científica como "datos en bruto" (Ramos-Lopez et al., 2011; Roy y Dupss, 2011; Bao et al., 2013; Ariza-Gracia et al., 2015). Existen algunos trabajos previos que, como el presente, han desarrollado la construcción de modelos a partir de estos datos en bruto de la primera etapa, entre otros, la caracterización geométrica de la córnea a partir de la evaluación de la simetría corneal utilizando parámetros de forma y posición (Bao et al., 2010), o el desarrollo de un modelo biomecánico personalizado basado en la obtención de la geometría del paciente (Roy y 
Dupss, 2011; Ariza-Gracia et al., 2015), realizados a partir de las coordenadas cartesianas $(\mathrm{x}, \mathrm{y}, \mathrm{z})$ que aporta el topógrafo Pentacam. Sin embargo, en los dos casos se mantiene el proceso de interpolación de estos datos en bruto, debido a los problemas extrínsecos del "trinomio" examinador-equipo-paciente que anteriormente han sido descritos, y que afectan al proceso de medida, ya que las pequeñas alteraciones morfológicas de la córnea debidas a una patología como el queratocono no pueden ser fielmente reproducidas, lo que resta sensibilidad a cualquier intento de caracterización de la enfermedad con fines diagnósticos, sobre todo si consideramos las mínimas diferencias que puedan presentar la morfología corneal en un grado incipiente de la enfermedad con respecto la córnea sana.

Para conocimiento de los autores, el único estudio similar al presentado en el que solamente se han considerado los datos espaciales obtenidos en bruto, sin interpolación en la reconstrucción de la superficie anterior de la córnea, es el de Ramos-Lopez et al. (2011). Estos autores utilizaron en su trabajo datos aportados por el topógrafo corneal EyeTop 2005 (CSO, Italia), presentando un modelo bidimensional de córneas de pacientes sanos y de córneas de pacientes diagnosticados con queratocono. La novedad de esta tesis, respecto al trabajo previo de Ramos-Lopez et al., es el procedimiento personalizado de reconstrucción y generación de un modelo sólido virtual en 3D de la córnea humana para un paciente in vivo y sin interpolación de los datos espaciales en bruto.

Trabajar en tres dimensiones permite caracterizar morfológicamente con mayor exactitud cualquier variación de la córnea: este modelo en 3D permite alcanzar uno de los objetivos propuestos en esta tesis doctoral, que es definir unos índices cuantitativos de la irregularidad de la superficie corneal, y que estos puedan distinguir los ojos sanos de los enfermos, de forma que los mismos puedan ser utilizados como una nueva técnica de diagnóstico clínico de la patología del queratocono a partir de un análisis morfológico preciso. Si bien existen en la actualidad índices para el diagnóstico del queratocono ampliamente aceptados por toda la comunidad oftalmológica, basados en sistemas cuantitativos de detección univariante o multivariante (Dingeldein et al., 1989; Wilson y Klyce, 1991; Maeda et al., 1994; Smolek y Klyce, 1997; Rabinowitz y Rasheed, 2000; Ambrosio et al., 2006; Abad et al., 2007), ninguno de ellos presenta un 100\% de sensibilidad y especificidad en el diagnóstico de ectasias corneales, y no son medidos directamente por los topógrafos corneales, sino que son calculados por complejos algoritmos internos de los equipos topográficos basados en los datos obtenidos a partir de las superficies corneales reconstruidas con los métodos modales anteriormente descritos, por lo que pueden ser fuente de errores asociados a posibles suposiciones o hipótesis implícitas en aras de simplificar los cálculos de los índices de diagnóstico propuestos (Espinosa et al., 2013).

De la misma forma, y al ser definidos y calculados para un equipo topográfico concreto, basado en una determinada tecnología, presentan una elevada especificidad para el equipo para el cual han sido desarrollados, por lo que es complejo establecer comparaciones entre estos índices, no siendo fácil extrapolar los resultados obtenidos 
por un equipo a otros equipos topográficos. Así, la técnica propuesta en el presente trabajo, además de permitir el diagnóstico clínico del queratocono, presenta la ventaja añadida de que el procedimiento definido para su cálculo no es específico para un topógrafo corneal en concreto, sino que es válido para cualquiera que presente ideonización; esto es, que se puede aplicar a cualquier modelo sólido virtual en 3D de la córnea generado a partir de los datos de altimetría, normalizados en bruto y obtenidos en la primera etapa de cualquier topógrafo corneal, independientemente de la tecnología que emplee para ello. Este tratamiento permite una técnica de diagnóstico objetiva, ya que se basa en un sistema cuantitativo de detección multivariante a partir de unos índices de valoración de la irregularidad de la superficie corneal, fundamentados en parámetros geométricos descriptivos. Aun partiendo de una aproximación más sencilla y bidimensional, los resultados del trabajo de Ramos-López et al. (2011) coinciden con los de esta tesis al demostrar que los nuevos índices propuestos para el diagnóstico clínico pueden resultar válidos.

Los índices definidos en este trabajo integran ambas superficies de la córnea y hacen innecesario el análisis aberrométrico de cada una de ellas, posibilitando una vía más sencilla y global para diferenciar ojos sanos de ojos enfermos a partir de cálculos volumétricos, paquimétricos, áreas de superficies y desviaciones en el plano XY. En relación a las variables volumétricas, se observan diferencias estadísticamente significativas entre grupos, tanto en la superficie como en el volumen de la córnea, sensiblemente menor en los individuos del grupo de ojos enfermos respecto a los sanos. El mismo comportamiento se observa en los volúmenes cilíndricos corneales R$\mathrm{x}$ : existe un mayor volumen en los ojos sanos en la intersección del modelo 3D y el cilindro con radio $\mathrm{x}$; con una tendencia similar en todos los radios estudiados (de 0.5 $\mathrm{mm}$ a $2 \mathrm{~mm}$ ) aunque más acusada en el cilindro de menor tamaño (0.5 mm). Estos cambios pueden deberse, fundamentalmente, al proceso de deterioro progresivo de la enfermedad que altera las proteínas en las fibras de colágeno que componen la córnea (Buey Salas y Peris Martinez, 2014), causando adelgazamiento de la capa estromal y lesiones en la membrana de Bowman. La red reticular constituida por las fibras de colágeno de una córnea sana son alteradas hasta llegar a una distribución irregular (Montalbán, 2013) y de esta forma se deterioran los puentes de colágeno. Esta observación de la reducción volumétrica se ha descrito en otros trabajos al comparar ojos sanos y ojos enfermos, lo que confirma los resultados obtenidos que indican la existencia de una significativa modificación de la protusión corneal (Emre et al., 2007; Cerviño et al., 2009; Mannion et al., 2011; Piñero et al., 2010b; Montalbán, 2013; VegaEstrada et al., 2013).

De la misma forma, la extensión de la superficie corneal, se observan diferencias entre la cara anterior y posterior de los ojos enfermos y los ojos sanos, siendo mayor en los casos patológicos, lo que es consecuente con los cambios en la protusión y la irregularidad del área que provoca la enfermedad y el aumento del radio de curvatura que causa el incremento del área de la superficie (Rabinowitz, 1998). Estos resultados, sin embargo, difieren de las observaciones realizadas del área de la superficie corneal total que ha sido examinada; para su cálculo se consideró la superficie total anterior y 
posterior, y el área de la córnea periférica. Esta área periférica es mayor en el caso de los ojos sanos, ya que los enfermos adolecen de un descenso en el número de lamelas estromales y una disminución en la interconexión entre la superficie lamelar al nivel de la córnea irregular (Fullwood et al., 1992; Sherwin et al., 2002; Uçakhan et al., 2006; Kobayashi et al., 2006). No obstante, la presencia de un área mayor no es tan importante como la de un volumen adecuado acompañado por una densidad alta: la red de fibras de colágeno es compacta, haciendo a la córnea más resistente a las fuerzas que la solicitan, y retrasando la progresión de esta enfermedad, en el caso de existir.

De nuevo, la misma tendencia se da en el caso de los planos sagitales en el área del ápex y en el área de mínimo espesor, siendo mayores en las córneas sanas que se han analizado. Con toda probabilidad el mayor volumen en las córneas sanas es la causa de estas diferencias; no obstante se puede destacar el trabajo de Rao et al. (2002), en el que no se han encontrado diferencias estadísticamente significativas en los valores de paquimetría central. En los puntos relacionados con el punto de mayor altura de la superficie anterior y posterior de la córnea, el denominado ápex corneal, se han observado diferencias significativas entre grupos en la desviación del ápex de ambas superficies, siendo mayor en los sujetos enfermos (Rabinowitz, 1998; Rabinowitz y McDonnell, 1998; Wilson et al., 1991).

En el caso de la desviación del ápex en la superficie de la cara anterior no se hayan resultados en las córneas sanas 0.000 (0.000-0.000 IC 95\%), pero sí una desviación ligera acusada en los ojos enfermos 0.008 (0.005-0.012 IC 95\%), lo que indica que se puede apreciar en esta superficie anterior la alteración más acusada en la posterior, que en la muestra estudiada es de 0.077 (0.063-0.090 IC 95\%) en el caso de los ojos sanos, con una repercusión menor que la que presentan los casos clínicos 0.1886 (0.1587-0.2185 IC $95 \%$ ). En el caso de las desviaciones en el punto de mínimo espesor del ápex de la superficie anterior y de la superficie posterior, se vuelven a constatar las diferencias estadísticamente significativas entre ambos grupos, siendo menor en el grupo de ojos sanos la desviación del ápex relativa al eje $\mathrm{Z}$ de ambas superficies, aunque más acusada en el área posterior, más curvada siempre que la anterior. La presencia de irregularidad en la superficie corneal en forma de protusión puede influir en este resultado, incrementando la curvatura corneal y disminuyendo la distancia de la desviación del ápex.

Algunos autores han evaluado los radios de irregularidad corneal, concluyendo que son significativamente mayores cuando se manifiesta el queratocono (Tanabe et al., 2004; Lim et al, 2007). Saad et al. (2010) han mostrado en un trabajo previo que sólo la combinación de esos índices de irregularidad de las zonas más delgadas de la córnea permite distinguir la enfermedad con un $92 \%$ de precisión, describiendo que la elevación posterior del punto de mínimo espesor de la córnea es significativamente mayor en el caso de ojos enfermos, corroborando la hipótesis de que este parámetro puede ser un elemento que permita discriminar bien la enfermedad, incluso en estadios iniciales de la misma (Schlegel et al., 2008). 
En definitiva, la nueva técnica no invasiva de diagnóstico clínico desarrollada en esta tesis doctoral puede complementar los actuales índices de valoración de la irregularidad corneal ampliamente aceptados por la comunidad oftalmológica; no en vano diferentes variables discriminan con facilidad ambos grupos con una sensibilidad y especificidad elevadas. Este nuevo concepto de análisis morfológico integral de la córnea puede permitir que se analicen, además de los datos obtenidos de los nuevos índices geométricos propuestos, los datos más significativos aportados por los diferentes índices basados en sistemas de detección univariante y multivariante, con el fin de que el médico oftalmólogo disponga de un conjunto de recursos fiables que sirvan para emitir un juicio clínico de diagnóstico de la patología del queratocono con la mayor sensibilidad y especificidad posible. 


\section{Conclusiones}




\subsection{Conclusiones}

Las conclusiones más relevantes de este trabajo de investigación se pueden dividir en dos aspectos diferentes: uno relativo a las conclusiones en el ámbito del modelado geométrico y otras en el ámbito del diagnóstico clínico en el campo de la oftalmología.

\subsubsection{Geométricas}

- Se ha demostrado que el Diseño Geométrico Asistido por Ordenador (DGAO) es una herramienta útil y potente que permite el modelado y estudio de las estructuras biológicas más eficiente que el análisis experimental de especímenes reales.

- Se ha demostrado que el modelado de la córnea in vivo en un entorno virtual es capaz de no prescindir de las características individuales de cada paciente, en particular frente a los modelos genéricos existentes en la literatura científica.

- El modelado sólido generado de la córnea presenta una elevada sensibilidad para la caracterización morfológica de la arquitectura corneal, distinguiendo córneas sanas de córneas enfermas en pacientes diagnosticados con la patología ectásica más común, el queratocono.

- Se ha demostrado que el conjunto discreto de los puntos espaciales obtenidos de la primera etapa por los topógrafos corneales basados en la proyección de una hendidura de luz sobre la córnea y en el principio de fotografía Scheimpflug, es válido para la reconstrucción de las superficies de la cara anterior y posterior de la córnea.

- Los métodos zonales utilizados para la reconstrucción de las superficies corneales son válidos frente a los tradicionales métodos modales empleados por los topógrafos corneales.

\subsubsection{Clínicas}

- Se ha generado un modelo virtual de la córnea que permite una nueva aproximación al estudio de la anatomía corneal in vivo y de forma personalizada.

- Se demostrado que trece de los nuevos índices propuestos para la valoración cuantitativa y cualitativa objetiva de la irregularidad de la superficie corneal, aplicados sobre los modelos virtuales generados, son capaces de distinguir córneas sanas de córneas con queratocono.

- La caracterización geométrica a partir de estos índices no es específica para un topógrafo corneal en concreto, sino que es válido para cualquier topógrafo que presente ideonización, dado que dicha caracterización se aplica al modelado solido virtual. 
- Once de los nuevos índices permiten discriminar diferentes grados de severidad del queratocono acorde al sistema de clasificación de AmslerKrumeich.

- Se ha demostrado que los índices más sensibles y específicos para el diagnóstico de los ojos enfermos son los volúmenes cilíndricos corneales R-x (de 0.5 a 2 $\mathrm{mm}$ ), el área del plano sagital que pasa por el ápex anterior, el área del plano sagital que pasa por el punto de mínimo espesor anterior, las áreas de las superficies corneales anterior y posterior y las desviaciones anterior y posterior del ápex. Estos índices permiten el diagnóstico anatómico con una probabilidad muy reducida de error de tipo I $(\alpha)$ y error de tipo II $(\beta)$, proporcionando en su conjunto un nuevo sistema cuantitativo de detección multivariante del queratocono.

\subsection{Contribuciones}

\subsubsection{Publicaciones indexadas en el Journal Citation Reports}

1. Cavas-Martinez F, Fernandez-Pacheco DG, De la Cruz-Sanchez E, Nieto Martínez J, Fernández Cañavate FJ, Vega-Estrada A, Plaza-Puche AB, Alió JL. Geometrical custom modeling of human cornea in vivo and its use for the diagnosis of corneal ectasia. PloS one 2014, 9(10):e110249.

2. Cavas-Martinez F, Fernandez-Pacheco DG, De la Cruz-Sanchez E, Nieto Martínez J, Fernández Cañavate FJ, Alió JL. Virtual biomodelling of a biological structure: the human cornea. DYNA (en prensa).

\subsubsection{Patentes}

Cavas-Martinez F, Fernandez-Pacheco DG, De la Cruz-Sanchez E, Nieto Martínez J, Fernández Cañavate FJ, Vega-Estrada A, Plaza-Puche AB, Bataille L, Alió JL. Procedimiento y sistema para detectar queratocono subclínico. Número de Solicitud: P201431361. Fecha de Registro: 19/09/2014. Entidad titular de derechos: Universidad Politécnica de Cartagena y Universidad de Murcia.

\subsubsection{Contratos de investigación $I+D$}

Título del contrato/proyecto: Análisis del Comportamiento Geométrico y Biomecánico de la Córnea y de las enfermedades de la Córnea (Ectasias Corneales) relacionadas con el debilitamiento estructural de los tejidos que forman parte de la Arquitectura Corneal. Empresa financiadora: Vissum Corporación S.L. Entidades participantes: Universidad Politécnica de Cartagena. Duración, desde: 01/10/2013 hasta: 01/10/2014 Investigador responsable: Daniel García Fernández-Pacheco. Director CientíficoTécnico: Francisco Cavas Martínez. Número de investigadores participantes: 7. IMPORTE TOTAL DEL PROYECTO: 33.456,25€ 
Título del contrato/proyecto: Diseño óptimo de un modelo geométrico de la córnea y sus tratamientos refractivos asociados mediante la aplicación de Tecnologías CAD. Empresa financiadora: Vissum Corporación S.L. Entidades participantes: Universidad Politécnica de Cartagena. Duración, desde: 01/10/2013 hasta: 1/10/2014. Investigador responsable: Francisco José Fernández Cañavate. Director Científico-Técnico: Francisco Cavas Martínez. Número de investigadores participantes: 7. IMPORTE TOTAL DEL PROYECTO: $36.258,05 €$

\subsubsection{Congresos internacionales}

Cavas-Martinez F, Fernandez-Pacheco DG, De la Cruz-Sanchez E, Nieto Martínez J, Fernández Cañavate FJ, Alió JL. Virtual biomodelling of a biological structure: the human cornea. XXV International Conference on Graphics Engineering. San Sebastian, España. 2015.

\subsubsection{Premios de investigación}

Premio a la mejor comunicación del XXV International Conference on Graphics Engineering. San Sebastian, España. 2015.

\subsubsection{Publicaciones en prensa}

Desarrollan un sistema para modelar la córnea con modelos geométricos, ABC.es. http://www.abc.es/agencias/noticia.asp?noticia=1699061

Investigadores de la UPCT desarrollan un sistema para corregir defectos en la vista. La verdad (Murcia). http://www.laverdad.es/murcia/cartagena/201410/22/investigadoresupct-desarrollan-sistema-20141022013025-v.html

La UPCT facilita el diagnóstico de enfermedades de córnea. La Opinión de Murcia. http://www.laopiniondemurcia.es/cartagena/2014/10/22/upct-facilita-diagnosticoenfermedades-cornea/598241.html

Investigadores de la UPCT contribuyen con geometría computacional al diagnóstico de enfermedades de la córnea. Europa Press. http://www.europapress.es/murcia/noticiainvestigadores-upct-contribuyen-geometria-computacional-diagnostico-enfermedadescornea-20141021093336.html

Premiados por desarrollar una herramienta que ayuda a los oftalmólogos a diagnosticar una enfermedad rara. Informativostelecinco.com. http://www.telecinco.es/informativos/ sociedad/Premiados-desarrollar-herramientaoftalmologos-diagnosticar 0 2012325151 html

La UPCT mejora la detección de problemas en la córnea. La verdad (Murcia). http://www.laverdad.es/murcia/cartagena/201507/02/upct-mejora-deteccion-problemas -20150702020311-v.html 


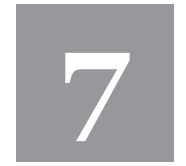

Prospectivas de estudio 
El trabajo de investigación desarrollado en esta tesis doctoral es el primero desarrollado por el Grupo de Ingeniería Multidisciplinar y Seguridad (Universidad Politécnica de Cartagena) en la línea de investigación sobre el modelado de estructuras biológicas en relación con la córnea humana, en el cual se han aglutinado diversos temas de interés clínico y geométrico, estableciendo una metodología para el modelado virtual de la córnea humana. En el futuro, sería de interés poder continuar desarrollando, desde el punto de vista geométrico, algunos aspectos ya abordados.

A continuación se presentan algunas líneas de investigación cuya motivación surge a partir de esta tesis doctoral, todas ellas de alto interés clínico:

- Desarrollo de un modelo virtual completo personalizado in vivo que comprenda todas las regiones de la córnea humana.

- Generar un modelo virtual personalizado in vivo de la córnea humana para ojos diagnosticados con otras ectasias corneales menos comunes, y aplicar los nuevos índices propuestos para la valoración objetiva de la irregularidad corneal debida a dicha patología.

- Mejorar la detección de los casos del queratocono temprano o subclínico, pudiendo formar parte de procedimientos de cribado diagnóstico en población de riesgo; de hecho, estudios preliminares que se están desarrollando han demostrado la eficacia de este enfoque en la detección temprana del queratocono subclínico.

- A medio plazo, permitirá evaluar desde un punto de vista morfológico el efecto de los diferentes tratamientos de estas patologías, y el análisis preciso de la acción de los distintos tipos de anillos intracorneales que se implantan para corregir el error de refracción en los pacientes con ectasia corneal; estos análisis permitirán la personalización y optimizarán los nomogramas de los implantes. Además, se puede establecer el estudio del efecto de los implantes intracorneales sobre los parámetros visuales de calidad y el comportamiento biomecánico de la córnea de los pacientes afectados de ectasias, lo que permitirá el desarrollo de nuevos implantes y terapias más eficaces.

- Adicionalmente al estudio de la variación morfológica debida al implante de anillos corneales, este nuevo método puede servir para el estudio longitudinal de tratamientos de refuerzo de la estructura corneal como el "crosslinking", y la efectividad de estos en la ralentización de la progresión de la enfermedad. 
Referencias 
Abad, J.C., Rubinfeld, R.S., Del Valle, M., Belin, M.W., \& Kurstin, J.M. (2007). Vertical D: a novel topographic pattern in some keratoconus suspects. Ophthalmology, 114 (5), 1020-1026.

Abalain, J.H., Dossou, H., Colin, J., \& Floch, H.H. (2000). Levels of collagen degradation products (telopeptides) in the tear film of patients with keratoconus. Cornea, 19 (4), 474476.

Akpek, E.K., \& Smith, R.A. (2013). Overview of age-related ocular conditions. The American journal of managed care, 19 (5 Suppl), S67-75.

Alastrue, V., Calvo, B., Pena, E., \& Doblare, M. (2006). Biomechanical modeling of refractive corneal surgery. Journal of biomechanical engineering, 128 (1), 150-160.

Albertazzi, R. (2010). Queratocono: pautas para su diagnóstico y tratamiento. Buenos Aires: Ediciones Científicas Argentinas.

Alessio, G., Boscia, F., La Tegola, M.G., \& Sborgia, C. (2001). Topography-driven excimer laser for the retreatment of decentralized myopic photorefractive keratectomy. Ophthalmology, 108 (9), 1695-1703.

Alió, J.L., \& I., B.J. (2004). Tratamiento del astigmatismo irregular y del queratocono. Miami: Highlights of Ophathalmology.

Alio, J.L., Pinero, D.P., Aleson, A., Teus, M.A., Barraquer, R.I., Murta, J., Maldonado, M.J., Castro de Luna, G., Gutierrez, R., Villa, C., \& Uceda-Montanes, A. (2011). Keratoconus-integrated characterization considering anterior corneal aberrations, internal astigmatism, and corneal biomechanics. Journal of cataract and refractive surgery, 37 (3), 552-568.

Alio, J.L., \& Shabayek, M.H. (2006). Corneal higher order aberrations: a method to grade keratoconus. Journal of refractive surgery (Thorofare, N.J. : 1995), 22 (6), 539-545.

Alkhaldi, W., Iskander, D.R., \& Zoubir, A.M. (2010). Model-order selection in zernike polynomial expansion of corneal surfaces using the efficient detection criterion. IEEE Transactions on Biomedical Engineering, 57 (10 PART 1), 2429-2437.

Alkhaldi, W., Iskander, D.R., Zoubir, A.M., \& Collins, M.J. (2009). Enhancing the standard operating range of a Placido disk videokeratoscope for corneal surface estimation. IEEE transactions on bio-medical engineering, 56 (3), 800-809.

Allgeier, S., Zhivov, A., Eberle, F., Koehler, B., Maier, S., Bretthauer, G., Guthoff, R.F., \& Stachs, O. (2011). Image reconstruction of the subbasal nerve plexus with in vivo confocal microscopy. Investigative ophthalmology \& visual science, 52 (9), 5022-5028.

Almeida, H.A., \& Bártolo, P.J. (2013). Computational technologies in tissue engineering. WIT Transactions on Biomedicine and Health (pp. 117-129). 
Alonso-Caneiro, D., Iskander, D.R., \& Collins, M.J. (2008). Estimating corneal surface topography in videokeratoscopy in the presence of strong signal interference. IEEE Transactions on Biomedical Engineering, 55 (10), 2381-2387.

Alonso-Caneiro, D., Szczesna-Iskander, D.H., Iskander, D.R., Read, S.A., \& Collins, M.J. (2013). Application of texture analysis in tear film surface assessment based on videokeratoscopy. Journal of Optometry, 6 (4), 185-193.

Ambrosio, R., Jr., Alonso, R.S., Luz, A., \& Coca Velarde, L.G. (2006). Corneal-thickness spatial profile and corneal-volume distribution: tomographic indices to detect keratoconus. Journal of cataract and refractive surgery, 32 (11), 1851-1859.

Ambrosio, R., Jr., Caiado, A.L., Guerra, F.P., Louzada, R., Roy, A.S., Luz, A., Dupps, W.J., \& Belin, M.W. (2011a). Novel pachymetric parameters based on corneal tomography for diagnosing keratoconus. Journal of refractive surgery (Thorofare, N.J. : 1995), 27 (10), 753-758.

Ambrosio, R., Jr., Nogueira, L.P., Caldas, D.L., Fontes, B.M., Luz, A., Cazal, J.O., Alves, M.R., \& Belin, M.W. (2011b). Evaluation of corneal shape and biomechanics before LASIK. International ophthalmology clinics, 51 (2), 11-38.

Ambrosio, R., Jr., Valbon, B.F., Faria-Correia, F., Ramos, I., \& Luz, A. (2013). Scheimpflug imaging for laser refractive surgery. Current opinion in ophthalmology, 24 (4), 310-320.

American National Standards Institute, (2004). Methods for reporting optical aberrations of eyes.

Amsler, M. (1961). The "forme fruste" of keratoconus. Wiener klinische Wochenschrift, 73, 842-843.

Anwer, N., Ballu, A., \& Mathieu, L. (2013). The skin model, a comprehensive geometric model for engineering design. CIRP Annals - Manufacturing Technology, 62 (1), 143-146.

Aras, E., \& Yip-Hoi, D. (2012). State-of-The-Art in geometric modeling for virtual machining. Proceedings of the ASME Design Engineering Technical Conference (pp. 737750).

Arba-Mosquera, S., Merayo-Lloves, J., \& de Ortueta, D. (2010). Asphericity analysis using corneal wavefront and topographic meridional fits. Journal of biomedical optics, 15 (2), 028003.

Ares, M., \& Royo, S. (2006). Comparison of cubic B-spline and Zernike-fitting techniques in complex wavefront reconstruction. Applied optics, 45 (27), 6954-6964. 
Argüeso, P., Beuerman, R., Bonini, S., Butovich, I., Dana, R., Dartt, D., Gamache, D., Ham, B., Jumblatt, M., Korb, D., Kruse, F., Ogawa, Y., Paulsen, F., Stern, M., Sweeney, D.F., Tiffany, J., Ubels, J., \& Willcox, M. (2007). Research in dry eye: report of the Research Subcommittee of the International Dry Eye WorkShop (2007). The ocular surface, 5 (2), 179-193.

Ariza-Gracia, M.A., Zurita, J.F., Pinero, D.P., Rodriguez-Matas, J.F., \& Calvo, B. (2015). Coupled biomechanical response of the cornea assessed by non-contact tonometry. A simulation study. PLoS One, 10 (3), e0121486.

Association, W.M., (2015). WMA Declaration of Helsinki - Ethical Principles for Medical Research Involving Human Subjects.

Atchison, D.A., Markwell, E.L., Kasthurirangan, S., Pope, J.M., Smith, G., \& Swann, P.G. (2008). Age-related changes in optical and biometric characteristics of emmetropic eyes. Journal of vision, 8 (4), 29.21-20.

Auerbach, S., Gmelig Meyling, R.H.J., Neamtu, M., \& Schaeben, H. (1991). Approximation and geometric modeling with simplex B-splines associated with irregular triangles. Computer Aided Geometric Design, 8 (1), 67-87.

Auffarth, G.U., Wang, L., \& Volcker, H.E. (2000). Keratoconus evaluation using the Orbscan Topography System. Journal of cataract and refractive surgery, 26 (2), 222-228.

Auvinet, E., Meunier, J., Ong, J., Durr, G., Gilca, M., \& Brunette, I. (2012). Methodology for the construction and comparison of 3D models of the human cornea. Proceedings of the Annual International Conference of the IEEE Engineering in Medicine and Biology Society, EMBS (pp. 5302-5305).

Avitabile, T., Marano, F., Uva, M.G., \& Reibaldi, A. (1997). Evaluation of central and peripheral corneal thickness with ultrasound biomicroscopy in normal and keratoconic eyes. Cornea, 16 (6), 639-644.

Bajaj, C., Ihm, I., \& Warren, J. (1993). Higher-order interpolation and least-squares approximation using implicit algebraic surfaces. ACM Transactions on Graphics, 12 (4), 327-347.

Bajaj, C.L., \& Ihm, I. (1992). Algebraic surface design with Hermite interpolation. ACM Transactions on Graphics, 11 (1), 61-91.

Bakaraju, R.C., Ehrmann, K., Papas, E., \& Ho, A. (2008). Finite schematic eye models and their accuracy to in-vivo data. Vision research, 48 (16), 1681-1694.

Bao, F., Chen, H., Yu, Y., Yu, J., Zhou, S., Wang, J., Wang, Q., \& Elsheikh, A. (2013). Evaluation of the shape symmetry of bilateral normal corneas in a Chinese population. PLoS One, 8 (8), e73412. 
Barraquer, R.I., De Toledo, M.C., \& Torres, E. (2004). Distrofias y degeneraciones corneales. Barcelona: Espax Publicaciones Médicas.

Barsky, B.A., \& Greenberg, D.P. (1980). Determining a set of B-spline control vertices to generate an interpolating surface. Computer Graphics and Image Processing, 14 (3), 203226.

Belmonte, C., \& Gallar, J. (2011). Cold thermoreceptors, unexpected players in tear production and ocular dryness sensations. Investigative ophthalmology $\mathcal{E}$ visual science, $52(6), 3888-3892$.

Binder, P.S., Lindstrom, R.L., Stulting, R.D., Donnenfeld, E., Wu, H., McDonnell, P., \& Rabinowitz, Y. (2005). Keratoconus and corneal ectasia after LASIK. Journal of cataract and refractive surgery, 31 (11), 2035-2038.

Birk, D.E., Fitch, J.M., Babiarz, J.P., Doane, K.J., \& Linsenmayer, T.F. (1990). Collagen fibrillogenesis in vitro: interaction of types I and V collagen regulates fibril diameter. Journal of cell science, 95 ( Pt 4), 649-657.

Birk, D.E., Fitch, J.M., \& Linsenmayer, T.F. (1986). Organization of collagen types I and $\mathrm{V}$ in the embryonic chicken cornea. Investigative ophthalmology \& visual science, 27 (10), 1470-1477.

Bizheva, K., Hutchings, N., Sorbara, L., Moayed, A.A., \& Simpson, T. (2011). In vivo volumetric imaging of the human corneo-scleral limbus with spectral domain OCT. Biomedical optics express, 2 (7), 1794-1702.

Blaker, J.W. (1980). Toward an adaptive model of the human eye. J Opt Soc Am, 70 (2), 220-223.

Boehm, W. (1980). Inserting new knots into B-spline curves. Computer-Aided Design, 12 (4), 199-201.

Böhm, W., Farin, G., \& Kahmann, J. (1984). A survey of curve and surface methods in CAGD. Computer Aided Geometric Design, 1 (1), 1-60.

Boote, C., Dennis, S., Huang, Y., Quantock, A.J., \& Meek, K.M. (2005). Lamellar orientation in human cornea in relation to mechanical properties. Journal of structural biology, 149 (1), 1-6.

Boote, C., Dooley, E.P., Gardner, S.J., Kamma-Lorger, C.S., Hayes, S., Nielsen, K., Hjortdal, J., Sorensen, T., Terrill, N.J., \& Meek, K.M. (2013). Quantification of collagen ultrastructure after penetrating keratoplasty - implications for corneal biomechanics. PLoS One, 8 (7), e68166.

Brand, M., Avrahami, I., Einav, S., \& Ryvkin, M. (2014). Numerical models of netstructure stents inserted into arteries. Computers in Biology and Medicine, 52, 102-110. 
Brookes, N.H., Loh, I.P., Clover, G.M., Poole, C.A., \& Sherwin, T. (2003). Involvement of corneal nerves in the progression of keratoconus. Experimental eye research, 77 (4), 515-524.

Bryant, M.R., \& McDonnell, P.J. (1996). Constitutive laws for biomechanical modeling of refractive surgery. Journal of biomechanical engineering, 118 (4), 473-481.

Buey Salas, M.A., \& Peris Martínez, C. (2014). Biomecánica y Arquitectura Corneal. Spain: ELSEVIER.

Buzard, K.A. (1992). Introduction to biomechanics of the cornea. Refractive $\mathcal{E}$ corneal surgery, 8 (2), 127-138.

C, I.C., Shyh-Yuan, L., Ming-Chang, W., Sun, C.W., \& Jiang, C.P. (2014). Finite element modelling of implant designs and cortical bone thickness on stress distribution in maxillary type IV bone. Computer methods in biomechanics and biomedical engineering, 17 (5), 516-526.

Calossi, A. (2003). The optical quality of the cornea. En: Caimi, F. \& Brancato, R. (eds.), The aberrometers: theory, clinical and surgical applications. Canelli (Italy): Fabiano Editore.

Calossi, A. (2007). Corneal asphericity and spherical aberration. Journal of refractive surgery (Thorofare, N.J. : 1995), 23 (5), 505-514.

Carney, L.G., Mainstone, J.C., \& Henderson, B.A. (1997). Corneal topography and myopia. A cross-sectional study. Investigative ophthalmology \& visual science, 38 (2), 311 320.

Carvalho, L.A. (2005). Accuracy of Zernike polynomials in characterizing optical aberrations and the corneal surface of the eye. Investigative ophthalmology $\mathcal{E}$ visual science, 46 (6), 1915-1926.

Cavas-Martínez, F., Fernández-Pacheco, D.G., De La Cruz-Sánchez, E., Nieto Martínez, J., Fernández Cañavate, F.J., Vega-Estrada, A., Plaza-Puche, A.B., \& Alió, J.L. (2014). Geometrical custom modeling of human cornea in vivo and its use for the diagnosis of corneal ectasia. PLoS ONE, 9 (10).

Cervino, A., Gonzalez-Meijome, J.M., Ferrer-Blasco, T., Garcia-Resua, C., Montes-Mico, R., \& Parafita, M. (2009). Determination of corneal volume from anterior topography and topographic pachymetry: application to healthy and keratoconic eyes. Ophthalmic $\mathcal{E}$ physiological optics : the journal of the British College of Ophthalmic Opticians (Optometrists), 29 (6), 652-660.

Chakravarti, S. (2006). Focus on molecules: keratocan (KERA). Experimental eye research, $82(2), 183-184$. 
Chan, J.S., Mandell, R.B., Burger, D.S., \& Fusaro, R.E. (1995). Accuracy of videokeratography for instantaneous radius in keratoconus. Optometry and vision science : official publication of the American Academy of Optometry, 72 (11), 793-799.

Charrot, P., \& Gregory, J.A. (1984). A pentagonal surface patch for computer aided geometric design. Computer Aided Geometric Design, 1 (1), 87-94.

Chastang, P.J., Borderie, V.M., Carvajal-Gonzalez, S., Rostene, W., \& Laroche, L. (2000). Automated keratoconus detection using the EyeSys videokeratoscope. Journal of cataract and refractive surgery, 26 (5), 675-683.

Chen, X.D., Yong, J.H., Wang, G., Paul, J.C., \& Xu, G. (2008). Computing the minimum distance between a point and a NURBS curve. CAD Computer Aided Design, 40 (10-11), 1051-1054.

Cheng, A.C., Rao, S.K., \& Lam, D.S. (2007). Accuracy of Orbscan II in the assessment of posterior curvature in patients with myopic LASIK. Journal of refractive surgery (Thorofare, N.J. : 1995), 23 (7), 677-680.

Cheng, E.L., Maruyama, I., SundarRaj, N., Sugar, J., Feder, R.S., \& Yue, B.Y. (2001). Expression of type XII collagen and hemidesmosome-associated proteins in keratoconus corneas. Current eye research, 22 (5), 333-340.

Cheng, R.K.C. (2014). Inside Rhinoceros 5. USA: Cengage Learning.

Cher, I. (2012). Fluids of the ocular surface: concepts, functions and physics. Clinical $\mathcal{E}$ experimental ophthalmology, 40 (6), 634-643.

Chotikavanich, S., de Paiva, C.S., Li de, Q., Chen, J.J., Bian, F., Farley, W.J., \& Pflugfelder, S.C. (2009). Production and activity of matrix metalloproteinase-9 on the ocular surface increase in dysfunctional tear syndrome. Investigative ophthalmology $\mathcal{E}$ visual science, 50 (7), 3203-3209.

Chu, C.J., Herrmann, P., Carvalho, L.S., Liyanage, S.E., Bainbridge, J.W., Ali, R.R., Dick, A.D., \& Luhmann, U.F. (2013). Assessment and in vivo scoring of murine experimental autoimmune uveoretinitis using optical coherence tomography. PLoS One, 8 (5), e63002.

Chung, W.T., Kim, K.J., Song, T.J., Kim, D.Y., Kim, J.L., Park, M.H., \& Shin, K.S. (2004). Simulation of an inter-block arc-welding robot for shipbuilding using a weaving motion algorithm based on a bezier spline. Proceedings of the IASTED International Conference on Modelling, Simulation, and Optimization (pp. 299-304).

Colin, J., Cochener, B., Savary, G., \& Malet, F. (2000). Correcting keratoconus with intracorneal rings. Journal of cataract and refractive surgery, 26 (8), 1117-1122. 
Conforti, G. (1983). Zernike aberration coefficients from Seidel and higher-order power-series coefficients. Optics letters, 8 (7), 407-408.

Cook, E.B. (2004). Tear cytokines in acute and chronic ocular allergic inflammation. Current opinion in allergy and clinical immunology, 4 (5), 441-445.

Coons, S.A. (1974). Surface patches and B-Spline curves. 1-16.

Cui, J., Tang, M., \& Liu, H. (2014). Dynamic shape representation for product modeling in conceptual design. Jisuanji Fuzhu Sheji Yu Tuxingxue Xuebao/Journal of Computer-Aided Design and Computer Graphics, 26 (10), 1879-1885.

Dahmen, W. (1989). Smooth piecewise quadric surfaces. En: Lyche, T. \& Schumaker, L.L. (eds.), Mathematical methods in computer aided geometric design, (pp. 181-194). New York: Academic Press Professional, Inc. .

Dahmen, W., \& Thamm-Schaar, T.M. (1993). Cubicoids: modeling and visualization. Computer Aided Geometric Design, 10 (2), 89-108.

Dai, G.M. (2006). Comparison of wavefront reconstructions with Zernike polynomials and Fourier transforms. Journal of refractive surgery (Thorofare, N.J. : 1995), 22 (9), 943948.

Dai, P., Wang, B., Bao, C., \& Ju, Y. (2010). Constructing a computer model of the human eye based on tissue slice images. International journal of biomedical imaging, 2010, 921469.

Dawson, D.G., Kramer, T.R., Grossniklaus, H.E., Waring, G.O., 3rd, \& Edelhauser, H.F. (2005). Histologic, ultrastructural, and immunofluorescent evaluation of human laserassisted in situ keratomileusis corneal wounds. Archives of ophthalmology (Chicago, Ill. : 1960), 123 (6), 741-756.

De Boor, C. (1972). On calculating with B-splines. Journal of Approximation Theory, 6 (1), 50-62.

De Boor, C. (1991). Basic B-splines. En: Piegl, L. (Ed.), Fundamental developments in CADCAM and geometric modelling. Guildford: Butterworth-Heinemann.

De Sanctis, U., Loiacono, C., Richiardi, L., Turco, D., Mutani, B., \& Grignolo, F.M. (2008). Sensitivity and specificity of posterior corneal elevation measured by Pentacam in discriminating keratoconus/subclinical keratoconus. Ophthalmology, 115 (9), 15341539.

Degen, W.L.F. (1990). Explicit continuity conditions for adjacent Bézier surface patches. Computer Aided Geometric Design, 7 (1-4), 181-189.

DelMonte, D.W., \& Kim, T. (2011). Anatomy and physiology of the cornea. Journal of cataract and refractive surgery, 37 (3), 588-598. 
DeRose, T.D. (1990). Necessary and sufficient conditions for tangent plane continuity of Bézier surfaces. Computer Aided Geometric Design, 7 (1-4), 165-179.

Diaz, J.A., Pizarro, C., \& Arasa, J. (2008). Single dispersive gradient-index profile for the aging human lens. Journal of the Optical Society of America. A, Optics, image science, and vision, 25 (1), 250-261.

Dimas, E., \& Briassoulis, D. (1999). 3D geometric modelling based on NURBS: A review. Advances in Engineering Software, 30 (9-11), 741-751.

Ding, S., Ye, Y., Tu, J., \& Subic, A. (2010). Region-based geometric modelling of human airways and arterial vessels. Computerized medical imaging and graphics : the official journal of the Computerized Medical Imaging Society, 34 (2), 114-121.

Dingeldein, S.A., Klyce, S.D., \& Wilson, S.E. (1989). Quantitative descriptors of corneal shape derived from computer-assisted analysis of photokeratographs. Refractive $\mathcal{E}$ corneal surgery, 5 (6), 372-378.

Djeu, P., Hunt, W., Wang, R., Elhassan, I., Stoll, G., \& Mark, W.R. (2011). Razor: An architecture for dynamic multiresolution ray tracing. ACM Transactions on Graphics, 30 (5).

Dogru, M., Karakaya, H., Ozcetin, H., Erturk, H., Yucel, A., Ozmen, A., Baykara, M., \& Tsubota, K. (2003). Tear function and ocular surface changes in keratoconus. Ophthalmology, 110 (6), 1110-1118.

Dong, F., \& Chen, S. (2014). A research to the ship hull form design based on parametric method and fairing criteria. Proceedings of the International Offshore and Polar Engineering Conference (pp. 738-741).

Donnelly, W., 3rd. (2008). The Advanced Human Eye Model (AHEM): a personal binocular eye modeling system inclusive of refraction, diffraction, and scatter. Journal of refractive surgery (Thorofare, N.J. : 1995), 24 (9), 976-983.

Dorairaj, S., Tsai, J.C., \& Grippo, T.M. (2012). Changing trends of imaging in angle closure evaluation. ISRN ophthalmology, 2012, 597124.

Draper, G.M., Livnat, Y., \& Riesenfeld, R.F. (2009). A survey of radial methods for information visualization. IEEE Transactions on Visualization and Computer Graphics, 15 (5), 759-776.

Drosdoff, D., \& Widom, A. (2005). Snell's law from an elementary particle viewpoint. American Journal of Physics, 73 (10), 973-975.

Dua, H.S., Faraj, L.A., Said, D.G., Gray, T., \& Lowe, J. (2013). Human corneal anatomy redefined: a novel pre-Descemet's layer (Dua's layer). Ophthalmology, 120 (9), 1778-1785. 
Duan, C.Y., Lü, H.B., \& Hu, J.Z. (2012). In vivo study on three-dimensional structure of lumbar facet joints based on computer-assisted medical image processing method. Yiyong Shengwu Lixue/Journal of Medical Biomechanics, 27 (2), 159-165.

Dubbelman, M., Sicam, V.A., \& Van der Heijde, G.L. (2006). The shape of the anterior and posterior surface of the aging human cornea. Vision research, 46 (6-7), 993-1001.

Dubbelman, M., Weeber, H.A., van der Heijde, R.G., \& Volker-Dieben, H.J. (2002). Radius and asphericity of the posterior corneal surface determined by corrected Scheimpflug photography. Acta ophthalmologica Scandinavica, 80 (4), 379-383.

Duchon, J. (1977). Splines minimizing rotation-invariant semi-norms in Sobolev spaces. En: Schempp, W. \& Zeller, K. (eds.), Constructive Theory of Functions of Several Variables, (pp. 85-100). Springer Berlin Heidelberg.

Duke- Elder, S., \& Wybar, K.C. (1961). System of Ophthalmology. Vol II The Anatomy of the Visual System. London.

Efron, N., \& Hollingsworth, J.G. (2008). New perspectives on keratoconus as revealed by corneal confocal microscopy. Clinical $\mathcal{E}$ experimental optometry : journal of the Australian Optometrical Association, 91 (1), 34-55.

Einighammer, J., Oltrup, T., Bende, T., \& Jean, B. (2009). The individual virtual eye: A computer model for advanced intraocular lens calculation. Journal of Optometry, 2 (2), 70-82.

Eisele, E.F. (1994). Best approximations of symmetric surfaces by biquadratic Bézier surfaces. Computer Aided Geometric Design, 11 (3), 331-343.

Eklund, A., Dufort, P., Forsberg, D., \& LaConte, S.M. (2013). Medical image processing on the GPU - past, present and future. Medical image analysis, 17 (8), 1073-1094.

Elbita, A., Qahwaji, R., Ipson, S., Sharif, M.S., \& Ghanchi, F. (2014). Preparation of 2D sequences of corneal images for 3D model building. Computer methods and programs in biomedicine, 114 (2), 194-205.

Elsheikh, A., Ross, S., Alhasso, D., \& Rama, P. (2009). Numerical study of the effect of corneal layered structure on ocular biomechanics. Current eye research, 34 (1), 26-35.

Emre, S., Doganay, S., \& Yologlu, S. (2007). Evaluation of anterior segment parameters in keratoconic eyes measured with the Pentacam system. Journal of cataract and refractive surgery, 33 (10), 1708-1712.

Emsley, H.H. (1952). Visual Optics. Butterworth, London.

Ertan, A. (2007). Differentiating keratoconus and pellucid marginal degeneration. Journal of refractive surgery (Thorofare, N.J. : 1995), 23 (3), 221-222; author reply 222. 
Escudero-Sanz, I., \& Navarro, R. (1999). Off-axis aberrations of a wide-angle schematic eye model. Journal of the Optical Society of America. A, Optics, image science, and vision, 16 (8), 1881-1891.

Espinosa, J., Mas, D., Perez, J., \& Illueca, C. (2010). Optical surface reconstruction technique through combination of zonal and modal fitting. Journal of biomedical optics, $15(2), 026022$.

Espinosa, J., Mas, D., Pérez, J., \& Roig, A.B. (2013). Open-access operating algorithms for commercial videokeratographer and improvement of corneal sampling. Applied Optics, 52 (7), C24-C29.

Farin, G. (1982). A construction for visual C1 continuity of polynomial surface patches. Computer Graphics and Image Processing, 20 (272-282.

Farin, G. (1986). Triangular Bernstein-Bézier patches. Computer Aided Geometric Design, $3(2), 83-127$.

Farin, G. (1992). From conics to NURBS, a tutorial and survey. IEEE Computer Graphics and Applications, 12 (5), 78-86.

Farin, G., Hoschek, J., \& Kim, M.S. (2002). Handbook of Computer Aided Geometric Desing. North Holland: Elsevier Science B.V.

Farouki, R.T., \& Hinds, J.K. (1985). Hierarchy of geometric forms. IEEE Computer Graphics and Applications, 5 (5), 51-78.

Faux, I., \& Pratt, M. (1979). Computational Geometry for Design and Manufacture. Ellis Horwood.

Fernandez, D.C., Niazy, A.M., Kurtz, R.M., Djotyan, G.P., \& Juhasz, T. (2006). A finite element model for ultrafast laser-lamellar keratoplasty. Annals of biomedical engineering, 34 (1), 169-183.

Fernandez-Garcia, P., Cervino, A., Quiles-Guinau, L., Albarran-Diego, C., GarciaLazaro, S., \& Sanchis-Gimeno, J.A. (2015). Corneal thickness differences between sexes after oxybuprocaine eye drops. Optometry and vision science : official publication of the American Academy of Optometry, 92 (1), 89-94.

Fini, M.E. (1999). Keratocyte and fibroblast phenotypes in the repairing cornea. Progress in retinal and eye research, 18 (4), 529-551.

Flynn, C., Stavness, I., Lloyd, J., \& Fels, S. (2015). A finite element model of the face including an orthotropic skin model under in vivo tension. Computer Methods in Biomechanics and Biomedical Engineering, 18 (6), 571-582. 
Fong, P., \& Seidel, H.P. (1993). An implementation of triangular B-spline surfaces over arbitrary triangulations. Computer Aided Geometric Design, 10 (3-4), 267-275.

Forster, E., Sturmer, M., Wallrabe, U., Korvink, J., \& Brunner, R. (2015). Bio-inspired variable imaging system simplified to the essentials: modelling accommodation and gaze movement. Optics express, 23 (2), 929-942.

Freund, D.E., McCally, R.L., Farrell, R.A., Cristol, S.M., L'Hernault, N.L., \& Edelhauser, H.F. (1995). Ultrastructure in anterior and posterior stroma of perfused human and rabbit corneas. Relation to transparency. Investigative ophthalmology $\mathcal{E}$ visual science, 36 (8), 1508-1523.

Fuller, D.G., \& Alperin, D. (2013). Variations in corneal asphericity (Q value) between African-Americans and whites. Optometry and vision science : official publication of the American Academy of Optometry, 90 (7), 667-673.

Fullwood, N.J., Tuft, S.J., Malik, N.S., Meek, K.M., Ridgway, A.E., \& Harrison, R.J. (1992). Synchrotron x-ray diffraction studies of keratoconus corneal stroma. Investigative ophthalmology \& visual science, 33 (5), 1734-1741.

Funderburgh, J.L., Corpuz, L.M., Roth, M.R., Funderburgh, M.L., Tasheva, E.S., \& Conrad, G.W. (1997). Mimecan, the 25-kDa corneal keratan sulfate proteoglycan, is a product of the gene producing osteoglycin. The Journal of biological chemistry, 272 (44), 28089-28095.

Fung, Y.C. (1993). Biomechanics. Mecanical properties of living tissues. New York, USA: Springer-Verlag.

Garcia Garrido, M., Beck, S.C., Muhlfriedel, R., Julien, S., Schraermeyer, U., \& Seeliger, M.W. (2014). Towards a quantitative OCT image analysis. PLoS One, 9 (6), e100080.

Gatinel, D., Malet, J., Hoang-Xuan, T., \& Azar, D.T. (2011). Corneal elevation topography: best fit sphere, elevation distance, asphericity, toricity, and clinical implications. Cornea, 30 (5), 508-515.

Gefen, A., Shalom, R., Elad, D., \& Mandel, Y. (2009). Biomechanical analysis of the keratoconic cornea. Journal of the mechanical behavior of biomedical materials, 2 (3), 224-236.

Genest, R., (2010). Effect of Intraocular Pressure on Chick Eye Geometry, Finite Element Modeling, and Myopia, Mechanical and Mechatronics Engineering. Universidad de Waterloo, Ontario, Canada.

Giovanzana, S., (2011). A virtual environment for modeling and analysis of human eye, Departamento de Arquitectura, Urbanismo y Estudio. Universidad de Padua, Padua, Italia, p. 163. 
Gipson, I.K. (1977). Cytoplasmic filaments: their role in motility and cell shape. Investigative ophthalmology \& visual science, 16 (12), 1081-1084.

Goldberg, A.V., \& Tarjan, R.E. (2014). Efficient maximum flow algorithms. Communications of the ACM, 57 (8), 82-89.

Goldman, X. (1987). The role of surfaces in solid modelling. En: Farin, G. (Ed.), Geometric Modelling. Philadelphia: SIAM Press.

Goncharov, A.V., \& Dainty, C. (2007). Wide-field schematic eye models with gradientindex lens. Journal of the Optical Society of America. A, Optics, image science, and vision, 24 (8), 2157-2174.

Gonzalez, L., Hernandez-Matamoros, J.L., \& Navarro, R. (2008). Multizone model for postsurgical corneas: analysis of standard and custom LASIK outcomes. Journal of biomedical optics, 13 (4), 044035.

Gregory, J.A. (1982). High order continuous polygonal patches. Computing 1-16.

Gregory, J.A., \& Hahn, J.M. (1989). A C2 polygonal surface patch. Computer Aided Geometric Design, 6 (1), 69-75.

Gregory, J.A., Lau, V.K., \& Zhou, J. (1990). Smooth parametric surfaces and n-sided patches NATO ASI Series C, 307. En: Dahmen, W., Casca, M. \& Michelli, C.A. (eds.), Computation of curves and surfaces. Dordrecht: Kluwer Academic Publishers.

Gregory, J.A., \& Yuen, P.K. (1992). An arbitrary mesh network scheme using rational splines. En: Lyche, T. \& Schumaker, T. (eds.), Mathematical methods in computer aided geometric design 2, (pp. 321-329). New York: Academic Press.

Greiner, G., \& Seidel, H.P. (1993). Modeling with triangular B-splines. (pp. 211-220).

Güemez-Sandoval, E., \& Güemez-Sandoval, J.C. (2009). Representaciones anatómicas del ojo a través de la historia. De Hipócrates a Mollineti. Revista Mexicana de Oftalmologia, 83 (3), 186-191.

Gutmark, R., \& Guyton, D.L. (2010). Origins of the keratometer and its evolving role in ophthalmology. Survey of ophthalmology, 55 (5), 481-497.

Hahnel, C., Somodi, S., Weiss, D.G., \& Guthoff, R.F. (2000). The keratocyte network of human cornea: a three-dimensional study using confocal laser scanning fluorescence microscopy. Cornea, 19 (2), 185-193.

Hamano, T. (2005). Lacrimal duct occlusion for the treatment of dry eye. Seminars in ophthalmology, 20 (2), 71-74. 
Han, Z., Sui, X., Zhou, D., Zhou, C., \& Ren, Q. (2013). Biomechanical and refractive behaviors of keratoconic cornea based on three-dimensional anisotropic hyperelastic models. Journal of refractive surgery (Thorofare, N.J. : 1995), 29 (4), 282-290.

Hatka, M., \& Haindl, M. (2011). BTF rendering in Blender. Proceedings of VRCAI 2011: ACM SIGGRAPH Conference on Virtual-Reality Continuum and its Applications to Industry (pp. 265-272).

He, J., \& Bazan, H.E. (2012). Mapping the nerve architecture of diabetic human corneas. Ophthalmology, 119 (5), 956-964.

Hermsen, V.M., \& Dreyer, R.F. (1982). Ophthalmic anatomy. Primary care, 9 (4), 627645 .

Hernandez-Camarena, J.C., Chirinos-Saldana, P., Navas, A., Ramirez-Miranda, A., de la Mota, A., Jimenez-Corona, A., \& Graue-Hernindez, E.O. (2014). Repeatability, reproducibility, and agreement between three different Scheimpflug systems in measuring corneal and anterior segment biometry. Journal of refractive surgery (Thorofare, N.J. : 1995), 30 (9), 616-621.

Ho, J.D., Tsai, C.Y., Tsai, R.J., Kuo, L.L., Tsai, I.L., \& Liou, S.W. (2008). Validity of the keratometric index: evaluation by the Pentacam rotating Scheimpflug camera. Journal of cataract and refractive surgery, 34 (1), 137-145.

Hoffmann, M., \& Juhász, I., (2008). On interpolation by spline curves with shape parameters, Lecture Notes in Computer Science (including subseries Lecture Notes in Artificial Intelligence and Lecture Notes in Bioinformatics), pp. 205-214.

Holladay, J.T. (1997). Corneal topography using the Holladay Diagnostic Summary. Journal of cataract and refractive surgery, 23 (2), 209-221.

Hollasch, S. (1994). Advanced animation and rendering techniques. By Alan Watt and Mark Watt, ACM press, ISBN 0-201-54412-1, \$39.95 (members), \$44.25 (non-members). Computers and Graphics, 18 (2), 249.

Hollingsworth, J.G., Bonshek, R.E., \& Efron, N. (2005). Correlation of the appearance of the keratoconic cornea in vivo by confocal microscopy and in vitro by light microscopy. Cornea, 24 (4), 397-405.

Hollingsworth, J.G., \& Efron, N. (2005). Observations of banding patterns (Vogt striae) in keratoconus: a confocal microscopy study. Cornea, 24 (2), 162-166.

Hong, B., Liu, W., Li, F., Ding, X., \& Yang, L. (2013). Metrological study on test methods for corneal topographer. Proceedings of 2013 IEEE 11th International Conference on Electronic Measurement and Instruments, ICEMI 2013 (pp. 492-496). 
Huang, J., Savini, G., Chen, H., Bao, F., Li, Y., Chen, H., Lu, W., Yu, Y., \& Wang, Q. (2015). Precision and agreement of corneal power measurements obtained using a new corneal topographer ophthatop. PLoS ONE, 10 (1).

Hwang, H.S., Shin, J.G., Lee, B.H., Eom, T.J., \& Joo, C.K. (2013). In Vivo 3D Meibography of the Human Eyelid Using Real Time Imaging Fourier-Domain OCT. PLoS One, 8 (6), e67143.

I.K. Gipson, N.C.J., J.D.Zieske. (2004). The Anatomy and cell Biology of the human cornea, limbus, conjunctiva and andnexa. Philadelphia: Lippicott Williams \& Wilkins.

Iskander, D.R., Alkhaldi, W., \& Zoubir, A.M. (2008). On the computer intensive methods in model selection. ICASSP, IEEE International Conference on Acoustics, Speech and Signal Processing - Proceedings (pp. 3461-3464).

Iskander, D.R., Collins, M.J., \& Davis, B. (2001). Optimal modeling of corneal surfaces with Zernike polynomials. IEEE transactions on bio-medical engineering, 48 (1), 87-95.

Johnson, D.H., Bourne, W.M., \& Campbell, R.J. (1982). The ultrastructure of Descemet's membrane. I. Changes with age in normal corneas. Archives of ophthalmology (Chicago, Ill. : 1960), 100 (12), 1942-1947.

Jongebloed, W.L., Dijk, F., \& Worst, J.G. (1989). Keratoconus morphology and cell dystrophy: a SEM study. Documenta ophthalmologica. Advances in ophthalmology, 72 (3-4), 403-409.

Joseph Antony, S. (2015). Imaging shear stress distribution and evaluating the stress concentration factor of the human eye. Scientific reports, 5, 8899.

Kaas-Hansen, M. (1993). The histopathological changes of keratoconus. Acta ophthalmologica, 71 (3), 411-414.

Kagemann, L., Nevins, J.E., Jan, N.J., Wollstein, G., Ishikawa, H., Kagemann, J., Sigal, I.A., Nadler, Z., Ling, Y., \& Schuman, J.S. (2014). Characterisation of Schlemm's canal cross-sectional area. The British journal of ophthalmology, 98 Suppl 2 (ii10-14.

Kamiya, K., Ishii, R., Shimizu, K., \& Igarashi, A. (2014). Evaluation of corneal elevation, pachymetry and keratometry in keratoconic eyes with respect to the stage of AmslerKrumeich classification. The British journal of ophthalmology, 98 (4), 459-463.

Kao, W.W., Funderburgh, J.L., Xia, Y., Liu, C.Y., \& Conrad, G.W. (2006). Focus on molecules: lumican. Experimental eye research, 82 (1), 3-4.

Karpecki, P.M. (2006). Bausch \& Lomb Orbscan II/IIz anterior segment analysis system. En: Wang, M. (Ed.), Corneal topography in the wavefront era. Thorofare, USA: Slack Inc. 
Kaschke, M., Donnerhacke, K.H., \& Rill, M.S. (2014). Optical Devices in Ophthalmology and Optometry: Technology, Design Principles and Clinical Applications.

Kasprzak, H.T., \& Robert Iskander, D. (2006). Approximating ocular surfaces by generalised conic curves. Ophthalmic and Physiological Optics, 26 (6), 602-609.

Kawamorita, T., Uozato, H., Kamiya, K., Bax, L., Tsutsui, K., Aizawa, D., \& Shimizu, K. (2009). Repeatability, reproducibility, and agreement characteristics of rotating Scheimpflug photography and scanning-slit corneal topography for corneal power measurement. Journal of cataract and refractive surgery, 35 (1), 127-133.

Kennedy, R.H., Bourne, W.M., \& Dyer, J.A. (1986). A 48-year clinical and epidemiologic study of keratoconus. American journal of ophthalmology, 101 (3), 267-273.

Kenney, M.C., Nesburn, A.B., Burgeson, R.E., Butkowski, R.J., \& Ljubimov, A.V. (1997). Abnormalities of the extracellular matrix in keratoconus corneas. Cornea, 16 (3), 345351.

Khachikian, S.S., \& Belin, M.W. (2009). Posterior elevation in keratoconus. Ophthalmology, 116 (4), 816, 816.e811; author reply 816-817.

Kineri, Y., Wang, M., Lin, H., \& Maekawa, T. (2012). B-spline surface fitting by iterative geometric interpolation/approximation algorithms. CAD Computer Aided Design, 44 (7), 697-708.

Kinoshita, S., Tanaka, F., Ohashi, Y., Ikeda, M., \& Takai, S. (1991). Incidence of prominent corneal nerves in multiple endocrine neoplasia type 2A. American journal of ophthalmology, 111 (3), 307-311.

Kling, S., Bekesi, N., Dorronsoro, C., Pascual, D., \& Marcos, S. (2014). Corneal viscoelastic properties from finite-element analysis of in vivo air-puff deformation. PLoS One, 9 (8), e104904.

Kling, S., \& Marcos, S. (2013). Finite-element modeling of intrastromal ring segment implantation into a hyperelastic cornea. Investigative ophthalmology $\mathcal{E}$ visual science, 54 (1), 881-889.

Klyce, S.D., Karon, M.D., \& Smolek, M.K. (2004). Advantages and disadvantages of the Zernike expansion for representing wave aberration of the normal and aberrated eye. Journal of refractive surgery (Thorofare, N.J. : 1995), 20 (5), S537-541.

Kobayashi, A., Yokogawa, H., \& Sugiyama, K. (2006). In vivo laser confocal microscopy of Bowman's layer of the cornea. Ophthalmology, 113 (12), 2203-2208.

Koch, D.D., Foulks, G.N., Moran, C.T., \& Wakil, J.S. (1989). The Corneal EyeSys System: accuracy analysis and reproducibility of first-generation prototype. Refractive $\mathcal{E}$ corneal surgery, 5 (6), 424-429. 
Kooijman, A.C. (1983). Light distribution on the retina of a wide-angle theoretical eye. $J$ Opt Soc Am, 73 (11), 1544-1550.

Kosinka, J., Sabin, M.A., \& Dodgson, N.A. (2015). Control vectors for splines. CAD Computer Aided Design, 58, 173-178.

Krachmer, J.H., Feder, R.S., \& Belin, M.W. (1984). Keratoconus and related noninflammatory corneal thinning disorders. Survey of ophthalmology, 28 (4), 293-322.

Ku, J.Y., Niederer, R.L., Patel, D.V., Sherwin, T., \& McGhee, C.N. (2008). Laser scanning in vivo confocal analysis of keratocyte density in keratoconus. Ophthalmology, 115 (5), 845-850.

Lai, M.J. (2012). Multivariate splines and their applications. En, Computational Complexity: Theory, Techniques, and Applications, (pp. 1939-1980).

Lai, T., \& Tang, S. (2014). Cornea characterization using a combined multiphoton microscopy and optical coherence tomography system. Biomedical optics express, 5 (5), 1494-1511.

Lanchares, E., Calvo, B., Cristobal, J.A., \& Doblare, M. (2008). Finite element simulation of arcuates for astigmatism correction. Journal of biomechanics, 41 (4), 797-805.

Le Grand, Y., \& El Hage, S.G. (2013). Physiological Optics. Springer.

Lee, B.W., Jurkunas, U.V., Harissi-Dagher, M., Poothullil, A.M., Tobaigy, F.M., \& Azar, D.T. (2007). Ectatic disorders associated with a claw-shaped pattern on corneal topography. American journal of ophthalmology, 144 (1), 154-156.

Lee, T., Choi, J.B., Schafer, B.W., Segars, W.P., Eckstein, F., Kuhn, V., \& Beck, T.J. (2009). Assessing the susceptibility to local buckling at the femoral neck cortex to age-related bone loss. Annals of biomedical engineering, 37 (9), 1910-1920.

Lema, I., \& Duran, J.A. (2005). Inflammatory molecules in the tears of patients with keratoconus. Ophthalmology, 112 (4), 654-659.

Lema, I., Sobrino, T., Duran, J.A., Brea, D., \& Diez-Feijoo, E. (2009). Subclinical keratoconus and inflammatory molecules from tears. The British journal of ophthalmology, 93 (6), 820-824.

Levy, D., Hutchings, H., Rouland, J.F., Guell, J., Burillon, C., Arne, J.L., Colin, J., Laroche, L., Montard, M., Delbosc, B., Aptel, I., Ginisty, H., Grandjean, H., \& Malecaze, F. (2004). Videokeratographic anomalies in familial keratoconus. Ophthalmology, 111 (5), 867-874. 
Li, H.F., Petroll, W.M., Moller-Pedersen, T., Maurer, J.K., Cavanagh, H.D., \& Jester, J.V. (1997). Epithelial and corneal thickness measurements by in vivo confocal microscopy through focusing (CMTF). Current eye research, 16 (3), 214-221.

Li, W., Vergnes, J.P., Cornuet, P.K., \& Hassell, J.R. (1992). cDNA clone to chick corneal chondroitin/dermatan sulfate proteoglycan reveals identity to decorin. Archives of biochemistry and biophysics, 296 (1), 190-197.

Lim, L., Wei, R.H., Chan, W.K., \& Tan, D.T. (2007). Evaluation of keratoconus in Asians: role of Orbscan II and Tomey TMS-2 corneal topography. American journal of ophthalmology, 143 (3), 390-400.

Liou, H.L., \& Brennan, N.A. (1997). Anatomically accurate, finite model eye for optical modeling. Journal of the Optical Society of America. A, Optics, image science, and vision, 14 (8), 1684-1695.

Liu, H., Zhang, C., \& Zhang, C. (2012). Visualization and surface rendering based on medical image. Computer-Aided Design and Applications, 9 (1), 79-86.

Liu, X., \& Gao, Y., (2003). B-spline based wavefront reconstruction for lateral shearing interferometric measurement of engineering surfaces, Key Engineering Materials, pp. 169-174.

Lizarbe, M.A. (2001). El colágeno, ¿un cemento biológico que mantiene la arquitectura y plasticidad tisular? En, Horizontes culturales : las fronteras de la ciencia : 2000, (pp. 119137). Real Academia de la Ciencia de España.

Lohfeld, S., Barron, V., \& McHugh, P.E. (2005). Biomodels of bone: A review. Annals of Biomedical Engineering, 33 (10), 1295-1311.

Lombardo, G., Serrao, S., Rosati, M., \& Lombardo, M. (2014). Analysis of the viscoelastic properties of the human cornea using Scheimpflug imaging in inflation experiment of eye globes. PLoS One, 9 (11), e112169.

Lotmar, W. (1971). Theoretical eye model with aspherics. J Opt Soc Amer, 61 (11), 15221529.

Lotmar, W., \& Lotmar, T. (1974). Peripheral astigmatism in the human eye: experimental data and theoretical model predictions. J Opt Soc Am, 64 (4), 510-513.

Lu, L. (2009). Approximating tensor product Bézier surfaces with tangent plane continuity. Journal of Computational and Applied Mathematics, 231 (1), 412-422.

Ma, W., \& Kruth, J.P. (1998). NURBS curve and surface fitting for reverse engineering. International Journal of Advanced Manufacturing Technology, 14 (12), 918-927. 
Maceo, B.M., Manns, F., Borja, D., Nankivil, D., Uhlhorn, S., Arrieta, E., Ho, A., Augusteyn, R.C., \& Parel, J.M. (2011). Contribution of the crystalline lens gradient refractive index to the accommodation amplitude in non-human primates: in vitro studies. Journal of vision, 11 (13), 23.

Maeda, N., Klyce, S.D., \& Smolek, M.K. (1995). Comparison of methods for detecting keratoconus using videokeratography. Archives of ophthalmology (Chicago, Ill. : 1960), 113 (7), 870-874.

Maeda, N., Klyce, S.D., Smolek, M.K., \& Thompson, H.W. (1994). Automated keratoconus screening with corneal topography analysis. Investigative ophthalmology $\mathcal{E}$ visual science, 35 (6), 2749-2757.

Mahadevan, R., Fathima, A., Rajan, R., \& Arumugam, A.O. (2014). An ocular surface prosthesis for keratoglobus and Terrien's marginal degeneration. Optometry and vision science : official publication of the American Academy of Optometry, 91 (4 Suppl 1), S34-39.

Mahmoud, A.M., Roberts, C., Lembach, R., Herderick, E.E., \& McMahon, T.T. (2006). Simulation of machine-specific topographic indices for use across platforms. Optometry and vision science : official publication of the American Academy of Optometry, 83 (9), 682693.

Maldonado, M.J., Nieto, J.C., Diez-Cuenca, M., \& Pinero, D.P. (2006a). Posterior corneal curvature changes after undersurface ablation of the flap and in-the-bed LASIK retreatment. Ophthalmology, 113 (7), 1125-1133.

Maldonado, M.J., Nieto, J.C., Diez-Cuenca, M., \& Pinero, D.P. (2006b). Repeatability and reproducibility of posterior corneal curvature measurements by combined scanning-slit and placido-disc topography after LASIK. Ophthalmology, 113 (11), 19181926.

Maldonado, M.J., Nieto, J.C., \& Pinero, D.P. (2008). Advances in technologies for laserassisted in situ keratomileusis (LASIK) surgery. Expert review of medical devices, 5 (2), 209-229.

Malecaze, F., Coullet, J., Calvas, P., Fournie, P., Arne, J.L., \& Brodaty, C. (2006). Corneal ectasia after photorefractive keratectomy for low myopia. Ophthalmology, 113 (5), 742746.

Mann, S., \& DeRose, T. (1995). Computing values and derivatives of Bézier and Bspline tensor products. Computer Aided Geometric Design, 12 (1), 107-110.

Martinez-Finkelshtein, A., Delgado, A.M., Castro, G.M., Zarzo, A., \& Alio, J.L. (2009). Comparative analysis of some modal reconstruction methods of the shape of the cornea from corneal elevation data. Investigative ophthalmology $\mathcal{E}$ visual science, 50 (12), 5639-5645. 
Martinez-Finkelshtein, A., Lopez, D.R., Castro, G.M., \& Alio, J.L. (2011). Adaptive cornea modeling from keratometric data. Investigative ophthalmology $\mathcal{E}$ visual science, 52 (8), 4963-4970.

Maurice, D.M. (1957). The structure and transparency of the cornea. The Journal of physiology, 136 (2), 263-286.

McCarey, B.E., Edelhauser, H.F., \& Lynn, M.J. (2008). Review of corneal endothelial specular microscopy for FDA clinical trials of refractive procedures, surgical devices, and new intraocular drugs and solutions. Cornea, 27 (1), 1-16.

McMahon, T.T., Szczotka-Flynn, L., Barr, J.T., Anderson, R.J., Slaughter, M.E., Lass, J.H., \& Iyengar, S.K. (2006). A new method for grading the severity of keratoconus: the Keratoconus Severity Score (KSS). Cornea, 25 (7), 794-800.

Meek, K.M., Blamires, T., Elliott, G.F., Gyi, T.J., \& Nave, C. (1987). The organisation of collagen fibrils in the human corneal stroma: a synchrotron X-ray diffraction study. Current eye research, 6 (7), 841-846.

Menon, J., Marisa, R.J., \& Zagajac, J. (1994). More powerful solid modeling through ray representations. IEEE Computer Graphics and Applications, 14 (3), 22-35.

Menon, J.P. (1993). Introduction to constructive shell representations for free-form surfaces and solids. (pp. 23-34).

Merklinger, H.M. (1993). Focusing the view camera: a scientific way to focus the view camera and estimate depth of field. Canada: Paperback.

Middleditch, A., \& Dimas, E. (1994). International Conference on CSG. Triangular algebraic surface patches. International Conference on CSG.

Moffatt, S.L., Cartwright, V.A., \& Stumpf, T.H. (2005). Centennial review of corneal transplantation. Clinical \& experimental ophthalmology, 33 (6), 642-657.

Moller-Pedersen, T., \& Ehlers, N. (1995). A three-dimensional study of the human corneal keratocyte density. Current eye research, 14 (6), 459-464.

Moller-Pedersen, T., Ledet, T., \& Ehlers, N. (1994). The keratocyte density of human donor corneas. Current eye research, 13 (2), 163-169.

Montalbán, R., (2013). Caracterización y validación diagnóstica de la correlación de la geometría de las dos superficies de la córnea humana, Óptica, Farmacología y Antomía. Universidad de Alicante, Alicante, p. 169.

Montaudouin, Y.d., Tiller, W., \& Vold, H. (1986). Applications of power series in computational geometry. Computer-Aided Design, 18 (10), 514-524. 
Montes-Mico, R., Cervino, A., Ferrer-Blasco, T., Garcia-Lazaro, S., \& Madrid-Costa, D. (2010). The tear film and the optical quality of the eye. The ocular surface, 8 (4), 185-192.

Moustakides, G., Briassoulis, D., Psarakis, E., \& Dimas, E. (2000). 3D image acquisition and NURBS based geometry modelling of natural objects. Advances in engineering software, 31 (12), 955-969.

Muller, L.J., Vrensen, G.F., Pels, L., Cardozo, B.N., \& Willekens, B. (1997). Architecture of human corneal nerves. Investigative ophthalmology \& visual science, 38 (5), 985-994.

Narli, E., \& Sarioz, K. (1998). Fairing of high speed displacement hull forms by B-spline approximation and fitting. Naval Engineers Journal, 110 (2), 35-47.

Nasser, C.K., Singer, R., Barkana, Y., Zadok, D., Avni, I., \& Goldich, Y. (2012). Repeatability of the Sirius imaging system and agreement with the Pentacam HR. Journal of refractive surgery (Thorofare, N.J. : 1995), 28 (7), 493-497.

Navarro, R., Gonzalez, L., \& Hernandez, J.L. (2006). Optics of the average normal cornea from general and canonical representations of its surface topography. Journal of the Optical Society of America. A, Optics, image science, and vision, 23 (2), 219-232.

Navarro, R., Palos, F., Lanchares, E., Calvo, B., \& Cristobal, J.A. (2009). Lower- and higher-order aberrations predicted by an optomechanical model of arcuate keratotomy for astigmatism. Journal of cataract and refractive surgery, 35 (1), 158-165.

Navarro, R., Rozema, J.J., \& Tassignon, M.J. (2013). Orientation changes of the main corneal axes as a function of age. Optometry and vision science : official publication of the American Academy of Optometry, 90 (1), 23-30.

Navarro, R., Santamaria, J., \& Bescos, J. (1985). Accommodation-dependent model of the human eye with aspherics. Journal of the Optical Society of America. A, Optics and image science, 2 (8), 1273-1281.

Nawa, Y., Masuda, K., Ueda, T., Hara, Y., \& Uozato, H. (2005). Evaluation of apparent ectasia of the posterior surface of the cornea after keratorefractive surgery. Journal of cataract and refractive surgery, 31 (3), 571-573.

Neame, P.J., Kay, C.J., McQuillan, D.J., Beales, M.P., \& Hassell, J.R. (2000). Independent modulation of collagen fibrillogenesis by decorin and lumican. Cellular and molecular life sciences : CMLS, 57 (5), 859-863.

Negris, R. (1992). Floppy eyelid syndrome associated with keratoconus. Journal of the American Optometric Association, 63 (5), 316-319.

Nejad, T.M., Foster, C., \& Gongal, D. (2014). Finite element modelling of cornea mechanics: a review. Arquivos brasileiros de oftalmologia, 77 (1), 60-65. 
Norrby, S. (2005). The Dubbelman eye model analysed by ray tracing through aspheric surfaces. Ophthalmic \& physiological optics : the journal of the British College of Ophthalmic Opticians (Optometrists), 25 (2), 153-161.

Nover, A. (1982). [100 years of ophthalmology]. Fortschritte der Medizin, 100 (47-48), 2222-2227.

Oie, Y., \& Nishida, K. (2013). Regenerative medicine for the cornea. BioMed research international, 2013, 428247.

Okrasiński, W., \& Płociniczak, Ł. (2012). A nonlinear mathematical model of the corneal shape. Nonlinear Analysis: Real World Applications, 13 (3), 1498-1505.

Ortiz, S., Perez-Merino, P., Alejandre, N., Gambra, E., Jimenez-Alfaro, I., \& Marcos, S. (2012). Quantitative OCT-based corneal topography in keratoconus with intracorneal ring segments. Biomedical optics express, 3 (5), 814-824.

Ortiz, S., Siedlecki, D., Perez-Merino, P., Chia, N., de Castro, A., Szkulmowski, M., Wojtkowski, M., \& Marcos, S. (2011). Corneal topography from spectral optical coherence tomography (sOCT). Biomedical optics express, 2 (12), 3232-3247.

P.G., M., C., S., \& C.N.J., M. (1997). Cornea anatomy, physiology and healing. En: Dunitz, M. (Ed.), EnExcimer lasers in Ophthalmology, (pp. 41-63). London.

Paluszny, M. (2008). Cubic polynomial patches through geodesics. CAD Computer Aided Design, 40 (1), 56-61.

Pandolfi, A., \& Manganiello, F. (2006). A model for the human cornea: constitutive formulation and numerical analysis. Biomechanics and modeling in mechanobiology, 5 (4), 237-246.

Penev, A. (2013). Computer graphics and geometric modelling - A hybrid approach. International Journal of Pure and Applied Mathematics, 85 (4), 781-811.

Perez-Merino, P., Ortiz, S., Alejandre, N., Jimenez-Alfaro, I., \& Marcos, S. (2013). Quantitative OCT-based longitudinal evaluation of intracorneal ring segment implantation in keratoconus. Investigative ophthalmology $\mathcal{E}$ visual science, 54 (9), 60406051.

Perry, H.D., Buxton, J.N., \& Fine, B.S. (1980). Round and oval cones in keratoconus. Ophthalmology, 87 (9), 905-909.

Peters, J. (1990). Local smooth surface interpolation: a classification. Computer Aided Geometric Design, 7 (1-4), 191-195. 
Petsche, S.J., \& Pinsky, P.M. (2013). The role of 3-D collagen organization in stromal elasticity: a model based on X-ray diffraction data and second harmonic-generated images. Biomechanics and modeling in mechanobiology, 12 (6), 1101-1113.

Piegl, L. (1986). A geometric investigation of the rational Bezier scheme of computer aided design. Computers in Industry, 7 (5), 401-410.

Piegl, L. (1989). Modifying the shape of rational B-Splines. Part 1, curves. Computer Aided Design, 21 (9), 509-518.

Piegl, L. (1991). On NURBS: A survey. IEEE Computer Graphics and Applications, 11 (1), $55-71$.

Piegl, L., \& Tiller, W. (1987). Curve and surface constructions using rational B-splines. Computer-Aided Design, 19 (9), 485-498.

Piegl, L., \& Tiller, W. (1997). The NURBS Book. U.S. Government Printing Office.

Pinero, D.P. (2013). Technologies for Anatomical and Geometric Characterization of the Corneal Structure and Anterior Segment: A Review. Seminars in ophthalmology.

Pinero, D.P., Alio, J.L., Aleson, A., Escaf Vergara, M., \& Miranda, M. (2010a). Corneal volume, pachymetry, and correlation of anterior and posterior corneal shape in subclinical and different stages of clinical keratoconus. Journal of cataract and refractive surgery, 36 (5), 814-825.

Pinero, D.P., Alio, J.L., Barraquer, R.I., Michael, R., \& Jimenez, R. (2010b). Corneal biomechanics, refraction, and corneal aberrometry in keratoconus: an integrated study. Investigative ophthalmology \& visual science, 51 (4), 1948-1955.

Pinero, D.P., Nieto, J.C., \& Lopez-Miguel, A. (2012). Characterization of corneal structure in keratoconus. Journal of cataract and refractive surgery, 38 (12), 2167-2183.

Pinero, D.P., Saenz Gonzalez, C., \& Alio, J.L. (2009). Intraobserver and interobserver repeatability of curvature and aberrometric measurements of the posterior corneal surface in normal eyes using Scheimpflug photography. Journal of cataract and refractive surgery, 35 (1), 113-120.

Płociniczak, L., Okrasiński, W., Nieto, J.J., \& Domínguez, O. (2014). On a nonlinear boundary value problem modeling corneal shape. Journal of Mathematical Analysis and Applications, 414 (1), 461-471.

Polette, A., Auvinet, E., Mari, J.L., Brunette, I., \& Meunier, J. (2014). Construction of a mean surface for the variability study of the cornea. Proceedings - Conference on Computer and Robot Vision, CRV 2014 (pp. 328-335). 
Pomerantzeff, O., Pankratov, M., Wang, G.J., \& Dufault, P. (1984). Wide-angle optical model of the eye. American journal of optometry and physiological optics, 61 (3), 166-176.

Popiolek-Masajada, A., \& Kasprzak, H. (2002). Model of the optical system of the human eye during accommodation. Ophthalmic \& physiological optics : the journal of the British College of Ophthalmic Opticians (Optometrists), 22 (3), 201-208.

Pottmann, H., Leopoldseder, S., Hofer, M., Steiner, T., \& Wang, W. (2005). Industrial geometry: Recent advances and applications in CAD. CAD Computer Aided Design, 37 (7), 751-766.

Prautzsch, H. (1984). Degree elevation of B-spline curves. Computer Aided Geometric Design, 1 (2), 193-198.

Preim, B., \& Botha, C.P. (2014). Visual Computing for Medicine: Theory, Algorithms, and Applications: Second Edition.

Prisant, O., Legeais, J.M., \& Renard, G. (1997). Superior keratoconus. Cornea, 16 (6), 693694.

Rabinowitz, Y.S. (1998). Keratoconus. Survey of ophthalmology, 42 (4), 297-319.

Rabinowitz, Y.S., \& McDonnell, P.J. (1989). Computer-assisted corneal topography in keratoconus. Refractive $\mathcal{E}$ corneal surgery, 5 (6), 400-408.

Rabinowitz, Y.S., \& Rasheed, K. (1999). KISA\% index: a quantitative videokeratography algorithm embodying minimal topographic criteria for diagnosing keratoconus. Journal of cataract and refractive surgery, 25 (10), 1327-1335.

Rabinowitz, Y.S., Yang, H., Brickman, Y., Akkina, J., Riley, C., Rotter, J.I., \& Elashoff, J. (1996). Videokeratography database of normal human corneas. The British journal of ophthalmology, 80 (7), 610-616.

Rada, J.A., Cornuet, P.K., \& Hassell, J.R. (1993). Regulation of corneal collagen fibrillogenesis in vitro by corneal proteoglycan (lumican and decorin) core proteins. Experimental eye research, 56 (6), 635-648.

Ramos-Lopez, D., Martinez-Finkelshtein, A., Castro-Luna, G.M., Piñero, D., \& Alio, J.L. (2011). Placido-based indices of corneal irregularity. Optometry and vision science : official publication of the American Academy of Optometry, 88 (10), 1220-1231.

Rand, R.H., Howland, H.C., \& Applegate, R.A. (1997). Mathematical model of a Placido disk keratometer and its implications for recovery of corneal topography. Optometry and vision science : official publication of the American Academy of Optometry, 74 (11), 926930. 
Randleman, J.B. (2006). Post-laser in-situ keratomileusis ectasia: current understanding and future directions. Current opinion in ophthalmology, 17 (4), 406-412.

Rao, S.N., Raviv, T., Majmudar, P.A., \& Epstein, R.J. (2002). Role of Orbscan II in screening keratoconus suspects before refractive corneal surgery. Ophthalmology, 109 (9), 1642-1646.

Read, S.A., Collins, M.J., Carney, L.G., \& Franklin, R.J. (2006). The topography of the central and peripheral cornea. Investigative Ophthalmology and Visual Science, 47 (4), 1404-1415.

Read, S.A., Collins, M.J., Iskander, D.R., \& Davis, B.A. (2009). Corneal topography with Scheimpflug imaging and videokeratography: Comparative study of normal eyes. Journal of Cataract and Refractive Surgery, 35 (6), 1072-1081.

Reilly, M.A. (2014). A quantitative geometric mechanics lens model: Insights into the mechanisms of accommodation and presbyopia. Vision Research, 103 (1), 20-31.

Reinstein, D.Z., Archer, T.J., \& Gobbe, M. (2011). Epithelial thickness up to 26 years after radial keratotomy: three-dimensional display with Artemis very high-frequency digital ultrasound. Journal of refractive surgery (Thorofare, N.J. : 1995), 27 (8), 618-624.

Requicha, A.A. (1980). Representations for rigid solids: theory, methods, and systems. Computing surveys, 12 (4), 437-464.

Requicha, A.A., \& Rossignac, J.R. (1992). Solid modeling and beyond. IEEE Computer Graphics and Applications, 5, 31-44.

Requicha, A.A.G., \& Voelcker, H.B. (1982). Solid modeling: a historical summary and contemporary assessment. IEEE Computer Graphics and Applications, 2 (2), 9-16, 18-20, 22-24.

Requicha, A.A.G., \& Voelcker, H.B. (1983). Solid modeling: current status and research directions. IEEE Computer Graphics and Applications, 3 (7), 25-30, 32-37.

Ribeiro, F., Castanheira-Dinis, A., \& Dias, J.M. (2013). Refractive error assessment: influence of different optical elements and current limits of biometric techniques. Journal of refractive surgery (Thorofare, N.J. : 1995), 29 (3), 206-212.

Ribeiro, F.J., Castanheira-Dinis, A., \& Dias, J.M. (2012). Personalized pseudophakic model for refractive assessment. PLoS One, 7 (10), e46780.

Rizzuti, A.B. (1970). Diagnostic illumination test for keratoconus. American journal of ophthalmology, 70 (1), 141-143. 
Roberts, C. (1994). Characterization of the inherent error in a spherically-biased corneal topography system in mapping a radially aspheric surface. Journal of refractive and corneal surgery, 10 (2), 103-111; discussion 112-106.

Roberts, C. (2000). The cornea is not a piece of plastic. Journal of refractive surgery (Thorofare, N.J. : 1995), 16 (4), 407-413.

Roberts, C., \& Züger, B.J., (2006). The adventage and principle of dual scheimpflug imaging for analyzing the anterior segment of the human eye.

Rocha, M., Pereira, J.P., \& De Castro, A.V. (2011). 3D modeling mechanisms for educational resources in medical and health area. Proceedings of the 6 th Iberian Conference on Information Systems and Technologies, CISTI 2011.

Rogers, D.F., \& Fog, N.R. (1989). Constrained B-spline curve and surface fitting. Computer-Aided Design, 21 (10), 641-648.

Rosen, E.S. (2007). Ectasia. Journal of cataract and refractive surgery, 33 (6), 931-932.

Rosenthal, P., \& Cotter, J.M. (1995). Clinical performance of a spline-based apical vaulting keratoconus corneal contact lens design. The CLAO journal : official publication of the Contact Lens Association of Ophthalmologists, Inc, 21 (1), 42-46.

Roy, A.S., \& Dupps, W.J., Jr. (2011). Patient-specific computational modeling of keratoconus progression and differential responses to collagen cross-linking. Investigative ophthalmology \& visual science, 52 (12), 9174-9187.

Saad, A., \& Gatinel, D. (2010). Topographic and tomographic properties of forme fruste keratoconus corneas. Investigative ophthalmology $\mathcal{E}$ visual science, 51 (11), 5546-5555.

Saad, A., Lteif, Y., Azan, E., \& Gatinel, D. (2010). Biomechanical properties of keratoconus suspect eyes. Investigative ophthalmology \& visual science, 51 (6), 2912-2916.

Sagrinati, C., Netti, G.S., Mazzinghi, B., Lazzeri, E., Liotta, F., Frosali, F., Ronconi, E., Meini, C., Gacci, M., Squecco, R., Carini, M., Gesualdo, L., Francini, F., Maggi, E., Annunziato, F., Lasagni, L., Serio, M., Romagnani, S., \& Romagnani, P. (2006). Isolation and characterization of multipotent progenitor cells from the Bowman's capsule of adult human kidneys. Journal of the American Society of Nephrology : JASN, 17 (9), 24432456.

Saika, M., Maeda, N., Hirohara, Y., Mihashi, T., Fujikado, T., \& Nishida, K. (2013). Four discriminant models for detecting keratoconus pattern using Zernike coefficients of corneal aberrations. Japanese Journal of Ophthalmology, 57 (6), 503-509.

Salouti, R., Nowroozzadeh, M.H., Zamani, M., Fard, A.H., \& Niknam, S. (2009). Comparison of anterior and posterior elevation map measurements between 2 Scheimpflug imaging systems. Journal of cataract and refractive surgery, 35 (5), 856-862. 
Sarkar, B., \& Menq, C.H. (1991). Parameter optimization in approximating curves and surfaces to measurement data. Computer Aided Geometric Design, 8 (4), 267-290.

Savini, G., Carbonelli, M., Barboni, P., \& Hoffer, K.J. (2011a). Repeatability of automatic measurements performed by a dual Scheimpflug analyzer in unoperated and postrefractive surgery eyes. Journal of cataract and refractive surgery, 37 (2), 302-309.

Savini, G., Barboni, P., Carbonelli, M., \& Hoffer, K.J. (2011b). Repeatability of automatic measurements by a new Scheimpflug camera combined with Placido topography. Journal of cataract and refractive surgery, 37 (10), 1809-1816.

Sawaguchi, S., Fukuchi, T., Abe, H., Kaiya, T., Sugar, J., \& Yue, B.Y. (1998). Threedimensional scanning electron microscopic study of keratoconus corneas. Archives of ophthalmology (Chicago, Ill. : 1960), 116 (1), 62-68.

Sawaguchi, S., Yue, B.Y., Chang, I., Sugar, J., \& Robin, J. (1991). Proteoglycan molecules in keratoconus corneas. Investigative ophthalmology \& visual science, 32 (6), 1846-1853.

Schlegel, Z., Hoang-Xuan, T., \& Gatinel, D. (2008). Comparison of and correlation between anterior and posterior corneal elevation maps in normal eyes and keratoconus-suspect eyes. Journal of cataract and refractive surgery, 34 (5), 789-795.

Schmidt, T., Pandya, D., \& Balzani, D. (2015). Influence of isotropic and anisotropic material models on the mechanical response in arterial walls as a result of supraphysiological loadings. Mechanics Research Communications, 64, 29-37.

Schneider, M., Iskander, D.R., \& Collins, M.J. (2009). Modeling corneal surfaces with rational functions for high-speed videokeratoscopy data compression. IEEE transactions on bio-medical engineering, 56 (2), 493-499.

Schubert, C., van Langeveld, M.C., \& Donoso, L.A. (2014). Innovations in 3D printing: a 3D overview from optics to organs. The British journal of ophthalmology, 98 (2), 159-161.

Schumaker, L. (1993). Triangulations in Computer Aided Geometric Design. IEEE Computer Graphics and Applications, 13 (1), 45-52.

Schwiegerling, J., \& Greivenkamp, J.E. (1996). Keratoconus detection based on videokeratoscopic height data. Optometry and vision science : official publication of the American Academy of Optometry, 73 (12), 721-728.

Scroggs, M.W., \& Proia, A.D. (1992). Histopathological variation in keratoconus. Cornea, 11 (6), 553-559.

Sheil, C.J., Bahrami, M., \& Goncharov, A.V. (2014). An analytical method for predicting the geometrical and optical properties of the human lens under accommodation. Biomedical optics express, 5 (5), 1649-1663. 
Sherwin, T., \& Brookes, N.H. (2004). Morphological changes in keratoconus: pathology or pathogenesis. Clinical \& experimental ophthalmology, 32 (2), 211-217.

Sicam, V.A., Snellenburg, J.J., van der Heijde, R.G., \& van Stokkum, I.H. (2007). Pseudo forward ray-tracing: a new method for surface validation in cornea topography. Optometry and vision science : official publication of the American Academy of Optometry, 84 (9), 915-923.

Smadja, D., Santhiago, M.R., Mello, G.R., Krueger, R.R., Colin, J., \& Touboul, D. (2013). Influence of the reference surface shape for discriminating between normal corneas, subclinical keratoconus, and keratoconus. Journal of refractive surgery (Thorofare, N.J. : 1995), 29 (4), 274-281.

Smith, G., Bedggood, P., Ashman, R., Daaboul, M., \& Metha, A. (2008). Exploring ocular aberrations with a schematic human eye model. Optometry and vision science : official publication of the American Academy of Optometry, 85 (5), 330-340.

Smolek, M.K., \& Klyce, S.D. (1997). Current keratoconus detection methods compared with a neural network approach. Investigative ophthalmology $\mathcal{E}$ visual science, 38 (11), 2290-2299.

Smolek, M.K., \& Klyce, S.D. (2003). Zernike polynomial fitting fails to represent all visually significant corneal aberrations. Investigative ophthalmology $\mathcal{E}$ visual science, 44 (11), 4676-4681.

Smolek, M.K., \& Klyce, S.D. (2005). Goodness-of-prediction of Zernike polynomial fitting to corneal surfaces. Journal of cataract and refractive surgery, 31 (12), 2350-2355.

Smolek, M.K., Klyce, S.D., \& Hovis, J.K. (2002). The Universal Standard Scale: proposed improvements to the American National Standards Institute (ANSI) scale for corneal topography. Ophthalmology, 109 (2), 361-369.

Sonmez, B., Doan, M.P., \& Hamilton, D.R. (2007). Identification of scanning slit-beam topographic parameters important in distinguishing normal from keratoconic corneal morphologic features. American journal of ophthalmology, 143 (3), 401-408.

Soumelidis, A., Fazekas, Z., Pap, M., \& Schipp, F. (2011). Generic Zernike-based surface representation of measured corneal surface data. MeMeA 2011 - 2011 IEEE International Symposium on Medical Measurements and Applications, Proceedings.

Studer, H.P., Riedwyl, H., Amstutz, C.A., Hanson, J.V., \& Buchler, P. (2013). Patientspecific finite-element simulation of the human cornea: a clinical validation study on cataract surgery. Journal of biomechanics, 46 (4), 751-758.

Sulek, K. (1967). [Prize for Allvar Gullstrand in 1911 for works on dioptrics of the eye]. Wiadomosci lekarskie (Warsaw, Poland : 1960), 20 (14), 1417. 
Sun, W., Darling, A., Starly, B., \& Nam, J. (2004). Computer-aided tissue engineering: Overview, scope and challenges. Biotechnology and Applied Biochemistry, 39 (1), 29-47.

Szczotka, L.B., \& Thomas, J. (1998). Comparison of axial and instantaneous videokeratographic data in keratoconus and utility in contact lens curvature prediction. The CLAO journal : official publication of the Contact Lens Association of Ophthalmologists, Inc, 24 (1), 22-28.

Talu, S., Stach, S., Sueiras, V., \& Ziebarth, N.M. (2015). Fractal Analysis of AFM Images of the Surface of Bowman's Membrane of the Human Cornea. Annals of biomedical engineering, 43 (4), 906-916.

Tanabe, T., Tomidokoro, A., Samejima, T., Miyata, K., Sato, M., Kaji, Y., \& Oshika, T. (2004). Corneal regular and irregular astigmatism assessed by Fourier analysis of videokeratography data in normal and pathologic eyes. Ophthalmology, 111 (4), 752-757.

Tao, A., Wang, J., Chen, Q., Shen, M., Lu, F., Dubovy, S.R., \& Shousha, M.A. (2011). Topographic thickness of Bowman's layer determined by ultra-high resolution spectral domain-optical coherence tomography. Investigative ophthalmology $\mathcal{E}$ visual science, 52 (6), 3901-3907.

Thibos, L.N., Ye, M., Zhang, X., \& Bradley, A. (1992). The chromatic eye: a new reduced-eye model of ocular chromatic aberration in humans. Applied optics, 31 (19), 3594-3600.

Thoft, R.A., \& Friend, J. (1983). The X, Y, Z hypothesis of corneal epithelial maintenance. Investigative ophthalmology \& visual science, 24 (10), 1442-1443.

Timoney, P.J., \& Breathnach, C.S. (2013). Allvar Gullstrand and the slit lamp 1911. Irish journal of medical science, 182 (2), 301-305.

Tomidokoro, A., Oshika, T., Amano, S., Higaki, S., Maeda, N., \& Miyata, K. (2000). Changes in anterior and posterior corneal curvatures in keratoconus. Ophthalmology, 107 (7), 1328-1332.

Torquetti, L., Ferrara, G., Almeida, F., Cunha, L., Araujo, L.P., Machado, A., Marcelo Lyra, J., Merayo-Lloves, J., \& Ferrara, P. (2014). Intrastromal corneal ring segments implantation in patients with keratoconus: 10-year follow-up. Journal of refractive surgery (Thorofare, N.J. : 1995), 30 (1), 22-26.

Turuwhenua, J. (2007). Corneal surface reconstruction algorithm using Zernike polynomial representation: Improvements. Journal of the Optical Society of America A: Optics and Image Science, and Vision, 24 (6), 1551-1561.

Turuwhenua, J. (2008). An improved low order method for corneal reconstruction. Optometry and Vision Science, 85 (3), E211-E218. 
Turuwhenua, J., \& Henderson, J. (2004). A novel low-order method for recovery of the corneal shape. Optometry and Vision Science, 81 (11), 863-871.

Tyson, R.K. (1982). Conversion of Zernike aberration coefficients to Seidel and higherorder power-series aberration coefficients. Optics letters, 7 (6), 262-264.

Ucakhan, O.O., Kanpolat, A., Ylmaz, N., \& Ozkan, M. (2006). In vivo confocal microscopy findings in keratoconus. Eye $\mathcal{E}$ contact lens, 32 (4), 183-191.

Varady, T. (1991). Overlap patches: a new scheme for interpolating curve networks with n-sided regions. Computer Aided Geometric Design, 8 (1), 7-27.

Várady, T., Salvi, P., \& Rockwood, A. (2012). Transfinite surface interpolation with interior control. Graphical Models, 74 (6), 311-320.

Vega-Estrada, A., Alio, J.L., Brenner, L.F., Javaloy, J., Plaza Puche, A.B., Barraquer, R.I., Teus, M.A., Murta, J., Henriques, J., \& Uceda-Montanes, A. (2013). Outcome analysis of intracorneal ring segments for the treatment of keratoconus based on visual, refractive, and aberrometric impairment. American journal of ophthalmology, 155 (3), 575-584 e571.

Vellara, H.R., \& Patel, D.V. (2015). Biomechanical properties of the keratoconic cornea: a review. Clinical $\mathcal{E}$ experimental optometry : journal of the Australian Optometrical Association, 98 (1), 31-38.

Verma, V., \& Walia, E. (2010). 3D Rendering - Techniques and challenges. International Journal of Engineering and Technology, 2 (2), 29-33.

Vesprille, K.J., (1975). Computer aided design applications of the rational BSpline approximation form. Syracuse University, Syracuse

von Helmholtz, H. (1962). Handbook of Physiological Optics. Dover, New York: Optical Society of America.

Vryghem, J.C., Devogelaere, T., \& Stodulka, P. (2010). Efficacy, safety, and flap dimensions of a new femtosecond laser for laser in situ keratomileusis. Journal of cataract and refractive surgery, 36 (3), 442-448.

W.J., G. (1969). Spline-blended surface interpolation through curve networks. J Math Mech, 18, 931-952.

Wahba, G. (1990). Spline Models for Observational Data. Philadelphia: Society for Industrial and Applied Mathematics.

Wang, B., Faure, F., \& Pai, D.K. (2012). Adaptive image-based intersection volume. ACM Transactions on Graphics, 31 (4). 
Wang, J., \& Yu, Z. (2011). Surface feature based mesh segmentation. Computers and Graphics (Pergamon), 35 (3), 661-667.

Wang, L., Chernyak, D., Yeh, D., \& Koch, D.D. (2007). Fitting behaviors of Fourier transform and Zernike polynomials. Journal of cataract and refractive surgery, 33 (6), 9991004.

Wang, Q., Savini, G., Hoffer, K.J., Xu, Z., Feng, Y., Wen, D., Hua, Y., Yang, F., Pan, C., \& Huang, J. (2012). A Comprehensive Assessment of the Precision and Agreement of Anterior Corneal Power Measurements Obtained Using 8 Different Devices. PLoS ONE, 7 (9).

Wang, X., Dong, J., Wang, X., \& Wu, Q. (2013). IOL tilt and decentration estimation from 3 dimensional reconstruction of OCT image. PLoS One, 8 (3), e59109.

Wang, Z., Liang, X., Wu, Z., Lin, J., \& Huang, J. (2015). A novel method for measuring anterior segment area of the eye on ultrasound biomicroscopic images using photoshop. PLoS One, 10 (3), e0120843.

Waring, G.O., 3rd, Bourne, W.M., Edelhauser, H.F., \& Kenyon, K.R. (1982). The corneal endothelium. Normal and pathologic structure and function. Ophthalmology, 89 (6), 531-590.

Weed, K.H., MacEwen, C.J., Cox, A., \& McGhee, C.N. (2007). Quantitative analysis of corneal microstructure in keratoconus utilising in vivo confocal microscopy. Eye (London, England), 21 (5), 614-623.

Weed, K.H., McGhee, C.N., \& MacEwen, C.J. (2005). Atypical unilateral superior keratoconus in young males. Contact lens $\mathcal{E}$ anterior eye : the journal of the British Contact Lens Association, 28 (4), 177-179.

Wenstrup, R.J., Florer, J.B., Brunskill, E.W., Bell, S.M., Chervoneva, I., \& Birk, D.E. (2004). Type V collagen controls the initiation of collagen fibril assembly. The Journal of biological chemistry, 279 (51), 53331-53337.

Wenstrup, R.J., Florer, J.B., Davidson, J.M., Phillips, C.L., Pfeiffer, B.J., Menezes, D.W., Chervoneva, I., \& Birk, D.E. (2006). Murine model of the Ehlers-Danlos syndrome. col5a1 haploinsufficiency disrupts collagen fibril assembly at multiple stages. The Journal of biological chemistry, 281 (18), 12888-12895.

Whitford, C., Studer, H., Boote, C., Meek, K.M., \& Elsheikh, A. (2015). Biomechanical model of the human cornea: considering shear stiffness and regional variation of collagen anisotropy and density. Journal of the mechanical behavior of biomedical materials, $42,76-87$.

Wilson, S.E., \& Klyce, S.D. (1991). Quantitative descriptors of corneal topography. A clinical study. Archives of ophthalmology (Chicago, Ill. : 1960), 109 (3), 349-353. 
Wilson, S.E., Klyce, S.D., \& Husseini, Z.M. (1993). Standardized color-coded maps for corneal topography. Ophthalmology, 100 (11), 1723-1727.

Wilson, S.E., Lin, D.T., \& Klyce, S.D. (1991). Corneal topography of keratoconus. Cornea, 10 (1), 2-8.

Wolffsohn, J.S., Safeen, S., Shah, S., \& Laiquzzaman, M. (2012). Changes of corneal biomechanics with keratoconus. Cornea, 31 (8), 849-854.

Wollensak, G., Spoerl, E., \& Seiler, T. (2003). Riboflavin/ultraviolet-a-induced collagen crosslinking for the treatment of keratoconus. American journal of ophthalmology, 135 (5), 620-627.

Wong, A., Genest, R., Chandrashekar, N., Choh, V., \& Irving, E.L. (2012). Automatic system for 3D reconstruction of the chick eye based on digital photographs. Computer methods in biomechanics and biomedical engineering, 15 (2), 141-149.

Woodward, C.D. (1987). Cross-sectional design of B-spline surfaces. Computers and Graphics, 11 (2), 193-201.

Woodward, C.D. (1988). Skinning techniques for interactive B-spline surface interpolation. Computer-Aided Design, 20 (8), 441-451.

Wu, Z., Fu, J., Wang, Z., Li, X., Li, J., Pei, Y., Pei, G., Li, D., Guo, Z., \& Fan, H. (2015). Three-dimensional virtual bone bank system for selecting massive bone allograft in orthopaedic oncology. International Orthopaedics.

Wygledowska-Promienska, D., Rokita-Wala, I., Gierek-Ciaciura, S., \& PiatekKoronowska, G. (1999). [The alterations in corneal structure at III/IV stage of keratoconus by means of confocal microscopy and ultrasound biomicroscopy before penetrating keratoplasty]. Klinika oczna, 101 (6), 427-432.

Wyman, A.L. (1992). Benedict Duddell: pioneer oculist of the 18th century. Journal of the Royal Society of Medicine, 85 (7), 412-415.

Xie, P., Hu, Z., Zhang, X., Li, X., Gao, Z., Yuan, D., \& Liu, Q. (2014). Application of 3dimensional printing technology to construct an eye model for fundus viewing study. PLOS ONE, 9 (11).

Xing, Q., \& Wei, Q. (2014). Human eyeball model reconstruction and quantitative analysis. Conference proceedings : ... Annual International Conference of the IEEE Engineering in Medicine and Biology Society. IEEE Engineering in Medicine and Biology Society. Annual Conference, 2014, 2460-2463.

Yang, X., \& Zheng, J. (2012). Approximate T-spline surface skinning. CAD Computer Aided Design, 44 (12), 1269-1276. 
Yebra-Pimentel, E., Gonzalez-Jeijome, J.M., Cervino, A., Giraldez, M.J., Gonzalez-Perez, J., \& Parafita, M.A. (2004). Corneal asphericity in a young adult population. Clinical implications. Archivos de la Sociedad Espanola de Oftalmologia, 79 (8), 385-392.

Ying, H. (2006). A new interpolating method using C-B-spline. WSEAS Transactions on Computers, 5 (10), 2191-2196.

Yoon, G., Pantanelli, S., \& MacRae, S. (2008). Comparison of Zernike and Fourier wavefront reconstruction algorithms in representing corneal aberration of normal and abnormal eyes. Journal of refractive surgery (Thorofare, N.J. : 1995), 24 (6), 582-590.

You, Q.S., Peng, X.Y., Chen, C.X., Xu, L., \& Jonas, J.B. (2013). Peripapillary intrachoroidal cavitations. The Beijing eye study. PLoS One, 8 (10), e78743.

Young, B., \& Heath, J.W. (2000). Wheater's Histologia Funcional. Elsevier España.

Zadnik, K., Barr, J.T., Edrington, T.B., Everett, D.F., Jameson, M., McMahon, T.T., Shin, J.A., Sterling, J.L., Wagner, H., \& Gordon, M.O. (1998). Baseline findings in the Collaborative Longitudinal Evaluation of Keratoconus (CLEK) Study. Investigative ophthalmology \& visual science, 39 (13), 2537-2546.

Zheng, S., Ying, J., Wang, B., Xie, Z., Huang, X., \& Shi, M. (2013). Three-dimensional model for human anterior corneal surface. Journal of Biomedical Optics, 18 (6).

Zhu, T.T., Xu, G., Ma, M.C., \& Liu, X.Y., (2013). A technology to multi-resolution surface reconstruction, Advanced Materials Research, pp. 1933-1936.

Zhu, Z., Janunts, E., Eppig, T., Sauer, T., \& Langenbucher, A. (2010). Iteratively reweighted bi-cubic spline representation of corneal topography and its comparison to the standard methods. Zeitschrift fur medizinische Physik, 20 (4), 287-298.

Zhu, Z., Janunts, E., Eppig, T., Sauer, T., \& Langenbucher, A. (2011). Tomographybased customized IOL calculation model. Current eye research, 36 (6), 579-589.

Zorn-Kruppa, M., Houdek, P., Wladykowski, E., Engelke, M., Bartok, M., Mewes, K.R., Moll, I., \& Brandner, J.M. (2014). Determining the Depth of Injury in Bioengineered Tissue Models of Cornea and Conjunctiva for the Prediction of All Three Ocular GHS Categories. PLoS One, 9 (12), e114181.

Zuo, B.Q., Huang, Z.D., Wang, Y.W., \& Wu, Z.J. (2015). Isogeometric analysis for CSG models. Computer Methods in Applied Mechanics and Engineering, 285, 102-124. 


\section{Relación de figuras adaptadas}

FIGURA 1.1. CHABACANO. WWW.GNU.ORG/COPYLEFT/FDL.HTML

FIGURA 1.2. PATRICK J. LYNCH, MEDICAL ILLUSTRATOR

FIGURA 1.5. FLICKR

FIGURA 1.10. WEBS DE LAS CASAS COMERCIALES DE LOS TOPÓGRAFOS CORNEALES

FIGURA 2.1. WWW.ALTSPACE.DE/MEDICIN

FIGURA 2.3. WWW.CORNEA.ES Y ECOBUILDINGS2.BLOGSPOT.COM.ES/2011/10/ESTRUCTURAS-

ARTIFICIALES.HTML

FIGURA 2.4. RUA.UA.ES/DSPACE/BITSTREAM/10045/35633/1/TESIS_RAULMONTALBAN.PDF

FIGURA 2.6. WWW.SPANISHDICT.COM/ANSWERS/270167/WEEKLY-MATCHING-REVIEW-LA-PALABRA-DELDA-2014-APRIL-PART-2

FIGURA 2.7. WWW.EYEROUNDS.ORG/TUTORIALS/LASER-VISION-CORRECTION-TUTORIAL/ANATOMY.HTM

FIGURAS 2.12, 2.13, 2.15,2.16. EPRINTS.UCM.ES/29772/1/T35997.PDF

FIGURA 2.14. WWW.ANGELARTEAGA.ES/ES/HIPERLAXITUD-PALPEBRAL-C-6.PHP

FIGURA 2.22. RUA.UA.ES/DSPACE/BITSTREAM/10045/35633/1/TESIS_RAULMONTALBAN.PDF

FIGURA 2.26. WWW.TOPCON-MEDICAL.ES/ES/PRODUCTS/56-OM-4.HTML

FIGURAS 2.27 Y 2.28. WWW.OFTALMO.COM/SEO/ARCHIVOS/MAQUETAS/9/32B642E9-7A33-C208-22AF000030FD6539/ARTICULO.HTML

FIGURA 2.29. WWW.SLIDESHARE.NET/DRAMP/CORNEAL-TOPOGRAPHY-BY-DR-MRINMAYEE

FIGURA 2.30. WWW.OPHTHALMOLOGYMANAGEMENT.COM/ARTICLEVIEWER.ASPX?ARTICLEID=86652

FIGURA 2.35. WWW.BAUSCH.COM/OUR-COMPANY/CHAT\#.VGPSN02HEUK

FIGURA 2.37. WWW.OCULUS.DE/ES/PAGINA-DE-INICIO/

FIGURA 2.38. WWW.ZIEMERGROUP.COM/PRODUCTS/GALILEI.HTML

FIGURA 2.39. WWW.CSOITALIA.IT/EN/ASP/HOME.ASP?PROD $=1 \& D B P I D=17$

FIGURA 2.57, 2.58, 2.59 Y 2.60. EPRINTS.UCM.ES/29772/1/T35997.PDF 


\section{- ftaRëd}

RETICS Patología Ocular 